\title{
Effect of an exposure-indicating light on noise reduction experienced during work at a factory
}

John A. Frazer

West Virginia University

Follow this and additional works at: https://researchrepository.wvu.edu/etd

\section{Recommended Citation}

Frazer, John A., "Effect of an exposure-indicating light on noise reduction experienced during work at a factory" (2011). Graduate Theses, Dissertations, and Problem Reports. 3368.

https://researchrepository.wvu.edu/etd/3368

This Dissertation is protected by copyright and/or related rights. It has been brought to you by the The Research Repository @ WVU with permission from the rights-holder(s). You are free to use this Dissertation in any way that is permitted by the copyright and related rights legislation that applies to your use. For other uses you must obtain permission from the rights-holder(s) directly, unless additional rights are indicated by a Creative Commons license in the record and/ or on the work itself. This Dissertation has been accepted for inclusion in WVU Graduate Theses, Dissertations, and Problem Reports collection by an authorized administrator of The Research Repository @ WVU.

For more information, please contact researchrepository@mail.wvu.edu. 


\title{
EFFECT OF AN EXPOSURE-INDICATING LIGHT ON NOISE REDUCTION EXPERIENCED DURING WORK AT A FACTORY
}

\author{
John A. Frazer \\ Dissertation submitted to the \\ College of Engineering and Mineral Resources \\ at West Virginia University \\ in partial fulfillment of the requirements \\ for the degree of
}

\section{Doctor of Philosophy \\ in}

Occupational Safety and Health

\author{
Approved by \\ Steven E. Guffey, Ph.D., CIH, Chair \\ Ronald C. Althouse, Ph.D. \\ Michael J. Klishis, Ph.D., CSHM \\ Kevin L. Michael, Ph.D. \\ Warren R. Myers, Ph.D., MPH, CIH
}

Department of Industrial and Management Systems Engineering

Morgantown, West Virginia

2011

Keywords: Behavior Modification, Noise Reduction, Hearing Conservation, Earplugs 


\title{
Abstract \\ Effect of an Exposure-Indicating Light on Noise Reduction Experienced During Work at a Factory
}

\author{
John Andrew Frazer
}

It is possible that providing quantitative feedback would help individual workers recognize that their hearing protector device (HPD) is either not properly seated or is not in place when needed. In this study, to test the effectiveness of alerting workers immediately when noise levels in their ears are excessive, noise levels were recorded using noise dosimeters proximal to HPD $(\mathrm{SPL} \mathrm{ear})$ and at the shoulder $\left(\mathrm{SPL}_{\mathrm{sh}}\right)$ during work. The average noise reduction $\left(\mathrm{NR}_{\mathrm{A}}\right)$ at the ear was calculated at times when a signal light was activated and when it was not. The signal light was positioned below the brim of a hard hat worn by each of twenty-two subjects (16 males and 6 females, average age 42) while they worked normal work shifts at a metal products manufacturing facility.

When activated, the signal light flashed continuously when noise levels recorded proximal to the ear exceeded 80 decibels, A-weighted (dBA). The expectation was that workers would wear their HPD a larger fraction of the time when noise levels in their ears exceeded $80 \mathrm{dBA}$. Likewise, it was expected that a worker whose HPD was on but not properly seated would be induced to re-position or otherwise re-fit the HPD if the light came on. Hence, changes in behavior due to signaling would produce effectively higher $\mathrm{NR}_{\mathrm{A}}$ values than would occur when no signaling was activated.

Results of the six tests per subject showed that minute-by-minute NR values fluctuated widely during their tested work shifts. Signaling with the light when noise levels were high had modest effects on $\mathrm{NR}_{\mathrm{A}}$, producing a statistically significant $(\mathrm{p}<0.0023)$ but very modest difference (8.4 dBA Light Deactivated and 10.6 dBA Light Activated), suggesting that the light modestly increased the average HPD NR for workers when activated.

Note that 7 of the 20 subjects showed values of $\mathrm{NR}_{\mathrm{A}}<5 \mathrm{dBA}$, both with and without the light signaling, suggesting that the plug provided poor protection for them at all times, perhaps making it impossible for them to improve their performance by re-adjusting their fits. On the other hand, Subject 6 obtained $\mathrm{NR}_{\mathrm{A}}=21.6 \mathrm{dBA}$ both with and without light signaling, the highest reduction experienced by any subject. It is possible that Subject 6 could not improve because he already had his best possible fit. It was noted that three other subjects had $\mathrm{NR}_{\mathrm{A}} \geq 15$ $\mathrm{dBA}$ both with and without the light. It is possible that both also experienced the best protection that they could achieve with this plug, making it impossible for the light to produce improvement.

Finally, four subjects experienced an improvement of more than $5 \mathrm{dBA}$, with the highest being $7.9 \mathrm{dBA}$. Five subjects experienced reductions in $\mathrm{NR}_{\mathrm{A}}$, with the greatest being $\mathrm{NR}_{\mathrm{A}}=13.6$ $\mathrm{dBA}$. That subject experienced the only decline greater than $1.1 \mathrm{dBA}$. Because eleven subjects 
experienced improvements less than $5 \mathrm{dBA}$, it is possible that the minor improvements and declines were actually due to variability of fits, not actual reductions or improvements.

Although the average improvement in $\mathrm{NR}_{\mathrm{A}}$ was less than $2.2 \mathrm{dBA}$, the light signaling acted as a fit test because the seven subjects who could not obtain even modest protection (i.e., $>5$ $\mathrm{dBA}$ ) all reported being unable to get the light to stop flashing, making it clear to them that the plugs were ineffective. It also produced $>5 \mathrm{dBA}$ improvements for another four subjects.

In conclusion, the results suggest that some of these highly experienced workers were doing their best to protect themselves, yet were not successful. Light signaling had three beneficial effects: (1) it revealed that some workers could not obtain a $\mathrm{NR}_{\mathrm{A}}>5 \mathrm{dBA}$ and needed either training or a different protector, (2) it revealed that only two employees had excellent protection $\left(\mathrm{NR}_{\mathrm{A}}>20 \mathrm{dBA}\right)$, and (3) it lead to an improvement of at least $5 \mathrm{dBA}$ for four of the workers. 


\section{Dedication}

The author wishes to dedicate this work to his two sons,

Justin Andrew Frazer and Jackson Ansel Frazer 


\section{Acknowledgment}

This study would not have been possible without the funding support provided by the National Institute for Occupational Safety and Health (Grant 1-RO1-OH008723).

Foremost I would like to thank the chair of my committee, Steven E. Guffey, Ph.D., CIH, without whose critical mind, countless hours and life's lessons this dissertation would never have been written; next, I would like to thank Kevin L. Michael, Ph.D., for his advice and for his enormous contribution to the laboratory study; Ronald C. Althouse for advice on statistical analysis; Warren R. Myers, Ph.D., MPH, CIH for generously agreeing to sit on my committee and reviewing the noise control recommendations chapter; and, Michael J. Klishis, Ph.D., CSHM for continual support for the last decade.

Brandon C. Takacs, a friend and colleague whose chance meeting led me to this research and for whose time in I am grateful; and William H. Dodrill, Ph.D. for developing the black box and tubing concept without which this study would have been extremely difficult.

My mother- and father-in-law, Vickie Jo and William J. Milleson, Sr., for encouragement and whose generous incentive, a 1922 Ford Model T, was very much appreciated.

I would like to especially thank my parents, Joy D. and John O. Frazer, my sister Jill D. Grant, and my "Pop Pop," Joseph A. Yearick, for their loving support and encouragement throughout my life.

Justin Andrew Frazer and Jackson Ansel Frazer, I am fully aware of the hours spent working on this research that were taken away from playtime hours. We will make it up soon.

Lastly, to my best friend and loving wife, Julie Ann Frazer, Esq., without whose immeasurable sacrifice, patience, and continuous support throughout this process I would have never accomplished this goal - thank you. That 272-mile drive to Morgantown, West Virginia in January 1992 truly changed my life! 


\section{Table of Contents}

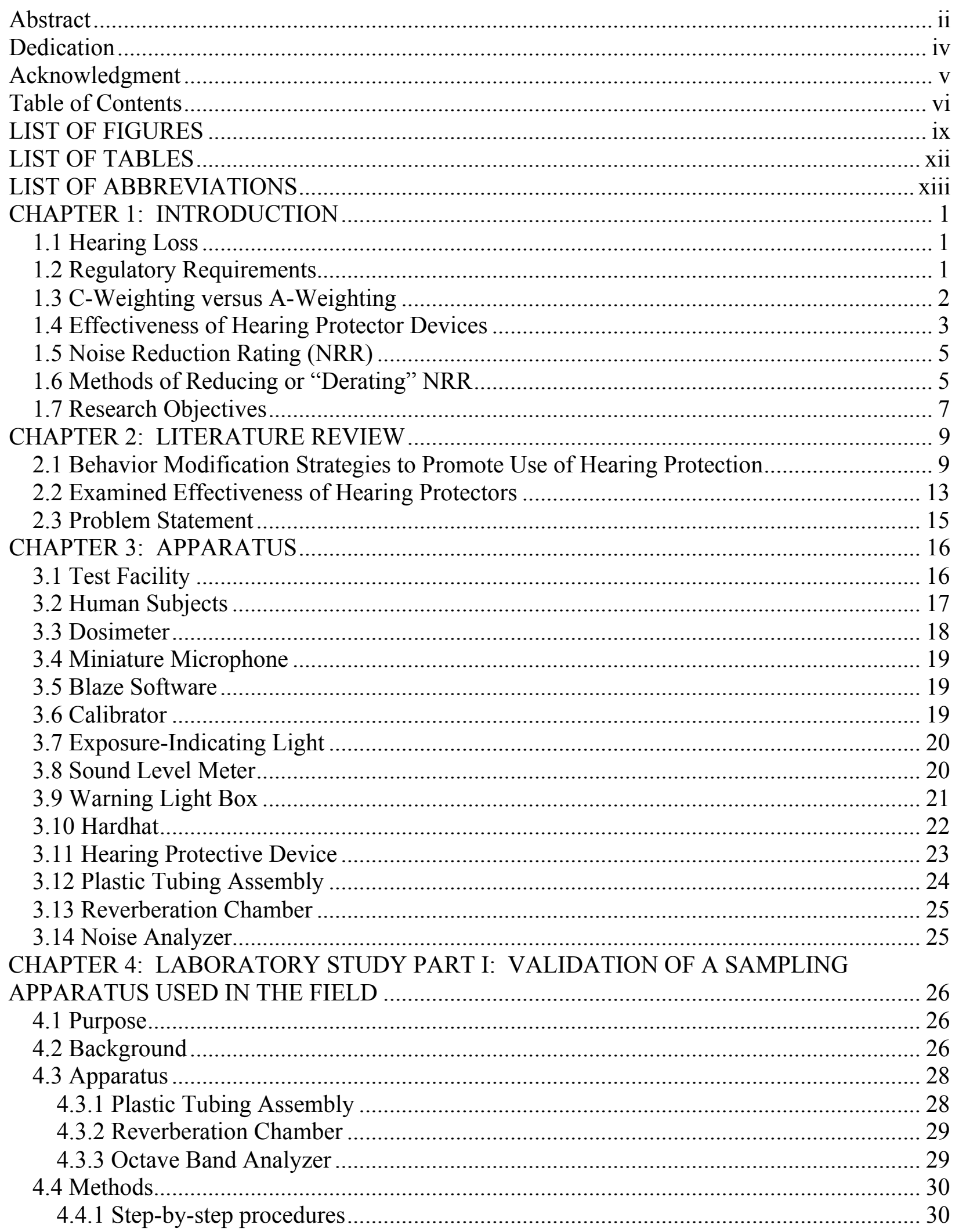




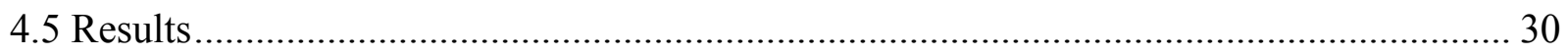

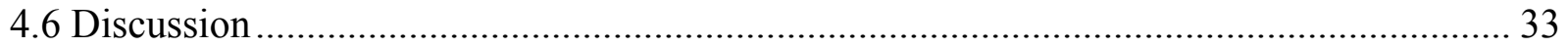

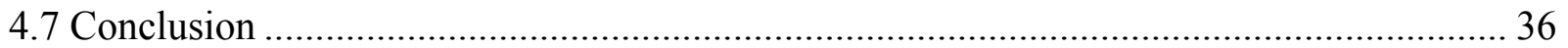

CHAPTER 5: LABORATORY STUDY PART II: INVESTIGATION OF MAXIMAL IL

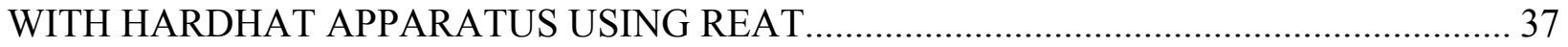

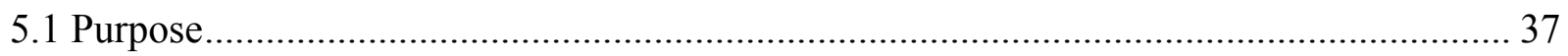

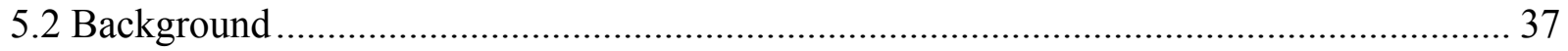

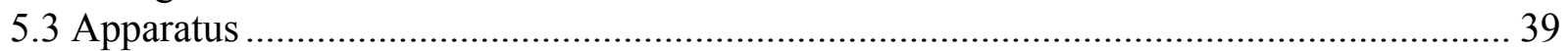

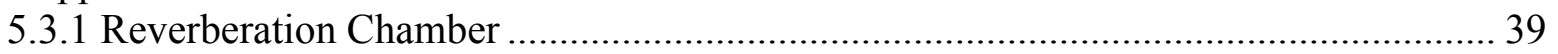

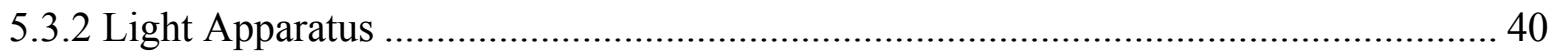

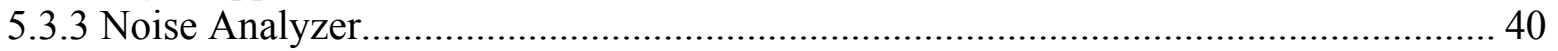

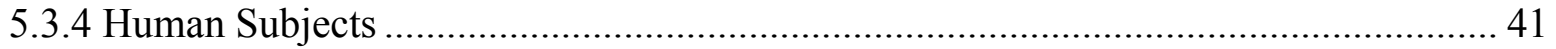

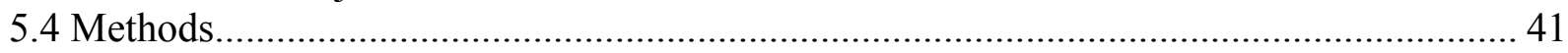

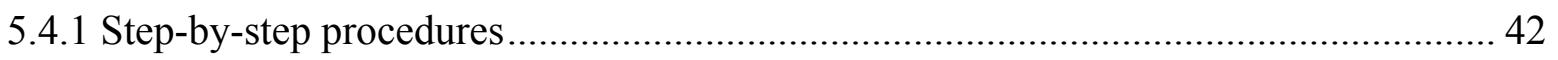

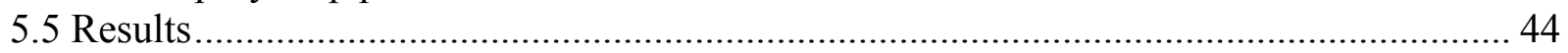

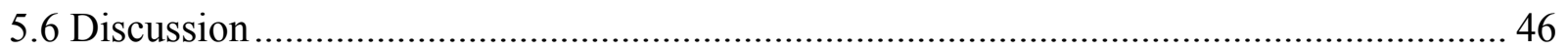

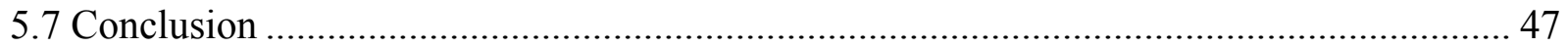

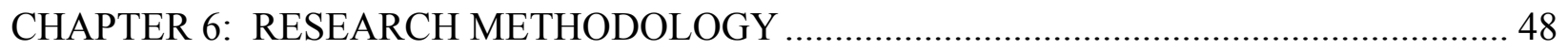

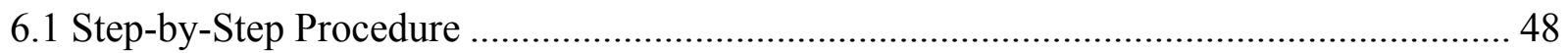

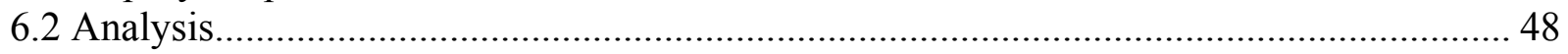

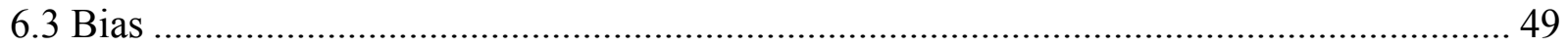

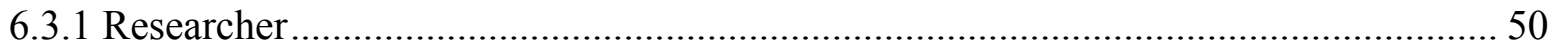

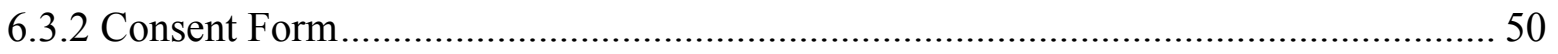

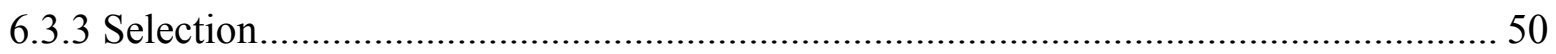

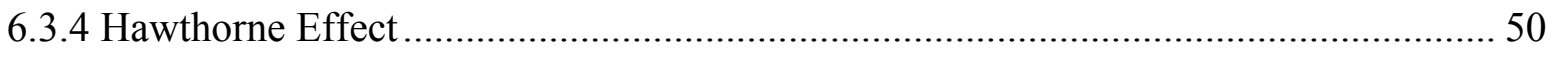

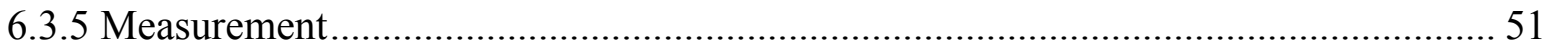

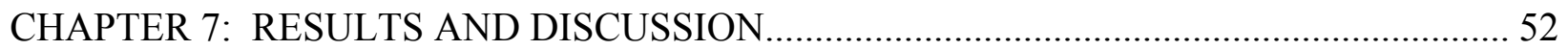

7.1 Overall NR Mean Values Compared to Published NRR Values ....................................... 53

7.2 Second-by-Second and Minute-by-Minute NR Values ....................................................... 54

7.3 Effects of Known Events on Second-by-Second Results .................................................. 72

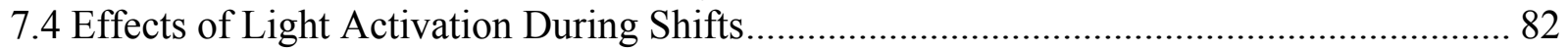

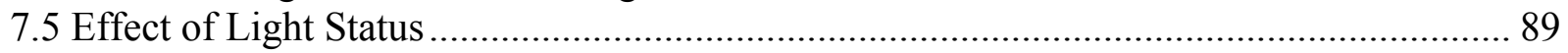

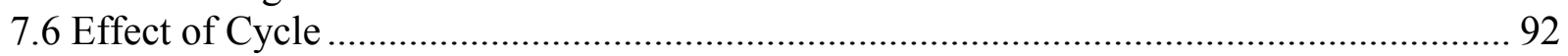

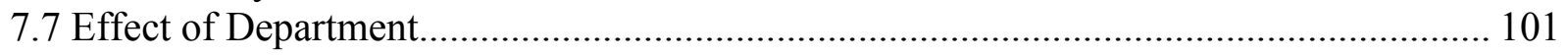

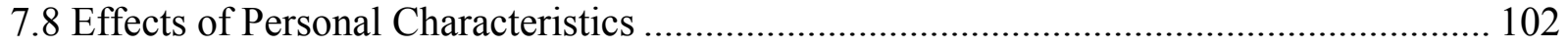

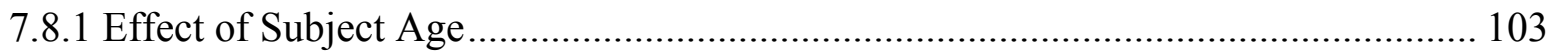

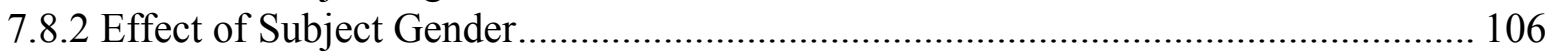

7.8.3 Effect of Subject Duration of Employment ............................................................ 107

7.9 Light Deactivated SD compared to Light Activated SD ................................................. 109

CHAPTER 8: COMPARING NR MEAN FOR FIT-TEST TO NR MEAN DURING PERIODS

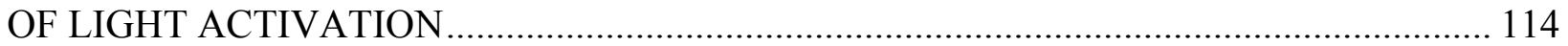

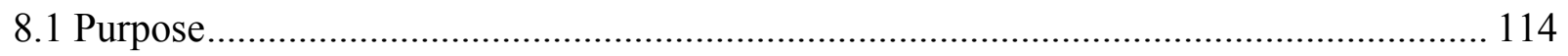

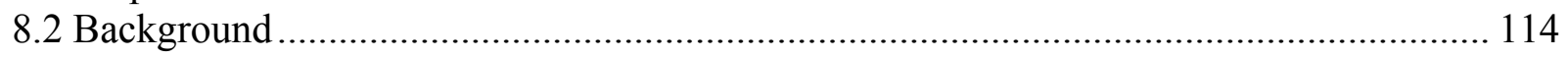

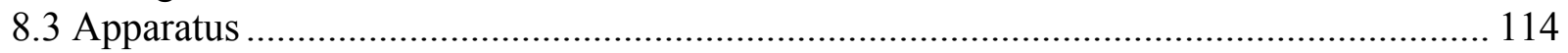

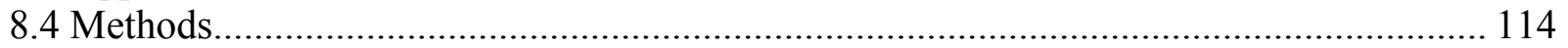

8.4.1 Step-By-Step Procedures for 20 Second NR Mean Rule.......................................... 115 
8.4.2 Step-by-step procedures for Maximum Flat NR Rule ....................................... 117

8.4.3 Step-by-step procedures for 60 Second $\mathrm{NR}_{\mathrm{A}}$ Rule ............................................ 117

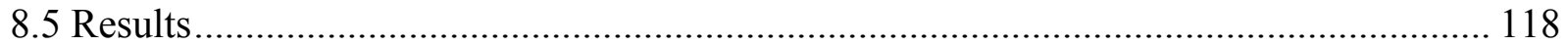

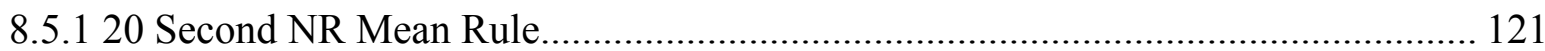

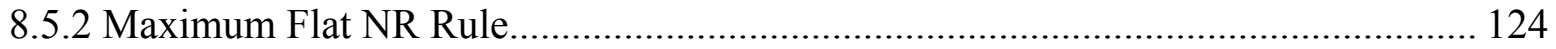

8.5.3 60 Second NR Mean Rule............................................................................ 127

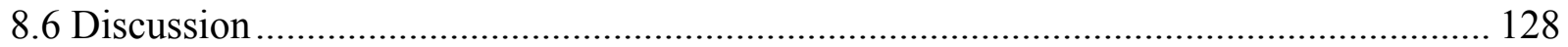

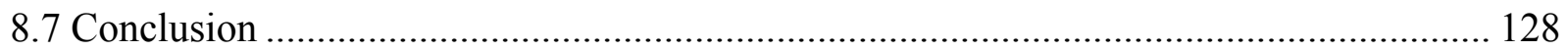

CHAPTER 9: CONCLUSIONS, CAVEATS, AND RECOMMENDATIONS ..................... 129

CHAPTER 10: NOISE CONTROL RECOMMENDATIONS .......................................... 131

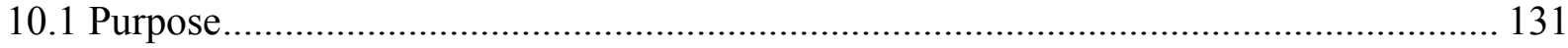

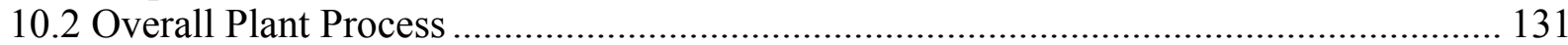

10.3 Overall Sound Map .............................................................................................. 132

10.4 Production Noise Sources and Control Measures by Department............................... 134

10.4.1 Coil Department Process Overview ............................................................... 134

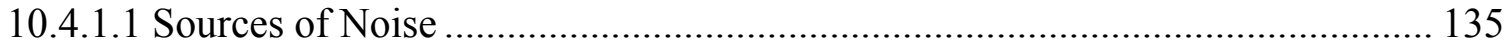

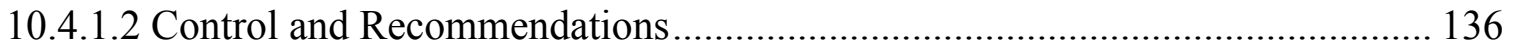

10.4.2 Coating Department Process Overview ............................................................ 139

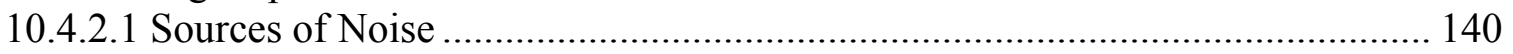

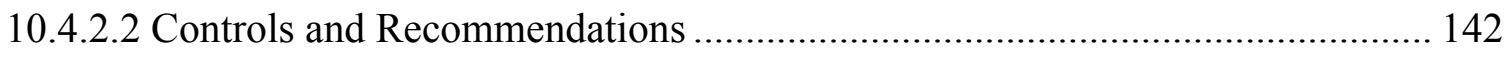

10.4.3 Stacker Department Process Overview ............................................................ 144

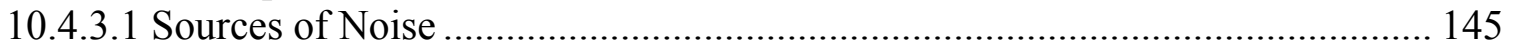

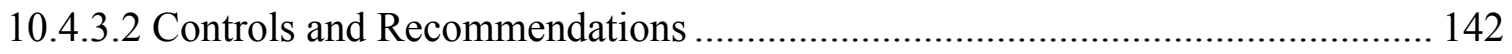

10.4.4 Press Department Process Overview ............................................................... 148

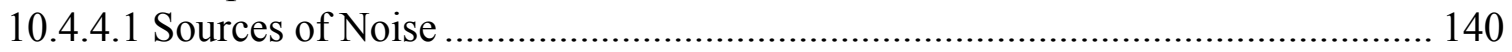

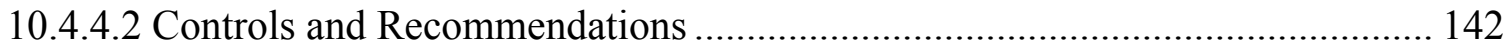

10.5 Summary of Noise Sources and Control Recommendations by Department ................ 153

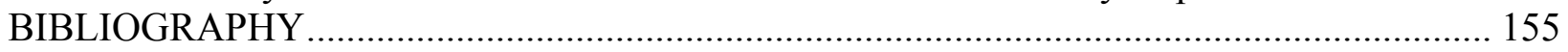

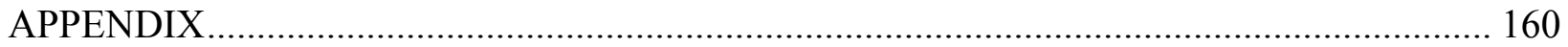




\section{LIST OF FIGURES}

Figure 1. Frequency spectra and $\mathrm{dBC}$ and dBA values for field test facility ...................... 16

Figure 2a. Human subject donning hardhat light apparatus (front view) ............................. 17

Figure 2b. Human subject donning hardhat light apparatus (back view) ............................. 17

Figure 3. Canvas belt pouch holding two dosimeters ...................................................... 18

Figure 4a. Miniature microphone with hollow plastic threaded core ................................ 19

Figure 4b. Miniature microphone with attached tubing................................................. 19

Figure 5a. Exposure-indicating light dosimeter with connected 1/16 inch miniature

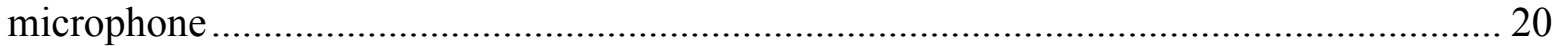

Figure 5b. Exposure-indicating warning light .............................................................. 20

Figure 6. Warning light box and photo resister cable ................................................... 21

Figure 7a. Subject wearing warning light box during Light Activated period ...................... 21

Figure 7b. Subject wearing warning light box during Light Deactivated period .................. 21

Figure 8a. Hardhat with warning light box (front) and blinking light system (back)............. 22

Figure 8b. Blinking warning light from subject point of view ......................................... 22

Figure 9a. Modified PVC foam roll-down earplug........................................................ 23

Figure 9b. Earplug modified by punching a 1/16-inch hold through the middle .................. 23

Figure 10. Plastic tubing assembly used for measuring SPL for shoulder and ear................ 24

Figure 11. Reverberation test chamber (drawing by Raphael W. Alwin Dodrill, WVU) ....... 24

Figure 12. Miniature microphone port locations shown on plastic tube assembly used for

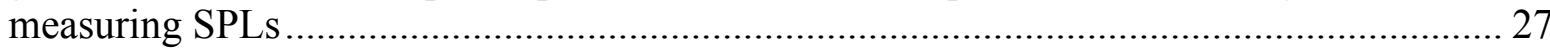

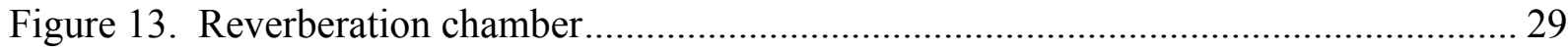

Figure 14. Sound penetration $\left(\mathrm{TL}_{\mathrm{wall}}\right)$ of tube assembly................................................. 31

Figure 15. Transmission loss ( $\left.\mathrm{TL}_{\mathrm{path}}\right)$ effect of tube assembly with both earplugs unblocked 32

Figure 16. Transmission loss $\left(\mathrm{TL}_{\mathrm{path}}\right)$ effect of tubing assembly with one earplug open/one

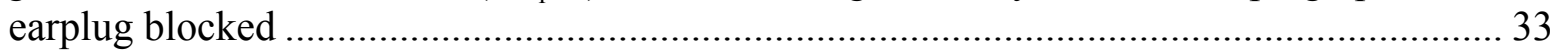

Figure 17. Human subject inserting HPD while donning hardhat apparatus........................ 37

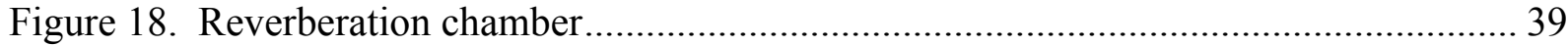

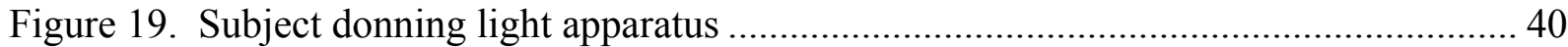

Figure 20. Custom designed automatic recording attenuator .......................................... 40

Figure 21. Attenuation versus frequency ................................................................... 45

Figure 22. Modified HPD compared to unmodified HPD ............................................... 46

Figure 23. Minute-by-minute results for Subject $6(\mathrm{NR}$ mean $=21.6 \mathrm{dBA}, \mathrm{SD}=0.2 \mathrm{dBA}) \ldots 54$

Figure 24. Second-by-second results for Subject 6 during first break................................. 55

Figure 25. Second-by-second results for Subject 6 during second break ............................. 56

Figure 26. Minute-by-minute results for Subject $2($ Mean $\mathrm{NR}=3.7 \mathrm{dBA}, \mathrm{SD}=4.6 \mathrm{dBA}) \ldots .58$

Figure 27. Minute-by-minute results for Subject $19(\mathrm{NR}$ Mean $=4.1 \mathrm{dBA}, \mathrm{SD}=3.3 \mathrm{dBA}) . .60$

Figure 28. Minute-by-minute results for Subject $20($ Mean $\mathrm{NR}=12.8 \mathrm{dBA}, \mathrm{SD}=2.7 \mathrm{dBA}) 61$

Figure 29. Minute-by-minute results for Subject 8 (Mean NR $=x x x$ dBA, $S D=x x x d B A) . .62$

Figure 30. Second-by-second results for Subject 8 between first and second break.............. 63

Figure 31. Second-by-second results for Subject 8 after first break................................. 64

Figure 32. Second-by-second results for Subject 8 (Mean NR=13.8 dBA, SD=9.2 dBA) .... 65

Figure 33. Second-by-second SPL $\mathrm{S}_{\text {shoulder }}$ mean versus NR mean for Subject $6(\mathrm{~N}=5) \ldots \ldots \ldots \ldots 6$

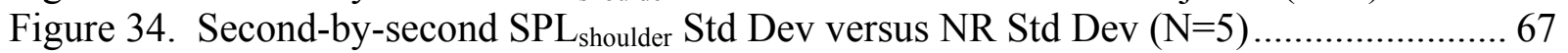

Figure 35. Minute-by-minute results for Subject 17 (Mean NR $=10.8 \mathrm{dBA}, \mathrm{SD}=5.5 \mathrm{dBA}) 68$ 


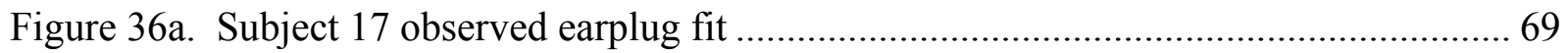

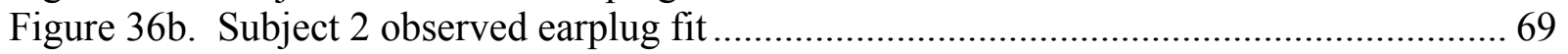

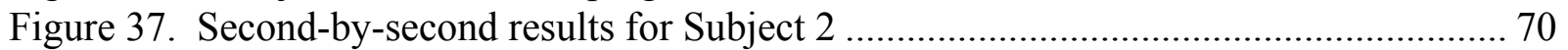

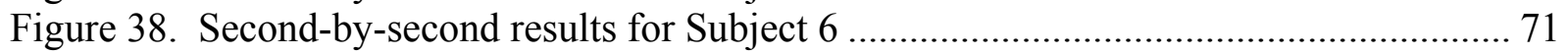

Figure 39. Observed second-by-second results .................................................................. 72

Figure 40. Observed second-by-second results ………................................................... 73

Figure 41. Observed second-by-second results ……………............................................. 74

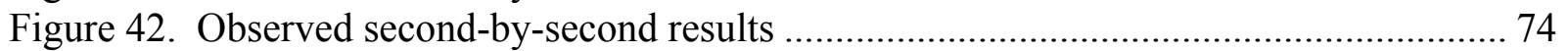

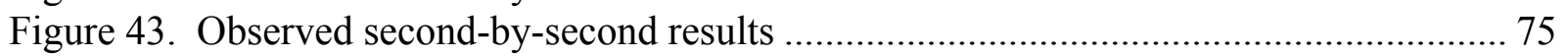

Figure 44. Observed second-by-second results ……….................................................... 75

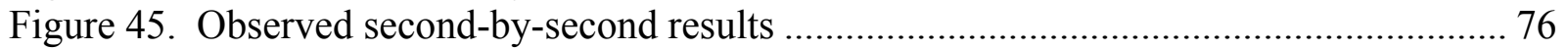

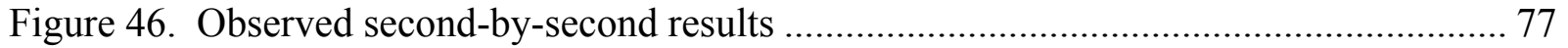

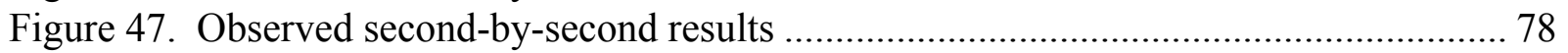

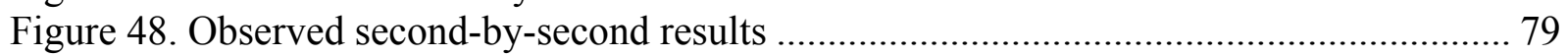

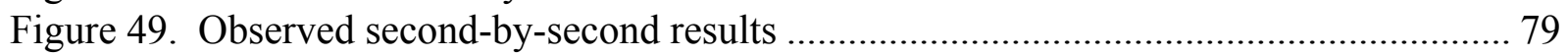

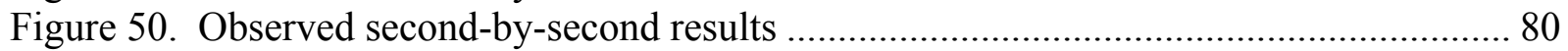

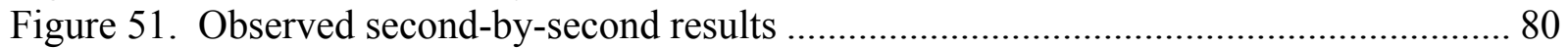

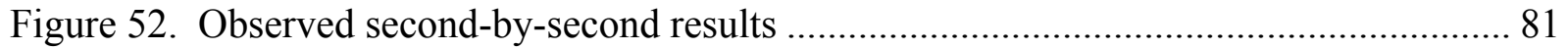

Figure 53. Percent of eligible times that light should be blinking ( $\left.\mathrm{SPL}_{\mathrm{ear}}>80 \mathrm{dBA}\right)$............ 82

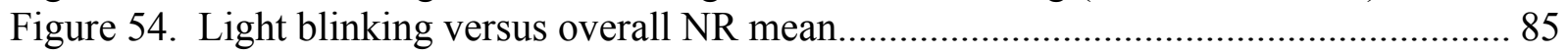

Figure 55. Light blinking versus overall NR Mean ............................................................... 86

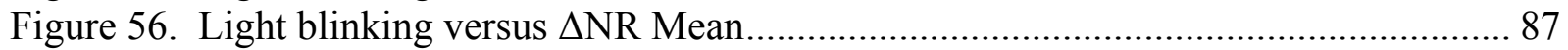

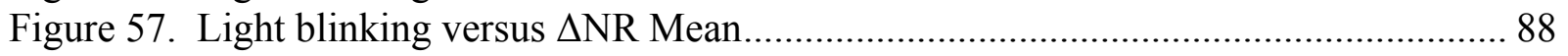

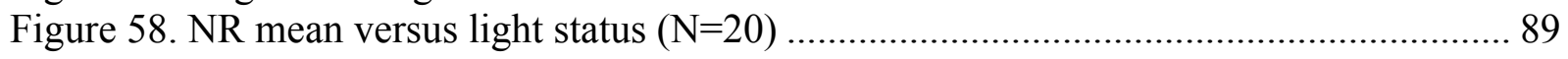

Figure 59. NR mean versus subject by light status........................................................... 90

Figure 60a. Distribution for all subjectsduring periods of Light Deactivation........................ 91

Figure 60b. Distribution for all subjects during periods of Light Activation .......................... 91

Figure 61. NR mean versus cycle by light status $(\mathrm{O}=$ light deactivated, $\mathrm{X}=$ light activated) ... 92

Figure 62. NR Mean (dBA) versus subject by cycle and light status $(\mathrm{O}=$ light deactivated,

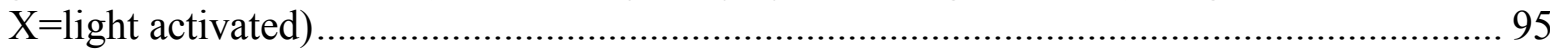

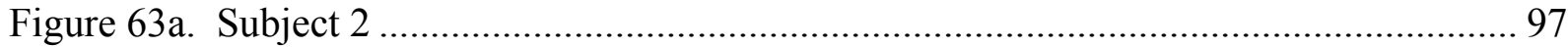

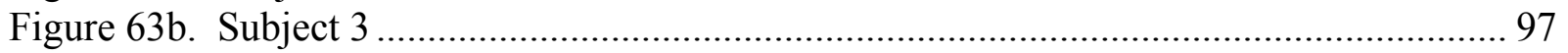

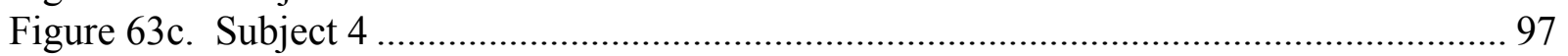

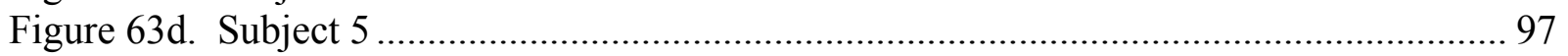

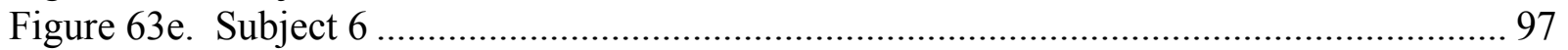

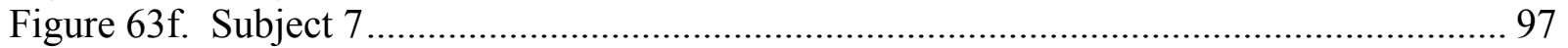

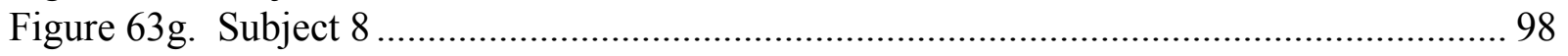

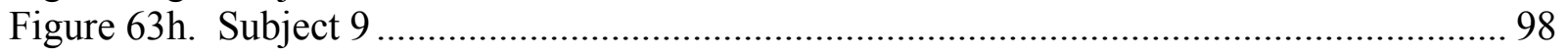

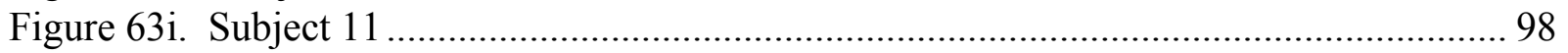

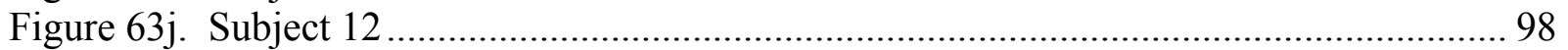

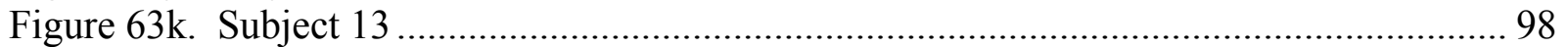

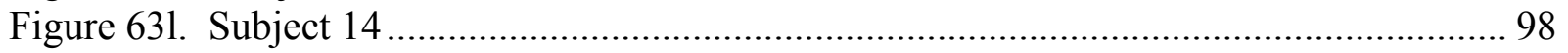

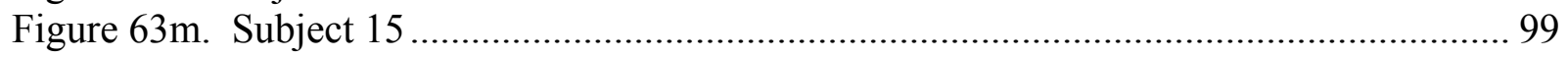

Figure 63n. Subject 16 ........................................................................................ 99

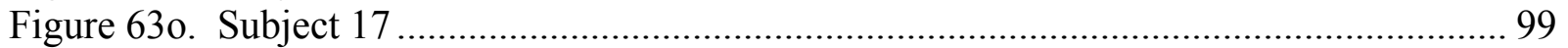

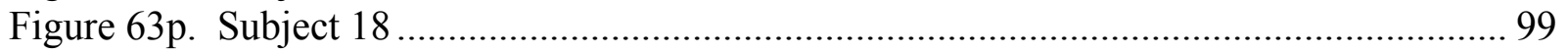




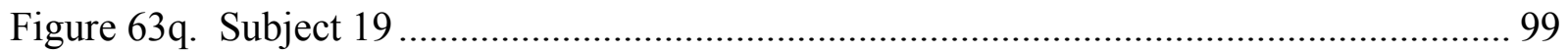

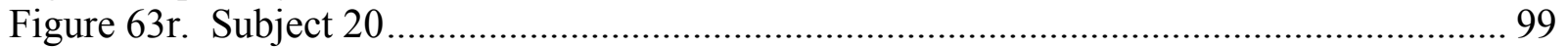

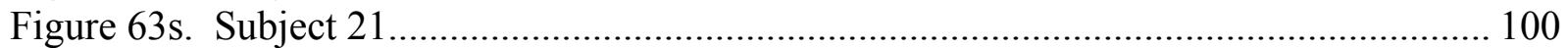

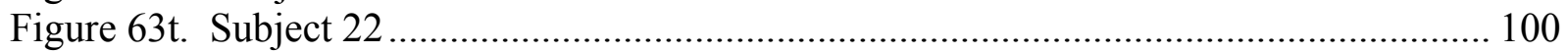

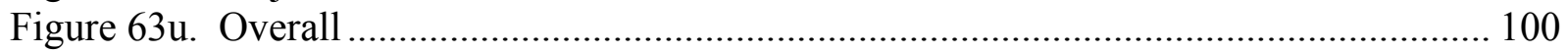

Figure 64. NR Mean versus department by light status (blue circle $=$ Light Deactivated, red X

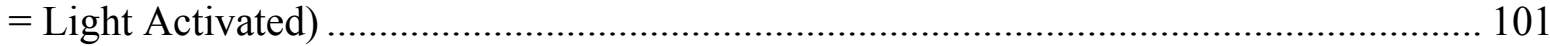

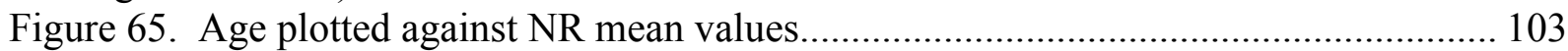

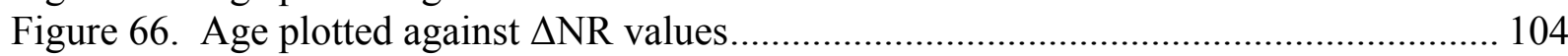

Figure 67. Gender plotted against NR Mean values ........................................................ 106

Figure 68. Duration of Employment plotted against NR Mean values.................................... 107

Figure 69. Duration of Employment plotted against $\Delta$ NR Mean values ................................ 108

Figure 70. Standard deviation plotted against light status .................................................. 109

Figure 71. NR std dev plotted against NR mean ............................................................... 111

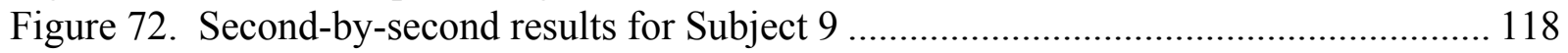

Figure 73. NR mean versus fit test mean...................................................................... 119

Figure 74. Comparison of NR Mean during fit test and during periods of Light Activated . 121

Figure 75. NR mean versus fit test mean...................................................................... 122

Figure 76. Comparison of NR Mean during fit test and during periods of Light Activation 124

Figure 77. NR mean versus fit test mean...................................................................... 125

Figure 78. Comparison of NR Mean during fit test and during periods of Light Activation 127

Figure 79. Sound map of metal products facility.............................................................. 133

Figure 80. Sound map of the coil department showing SPL (dBA) (operator locations = red

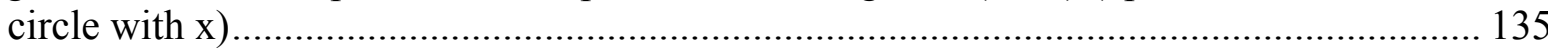

Figure 81. Frequency band measurements for coil department ......................................... 136

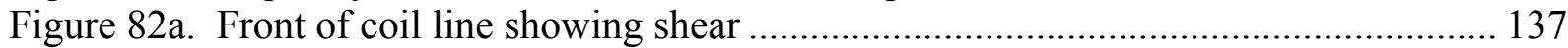

Figure 82b. Operator observing front of coil line from workstation .................................. 137

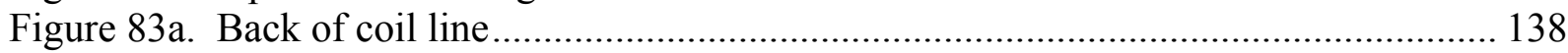

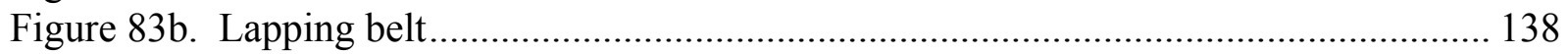

Figure 84. Sound map of the coating department SPL (dB) (operator locations = red circle

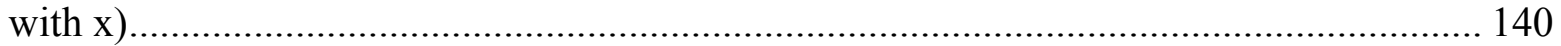

Figure 85. Frequency band measurements for coating department ....................................... 141

Figure 86. Coating department equipment...................................................................... 142

Figure 87. Door left open on enclosed coating operation .................................................... 143

Figure 88. Sound map of the stacker department SPL (dB) (operator locations = red circle with

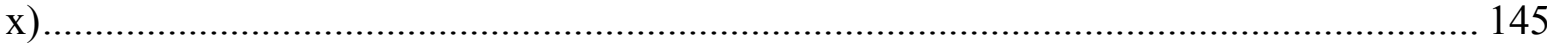

Figure 89. Frequency band measurements for stacker department..................................... 146

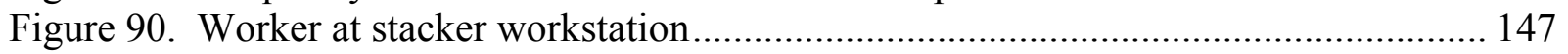

Figure 91. Oven exhaust fan at stacker ............................................................................. 148

Figure 92. Sound map of the press department SPL (dB) (operator locations $=$ red circle with

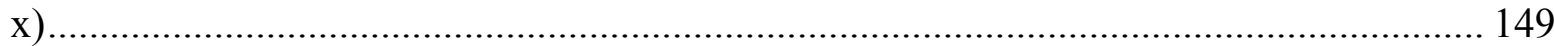

Figure 93. Frequency band measurements for press area ................................................. 150

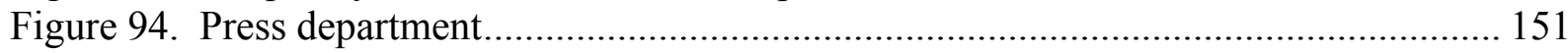

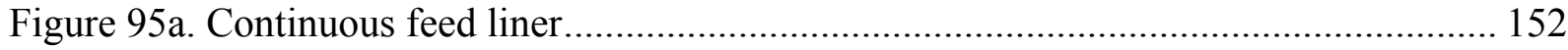

Figure 95b. Worker visually inspecting liner from the packing workstation ....................... 152 


\section{LIST OF TABLES}

Table 1. Corrections for A- and C-Weightings............................................................. 2

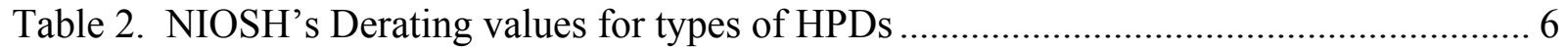

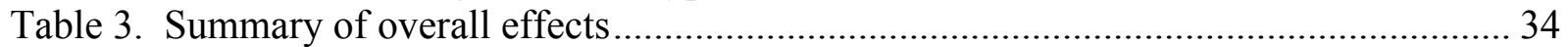

Table 4. Example of calculating $\mathrm{TL}_{\text {path }}$ effect on test spectrum ....................................... 35

Table 5. Example of calculating $\mathrm{TL}_{\text {path }}$ effect on low frequency dominated spectrum ........... 35

Table 6. Example of calculating $\mathrm{TL}_{\text {path }}$ effect on high frequency dominated spectrum .......... 36

Table 7. Tabular attenuation data by frequency for each subject and replication ................. 43

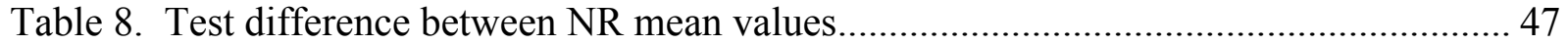

Table 9. Overall descriptive statistics for minute-by-minute NR results in dBA ................. 53

Table 10. Descriptive statistics of NR mean by light status ........................................... 57

Table 11. Percent of eligible times that light should be blinking (SPL $\left.L_{\text {ear }}>80 \mathrm{dBA}\right) \ldots \ldots \ldots \ldots . . . .84$

Table 12. Descriptive statistics of NR mean (dBA) by cycle and light status for all subjects

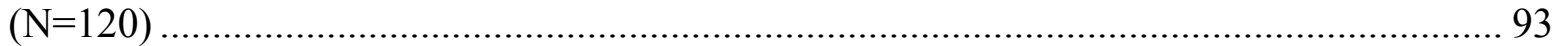

Table 13. Mean NR by department during periods of light deactivated and light activated 102

Table 14. Descriptive statistics by personal characteristics............................................ 105

Table 15. Descriptive statistics of NR Mean for male versus female................................. 105

Table 16. Standard deviation $\left(\mathrm{SPL}_{\mathrm{sh}}>80\right)$ plotted by light status...................................... 110

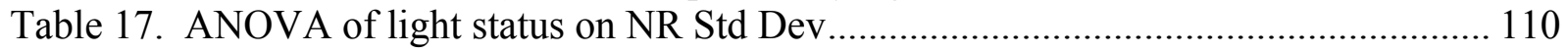

Table 18. ANOVA of light status, subject, cycle and interactions on NR mean.................. 112

Table 19. ANOVA of all periods on NR mean............................................................ 112

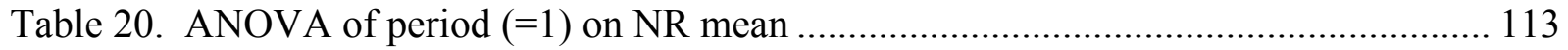

Table 21. Example of calculating the 60 second NR rule for Subject 5 ( $\cdots=$ hidden rows) $\ldots 116$

Table 22. NR mean "20 second" fit-test compared to NR mean during periods of light

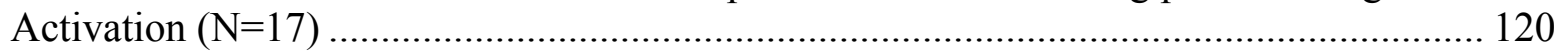

Table 23. NR mean "maximum flat NR fit-test compared to NR mean during periods of light

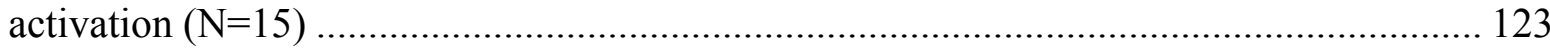

Table 24. NR mean "60 second" fit-test compared to NR mean during periods of light

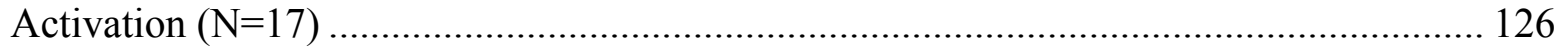

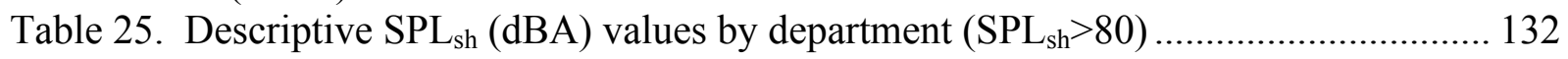

Table 26. Summary of noise sources and control recommendations by department............ 154

Table 27. Raw data (SPL, dB) by subject for each replication ...................................... 161

Table 28. Aggregate results by important variables .................................................... 162 


\section{LIST OF ABBREVIATIONS}

\begin{tabular}{|c|c|}
\hline AL & Action Limit \\
\hline ANSI & American National Standards Institute \\
\hline APF & Assigned Protection Factors \\
\hline $\mathrm{dB}$ & Decibel \\
\hline dBA & Decibel, A-weighted \\
\hline $\mathrm{dBC}$ & Decibel, C-weighted \\
\hline FLS & Flashing Light System \\
\hline HPD & Hearing Protection Device \\
\hline $\mathrm{Hz}$ & Hertz \\
\hline IL & Insertion Loss \\
\hline MIRE & Microphone in Real Ear \\
\hline NIOSH & National Institute for Occupational Safety and Health \\
\hline NIHL & Noise Induced Hearing Loss \\
\hline NR & Noise Reduction \\
\hline $\mathrm{NR}_{\mathrm{A}}$ & Noise Reduction Average \\
\hline NRR & Noise Reduction Rating \\
\hline OSHA & Occupational Safety and Health Administration \\
\hline PEL & Permissible Exposure Limit \\
\hline PVC & Polyvinylchloride \\
\hline $\mathrm{RCA}$ & Radio Corporation of America \\
\hline REAT & Real Ear at Threshold \\
\hline SPL & Sound Pressure Level \\
\hline $\mathrm{SPL}_{\mathrm{ear}}$ & Sound Pressure Level for Ear \\
\hline $\mathrm{SPL}_{\text {meter }}$ & Sound Pressure Level for Meter \\
\hline $\mathrm{SPL}_{\mathrm{sh}}$ & Sound Pressure Level for Shoulder \\
\hline SPL $_{\text {TWA }}$ & Sound Pressure Level for Time-Weighted Average \\
\hline TFOE & Transfer Function of Open Ear \\
\hline $\mathrm{TL}_{\text {path }}$ & Transmission Loss Through Path \\
\hline $\mathrm{TL}_{\text {wall }}$ & Transmission Loss Through Wall \\
\hline TWA & Time-Weighted Average \\
\hline
\end{tabular}




\section{CHAPTER 1: INTRODUCTION}

\subsection{Hearing Loss}

Hearing loss is arguably one of the most insidious health problems facing a worker in the manufacturing industry. Processing equipment, forklifts, power tools, air compressors, and even radios, are sources of occupational noise in manufacturing. The National Institute for Occupational Safety and Health (NIOSH) estimates that nearly 30 million workers daily are exposed to hazardous noise in the workplace (NIOSH, 1996). Those exposed long-term to noise levels above 85 decibels, A-weighted (dBA) have substantial risks of irreversible noise-induced hearing loss (NIOSH, 1998).

The slow progression of occupational hearing loss from exposure to noise may be less dramatic and painful than an injury resulting from a workplace incident, but it is nevertheless a permanent disability since hearing loss is irreversible (NIOSH, 1996). Hearing damage comes from the cumulative effect of long periods of high exposure to noise. Workers may not notice their hearing loss until it is too late, and many workers may believe hearing loss is an unavoidable part of their job. Fortunately, noise-induced hearing loss can be reduced or eliminated through the use of an effective hearing conservation program.

\subsection{Regulatory Requirements}

Due to the magnitude of hearing loss in the workplace, the Occupational Safety and Health Administration (OSHA) promulgated the Occupational Noise Exposure Standard in 1971. In 1983, OSHA amended the standard to require workplaces to enroll workers in hearing conservation programs when 8-hour time-weighted average (TWA) ambient noise exposures are at or above the action limit (AL) of $85 \mathrm{dBA}$. A hearing conservation program is a written safety program designed to eliminate or reduce hearing loss in the workplace. It includes noise monitoring, training, recordkeeping, audiometric testing, and use of hearing protector devices (HPDs). As part of the program, OSHA requires employers to implement feasible administrative or engineering controls to reduce worker noise exposure to below the permissible exposure limit (PEL) of $90 \mathrm{dBA}$. Under the standard, employers must use administrative or engineering controls rather than HPDs to reduce noise exposures that are above acceptable levels when such controls are feasible. 
In October 2010, OSHA issued an interpretation of the term "feasible administrative or engineering controls" as used in the occupational noise exposure standard. The agency proposed to define "feasible" as meaning "capable of being done." However, in January 2011, OSHA withdrew the proposed interpretation, citing concerns over the potential costs of making such an interpretation.

Because engineering controls can be costly, impractical or unable to reduce noise levels, employers often rely on the use of HPDs as the only method of protection for workers (Neitzel, et. al., (2008). This practice is contrary to the noise standard, as the regulation intends for HPD use to be only on a "temporary" basis. More importantly, reliance on hearing protection has too often failed to prevent hearing loss (Neitzel, et. al., (2008). Despite nearly forty years of enforcement and employer attempts at controlling noise in the manufacturing industry, workers still experience hearing loss.

\subsection{C-Weighting versus $\mathrm{A}$-Weighting}

The HPD literature frequently refers to C- and A-weighted noise measurements. These weighted measurements refer to different weighting scales (see Table 1).

Table 1. Corrections for A- and C-Weightings

\begin{tabular}{ccccccccc}
\hline $\begin{array}{c}\text { Frequency } \\
(\mathrm{Hz})\end{array}$ & 31.5 & 125 & 250 & 500 & 1000 & 2000 & 4000 & 8000 \\
\hline $\begin{array}{c}\text { C-Weighting } \\
(\mathrm{dB})\end{array}$ & -3.0 & -0.2 & 0.0 & 0.0 & 0.0 & -0.2 & -0.8 & -3.0 \\
$\begin{array}{c}\text { A-Weighting } \\
(\mathrm{dB})\end{array}$ & -39.4 & -16.1 & -8.6 & -3.2 & 0.0 & 1.2 & 1.0 & -1.1 \\
\hline
\end{tabular}

The $\mathrm{C}$-weighting $(\mathrm{dBC})$ deviates from unweighted values very little. It is intended to match the frequency sensitivity of the human ear at high noise levels. For that reason, laboratories conduct their measurements in $\mathrm{dBC}$ for purposes of calculating HPD attenuation. On the other 
hand, the A-weighting (dBA) filters out much of the low frequency noise and slightly emphasizes the upper middle frequencies $(2 \mathrm{~K}-3 \mathrm{~K}, \mathrm{~Hz})$. Of the two scales, A-weighting is more similar to the response of the human ear, and for that reason is more commonly used in field measurements (Earshen, 2003).

Therefore, $\mathrm{C}$-weighted values are calculated as:

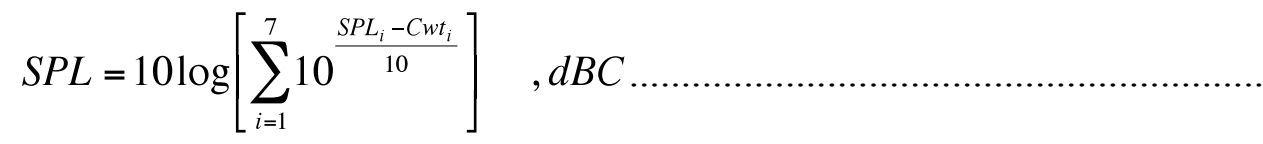

$$
\begin{aligned}
& \text { Where: } \quad i=\text { index for octave band test frequencies } \\
& \mathrm{Cwt}_{\mathrm{i}}=\mathrm{C} \text {-weighting for band } i \text { (see Table 1) }
\end{aligned}
$$

Conversely, A-weighted values are calculated as:

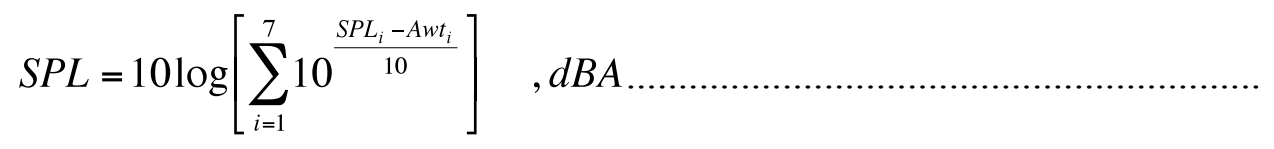

$$
\begin{aligned}
& \text { Where: } \quad \mathrm{Awt}_{\mathrm{i}}=\mathrm{A} \text {-weighting for band } i \text { (see Table 1) }
\end{aligned}
$$

It is also common practice in hearing conservation and when implementing engineering controls to report noise exposures in terms of A-weighted measurements. For example, when referring to noise induced hearing loss, OSHA in 29 CFR 1910.95(c)(1) states that, "The employer shall administer a continuing, effective hearing conservation program, ..., whenever employee noise exposures equal or exceed an 8-hour time-weighted average sound level (TWA) of 85 decibels measured on the A scale ...". Therefore, given that nearly all sound level exposures in the field are typically measured in $\mathrm{dBA}$, and conversion to $\mathrm{dBC}$ depends on what the actual frequencies are, then it becomes convenient to report noise exposure based on the $\mathrm{A}$ scale.

\subsection{Effectiveness of Hearing Protector Devices}

Hearing protector device attenuation or effectiveness is quantified as insertion loss (IL) or noise reduction (NR). The primary method of calculating IL is real-ear attenuation at threshold 
(REAT). The most commonly used method of calculating NR is microphone in real-ear (MIRE) (Berger et. al., 2005).

Real-ear attenuation at threshold is considered the "gold standard" of HPD testing (Berger, 2005). The test requires measuring a subject's hearing threshold both with ears open and with ears occluded by HPDs and must be conducted in an extremely quiet environment. The difference between the two subjective, non-simultaneous measurements is assumed to be the amount of protection (IL) afforded by the HPD.

Insertion loss is calculated as:

$$
\mathrm{IL}=\mathrm{SPL}_{\text {ear }} \text { (without HPD) }-\mathrm{SPL}_{\text {ear (with HPD) }}
$$

Where: $\mathrm{SPL}_{\mathrm{ear}}=$ noise level measured proximal to the hearing protector

The other primary approach, MIRE, involves measurement of SPL outside (i.e., shoulder) and inside the HPD. The computed difference can be either IL (sequentially measured) or NR (simultaneously measured) (Berger, 2005).

The objective, simultaneous measurement is defined as NR and is calculated using:

$$
\mathrm{NR}=\mathrm{SPL}_{\text {ambient }}-\mathrm{SPL}_{\mathrm{ear}} \text { (with HPD) }
$$

Where: $\mathrm{SPL}_{\text {ambient }}=$ noise level measured proximal to the shoulder

The relationship between IL and NR may be calculated using (Berger, 1986):

$$
\mathrm{IL}=\mathrm{NR}+\mathrm{TFOE}
$$

Where: TFOE is the transfer function of the open ear

The transfer function of the open ear is used when comparing the relationship between IL and NR. The TFOE is the amplification of the undisturbed sound field caused by the human ear canal and pinna. It varies with the noise frequency and subject (Casali et. al., 1995). For these 
reasons, Neitzel, et. al., (2006) suggested using the NR of HPD to predict noise protection in the field, although it provides lower values than IL.

Real-ear attenuation at threshold and MIRE each have advantages and disadvantages. Both assess HPD effectiveness only for the time of testing (Hager, 2007). To achieve a higher level of accuracy and precision, the test should be repeated frequently, preferably during the work shift. Unfortunately little is known about the representativeness of fit-tests done once in an office environment to actual NRs experienced during work. The theory of repeated measures of NR during work has not been experimentally demonstrated.

\subsection{Noise Reduction Rating (NRR)}

To help ensure that HPDs are effective the Environmental Protection Agency (EPA) requires a noise reduction rating (NRR) on all HPDs sold in the United States. The NRR is intended to be an easily understood estimate of the HPD's ability to reduce noise reaching the ear canal (EPA, 1979).

The NRR is intended to be the amount of attenuation that a specific earplug will provide to over 95 percent of workers if it is worn correctly (ANSI, 1974). Thus, if employers ensure that exposed workers wear HPDs whose NRR values are high enough to reduce exposure in the ear to below $90 \mathrm{dBA}$, the workers' hearing would not decline as much as they would without any protection. Reducing true exposures from $90 \mathrm{dBA}$ ( 29 percent excess risk) to $80 \mathrm{dBA}$ ( 3 percent excess risk) or less would further reduce noise induced hearing loss (NIOSH, 1998).

The efficacy of NRR values is very much in doubt (Berger, 2003). Indeed, several studies documented substantial hearing loss even when workers were supplied appropriate HPDs (Neitzel and Seixas, 2005). For that reason, two important issues need to be considered in order to prevent hearing loss with use of HPDs: improper fit and wear time (Tsukada and Sakakibara, 2008). However, few studies to date have had objective measures of these issues.

\subsection{Methods of Reducing or "Derating" NRR}

The NRR is a REAT method with investigator coaching of the subject to ensure the best possible fit. The single number NRR estimates the $98^{\text {th }}$ percentile of protection obtained by users when properly fitted. It is intended for use with $\mathrm{dBC}$ noise measurements, therefore 
NIOSH recommended, and the EPA mandated, that 7-dB conversion estimate between $\mathrm{C}$ - and Aweighting be applied when the NRR is used with A-weighted noise levels.

Well-documented discrepancies between laboratory and real world use of HPDs (Berger, 1993) have led OSHA and NIOSH to develop formulas to reduce the published NRR to a more likely estimate.

In their technical manual for inspectors OSHA has stated that the hearing protection should be reduced or "derated" to account for how workers typically wear protection as opposed to how laboratories test the protector's attenuation (OSHA, 1999). For all types of hearing protection, OSHA's “derating" factor is 50 percent. Therefore, the reduced NRR is calculated as:

$$
\mathrm{NRR}_{\text {reduced }}=\frac{N R R}{2} \mathrm{~dB}
$$

For example, using Equation 6, a slow recovery formable earplug with a published NRR value of $29 \mathrm{~dB}$ would have the following "derating":

$$
\mathrm{NRR}_{\text {reduced }}=\frac{29}{2}=14.5 \mathrm{~dB}
$$

On the other hand, NIOSH has a different, more detailed manner to adjust the published NRR based upon the type of protector (NIOSH, 1998). Their "derating" factors for various types of HPD are shown in Table 2.

Table 2. NIOSH's Derating values for types of HPDs

\begin{tabular}{cc}
\hline Hearing Protection Type & $\begin{array}{c}\text { Percentage to Subtract from Published NRR } \\
(\%)\end{array}$ \\
\hline Earmuffs & 25 \\
Slow-Recovery Formable Plugs & 50 \\
All Other Earplugs & 70 \\
\hline
\end{tabular}




\subsection{Research Objectives}

Although hearing conservation programs require the use of HPDs, the programs fall short on ensuring the proper fit of HPDs. Levels of protection provided by HPDs are diminished by workers' failure to consistently wear the protectors correctly and when needed (Berger 2003). Sometimes hearing conservation programs implement disciplinary actions, including firing, for failure to use HPDs. Furthermore, it is not at all certain that particular earplugs protect workers, even when they do their best to wear them properly. Hearing protection devices fail either because of inadequate training of workers or undetected mismatches between workers and their earplugs.

This research attempts to modify the behavior of employees more diligent in wearing their earplugs properly and provide feedback to let them know when adjustments are necessary. It is possible that providing quantitative feedback would help individual workers recognize that their hearing protector is either not properly seated or is not in place when needed. It is also possible that workers sometimes forget to re-insert the HPD after removing it temporarily, underestimate the cumulative effects of "temporary" non-usage, and underestimate the noise level. If so, it is possible that immediate feedback of their exposure would both alert them and prod them to redon their HPD when alerted of high noise levels in their ears. And ultimately, a more positive attempt of influencing behavior is simply alerting workers immediately when their HPD fails to protect their hearing.

In this study each subject was fitted with an electronic device set to cause a light to blink if the SPL exceeded $80 \mathrm{dBA}$ in the ear canal and the light system was activated. The work shift was divided into six roughly equal periods with alternating periods of light system activated and light system deactivated. During the first, third, and fifth periods the light was deactivated and covered with a black cap but otherwise was unchanged. For periods two, four, and six, the light was activated.

The main goal of this research was to test the effectiveness of alerting workers immediately when noise levels in their ears exceed $80 \mathrm{dBA}$. The research provides information knowledge based on real-time fit of HPDs in the workplace by quantitatively measuring SPLs using MIRE to determine the effectiveness of a behavior modification intervention. 
Specifically, the goals of this research are to:

1. Develop and validate a signaling intervention that warns workers when noise inside their ears is excessive (laboratory study I).

2. Determine REAT insertion loss values for experienced subjects tested while wearing the measurement apparatus and compare to NRR values for the same earplug (laboratory study II)

3. Measure $\mathrm{SPL}_{\text {ear }}$ and $\mathrm{SPL}_{\mathrm{sh}}$ second-by-second and determine minute-by-minute NR mean values for manufacturing workers during six alternating test periods (realworld study).

4. Evaluate effectiveness of light alert by comparing mean and SD of NR when the signal light is potentially active to when it is deactivated.

5. Determine percentage of the times when the light blinking system was activated (should be blinking) for each subject to identify opportunity to improve behavior.

6. Compare personal characteristics (age, gender and duration of employment) to NR mean value.

7. Determine if "working fit-test" NR mean values predict NR averages for selected periods.

8. Identify sources of noise exposure in four departments and recommend noise controls. 


\section{CHAPTER 2: LITERATURE REVIEW}

\subsection{Behavior Modification Strategies to Promote Use of Hearing Protection}

Studies of behavior modification strategies intended to promote the use of hearing protection have primarily focused on educational programs, reinforcements ("boosters"), and information feedback. For example, Zohar, et. al., (1980) evaluated an information feedback intervention by comparing observed workers' use of earplugs in two departments over a five month period at an Israeli manufacturing plant. The tested outcome was the observed behavior of earplug use (number of observed workers using earplugs / number of observed workers) during three stages (baseline, treatment, and follow-up) over five months. The subjects in the treated department received a lecture and information feedback (pre- and post-shift audiometric testing). This feedback provided the amount of temporary threshold shift that each individual had incurred during shifts they had worn their earplugs and shifts when they had not. A similar department used as a control received a lecture but did not receive a hearing test or associated feedback. During the three stages, random safety observation walkthroughs were conducted in which earplug use was observed and recorded. After five months of safety observations, the treated department showed a significant $(\mathrm{p}<0.01)$ increase from 30-50 percent at baseline to 80-90 percent of observed earplug users over the control department. In addition, the difference in observed earplug users in the treatment department during the baseline and fifth month were compared and found to be significant $(\mathrm{p}<0.001)$. There was no objective determination of whether hearing was better conserved with the intervention than without it.

In a follow-up study, Zahar and Fussfeld (1981) used an incentive program to modify earplug-wearing behavior of textile workers in an Israeli factory. During walkthroughs they recorded the observed use of earplugs. The results of the intervention were found to be highly effective at both enhancing and maintaining behavior change. There was no objective determination of whether hearing was better conserved with the intervention than without it.

Ewigman, et. al., (1990) evaluated the effects of an educational intervention on noise induced hearing loss for 89 active full time firefighters in Columbia, Missouri. The intervention was conducted in two phases over a three-month period. Phase one was the delivery of an intensive education program on prevention of NIHL over the course of one month. Phase two 
included a two-month hearing protection test period with three choices of protection (muffs, formable plugs, or pre-molded plugs). A pre-intervention questionnaire was used as a baseline measurement of knowledge and attitudes towards noise induced hearing loss. One month later, an identical questionnaire was completed post-intervention. The results indicated that noise induced hearing loss knowledge and attitudes towards prevention of noise induced hearing loss increased. Most importantly, exposure to the intervention brought about a dramatic change in behavior, with 20 percent use of hearing protection at the pre-intervention and 85 percent use after the intervention based on self-reports on the questionnaire. A limitation of the study was the underestimation of the effect of the intervention due to a low response rate on the preintervention questionnaire (56 of 89 firefighters). Finally, the noise reduction rating of the protection was not determined. Once again, there was no objective determination of whether hearing was better conserved with the intervention than without it.

Lusk, et. al., (1999), measured the effect of an intervention to increase the use of hearing protection devices among a group of Midwestern construction workers $(\mathrm{N}=652)$ and a national group of plumber/pipefitters $(\mathrm{N}=185)$. The intervention consisted of an interactive 20-minute video and pamphlets, plus guided practice with various types of hearing protection devices. Frequency of use of hearing protection devices, and intention to use hearing protection devices in the future, were self-reported. After the 10 to 12 month follow-up post-test, the results indicated that the intervention resulted in a $30 \%$ increase in the self-reported use of hearing protection devices from $34 \%$ to $64 \%$, but had no effect on intention to use HPDs in the future. Nevertheless, studies of HPD use should incorporate audiometric testing for an accurate assessment of hearing ability.

Lusk, et. al., (2003) tested two interventions to increase factory workers' use of hearing protection devices at an automotive factory in the Midwest. The group study examined selfreported use of hearing protection devices for 1,325 subjects. Subjects were randomly assigned to receive one of the three computer-based programs (control, tailored, and non-tailored). The results indicated that workers in the non-tailored intervention decreased their use from 78.1\% pre- to $76.9 \%$ post-test $(\mathrm{p}=0.264)$, while the control group increased from $74.6 \%$ to $76.2 \%(\mathrm{p}=$ 0.138). The tailored intervention increased reported use from $79.1 \%$ to $82.6 \%(\mathrm{p}=0.001)$. 
There was no objective determination of whether hearing was better conserved with the intervention than without it.

Lusk, et. al., (2004) evaluated the effect of four "booster" timings (30 days, 90 days, 30 and 90 days, no booster) on 1,325 subjects. Results indicated that although the 30-day booster intervention group tended to have a higher self-reported use of hearing protection devices $(82.6 \%$ to $87.4 \%$ ), there were no significant effects on post-test hearing protection device use across the four booster conditions. The results suggest that maintaining changed behavior is difficult. There was no objective determination of whether hearing was better conserved with the intervention than without it.

Stephenson, et. al., (2005) evaluated the effectiveness of postcard mailings containing three messages (positive, negative, or neutral) on self-reported hearing protection use for 307 coal miners in West Virginia and Pennsylvania. A post-test measurement of the effectiveness of the messages was conducted about a week after the cards were mailed, while a post-test measurement was conducted six weeks later. The results of the one-week post-test suggested that positive or neutral messages generated significantly more self-reported hearing protection behaviors than the negative message. Identical results were obtained in an assessment six weeks after the messages. There was no objective determination of whether hearing was better conserved with the intervention than without it.

Hong, et. al., (2006) evaluated a tailored intervention combined with a self-administered hearing test to increase the use of hearing protection devices. The study examined both short and long term effects of the intervention. Based on subjects' hearing test results, the treatment group received further feedback via a computer-based program. Pre- and post-intervention questionnaires were used to assess intervention success. The results indicate the short-term intervention significantly increased subject's self-reported hearing protection use, while the longterm intervention results did not further improve subject's self-reported hearing protection use. The authors acknowledged that changing and sustaining worker behaviors in regard to the use of hearing protection devices was not easy. There was no objective determination of whether hearing was better conserved with the intervention than without it. 
El Dib, et. al., (2007) summarized literature for the effectiveness of interventions to enhance the wearing of hearing protection among workers. Of the 1,500 articles, only three studies met the minimum methodological criteria outlined by the authors. The articles were included only if noise exposed workers were exposed to an intervention to promote the wearing of hearing protection and with the use of hearing protection being the measured outcome. Two of the three studies included used the same participants to study two different interventions. In all three studies, there was no objective determination of whether hearing was better conserved with the intervention than without it.

Kerr, et. al., (2007) studied the effectiveness of two computer-based educational interventions "tailored" and "targeted" with and without booster messages to promote the use of hearing protection among 343 construction workers. The self-reported results indicated that workers improved use of hearing protection from 42 to 50 percent of the time after one year ( $p<$ 0.001 ). Differences between the two educational intervention groups were not significant and therefore, the authors suggested, "since targeted interventions are less costly to develop, targeted interventions offer greater value." Low retention rates, use of a "convenience" sample of workers, and high variability across subject trade groups were stated limitations of the study. Again, there was no objective determination of whether hearing was better conserved with the intervention than without it.

To investigate the effectiveness of inserting different HPDs in trained and non-trained subjects, Goncalves, et. al., (2009) measured the IL of hearing protectors (foam earplugs, threeflange silicone earplugs, "olive-end" earplugs and "shell" earplugs) by means of free-field audiometry and microphone probe measurements with and without HPD. Two groups were evaluated: Group 1, with 23 workers trained in the use of hearing protectors, and Group 2, with 8 non-trained ones. The results indicated that the differences of hearing thresholds with and without HPD were greater for the trained group than those with no training. "Shell" earplugs produced average values higher than those of the other types tested; and "olive-end" earplugs produced the lowest values. In conclusion, training on hearing protector use is necessary and must be included in hearing conservation programs. 
Despite numerous studies of interventions intended to promote hearing protection use, many questions remain unanswered. Some of the interventions studied appeared to have some success in modifying hearing protection use at least in the short term, though not necessarily successful in the long term. Only a few studies addressed long term behavior following interventions intended to promote hearing protection use. They found varying degrees of persistence of effectiveness. Even if hearing protectors were worn 100 percent of the time it would not matter

for those individuals whose protector was ineffective when they were wearing it. In other words, there was no objective determination of whether hearing was better conserved with the intervention than without it.

\subsection{Examined Effectiveness of Hearing Protectors}

Although it is important to improve worker compliance in wearing hearing protection when needed, it is also important that the hearing protector is actually effective when the worker wears them with diligence. One approach to hearing conservation is based on the idea that workers need quantitative feedback on their actual noise exposure (Burks and Michael, 2003). The idea led to the development of a unique technology called the Exposure Smart Protector (ESPTM) (Burks and Michael, 2003). The instrument monitors noise level proximate to the HPD (SPLear) during a normal work shift. Developed by doseBusters USA (College Park, PA), the instrument integrates a personal noise dosimeter with traditional hearing protection to measure dose at the ear. According to Burks and Michael (2003), field studies have been conducted by doseBusters USA and have demonstrated when workers wore the ESP as instructed, they achieved daily noise exposures below OSHA's AL. Furthermore, Burks and Michael (2003) found that most noise exposures could be maintained below a TWA of $80 \mathrm{dBA}$ in the mining industry.

Neitzel and Seixas (2005) studied the effectiveness of HPDs among construction workers. Simultaneous noise exposure measurements and self-reported use of HPDs were collected on workers over full shifts. Results showed that exposure levels exceeded $85 \mathrm{dBA}$ nearly $30 \%$ of the shift, during which workers self-reported HPD use was nearly 17\%. The percentage of time that workers used HPDs when exposed to levels exceeding $90 \mathrm{dBA}$ was nearly the same $(17.5 \%)$. In addition, direct measurements of HPD attenuation using a fit-test (FitCheck) to determine the actual attenuation achieved by workers found that workers achieved the highest 
mean binaural personal attenuation rating using Max-Lite (Howard Leight) plugs (20.4 dB). Neitzel and Seixas (2005) state, "By combining information on usage time of HPDs and simultaneously-measured noise exposure data with direct measurements of HPD attenuation, this study has demonstrated that the protection afforded to construction workers by their hearing protection is small, and that they remain at high risk of hearing loss despite the industry's limited efforts." The study also found that workers, on average, achieved greater than half the published NRR with a large variability between subjects resulting in some workers achieving more than the NRR, while others achieved almost none.

Tsukada and Sakakibara (2008) investigated the effect of group and individual training with a fit-testing device to promote the use of hearing protection devices. They tested 68 male workers exposed to noise levels above $80 \mathrm{dBA}$ at an electronic parts manufacturer in Japan. Preand post-education questionnaire surveys were conducted on the status of earplug use. In addition, a fit test device was used to measure the actual noise attenuation provided from using the earplugs. The results indicated that individual noise protection training using a fit-tester was effective in increasing both the wearing rate and proper use of hearing protection devices. Among workers in loud working environments, training with a fit-testing device increased earplug use from $46 \%$ to $66 \%$ over two months after the training $(\mathrm{p}<0.05)$. The percentage of workers who obtained a sufficient NR of $\geq 25 \mathrm{~dB}$ in both ears with the proper use of earplugs increased from $46 \%$ to $72 \%$ just after training $(\mathrm{p}<0.001)$. Study weaknesses were the small number $(n=68)$ of subjects, and the lack of a control group. Additionally, the workplace ambient noise exposure level was relatively low $\left(\mathrm{L}_{\mathrm{eq}}=80 \mathrm{dBA}\right)$. The advantages of this study were that the subjects were fit-tested and the individual's noise reduction rating of the hearing protection was determined. The feedback of being told the NR one has achieved when fitting an earplug in this study was shown to improve NR values. Therefore, one cannot assume a hearing protector works. Fit-testing has been used as an intervention to train and provide feedback to workers of their fit test results so they could better adjust their HPD. However, it is not clear whether the beneficial results were due to workers switching from a hearing protector that could not work for them to one that did and how much was due to improving the fit of a given protector. 
Because it is not clear how effective HPDs are during actual use and it is not clear that fittesting represents protection during work, $\mathrm{Wu}$ (2010) investigated both issues for coal miners using two hearing protectors (E-A-R earplug and Peltor earmuff). The results found that failure to wear HPDs was the main cause of low NR mean values during coal mine work and that a onetime fit-test was not adequate. The author suggested that multiple fit-test measurements should be taken in order to determine a worker's achieved HPD noise protection.

\subsection{Problem Statement}

Few studies to date (Burks and Michael (2003), Neitzel and Seixas (2005), Tsukada and Sakakibara (2008), Wu (2010)) have had objective measures of protection. There are other possible interventions that could be best studied using objective measures of actual protection achieved while working, but did not appear in the literature. This study tested one possible intervention. This study investigates the real time improvement in experienced protection due to using a signaling light to indicate when HPDs are failing to adequately protect subjects. The assumption is that workers will put HPDs back on or attempt to improve the fit of HPDs when a blinking light lets them know that at least one of their ears is overexposed. 


\section{CHAPTER 3: APPARATUS}

This research was carried out at a metal products manufacturing facility. The main equipment (noise instrumentation, plastic tube assembly, flashing light system), and its use in this study are discussed in this section.

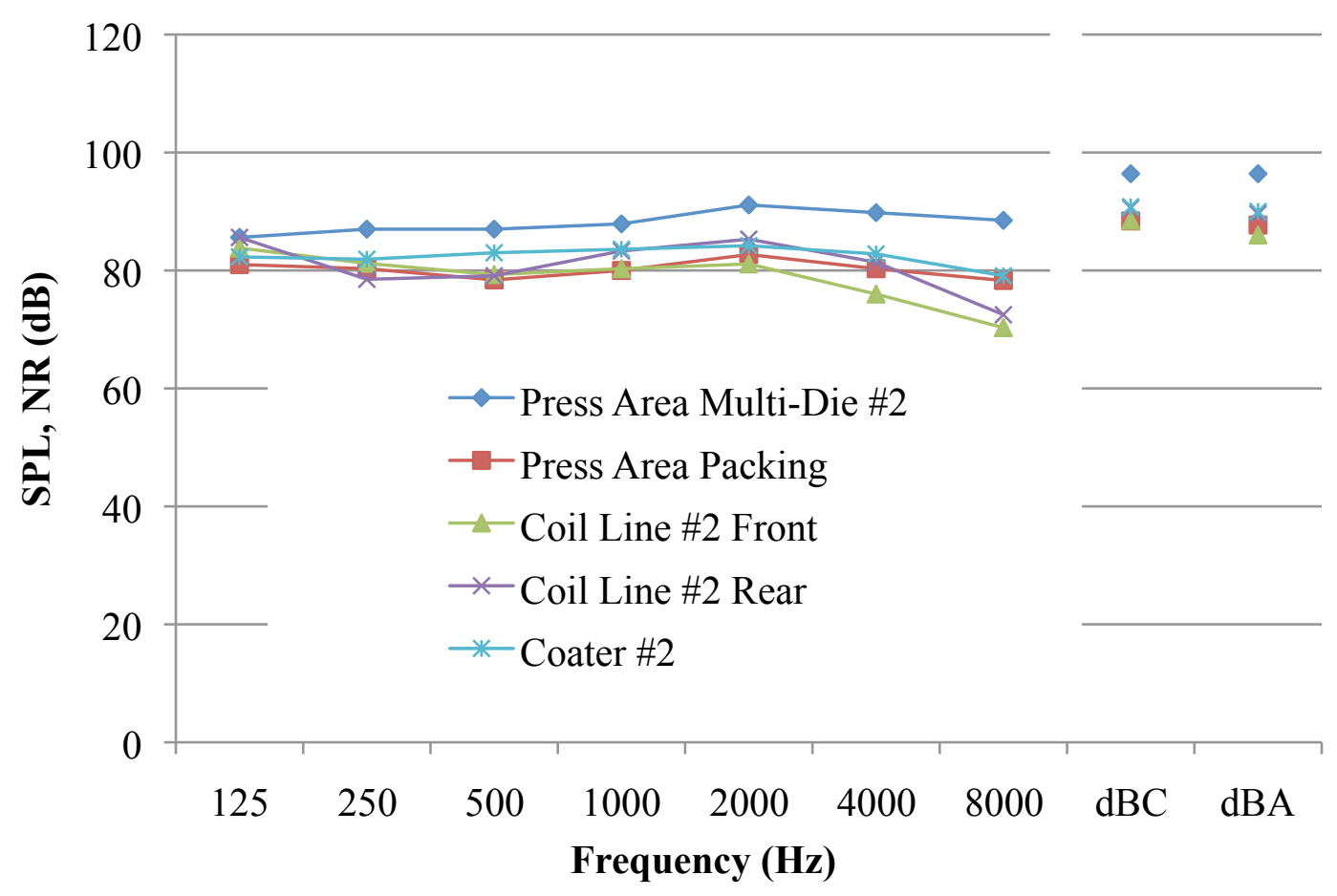

Figure 1. Frequency spectra and $\mathrm{dBC}$ and $\mathrm{dBA}$ values for field test facility

\subsection{Test Facility}

Production at the test facility consisted of five processes, which were described as: un-coil, cut, coat, stack, and press steel. These processes ran continuously 24-hours per day, five days per week. All of the studied processes were in one building without walls separating the processes. The lack of dividing walls allowed noise to travel across the building from all sources and the hard surfaces produced a reverberant background noise level that generally exceeded 80 dBA. The frequency spectra for the field test facility are shown in Figure 1. As can be seen, 
jobs had similar, relatively flat spectra. Hence the overall levels were not dominated by low or high frequency sound. Note coil and coating processes were at background levels.

All data was collected over full work shifts between September 2008 and May 2009. At the time of data collection, all workers were included in the plant's hearing conservation program, which required hearing protection in all production areas of the facility. The plant employed 115 workers during the sampling period. The manufacturing facility operated three, 8 -hour shifts per day, five days per week.

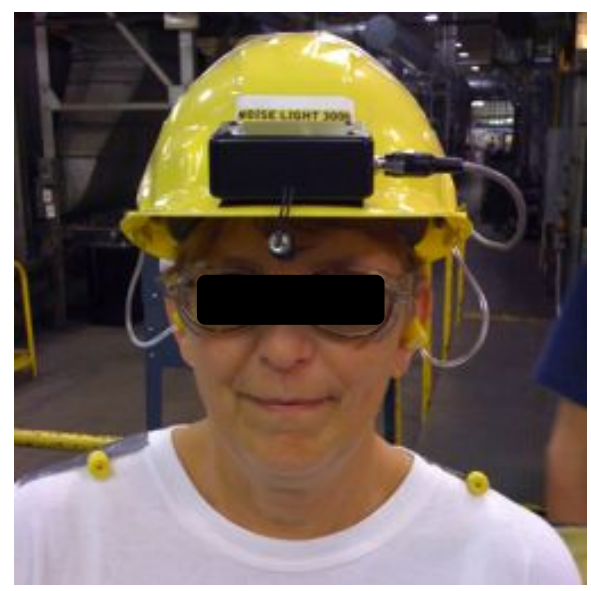

Figure 2a. Human subject donning hardhat light apparatus (front view)

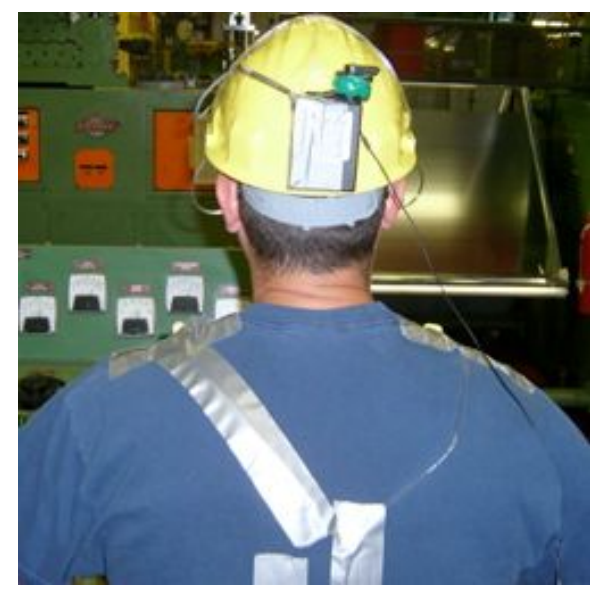

Figure 2b. Human subject donning hardhat light apparatus (back view)

\subsection{Human Subjects}

Volunteer subjects ( 16 male, 6 female) were recruited from a metal products manufacturing facility located in West Virginia (see Figures 2a and 2b). Of the 22 subjects, 73 percent were male. The average subject age was 42 years $(\mathrm{SD}=8)$. Subjects self-reported race consisted of white, not of Hispanic origin; black, not of Hispanic origin; and Asian or Pacific Islander.

Subjects were selected from among volunteers in the plant workforce. Each subject was asked to sign a "Consent and Information Form for Workers on the Job" prior to data collection. 
All research protocols were reviewed and approved by West Virginia University's Institutional Review Board (IRB) for Protection of Human Research Subjects (compliance \#9999-16617 02/12/2008 through 02/24/2010).

\subsection{Dosimeter}

Second-by-second sound pressure level values at the shoulder $\left(\mathrm{SPL}_{\mathrm{sh}}\right)$ and ear ( $\mathrm{SPL}$ ear $)$ were simultaneously measured and recorded using Spark 705+ "custom" dosimeters manufactured by Larson Davis, Inc. (Provo, Utah). The dosimeters were customized by the manufacturer to replace the standard 1/4-inch microphone harness with a 6-mm in diameter miniature microphone developed by Horn Industrial Company (Model EM6050-423). The miniature microphone was contained in a black plastic holder designed by Kevin Michael, Ph.D., and Alton Burks, Ph.D. (Michael and Associates, State College, PA).

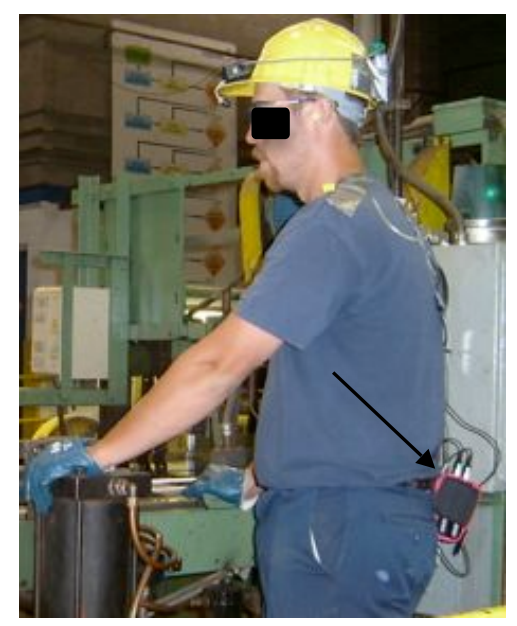

Figure 3. Canvas belt pouch holding two dosimeters

A canvas belt pouch was used to hold two Larson Davis "Custom" dosimeters. The researcher clipped the pouch to the waistband of each subject as shown in Figure 3. 


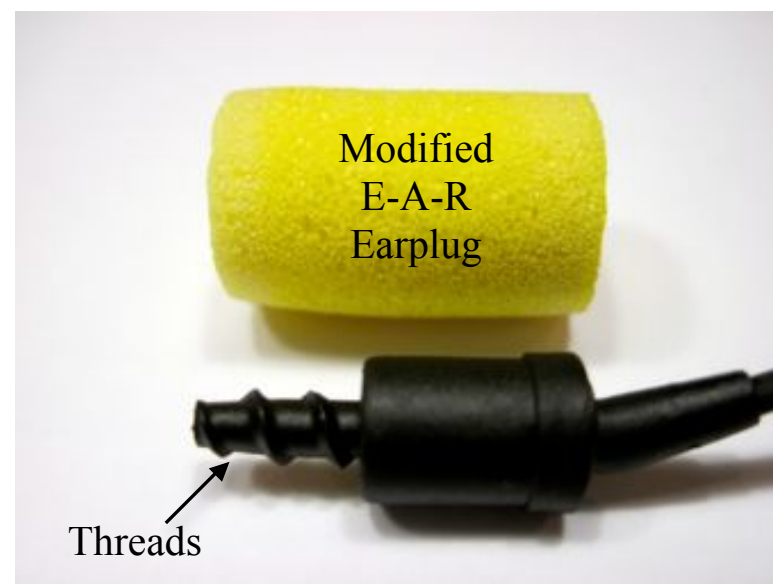

Figure 4a. Miniature microphone with hollow plastic threaded core

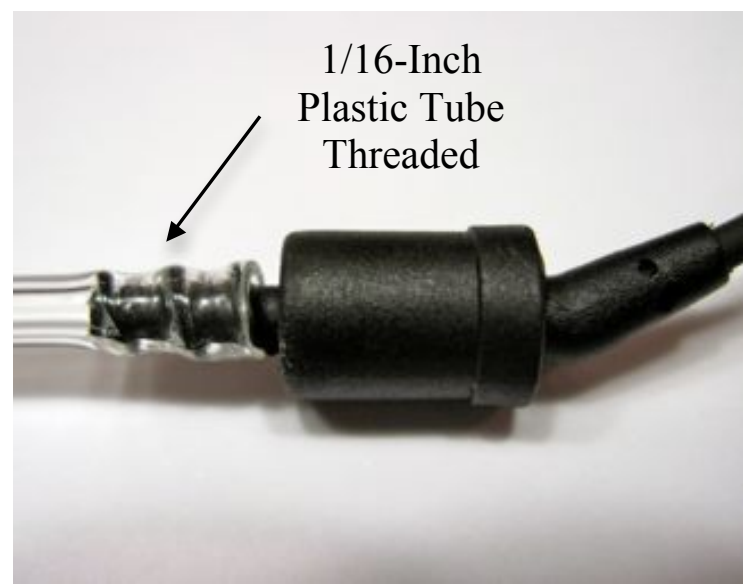

Figure 4b. Miniature microphone with attached tubing

\subsection{Miniature Microphone}

The microphones used for this research were miniature, 6-millimeter in diameter microphones manufactured by Horn Industrial Company (Model EM6050-423). The black plastic microphone holder, as shown in Figures 4a and 4b, was designed by doseBusters USA, Inc. (State College, PA). The plastic hollow core miniature microphone holder was threaded (Figure 4a) to allow the miniature microphone to be securely screwed directly into the plastic tubing as shown in Figure $4 b$.

\subsection{Blaze Software}

Blaze $^{\mathrm{TM}}$ (Version 5.2) proprietary software from Larson Davis, Inc. (Provo, Utah) was used to allow communication from dosimeters to a computer, set parameters, and to calibrate dosimeters.

\subsection{Calibrator}

A CAL200 (Larson Davis, Inc., Provo, Utah) sound level calibrator was used to calibrate the Larson Davis “custom” dosimeters and a Larson Davis DSP81 Type 1 sound level meter. The calibrator had an option to use either a $94.0 \mathrm{~dB}$ or $114.0 \mathrm{~dB}$ output level at a frequency of 1000 Hz. For the purposes of this study, the $114.0 \mathrm{~dB}$ output level was used. 


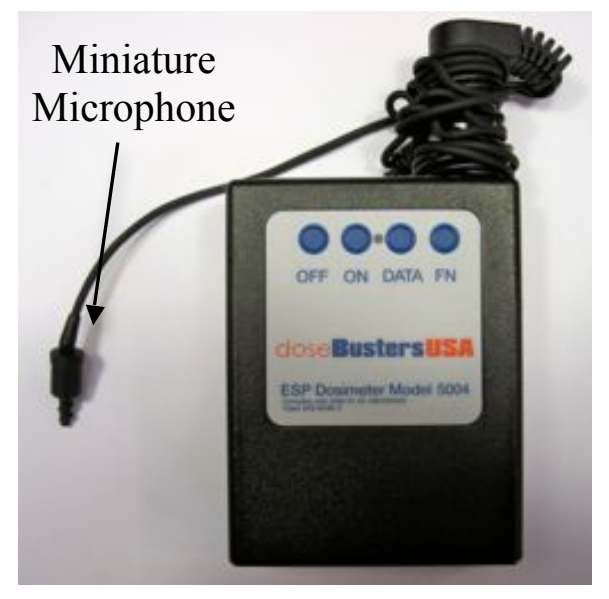

Figure 5a. Exposure-indicating light dosimeter with connected 6-mm miniature microphone

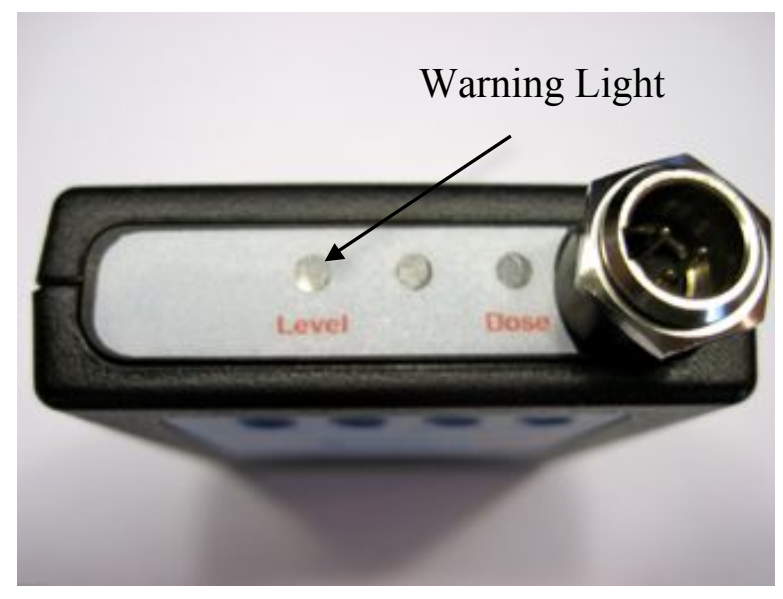

Figure 5b. Exposure-indicating warning light

\subsection{Exposure-Indicating Light}

The standard ANSI Type II compliant Exposure Smart Protector ${ }^{\mathrm{TM}}$ was developed by doseBuster USA, Inc. (State College, PA). The dosimeter (Figure 5a) was used to generate the exposure-indicating light shown in Figure 5b. A photo resister was used to simultaneously transmit the detected signal to a warning light box mounted on the brim of the hardhat. The red warning light was normally set to blink when the unit's miniature microphone sound pressure level exceeds $85 \mathrm{dBA}$ for 3 consecutive seconds. The manufacturer modified the exposureindicating light for this study to activate when a sound level equal to or above 80 decibels (threshold) for 3 consecutive seconds was detected. The light will continue to blink at 1 -second intervals until the SPL decreases below the threshold.

\subsection{Sound Level Meter}

The sound level meter used was a Larson Davis (Model DSP81 Type 1) manufactured by Larson Davis, Inc. (Provo, Utah). 


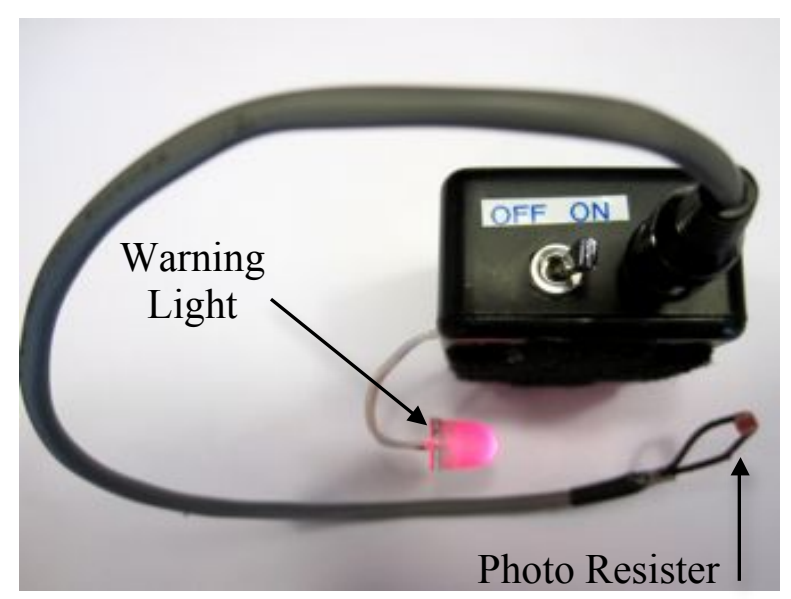

Figure 6. Warning light box and photo resister cable
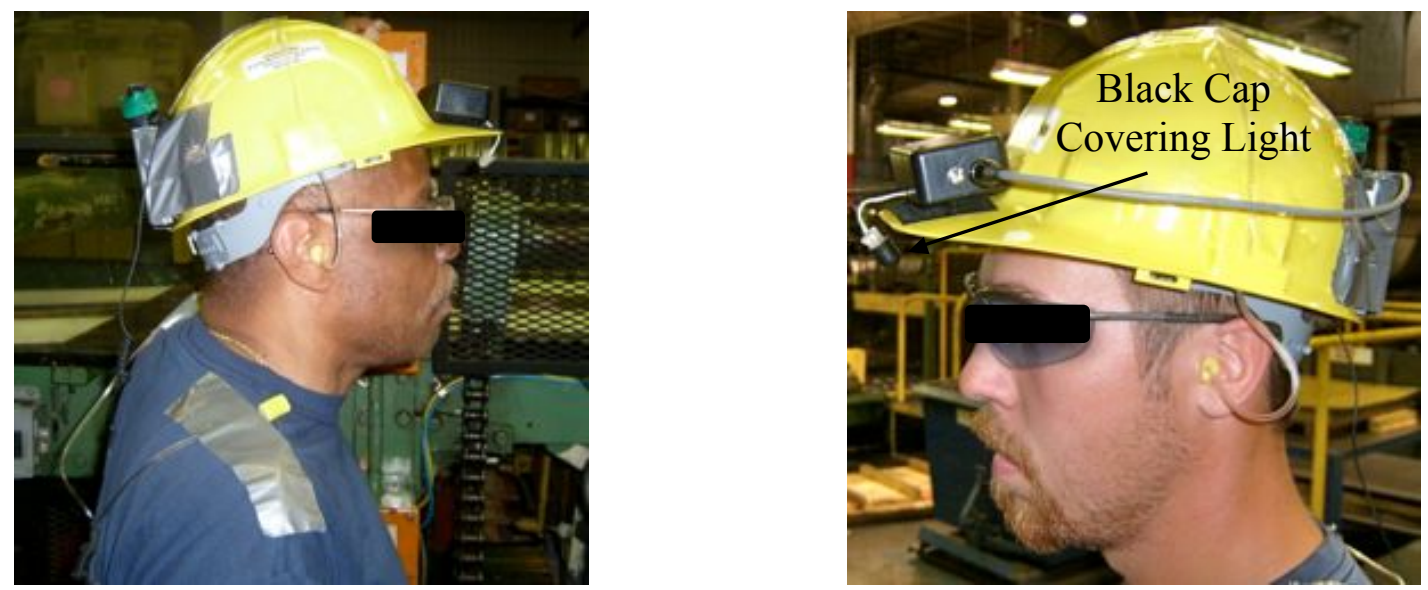

Figure 7a. Subject wearing warning light box during Light Activated period

Figure $7 b$. Subject wearing warning light box during Light Deactivated period

\subsection{Warning Light Box}

The warning light box, as shown in Figure 6, was a circuit board encased in a three inch by two inch by one inch black plastic box. The box was equipped with an activation and deactivation toggle switch. Additionally, the box included an RCA female plug that was used in conjunction with a photo resister cable. The warning light box was fitted with a red, $1 / 2$ inch light 
emitting diode that was suspended on four-inch wire. The wire length allowed for the light to be manipulated into the subject's field of vision. The back portion of the light was painted black, which increased the contrast of the red light. Figure 7 a shows the warning light in the "activated" position. A black rubber cap, as shown in Figure 7b, was used to cover the warning light when in the "deactivated" position. The cap provided a definitive "warning light deactivated" reminder to the subject.

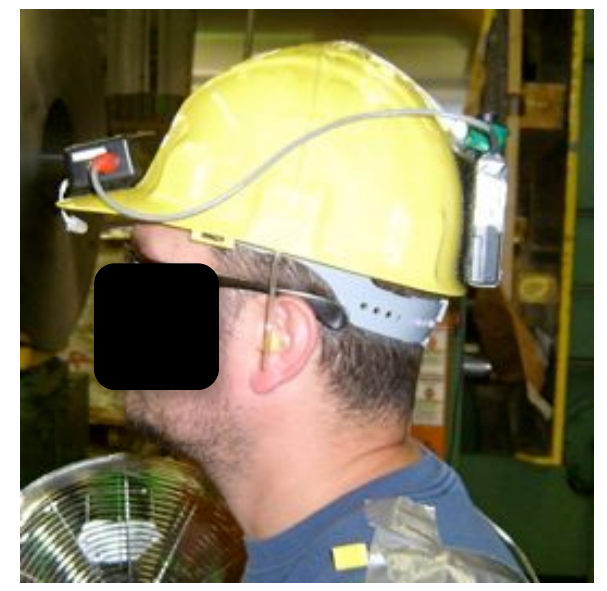

Figure 8a. Hardhat with warning light box (front) and blinking light system (back)

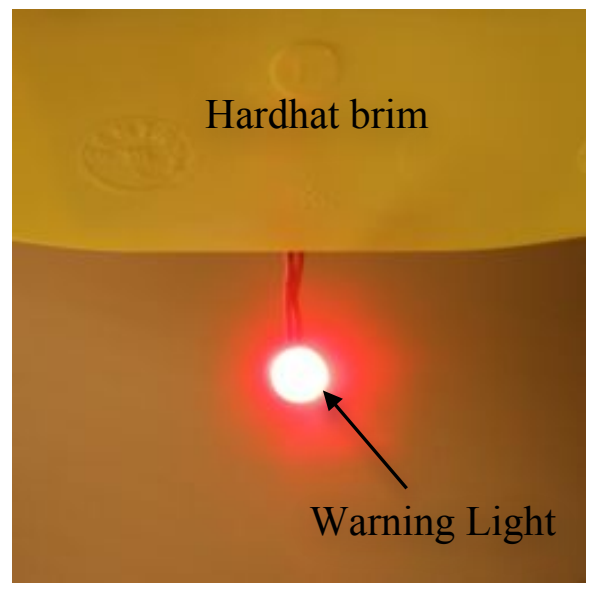

Figure 8b. Blinking warning light from subject point of view

\subsection{Hardhat}

Sentry class G, E, C (Type 1) hardhats were used as a mounting platform to hold the warning light box and exposure-indicating light dosimeter as shown in Figure 8a. Both pieces of equipment were secured to the hardhat using hook and loop fasteners. In some cases, duct tape was used as an additional fastener. The subject point-of-view of a blinking warning light is shown in Figure 8b. 


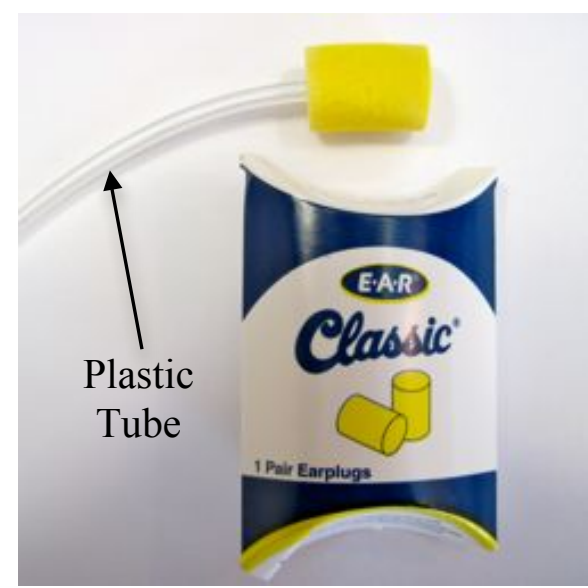

Figure 9a. Modified PVC foam roll-down earplug

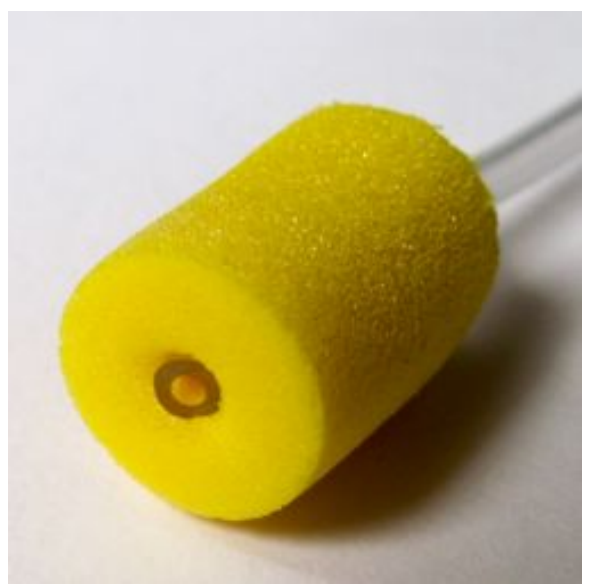

Figure 9b. Earplug modified by punching a 1/16-inch hold through the middle

\subsection{Hearing Protective Device}

The HPD tested (see Figure 9a) in this study was a disposable, expandable, cylindrical shaped, poly vinyl chloride (PVC) foam earplug (E-A-R Classic, Aearo Corporation, Indianapolis, IN) with a published NRR of $29 \mathrm{~dB}$. The earplugs were modified using a leather punch to create a 1/16-inch hole through the middle of the plug as shown in Figure $9 \mathrm{~b}$. The purpose of the punched hole was to permit a piece of 1/16-inch plastic tube to be inserted through the earplug. The purpose of the inserted plastic tubing was to allow sound to travel through the hearing protector to the outside for recording SPLs. Once the tube was inserted for fit, the researcher pulled the tube half way out of the earplug and Loctite ${ }^{\circledR}$ super glue gel was applied on the outside portion of the exposed tube. Just before the glue started to dry, the tube was reinserted into the earplug. During the reinsertion, the researcher made certain the tube end was flush with the interior earplug hole. The secured tube provided a complete acoustic seal of the punched hole and did not interfere with the effectiveness of the protector. To demonstrate the modified earplug's effectiveness, the acoustic seal attenuation was tested in the reverberation chamber and found to be unchanged from unmodified earplugs (see Chapter 4). 


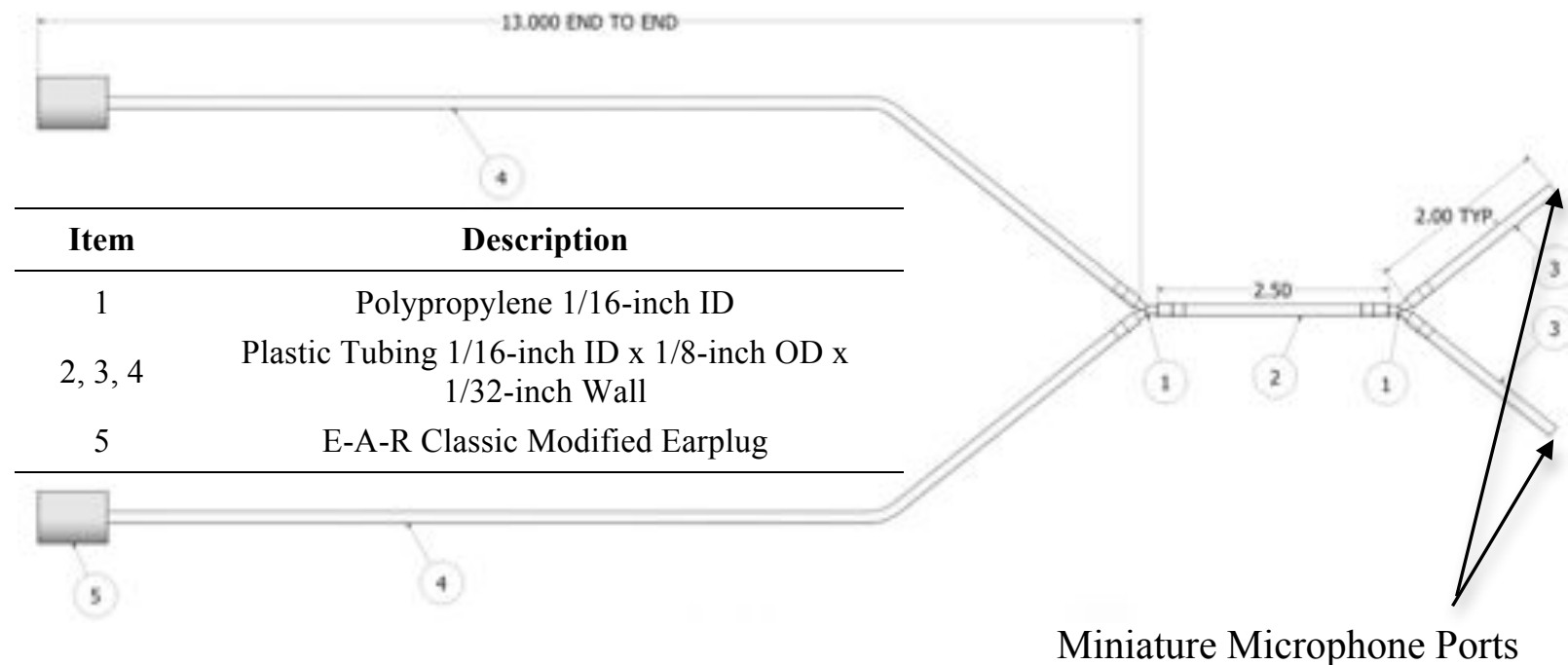

Figure 10. Plastic tubing assembly used for measuring SPL for shoulder and ear

\subsection{Plastic Tubing Assembly}

The tubing assembly was created using 1/8-inch outside diameter plastic tubing (Tygon, formulation S-50-HL), with an inside diameter of 1/16-inch. The shoulder and ear tube assemblies were identical as shown in Figure 10.

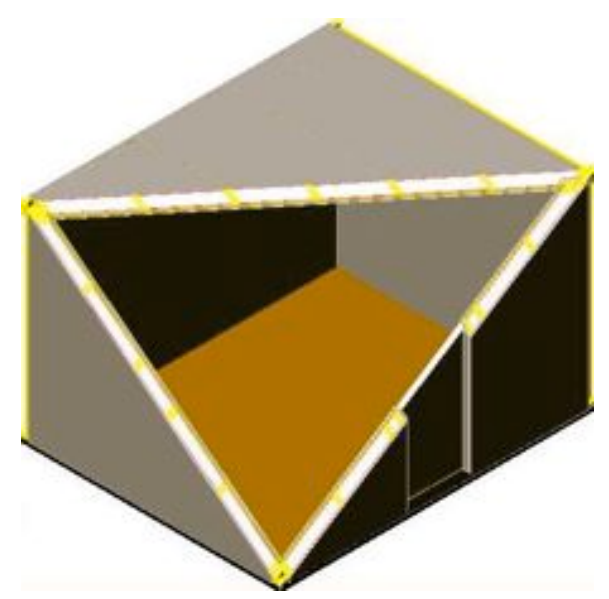

Figure 11. Reverberation test chamber (drawing by Raphael W. Alwin Dodrill, WVU) 


\subsection{Reverberation Chamber}

As shown in Figure 11, the reverberation chamber used in this study was a custom built, 30 foot by 25 foot by 8 foot, fully equipped reverberation chamber (Noise Laboratory at West Virginia University, Room 242 Mineral Resources Building). The construction consisted of two by four pine stud framing with 3-1/2 inch R-19 fiberglass insulation. The insulation was placed between 2" x 4" pine studs. The interior walls and ceiling were faced with 5/8-inch plywood. The plywood was covered by $1 / 2$ inch drywall and covered with several coats of glossy white enamel paint. All exterior walls and the roof were faced with $1 / 2$ inch drywall. The entire reverberation chamber is mounted on top of a one-inch dense polyurethane foam mat. The foam mat rested on top of 3/8-inch laminate floor tiles on a concrete foundation. All construction of the chamber was in compliance with the requirements of ANSI 12.42-1995. The diffuse sound field measured at any location inside the chamber was within two decibels of the value measured where subjects' heads would be.

\subsection{Noise Analyzer}

A National Instruments noise analyzer with “custom” Labview software was used to data $\log$ sound pressure levels and frequency spectrum during preliminary testing in the reverberation chamber. 


\section{CHAPTER 4: LABORATORY STUDY PART I: VALIDATION OF A SAMPLING APPARATUS USED IN THE FIELD}

As is discussed later, it was necessary to use plastic tubing to conduct sound to miniature microphones. Prior to the field study, transmission loss ( $\left.\mathrm{TL}_{\mathrm{path}}\right)$ and sound penetration loss ( $\left.\mathrm{TL}_{\text {wall }}\right)$ of the tubing were measured in a reverberation chamber. This chapter describes the results of more comprehensive testing of $\mathrm{TL}_{\text {wall }}$ and $\mathrm{TL}_{\mathrm{path}}$ for the tubing.

\subsection{Purpose}

A plastic tube sampling apparatus was used to study the efficacy of a signal light intervention at a metal products manufacturing facility. This laboratory study tested the errors due to transmission loss through the tubing walls $\left(\mathrm{TL}_{\text {wall }}\right)$ and the sound pressure change due to transmission loss down the length of the tubing $\left(\mathrm{TL}_{\mathrm{path}}\right)$. Ideally, the first would be high and the latter low.

\subsection{Background}

The overall goal of the field study was to test the effectiveness of alerting each subject immediately by flashing a light when noise levels in their ears exceeded $80 \mathrm{dBA}$. Noise levels were recorded using noise dosimeters connected to the same tube inserted into the ear proximal to HPD (SPL $\mathrm{Sear}_{\text {er }}$ and at the shoulder $\left(\mathrm{SPL}_{\mathrm{sh}}\right)$ during work. For part of each shift the light was activated. When activated, the signal light blinked continuously as long as noise levels measured proximal to the ear exceeded the 80-decibel threshold for greater than three seconds.

During the initial design phase of the study the investigator discovered that it was necessary to have the light activated if noise were excessive in either ear. The investigator observed that subjects otherwise avoided activating the light when they wanted to talk by simply removing the HPD from the un-sampled ear. That evasion demonstrated that the apparatus did modify subject behavior to avoid activating the light. However, because both ears were not sampled this behavior was not reflected in sampling results. Furthermore, since it is not acceptable to have either ear overexposed to noise, the light should be activated when either ear is over exposed. Although it would be possible to both activate the light and record SPLs in the ear using a device with a single miniature microphone, it was convenient to use an available device designed to 
record noise levels and flash a light when the $\mathrm{SPL}_{\mathrm{ear}}$ exceeded a preset level. Therefore, in order to use that device and measure SPLs in the ear simultaneously, the investigator had to use two different instruments, each with their own miniature microphone. Because it would be infeasible to have two-miniature microphones in the ear canal, the alternative chosen was to have a single tube penetrate the earplug as previously shown in Chapter 3, Figure 9b.

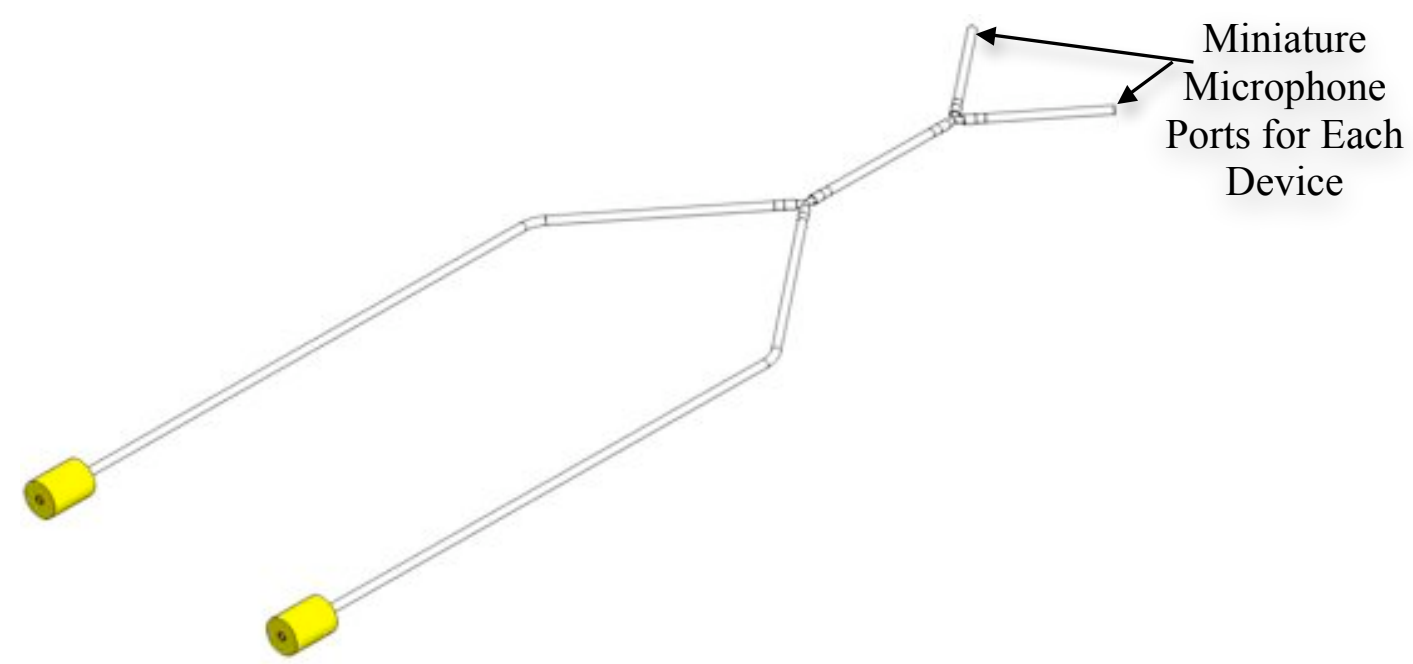

Figure 12. Miniature microphone port locations shown on plastic tube assembly used for measuring SPLs

The single tube conducted sound to a set of three tubes connected in a "Y" junction such that one penetrated the earplug and conducted sound to a common single tube connected in a "Y" junction to each device (see Figure 12). Therefore, each device would be measuring the same SPLs and the intrusiveness at the ear would be minimized. This configuration presented a further advantage of making the earplug more similar to an unaltered earplug and therefore having less effect on the stiffness, which could affect subject-fitting practices. 
One of the two errors examined was the transmission loss of the tubing apparatus as the sound traveled down the length of the tubing $\left(\mathrm{TL}_{\mathrm{path}}\right)$. The other error studied was the transmission loss due to the loss through a tube wall $\left(\mathrm{TL}_{\mathrm{wall}}\right)$. The $\mathrm{TL}_{\mathrm{path}}$ error is calculated as:

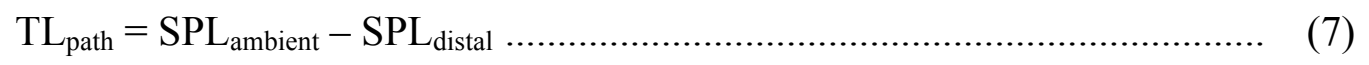

$$
\begin{aligned}
& \text { Where: } \quad \mathrm{SPL}_{\text {distal }} \text { is the sound level at the distal end of the tubing }
\end{aligned}
$$

Likewise the transmission loss $\left(\mathrm{TL}_{\mathrm{wall}}\right)$ due to penetration of the tubing wall is calculated as:

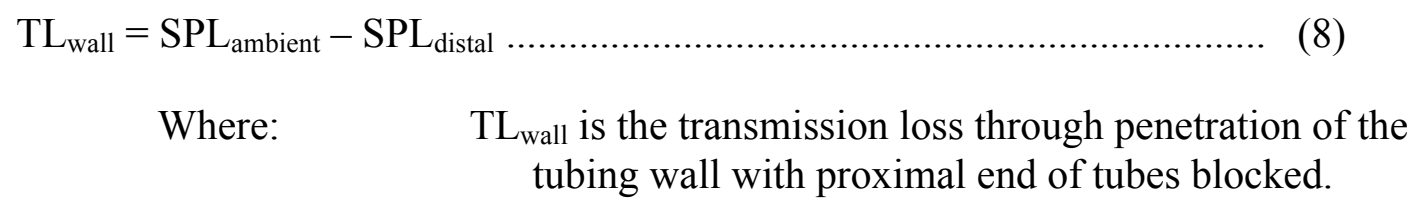

For the purposes of the overall study, low values of $\mathrm{TL}_{\mathrm{path}}$ and high values of $\mathrm{TL}_{\mathrm{wall}}$ are desirable.

\subsection{Apparatus}

This research was carried out at the audiometric laboratory of Michael \& Associates, Inc. (State College, PA). The tubing assembly, reverberation chamber, and octave band analyzer are discussed next.

\subsubsection{Plastic Tubing Assembly}

The tubing apparatus is described at length in Chapter 3, Figure 10 and is briefly reviewed here. The tubing assembly was created using 1/8-inch outside diameter plastic tubing (Tygon, formulation S-50-HL), with an inside diameter of 1/16-inch (1/32-inch wall thickness). During the field study, identical shoulder and ear tube assemblies were used. 


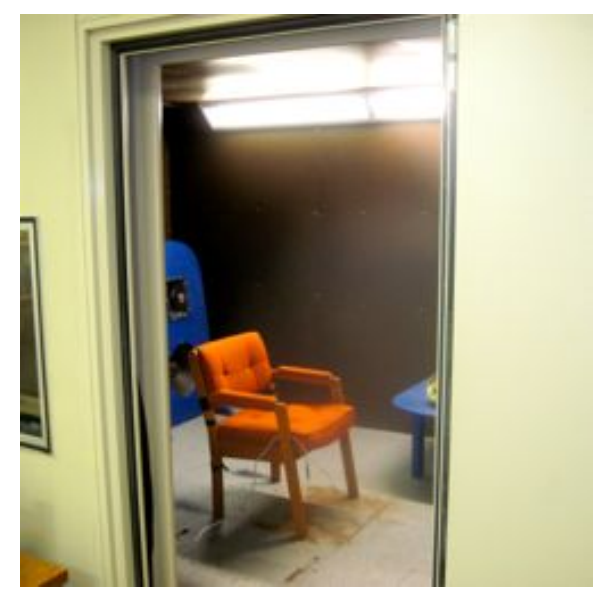

Figure 13. Reverberation chamber

\subsubsection{Reverberation Chamber}

The test chamber used in this study was a fully equipped reverberation chamber $\left(9^{\prime} \mathrm{x} 11^{\prime} \mathrm{x}\right.$ 7'), as shown in Figure 13, at the audiometric laboratory of Michael and Associates, Inc. (State College, PA). The interior walls, ceiling and floor were faced with hardened 1/4-inch masonite which provided a reflective surface. The double wall reverberation chamber was mounted on springs to avoid solid-borne vibration. Additionally, the chamber was located underground which kept ambient noise levels low. The reverb time was measured to be $>0.5$ and $<1.6$ seconds. All construction of the chamber was in compliance with the specifications of ANSI 12.6 and 3.19 standards.

\subsubsection{Octave Band Analyzer}

The octave band analyzer used for this study was a Norsonic (Model N118) manufactured by Norsonic (Norway). 


\subsection{Methods}

All tests were done in a reverberation chamber at the audiometric laboratory of Michael \& Associates, Inc. (State College, PA).

\subsubsection{Step-by-step procedures}

The steps for testing the plastic tube apparatus were as follows:

1. Check and calibrate equipment.

2. Place tube apparatus in the center of the reverberation chamber midway between floor and ceiling.

3. Determine the sound penetration $\left(\mathrm{TL}_{\mathrm{wall}}\right)$ by recording the SPL at the distal end of the tube assembly while fully blocking both earplug openings with non-working miniature microphones.

4. Determine the transmission loss $\left(\mathrm{TL}_{\mathrm{path}}\right)$ by recording the SPL at the distal end of the tubing while both earplug openings remained unblocked. An identical test was repeated with one earplug opening blocked with a non-working miniature microphone while the other was unblocked.

\subsection{Results}

This laboratory study determined $\mathrm{TL}_{\text {wall }}$ and $\mathrm{TL}_{\text {path }}$ due to the plastic tube apparatus used in the field study. 


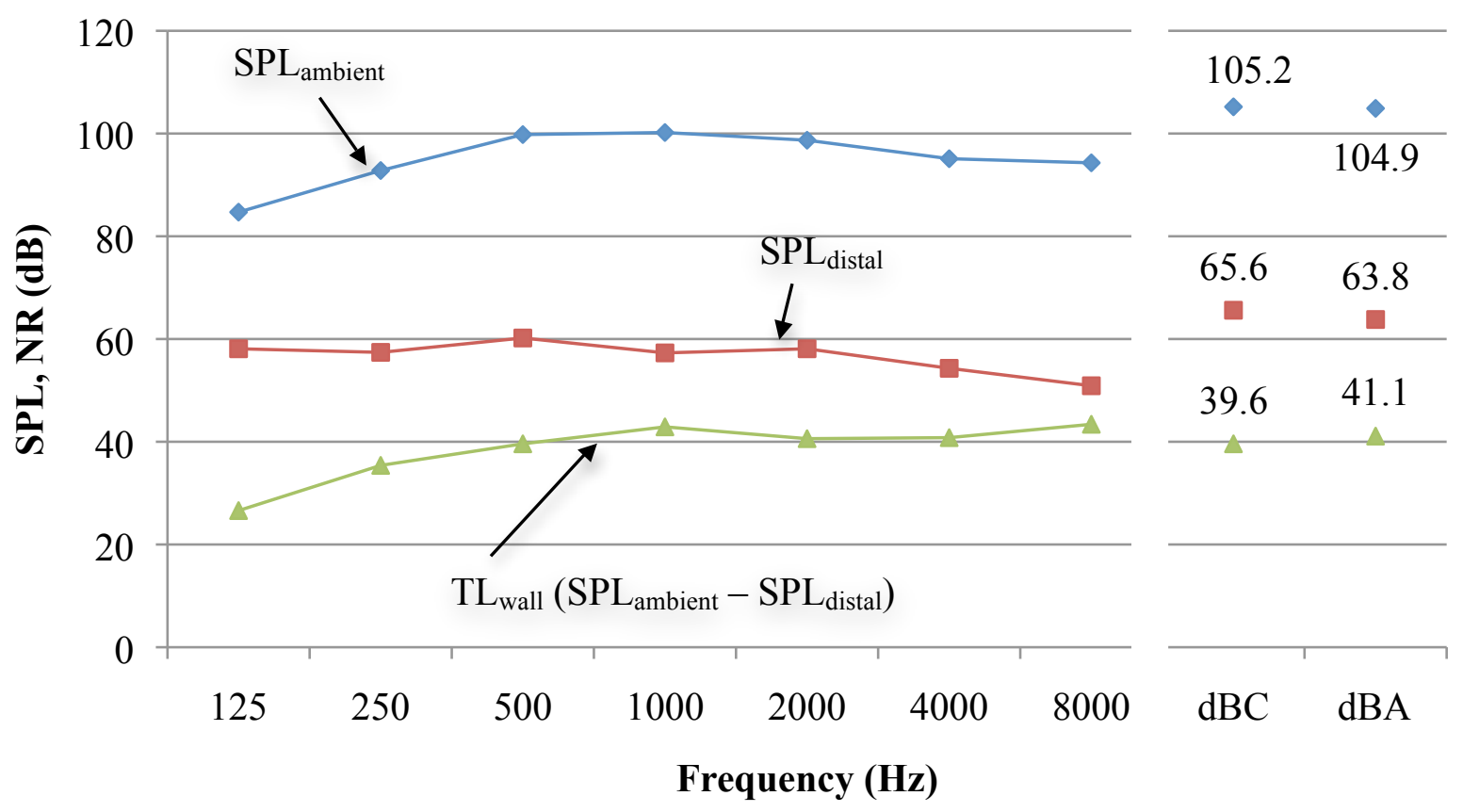

Figure 14. Sound penetration ( $\left.\mathrm{TL}_{\mathrm{wall}}\right)$ of tube assembly

The experimental transmission loss ( $\left.\mathrm{TL}_{\text {wall }}\right)$ values of the tube assembly are shown in Figure 14. The $T L_{\text {wall }}$ frequency values were calculated using equation 8 . In order to compute $d B C$ and $\mathrm{dBA}$ values, the relative response weighting correction was applied across all frequencies and equations 1 and 2 were used to calculate total band frequency for each respective weighting. It should be noted that a common fallacy is to compute total band power values by taking each of the $T L_{\text {wall }}$ effect values and applying equations 1 and 2 . Note $T L_{\text {wall }}$ values in $\mathrm{dBC}$ and $\mathrm{dBA}$ cannot be computed using Equations 1 and 2, but are calculated using:

$$
\begin{aligned}
& \mathrm{TL}_{\text {wall }} \mathrm{dBC}=\mathrm{dBC}_{\text {ambient }}-\mathrm{dBC}_{\text {distal }} \\
& \mathrm{TL}_{\text {wall }} \mathrm{dBA}=\mathrm{dBA}_{\text {ambient }}-\mathrm{dBA}_{\text {distal }}
\end{aligned}
$$

As can be seen, the tube walls blocked $42.9 \mathrm{~dB}$ at $1000 \mathrm{~Hz}$ with an overall band power value of $39.6 \mathrm{dBC}$ or $41.1 \mathrm{dBA}$ across all test signals. Thus, the investigator speculates the $\mathrm{TL}_{\text {wall }}$ 
values shown in Figure 14 should match the upper limits of NR measured during the REAT study (see Chapter 5).

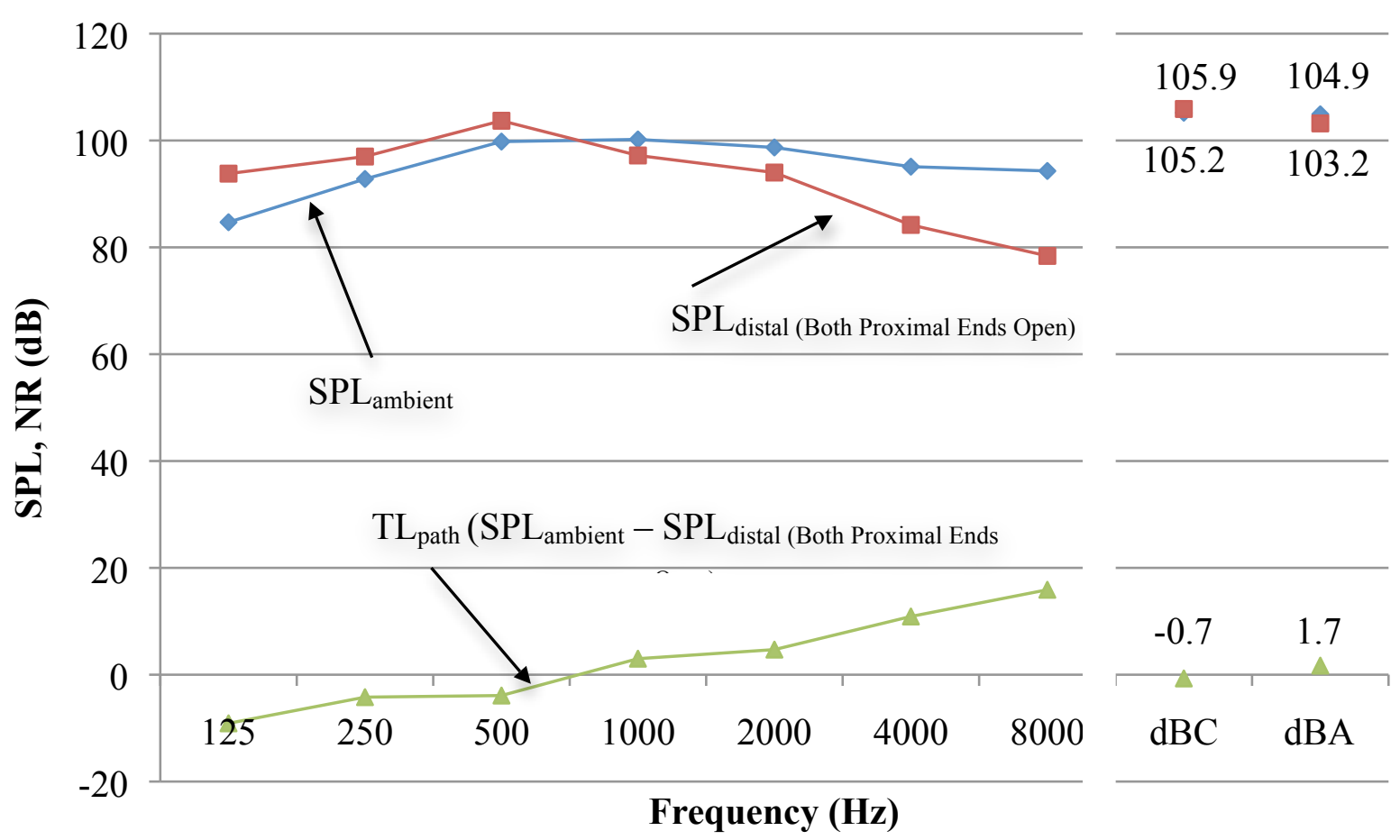

Figure 15. Transmission loss $\left(\mathrm{TL}_{\mathrm{path}}\right)$ effect of tube assembly with both earplugs unblocked

The $\mathrm{TL}_{\text {path }}$ of the plastic tube assembly (i.e. both earplugs open) is shown in Figure 15 . The $\mathrm{TL}_{\text {path }}$ frequency values were calculated using equation 7. The $\mathrm{TL}_{\text {path }}$ was less than $5 \mathrm{~dB}$ for $2000 \mathrm{~Hz}$ and lower frequencies but gained steadily to $15.9 \mathrm{~dB}$ at $8000 \mathrm{~Hz}$. At $125 \mathrm{~Hz}$ the $\mathrm{TL}_{\text {path }}$ was $-9.1 \mathrm{~dB}$. In other words, low frequency sounds were muted and high frequency sounds were amplified. Therefore, if the tubing assembly were used in a high frequency dominated work

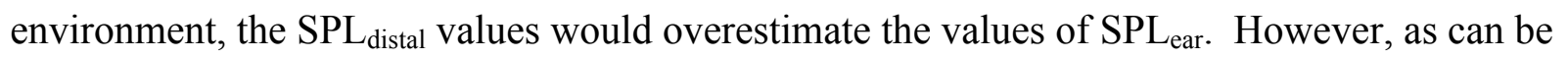
seen in Figure 1, it is highly unlikely that the metal manufacturing environment was dominated by low or high frequency sound. The $\mathrm{TL}_{\text {path }}$ effect of the tube assembly at $1000 \mathrm{~Hz}$ was $3 \mathrm{~dB}$ with an overall band power value of $-0.7 \mathrm{dBC}$ or $1.7 \mathrm{dBA}$ across all test signals. 


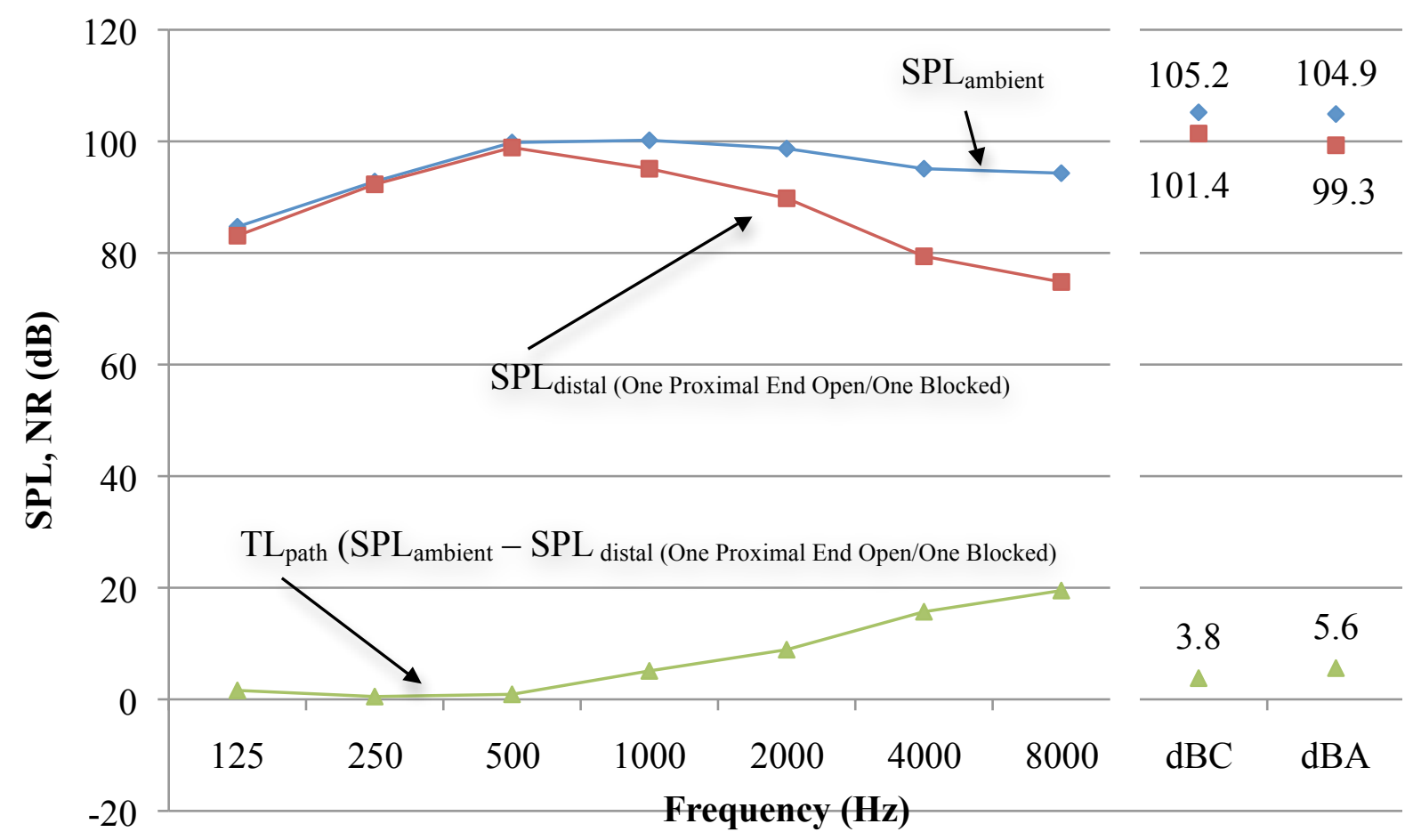

Figure 16. Transmission loss ( $\left.\mathrm{TL}_{\mathrm{path}}\right)$ effect of tubing assembly with one earplug open/one earplug blocked

Figure 16 shows the transmission loss $\left(\mathrm{TL}_{\mathrm{path}}\right)$ effect of tubing with one earplug open and one earplug blocked. This situation is likely to occur at times as workers sometimes remove one side of HPDs to communicate. The $\mathrm{TL}_{\text {path }}$ frequency values were calculated using equation 7. Similar to the findings in Figure 15, the effect of tube assembly was less than $2 \mathrm{~dB}$ of open-air measurements for frequencies less than $500 \mathrm{~Hz}$ and increased to $19.5 \mathrm{~dB}$ at $8000 \mathrm{~Hz}$ when one earplug was open and one earplug was blocked. The $\mathrm{TL}_{\mathrm{path}}$ effect of the tube assembly at 1000 $\mathrm{Hz}$ was $5.1 \mathrm{~dB}$ with an overall band power value of $3.8 \mathrm{dBC}$ or $5.6 \mathrm{dBA}$ across all test signals.

\subsection{Discussion}

It is very likely that the plastic tube apparatus used in the field study to conduct sound from the ear to miniature microphones would affect results. If the $\mathrm{TL}_{\mathrm{path}}$ error was large, the signal light would not signal workers accurately and therefore, their behavior would not change 
falsifying the hypothesis. The $\mathrm{TL}_{\mathrm{path}}$ effect was found to be within 5 decibels of open-air measurements with the exception of $125 \mathrm{~Hz}$ and frequencies greater than $2000 \mathrm{~Hz}$ (see Table 3).

Table 3. Summary of overall effects

\begin{tabular}{ccccccccccc}
\hline Effect & \multicolumn{9}{c}{ Frequency (Hz) } & \multicolumn{4}{c}{$\begin{array}{c}\text { Total Band } \\
\text { Power }\end{array}$} \\
& 125 & 250 & 500 & 1000 & 2000 & 4000 & 8000 & $\mathrm{dBC}$ & $\mathrm{dBA}$ \\
\hline $\mathrm{TL}_{\text {wall }}$ & 26.6 & 35.4 & 39.6 & 42.9 & 40.6 & 40.8 & 43.4 & 39.6 & 41.1 \\
$\mathrm{TL}_{\text {path (both }}$ & -9.1 & -4.2 & -3.9 & 3 & 4.7 & 10.9 & 15.9 & -0.7 & 1.7 \\
earplugs open) \\
$\begin{array}{r}\mathrm{TL}_{\text {path (one }} \\
\text { earplug open) }\end{array}$ & 1.6 & 0.5 & 0.9 & 5.1 & 8.9 & 15.7 & 19.5 & 3.8 & 5.6 \\
\hline
\end{tabular}

Therefore, if tested in a high frequency dominated spectrum, the measurements would underestimate the true values. However, it is highly unlikely that the metal manufacturing environment will consist of dominated high frequency sound. In fact, during the field study it was shown that workstations had similar, flat frequency spectra; not dominated by low or high frequencies (see Chapter 3, Figure 1). Thus, when conducting the field study the tubing effect was considered minimal.

Furthermore, if ambient sound penetrated ( $\left.\mathrm{TL}_{\text {wall }}\right)$ the tubing easily then it would present an alternative pathway for the sound to reach the miniature microphones, therefore introducing inaccuracies to the measurements. However, this study showed an overall error of less than 39.6 $\mathrm{dBC}$ or $41.1 \mathrm{dBA}$ (see Table 3). Unless the $\mathrm{NR}_{\mathrm{A}}$ for the earplugs exceeds $35 \mathrm{dBC}$, the effect of this alternate pathway would be trivial.

As shown in Table 4, the overall effect of $\mathrm{TL}_{\mathrm{path}}$ on the test frequency is minimal, with a -7.7 dBA reduction. 
Table 4. Example of calculating $\mathrm{TL}_{\mathrm{path}}$ effect on test spectrum

\begin{tabular}{|c|c|c|c|c|c|c|c|c|c|}
\hline & \multicolumn{7}{|c|}{ Frequency $(\mathrm{Hz})$} & \multicolumn{2}{|c|}{$\begin{array}{l}\text { Logarithmic } \\
\text { Sum Across } \\
\text { Frequencies }\end{array}$} \\
\hline & 125 & 250 & 500 & 1000 & 2000 & 4000 & 8000 & $\mathrm{dBC}$ & $\mathrm{dBA}$ \\
\hline $\begin{array}{c}\text { Test } \\
\text { Frequency }\end{array}$ & 84.7 & 92.8 & 99.8 & 100.2 & 98.7 & 95.1 & 94.3 & 105.2 & 104.9 \\
\hline $\begin{array}{l}\mathrm{TL}_{\text {path }} \\
\text { Effect }\end{array}$ & -9.1 & -4.2 & -3.9 & 3 & 4.7 & 10.9 & 15.9 & -0.7 & 1.7 \\
\hline $\begin{array}{l}\text { Estimated } \\
\text { SPLs } \\
\text { (Test } \\
\text { Frequency } \\
+ \text { TL }_{\text {path }} \\
\text { Effect) }\end{array}$ & 75.6 & 88.6 & 95.9 & 103.2 & 103.4 & 106 & 110.2 & 111.2 & 112.6 \\
\hline
\end{tabular}

A broader application would be using the tubing in environments where high or low frequencies dominate the spectrum and therefore may introduce inaccuracies to the recorded values (see Tables 5 and 6).

Table 5. Example of calculating $\mathrm{TL}_{\mathrm{path}}$ effect on low frequency dominated spectrum

\begin{tabular}{|c|c|c|c|c|c|c|c|c|c|}
\hline & \multicolumn{7}{|c|}{ Frequency (Hz) } & \multicolumn{2}{|c|}{$\begin{array}{l}\text { Logarithmic } \\
\text { Sum Across } \\
\text { Frequencies }\end{array}$} \\
\hline & 125 & 250 & 500 & 1000 & 2000 & 4000 & 8000 & $\mathrm{dBC}$ & $\mathrm{dBA}$ \\
\hline $\begin{array}{l}\text { Low Frequency } \\
\text { Dominated }\end{array}$ & 95 & 95 & 95 & 75 & 75 & 75 & 75 & 99.8 & 93.4 \\
\hline $\mathrm{TL}_{\text {path }}$ Effect & -9.1 & -4.2 & -3.9 & 3 & 4.7 & 10.9 & 15.9 & -0.7 & 1.7 \\
\hline $\begin{array}{c}\text { Estimated SPLs } \\
\text { (Low Frequency }+ \\
\left.\text { TL }_{\text {path }} \text { Effect }\right)\end{array}$ & 85.9 & 90.8 & 91.1 & 78 & 79.7 & 85.9 & 90.9 & 96.0 & 93.8 \\
\hline
\end{tabular}


Table 6. Example of calculating $\mathrm{TL}_{\mathrm{path}}$ effect on high frequency dominated spectrum

\begin{tabular}{|c|c|c|c|c|c|c|c|c|c|}
\hline & \multicolumn{7}{|c|}{ Frequency $(\mathrm{Hz})$} & \multicolumn{2}{|c|}{$\begin{array}{l}\text { Logarithmic } \\
\text { Sum Across } \\
\text { Frequencies }\end{array}$} \\
\hline & 125 & 250 & 500 & 1000 & 2000 & 4000 & 8000 & $\mathrm{dBC}$ & $\mathrm{dBA}$ \\
\hline $\begin{array}{l}\text { High Frequency } \\
\text { Dominated }\end{array}$ & 75 & 75 & 75 & 85 & 95 & 95 & 95 & 98.8 & 100.4 \\
\hline $\mathrm{TL}_{\text {path }}$ Effect & -9.1 & -4.2 & -3.9 & 3 & 4.7 & 10.9 & 15.9 & -0.7 & 1.7 \\
\hline $\begin{array}{c}\text { Estimated SPLs } \\
\text { (High Frequency }+ \\
\text { TL }_{\text {path Effect) }}\end{array}$ & 65.9 & 70.8 & 71.1 & 88 & 99.7 & 105.9 & 110.9 & 110.2 & 112.0 \\
\hline
\end{tabular}

\subsection{Conclusion}

For the $\mathrm{TL}_{\mathrm{Path}}$ effect, there was a $-0.7 \mathrm{dBC}$ gain compared to $1.7 \mathrm{dBA}$ reduction when using tubing. This finding corresponds to low values of $\mathrm{TL}_{\text {path }}$, which were desirable for the field study.

The second error, $\mathrm{TL}_{\text {wall }}$ showed values of $39.6 \mathrm{dBC}$ and $41.1 \mathrm{dBA}$. These values were higher than the NRR of the tested earplug (29 NRR), which was required to conduct the field study.

Overall, these effect levels are modest "errors" in the context of the field study. Hence, the errors introduced by the tubing should not affect conclusions drawn in the field study. 


\section{CHAPTER 5: LABORATORY STUDY PART II: INVESTIGATION OF MAXIMAL IL WITH HARDHAT APPARATUS USING REAT}

\subsection{Purpose}

A REAT study was conducted because of a restriction put upon subjects by the field test methodology. Each subject's ability to insert HPDs was tested by measuring IL while donning a hardhat. Ideally, the average IL of each subject would be equal to or higher than the published unmodified HPD NRR (NRR=29 dB) (E-A-R Classic, Aearo Corporation, Indianapolis, IN).

\subsection{Background}

The REAT method was described at length in Chapter 1 (see Section 1.4) and is briefly reviewed here. The REAT method is based upon the difference between the minimum level of sound that a subject can hear with ears un-occluded (open threshold) and the level needed with ears blocked by HPDs (occluded threshold). The difference between the two subjective, nonsimultaneous measurements (IL) is assumed to be the amount of protection afforded by the HPD (see Equation 3, Section 1.4).

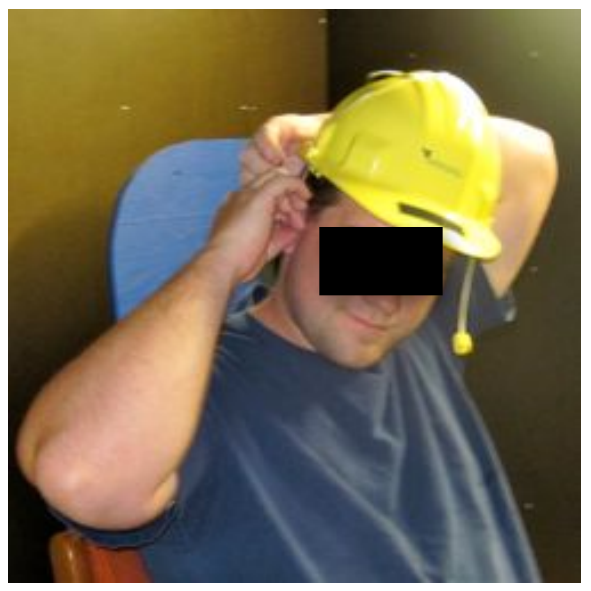

Figure 17. Human subject inserting HPD while donning hardhat apparatus 
During the field study, subjects were required to insert modified earplugs while wearing a hardhat (see Figure 17). One might suppose that wearing a hardhat would interfere with inserting earplugs correctly and would therefore reduce calculated NRs afforded by earplugs during the field study.

Additionally it should be noted that there might be many times when workers may have to insert earplugs in an environment where it is not safe to remove their hardhat. For example, workers in the construction and mining industries are required to wear hardhats and HPDs during work.

It has been alleged that subjects may not have the ability to correctly insert HPDs while wearing a hardhat. Logically if the subject's ability to insert the earplug correctly was hindered substantially by the hardhat apparatus, then the ability to achieve a reasonable NR would be impossible. The correct way to insert a foam earplug is to use the thumb and forefingers to roll down and make the earplug thinner. Then using one hand to reach behind the head and pull the ear outward and upward to widen the auditory canal allowing the earplug to be inserted well into the ear until it expands. For that reason REAT testing using human subjects was conducted to further explore issues of HPD insertion while wearing the hardhat apparatus. 


\subsection{Apparatus}

This research was carried out at the audiometric laboratory of Michael \& Associates, Inc. (State College, PA). The reverberation chamber, light apparatus, noise analyzer, and human subjects are discussed next.

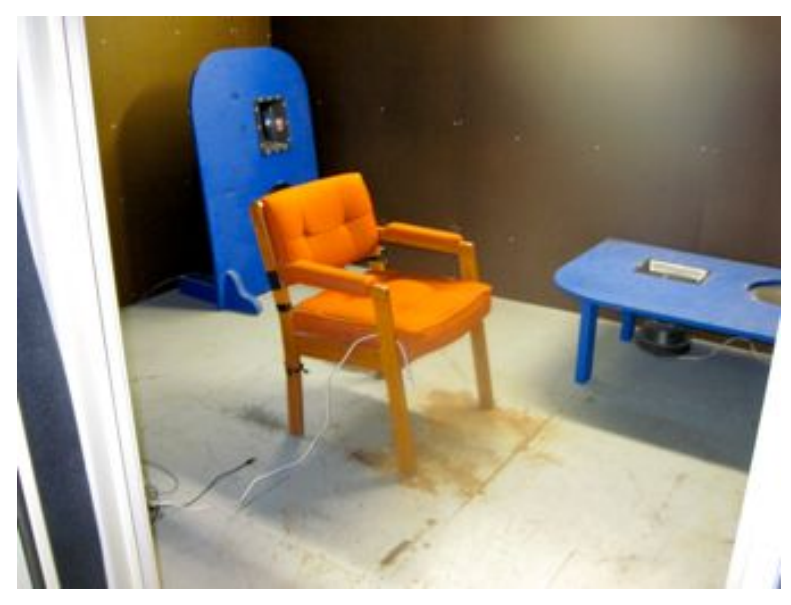

Figure 18. Reverberation chamber

\subsubsection{Reverberation Chamber}

The same reverberation chamber as described at length in Chapter 4 (see Section 4.3.2) was used and is briefly reviewed here. The chamber (see Figure 18) used in this study was a fully equipped reverberation chamber at the audiometric laboratory of Michael and Associates, Inc. (State College, PA). The chamber was in compliance with the specifications of ANSI S12.62008. 


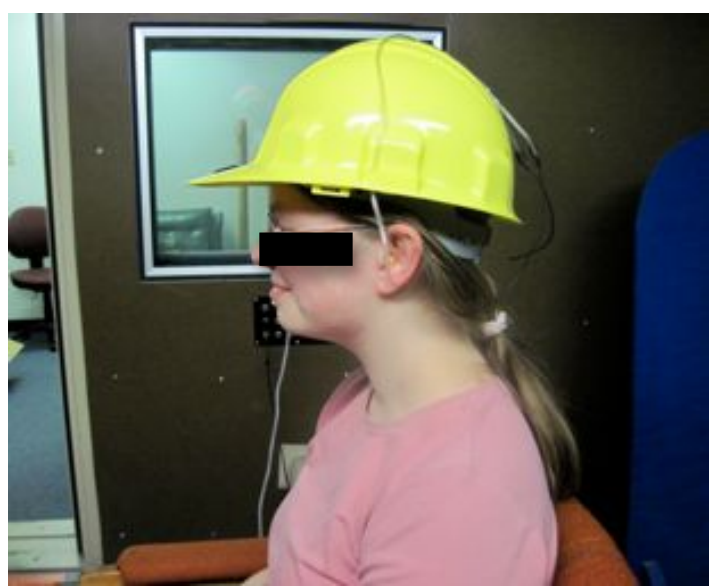

Figure 19. Subject donning light apparatus

\subsubsection{Light Apparatus}

The light apparatus (see Figure 19) was created using 1/8-inch outside diameter plastic tubing (Tygon, formulation S-50-HL), with an inside diameter of 1/16-inch. The shoulder and ear tube assemblies were described at length in Chapter 3 (see Section 3.12).

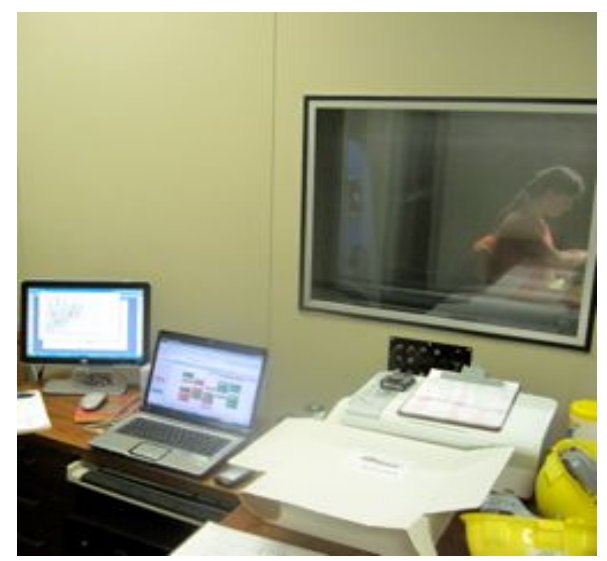

Figure 20. Custom designed automatic recording attenuator

\subsubsection{Noise Analyzer}

As shown in Figure 20, a custom designed automatic recording attenuator was used to record SPLs for all subjects (Michael \& Associates, State College, PA). 


\subsubsection{Human Subjects}

Volunteer subjects (12 male, 8 female) were selected randomly from volunteers at State College, PA. All data was collected during July 2010. The research protocols were reviewed and approved by West Virginia University's Institutional Review Board (IRB) for Protection of Human Research Subjects (compliance \#9999-16617 02/24/2010 through 02/23/2011) and informed consent was obtained from all subjects in compliance with the approved consent procedures.

\subsection{Methods}

All tests were done in a reverberation chamber at the audiometric laboratory of Michael \& Associates, Inc. (State College, PA). The REAT testing was performed according to the American National Standards Institute (ANSI) Specifications, ANSI S12.6-2008, Method A. The ANSI standard requires that:

1. Specified threshold measurement data are obtained using twenty normally-hearing listeners,

2. Subjects are selected randomly,

3. Acoustic characteristics of the room meet specific requirements,

4. Ambient noise levels in the room are below specified limits,

Likewise, open ear thresholds are used on a continuing basis to monitor the background noise levels.

Each of the 20 subjects was tested two (2) times at each of the seven test frequencies (125, $250,500,1 \mathrm{~K}, 2 \mathrm{~K}, 4 \mathrm{~K}$ and $8 \mathrm{~K} \mathrm{~Hz}$ ). For each test frequency, mean attenuation (IL) values were computed according to Equation 3 (see Section 1.4).

The assumed protective values (APVs) are a measure of hearing protector attenuation by frequency $(f)$. The $\mathrm{APV}_{\mathrm{f}_{\mathrm{x}}}$ is used in calculating other hearing protector related values, such as the single number rating (SNR) and the high medium low (HML) rating. The APV may also be used alone as a direct estimate of NR at a particular frequency band. The APV $\mathrm{f}_{\mathrm{f}_{\mathrm{x}}}$ is calculated by subtracting a multiple of the standard deviation of the attenuations from the mean attenuation for 
each frequency band. The standard deviation multiplier $(\alpha)$ is chosen based on the desired protection performance level $(\chi)(\mathrm{NIOSH}, 2010)$. The APV is calculated as:

$$
\mathrm{APV}_{\mathrm{f}_{\mathrm{x}}}=\mathrm{IL}_{\text {mean }}-\chi \times \mathrm{SD}
$$

Where $\chi=$ number of standard deviations

Standard deviations for the 40 different attenuation determinations for each test signal were also calculated. The Michael \& Associates custom designed automatic recording attenuator reported values in SPL (dB) for each tested frequency band.

\subsubsection{Step-by-step procedures}

The steps for REAT testing were as follows:

1. Check and calibrate equipment.

2. Describe test to subject.

3. Have subject enter the chamber and sit down in chair.

4. Shut the chamber's door and sit at the monitoring station where the investigator could signal the subject through a glass window during the test.

5. Record two open threshold measurements consecutively.

6. While wearing the light equipped helmet, have subject insert both earplugs with the use of a fitting noise, but with no assistance from investigator.

7. Wait at least 30 seconds for earplugs to fully expand.

8. Record one occluded threshold (i.e., HPD inserted).

9. Have subject remove both earplugs and the light-equipped helmet.

10. Record one open threshold (i.e., no HPD).

11. Have subject don a different light-equipped helmet and insert a new set of earplugs.

12. Record one occluded threshold.

13. Repeat steps 2 through 12 for each of the 20 subjects. 
Table 7. Tabular attenuation data by frequency for each subject and replication

\begin{tabular}{|c|c|c|c|c|c|c|c|c|c|c|}
\hline Subject & Trial & $\begin{array}{c}\text { Trial } \\
\text { NR }\end{array}$ & $\begin{array}{l}125 \\
\mathrm{~Hz}\end{array}$ & $\begin{array}{l}250 \\
\mathrm{~Hz}\end{array}$ & $\begin{array}{l}500 \\
\mathrm{~Hz}\end{array}$ & $\begin{array}{c}1000 \\
\mathrm{~Hz}\end{array}$ & $\begin{array}{c}2000 \\
\mathrm{~Hz}\end{array}$ & $\begin{array}{c}4000 \\
\mathrm{~Hz}\end{array}$ & $\begin{array}{c}8000 \\
\mathrm{~Hz}\end{array}$ & $\begin{array}{c}\text { Overall } \\
\text { NRA }_{A}\end{array}$ \\
\hline \multirow[t]{2}{*}{1} & 1 & 38 & 38.3 & 29.0 & 34.2 & 35.7 & 38.8 & 48.7 & 49.2 & 39.1 \\
\hline & 2 & 37 & 35.4 & 28.4 & 33.7 & 34.5 & 38.1 & 46.9 & 51.2 & 38.3 \\
\hline \multirow[t]{2}{*}{2} & 1 & 38 & 37.7 & 30.4 & 33.0 & 38.9 & 39.4 & 40.8 & 39.8 & 37.1 \\
\hline & 2 & 35 & 37.2 & 28.8 & 30.6 & 39.4 & 33.2 & 41.8 & 40.5 & 35.9 \\
\hline \multirow[t]{2}{*}{3} & 1 & 37 & 32.1 & 30.6 & 34.9 & 32.8 & 40.2 & 44.0 & 44.2 & 37.0 \\
\hline & 2 & 36 & 35.1 & 30.6 & 34.5 & 31.1 & 39.6 & 43.3 & 46.4 & 37.2 \\
\hline \multirow[t]{2}{*}{4} & 1 & 31 & 25.2 & 22.1 & 27.1 & 28.1 & 35.0 & 39.8 & 42.7 & 31.4 \\
\hline & 2 & 31 & 24.4 & 23.8 & 28.4 & 28.7 & 32.6 & 41.7 & 43.5 & 31.9 \\
\hline \multirow[t]{2}{*}{5} & 1 & 33 & 25.7 & 26.2 & 30.7 & 31.6 & 31.3 & 47.3 & 45.9 & 34.1 \\
\hline & 2 & 33 & 22.3 & 23.7 & 28.9 & 32.5 & 32.4 & 47.6 & 47.1 & 33.5 \\
\hline \multirow[t]{2}{*}{6} & 1 & 40 & 38.5 & 30.6 & 37.7 & 39.1 & 40.7 & 40.9 & 52.4 & 40.0 \\
\hline & 2 & 40 & 40.2 & 32.6 & 38.0 & 37.8 & 38.6 & 47.9 & 50.2 & 40.8 \\
\hline \multirow[t]{2}{*}{7} & 1 & 33 & 33.5 & 23.1 & 32.5 & 31.5 & 33.3 & 46.6 & 45.5 & 35.1 \\
\hline & 2 & 32 & 34.8 & 25.4 & 28.4 & 32.3 & 29.8 & 48.4 & 44.9 & 34.9 \\
\hline \multirow[t]{2}{*}{8} & 1 & 40 & 39.7 & 34.7 & 45.1 & 37.1 & 42.8 & 41.0 & 43.9 & 40.6 \\
\hline & 2 & 40 & 38.2 & 34.6 & 41.1 & 37.1 & 40.2 & 41.5 & 44.4 & 39.6 \\
\hline \multirow[t]{2}{*}{9} & 1 & 38 & 40.0 & 33.5 & 36.6 & 37.4 & 35.3 & 45.2 & 51.9 & 40.0 \\
\hline & 2 & 38 & 36.9 & 35.6 & 37.2 & 37.4 & 35.6 & 44.2 & 52.8 & 40.0 \\
\hline \multirow[t]{2}{*}{10} & 1 & 35 & 32.8 & 31.4 & 35.7 & 32.8 & 33.8 & 38.2 & 48.3 & 36.1 \\
\hline & 2 & 37 & 38.4 & 35.3 & 37.1 & 34.1 & 35.6 & 45.0 & 51.2 & 39.5 \\
\hline \multirow[t]{2}{*}{11} & 1 & 31 & 25.0 & 23.5 & 28.3 & 27.2 & 34.6 & 40.7 & 42.2 & 31.6 \\
\hline & 2 & 32 & 29.0 & 25.0 & 28.2 & 27.8 & 36.7 & 38.4 & 41.8 & 32.4 \\
\hline \multirow[t]{2}{*}{12} & 1 & 34 & 33.6 & 24.6 & 29.9 & 31.6 & 35.8 & 47.8 & 46.5 & 35.7 \\
\hline & 2 & 39 & 35.5 & 28.7 & 34.5 & 39.1 & 40.7 & 49.8 & 47.1 & 39.3 \\
\hline \multirow[t]{2}{*}{13} & 1 & 27 & 25.7 & 19.3 & 25.7 & 23.2 & 32.4 & 37.5 & 31.2 & 27.9 \\
\hline & 2 & 31 & 31.2 & 23.6 & 29.0 & 28.0 & 32.5 & 42.3 & 39.4 & 32.3 \\
\hline
\end{tabular}


Table 7 (cont.). Tabular attenuation data by subject for each replication

\begin{tabular}{|c|c|c|c|c|c|c|c|c|c|c|}
\hline Subject & Trial & $\begin{array}{l}\text { Trial } \\
\text { NR }\end{array}$ & $\begin{array}{l}125 \\
\mathrm{~Hz}\end{array}$ & $\begin{array}{l}250 \\
\mathrm{~Hz}\end{array}$ & $\begin{array}{l}500 \\
\mathrm{~Hz}\end{array}$ & $\begin{array}{c}1000 \\
\mathrm{~Hz}\end{array}$ & $\begin{array}{c}2000 \\
\mathrm{~Hz}\end{array}$ & $\begin{array}{c}4000 \\
\mathrm{~Hz}\end{array}$ & $\begin{array}{c}8000 \\
\mathrm{~Hz}\end{array}$ & $\begin{array}{c}\text { Overall } \\
\mathbf{N R}_{\mathbf{A}}\end{array}$ \\
\hline \multirow[t]{2}{*}{14} & 1 & 32 & 29.7 & 25.7 & 26.5 & 28.9 & 37.4 & 45.3 & 49.4 & 34.7 \\
\hline & 2 & 35 & 28.8 & 26.9 & 31.3 & 32.9 & 36.3 & 44.9 & 47.6 & 35.5 \\
\hline \multirow[t]{2}{*}{15} & 1 & 32 & 26.6 & 23.9 & 27.5 & 29.3 & 41.4 & 42.3 & 47.2 & 34.0 \\
\hline & 2 & 37 & 35.3 & 28.5 & 33.2 & 33.5 & 41.1 & 42.8 & 49.1 & 37.6 \\
\hline \multirow[t]{2}{*}{16} & 1 & 30 & 26.7 & 21.2 & 26.0 & 26.3 & 37.5 & 44.3 & 43.9 & 32.3 \\
\hline & 2 & 30 & 23.8 & 20.4 & 27.4 & 27.1 & 36.3 & 42.1 & 42.9 & 31.4 \\
\hline \multirow[t]{2}{*}{17} & 1 & 30 & 25.7 & 25.5 & 22.1 & 30.8 & 38.8 & 37.7 & 41.8 & 31.8 \\
\hline & 2 & 33 & 29.2 & 23.4 & 26.4 & 31.7 & 40.8 & 40.2 & 42.0 & 33.4 \\
\hline \multirow[t]{2}{*}{18} & 1 & 34 & 31.6 & 25.3 & 28.4 & 31.6 & 39.1 & 45.6 & 47.9 & 35.6 \\
\hline & 2 & 32 & 29.9 & 21.7 & 27.9 & 30.4 & 36.6 & 45.8 & 48.4 & 34.4 \\
\hline \multirow[t]{2}{*}{19} & 1 & 29 & 27.2 & 20.0 & 25.7 & 27.1 & 34.9 & 37.0 & 32.4 & 29.2 \\
\hline & 2 & 30 & 31.5 & 20.9 & 25.2 & 28.5 & 35.1 & 39.3 & 37.4 & 31.1 \\
\hline \multirow[t]{2}{*}{20} & 1 & 37 & 27.4 & 27.1 & 40.7 & 35.3 & 36.5 & 47.5 & 43.5 & 36.9 \\
\hline & 2 & 37 & 35.3 & 33.0 & 42.0 & 32.9 & 36.3 & 47.4 & 43.5 & 38.6 \\
\hline \multirow{2}{*}{ Overall } & $\mathrm{NR}_{\mathrm{A}}$ & 34.4 & 31.9 & 27.0 & 31.8 & 32.3 & 36.7 & 43.5 & 45.0 & 35.4 \\
\hline & SD & 3.5 & 5.3 & 4.6 & 5.3 & 4.1 & 3.2 & 3.5 & 4.9 & 4.4 \\
\hline
\end{tabular}

\subsection{Results}

This laboratory study determined maximal IL of the light-equipped helmet using a REAT method. The raw results by subject for each replication are shown in Tables 7 and 24 (see Appendix for Table 24).

Note that with the exception of two subjects (13 and 19), the remaining 18 achieved a NR with the modified earplug that exceeded the manufacturer's published NRR $(29 \mathrm{~dB})$ for the unmodified earplug. 
The average $\mathrm{NR}$ for all subjects was $35.4 \mathrm{~dB}(\mathrm{SD}=4.4,95 \% \mathrm{CI}=34.8,36.1)$ across all test signals.

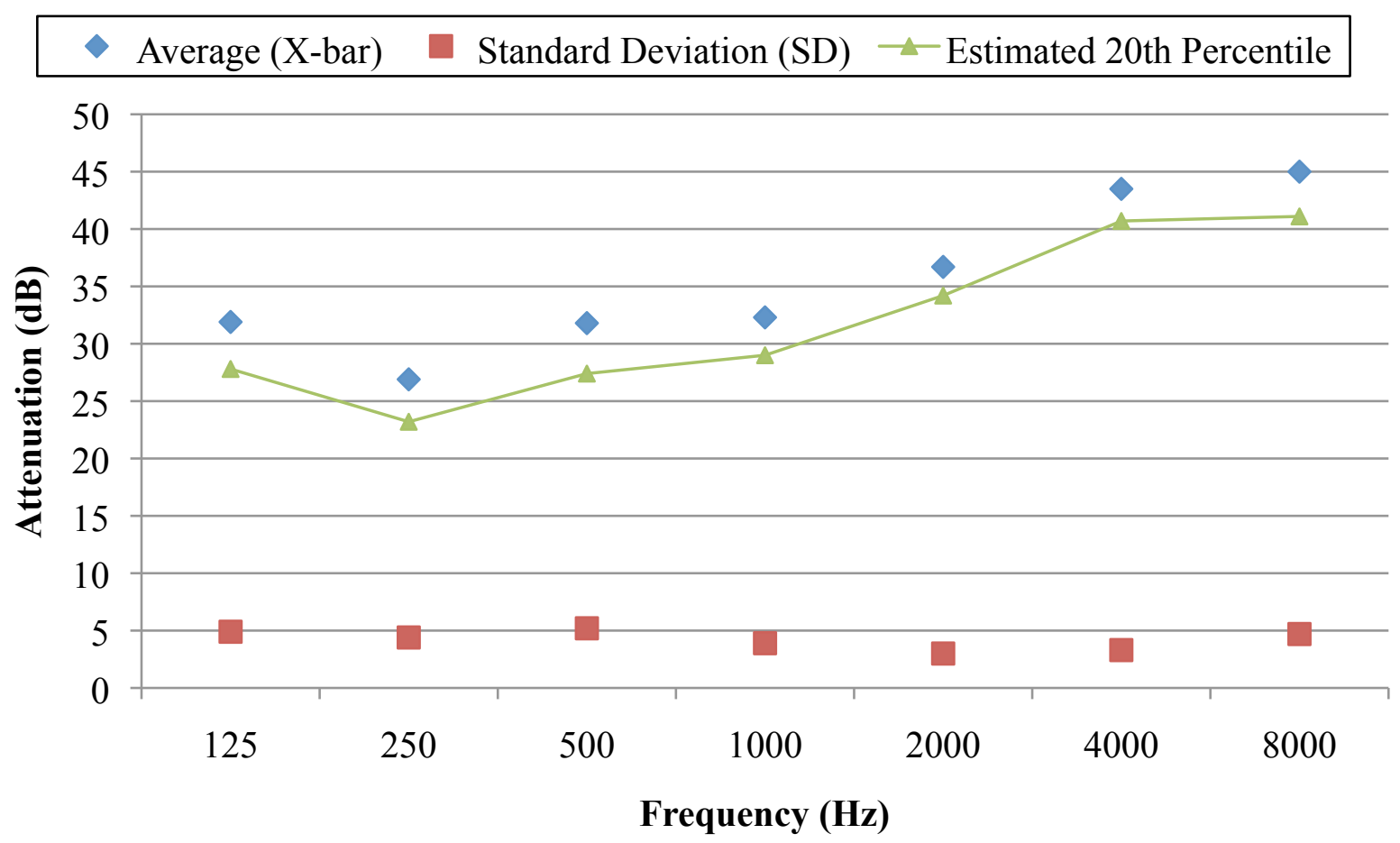

Figure 21. Attenuation versus frequency

As shown in Figure 21 and Table 7, the average NR at $1000 \mathrm{~Hz}$ was $32.3 \mathrm{~dB}$ when subjects wore the light-equipped helmet during earplug insertion. For Figure $21, \chi$ was $80 \%$, so that the $\mathrm{APV}_{\mathrm{f}_{\mathrm{x}}}$ estimates the $20^{\text {th }}$ percentile protection. Therefore, the $\mathrm{APV}_{f 80}$ values for the tubing assembly are calculated; that is, the selected protection performance, $\alpha$, of $80 \%(0.84$ standard deviation). 


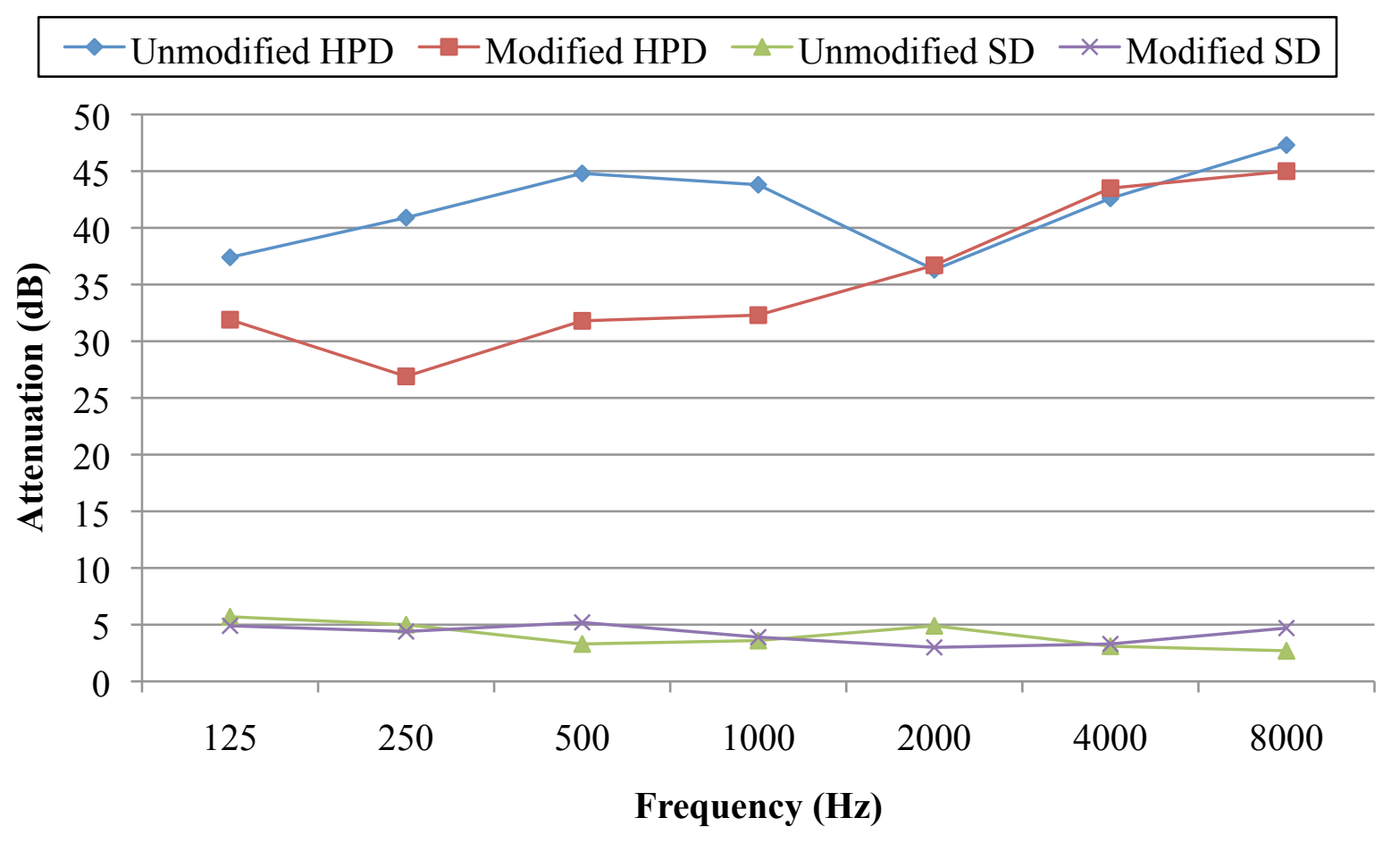

Figure 22. Modified HPD compared to unmodified HPD

The mean attenuation differences are plotted by frequency for the unmodified and modified earplugs (see Figure 22). Note the difference between the two mean values between $125 \mathrm{~Hz}$ and $1000 \mathrm{~Hz}$. The difference is probably due to the tube effect of $\mathrm{TL}_{\text {path }}$ (see Figure 15, Section 4.5).

\subsection{Discussion}

A concern of the field study was the achievable fit of earplugs with a plastic tube penetrating the earplug while wearing a hardhat.

Results of the REAT testing show subjects ability to fit HPDs was not impaired due to wearing the hardhat during earplug insertion since most individually trained users (18 subjects) achieved or exceeded the published NRR of $29 \mathrm{~dB}$ for the earplug. In addition, many (15 subjects) achieved or exceeded a NR of $37 \mathrm{~dB}$ with only one subject receiving values less than $29 \mathrm{~dB}$ (see Table 7). 
Results of the difference between the published NRR of the Classic E-A-R earplug and the tubing apparatus are shown in Table 8. Results indicate that there is a difference between means.

Table 8 . Test difference between NR mean values

E-A-R Classic

$$
\text { Plug } \mathrm{n}_{\mathrm{NRR}}=10
$$

\begin{tabular}{|c|c|c|c|c|c|c|c|c|}
\hline $\begin{array}{l}125 \\
\mathrm{~Hz} \\
\end{array}$ & $\begin{array}{l}250 \\
\mathrm{~Hz} \\
\end{array}$ & $\begin{array}{l}500 \\
\mathrm{~Hz}\end{array}$ & $\begin{array}{c}1000 \\
\mathrm{~Hz}\end{array}$ & $\begin{array}{c}2000 \\
\mathrm{~Hz}\end{array}$ & $\begin{array}{c}4000 \\
\mathrm{~Hz} \\
\end{array}$ & $\begin{array}{c}8000 \\
\mathrm{~Hz}\end{array}$ & $\begin{array}{c}\text { Overall } \\
\mathrm{NR}_{\mathrm{A}}\end{array}$ & NRR \\
\hline 37.4 & 40.9 & 44.8 & 43.8 & 36.3 & 42.6 & 47.3 & 41.9 & \multirow{2}{*}{29.0} \\
\hline 5.7 & 5.0 & 3.3 & 3.6 & 4.9 & 3.1 & 2.7 & 4.0 & \\
\hline 10.0 & 10.0 & 10.0 & 10.0 & 10.0 & 10.0 & 10.0 & 10.0 & 10.0 \\
\hline
\end{tabular}

Tubing Apparatus $\mathrm{n}_{\text {tubing }}$

\begin{tabular}{|c|c|c|c|c|c|c|c|c|c|c|}
\hline with Plug & $=$ & 20 & & & & & & & & \\
\hline & $\begin{array}{l}125 \\
\mathrm{~Hz}\end{array}$ & $\begin{array}{l}250 \\
\mathrm{~Hz}\end{array}$ & $\begin{array}{l}\mathbf{5 0 0} \\
\mathrm{Hz} \\
\end{array}$ & $\begin{array}{c}1000 \\
\mathrm{~Hz}\end{array}$ & $\begin{array}{c}2000 \\
\mathrm{~Hz} \\
\end{array}$ & $\begin{array}{c}4000 \\
\mathrm{~Hz} \\
\end{array}$ & $\begin{array}{c}8000 \\
\mathrm{~Hz} \\
\end{array}$ & $\begin{array}{c}\text { Overall } \\
\mathrm{NR}_{\mathrm{A}} \\
\end{array}$ & NRR & Mean \\
\hline Mean (dB) & 31.9 & 26.9 & 31.8 & 32.3 & 36.7 & 43.5 & 45.0 & 35.4 & 30 & 35.4 \\
\hline $\mathrm{SD}(\mathrm{dB})$ & 4.9 & 4.4 & 5.2 & 3.9 & 3.0 & 3.3 & 4.7 & 4.2 & & 4.2 \\
\hline $\mathrm{n}$ & 20 & 20 & 20 & 20 & 20 & 20 & 20 & 20 & 20 & 20 \\
\hline$\Delta \mathrm{NR}$ & 5.50 & 14.0 & 13.0 & 11.5 & -0.4 & -0.9 & 2.3 & 6.4 & -1.0 & 6.4 \\
\hline $\mathrm{s}_{\mathrm{p}}$ & 5.17 & 4.60 & 4.67 & 3.81 & 3.72 & 3.24 & 4.16 & 4.15 & & 4.15 \\
\hline $\mathrm{t}_{2.5 \%}$ & 2.048 & 2.048 & 2.048 & 2.048 & 2.048 & 2.048 & 2.048 & 2.048 & & 1.701 \\
\hline
\end{tabular}

\begin{tabular}{cccccccccc} 
LCL & 1.40 & 10.35 & 9.29 & 8.48 & -3.35 & -3.47 & -1.00 & 3.14 & 3.69 \\
UCL & 9.60 & 17.65 & 16.71 & 14.52 & 2.55 & 1.67 & 5.60 & 9.72 & 9.16 \\
\hline
\end{tabular}

Note: if the confidence interval includes zero, then no sig difference. At alpha $=5 \%$

\subsection{Conclusion}

Subjects achieved good fits while wearing the hardhat. 


\section{CHAPTER 6: RESEARCH METHODOLOGY}

\subsection{Step-by-Step Procedure}

Tests were conducted at a metal products manufacturing facility located in West Virginia. In each case, all provisions of IRB Human Subjects Protocol 9999-16617 were followed rigorously. Prior to running the tests at the plant, paid, volunteer subjects were recruited and informed consent was obtained. The following was followed for data collection for each of the 22 subjects.

1. Checked and pre-calibrated equipment.

2. Assisted subject donning of light helmet and dosimeter pouch.

3. Set light to deactivated and covered bulb with rubber cap. During this and other "deactivated" periods, a black rubber cap was placed over the light to make it clear to the subject that no blinking light could be expected.

4. Instructed subject that light was now deactivated.

5. Started dosimeters and doseBuster unit.

6. Subjects worked for approximately 70 -minutes.

7. Removed the rubber cap from the light and switched on signal light.

8. Instructed subject that light was now on.

9. Repeated steps 6 through 7 twice more (i.e., three periods of 70 minutes Light Deactivated and 70 minutes Light Activated).

10. During each tested shift, a "working fit-test" was conducted at times selected as randomly as possible.

11. Just after the last cycle, the investigator assisted subject in removing light helmet and dosimeter pouch.

12. Re-checked and post-calibrated equipment (only Subjects 1 and 10 failed).

\subsection{Analysis}

Sound pressure levels are expressed as decibels and therefore are a logarithmic measurement. The second-by-second values of $\mathrm{SPL}_{\mathrm{sh}}$ and $\mathrm{SPL} \mathrm{L}_{\text {ear }}$ recorded by two dosimeters 
were synchronized by computer time to pair the data. The arithmetic and equivalent averages were calculated by period.

This study was designed to test the hypothesis that there was no difference in overall $\mathrm{NR}_{\mathrm{A}}$ between alternating and treatment periods in a metal products facility.

The dependent variable for this study was $\mathrm{NR}_{\mathrm{A}}$. Values were computed using Equation 4. The independent variables were light status (deactivated or activated), subject, cycle, and period. The hypothesis tested was:

$$
\begin{array}{ll}
\mathrm{H}_{\mathrm{o}}: & \mathrm{NR}_{\text {Awithlight }}=\mathrm{NR}_{\text {Awithoutlight }} \\
\mathrm{H}_{\mathrm{a}}: & \mathrm{NR}_{\text {Awithlight }} \neq \mathrm{NR}_{\text {Awithoutlight }}
\end{array}
$$

ANOVA was used to analyze the difference of $\mathrm{NR}_{\mathrm{A}}$ values between Light Deactivation and Light Activation. Stated non-mathematically, there is no difference between treatments or there is a difference. The statistical significant of the independent variable will be done by using JMP (version 8.0.2) (SAS Institute, Inc., Cary, NC).

- Dependent variable: $\mathrm{NR}_{\mathrm{A}}=\left(\mathrm{SPL}_{\mathrm{sh}}-\mathrm{SPL}_{\text {ear }}\right)$ (with $\left.\mathrm{HPD}\right)$

- Independent variable: Light Status (i.e., deactivated or activated)

- ANOVA

- $\mathrm{H}_{\mathrm{o}}: \quad\left(\mathrm{NR}_{\mathrm{A}}\right)_{\text {with use of light }}-\left(\mathrm{NR}_{\mathrm{A}}\right)_{\text {without use of light }}=0$

- $\mathrm{H}_{\mathrm{a}}: \quad\left(\mathrm{NR}_{\mathrm{A}}\right)_{\text {with use of light }}-\left(\mathrm{NR}_{\mathrm{A}}\right)_{\text {without use of light }}>0$

\subsection{Bias}

In intervention studies such as this one, there is great potential for bias. The potential biases and the attempts to minimize them were as follows: 


\subsubsection{Researcher}

Researcher bias is the process where the experimenter performing the research influences the results in order to favor a certain outcome. Minimized by keeping the subjects uninformed as to the study purpose.

\subsubsection{Consent Form}

Consent form bias occurs when subjects change their awareness level from material found in the consent form. Minimized by providing an overview of the consent form verbally, focusing on confidentiality, volunteer participation and compensation.

\subsubsection{Selection}

Selection bias occurs when the process of subject selection actually introduces an inherent bias into the study. There are two types:

\subsubsection{Omission}

This research bias occurs when certain groups are omitted from the sample. Minimized by diversifying volunteer subjects by race and sex characteristics.

\subsubsection{Inclusive}

Inclusive bias occurs when subjects are selected based on convenience. For example, volunteer subjects are the only group available, and they tend to fit a narrow demographic range. Minimized by diversifying volunteer subjects by race and sex characteristics.

\subsubsection{Hawthorne Effect}

Performance improved because subjects got extra attention from being in the study. Minimized by collecting full-shift measurements and casual observations. The assumption would be subjects fail to remember the researcher after the first hour. 


\subsubsection{Measurement}

Measurement bias occurs from an error in the data collection or process of data collection. Minimized by conducting a preliminary study on apparatus, meticulous calibration of instrumentation and precise data management. 


\section{CHAPTER 7: RESULTS AND DISCUSSION}

A metal products manufacturing facility was chosen for the field study. Twenty-two subjects from five departments served as paid volunteer participants. The departments included coil, coating, stacker, press and forklift. Subjects recruited for the study were diverse in age and experience. Six were females and 16 were males. They had an average age of 41 years $(\mathrm{SD}=$ 8.3 ) and a self-reported working experience at the facility of 9 years $(\mathrm{SD}=4.7)$. Only those subjects who were exposed continuously to noise during their work shifts were selected to participate in the study. Supervisors, maintenance workers and custodial staff were excluded because nearly $35 \%$ of their time was spent in quiet office settings (office noise exposure level $<$ $70 \mathrm{dBA})$. In addition, every subject was observed by the investigator to be wearing earplugs prior to volunteering. Management at the facility mandated hearing protection device use and subjects were observed by the investigator to be complying.

Sound pressure level values (SPLs) were measured for each of the 22 workers as they performed normal duties during their normal work schedules. Overall, 20 of the 22 exposed workers were included in the study. Subjects 1 and 10 were excluded later because their sampling equipment failed. Subject 9 experienced an equipment failure during period six, so his results for cycle 3 were discarded. The investigator's observations confirmed seven subjects' comments that the light would blink when they were talking.

The shift was divided into six roughly equal periods. During the first, third, and fifth periods the light was deactivated and covered with a black cap but otherwise was unchanged. For periods two, four, and six, the light was activated and the black cap removed. For both treatment conditions the subjects were informed by the investigator as to whether the light was activated or not. 
Table 9. Overall descriptive statistics for minute-by-minute NR results in dBA

\begin{tabular}{|c|c|c|c|c|}
\hline Subject & $\mathrm{N}$ & NR Mean & NR Std Dev & NR Median \\
\hline 2 & 6 & 3.7 & 4.6 & 3.7 \\
\hline 3 & 6 & 8.1 & 0.9 & 8.4 \\
\hline 4 & 6 & 5.4 & 1.2 & 5.4 \\
\hline 5 & 6 & 19.6 & 5.3 & 20.8 \\
\hline 6 & 6 & 21.6 & 0.2 & 21.7 \\
\hline 7 & 6 & 2.1 & 1.1 & 2.5 \\
\hline 8 & 6 & 13.9 & 7.3 & 15.8 \\
\hline 9 & 6 & 20.7 & 2.9 & 20.2 \\
\hline 11 & 6 & 1.8 & 2.8 & 1.0 \\
\hline 12 & 6 & 1.5 & 3.1 & 0.5 \\
\hline 13 & 6 & 13.6 & 3.9 & 12.1 \\
\hline 14 & 6 & 1.5 & 3.0 & 1.5 \\
\hline 15 & 6 & 12.1 & 3.5 & 12.8 \\
\hline 16 & 6 & 5.6 & 6.2 & 3.8 \\
\hline 17 & 6 & 10.8 & 5.5 & 11.5 \\
\hline 18 & 6 & 13.3 & 6.3 & 16.1 \\
\hline 19 & 6 & 4.1 & 3.3 & 4.2 \\
\hline 20 & 6 & 12.8 & 2.7 & 12.1 \\
\hline 21 & 6 & 2.1 & 5.3 & 0.4 \\
\hline 22 & 6 & 15.0 & 2.6 & 14.6 \\
\hline Overall & 120 & 9.4 & 7.5 & 8.5 \\
\hline
\end{tabular}

\subsection{Overall NR Mean Values Compared to Published NRR Values}

One would have expected subjects' observed NRs would equal or exceed published NRR values; instead, they were much lower. The minute-by-minute NR mean values achieved by each subject are shown in Table 9. As can be seen, four subjects obtained relatively good NRs (i.e., NR mean $\geq 15 \mathrm{dBA}$ ); while seven subjects had poor NRs (i.e., NR mean $<5 \mathrm{dBA}$ ). The remaining nine subjects had modest NRs (i.e., NR mean between 5 and $15 \mathrm{dBA}$ ). As shown in Table 9, the minute-by-minute observed NR values ranged from 1.5 to $21.6 \mathrm{dBA}$ (median $=8.5$ $\mathrm{dBA}, \mathrm{SD}=7.5 \mathrm{dBA}$ ), indicating that all subjects were well below the published NRR for the 
tested earplug $(\mathrm{NRR}=29 \mathrm{dBA})$. Observed average NRs for individual subjects were on average less than one-third of the rated NRR value, with the highest less than three-quarters of the rated NRR value.

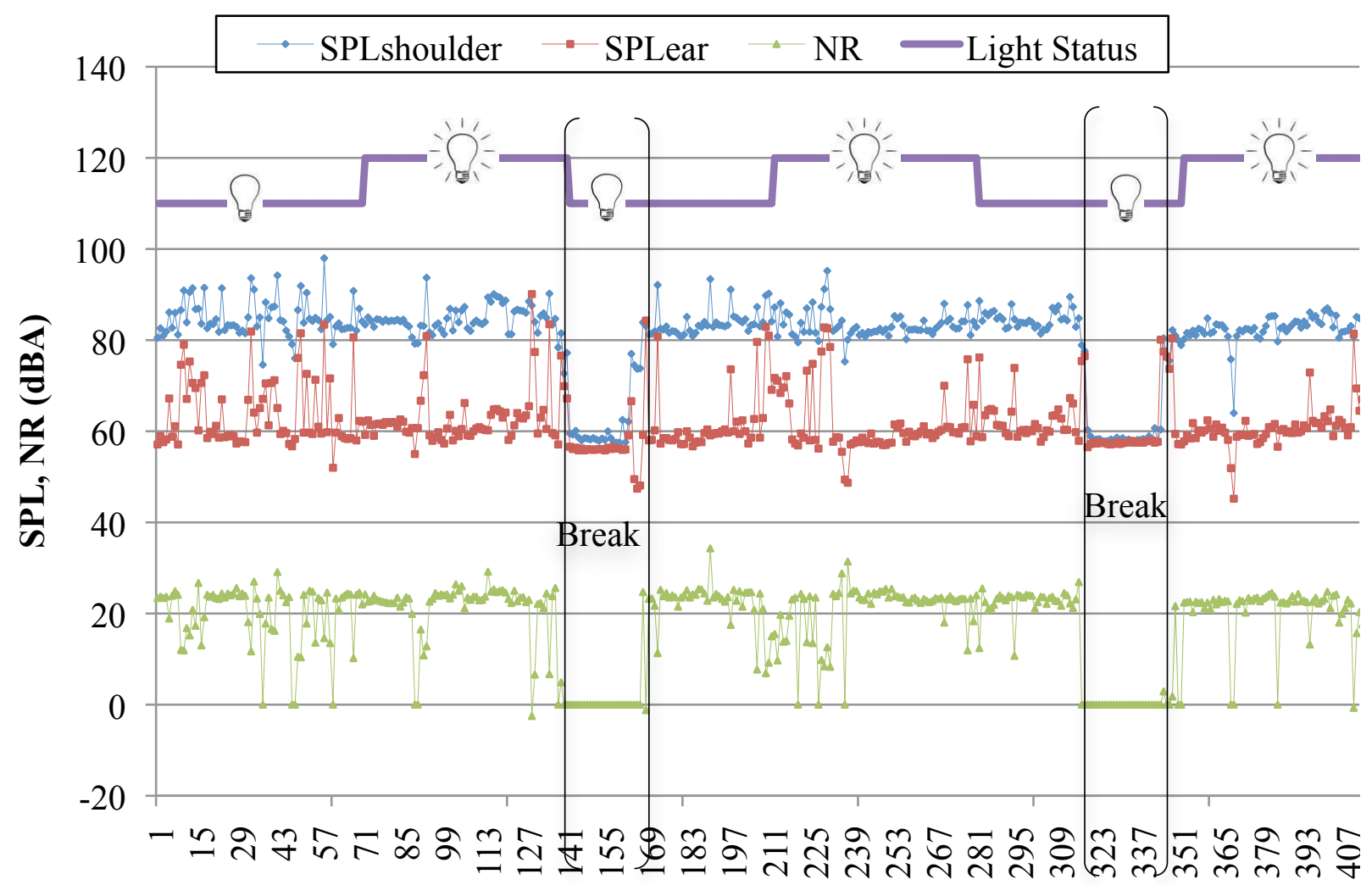

Duration (minutes)

Figure 23. Minute-by-minute results for Subject $6(\mathrm{NR}$ mean $=21.6 \mathrm{dBA}, \mathrm{SD}=0.2 \mathrm{dBA})$

\subsection{Second-by-Second and Minute-by-Minute NR Values}

Noise reduction values for all of the tested subjects, whether their NRs were good or poor, experienced a high degree of variability (average $\mathrm{SD}=7.5 \mathrm{dBA}$ ). As shown in Figure 23 for an example period, it was also clear that the variability extended over the entire work shift and that for some times the variability was more extreme than at other times. Note the brackets in Figure 23 indicate approximately the beginnings and endings of subject breaks. 
As with most subjects, $\mathrm{SPL}_{\text {sh }}$ values for Subject 6 were above $80 \mathrm{dBA}$ for the entire shift, except during breaks and lunch. During the two breaks the ambient noise level $\left(\mathrm{SPL}_{\mathrm{sh}}\right)$ decreased from 80 to about $60 \mathrm{dBA}$. The investigator observed Subject 6 with his earplugs not in his ears during the breaks. For that reason, NR values are not shown during breaks since $\mathrm{SPL}_{\text {sh }}$ values were less than $80 \mathrm{dBA}$ during breaks. In any case, the study protocol omitted all data for which $\mathrm{SPL}_{\mathrm{sh}}<80 \mathrm{dBA}$ in all data analyses and descriptive statistics.

From Figure 23, it appears that the greatest NR (34.3 dBA) achieved by Subject 6 was 5.3 dBA higher than the published NRR of the tested plug $(N R R=29 \mathrm{~dB})$. Because the subject's initial NR was very high, the potential for improvement when using the light as a prompt was minimal. If nothing else, he would have not seen the light blink very often and thus had little inducement or opportunity to improve his fit.

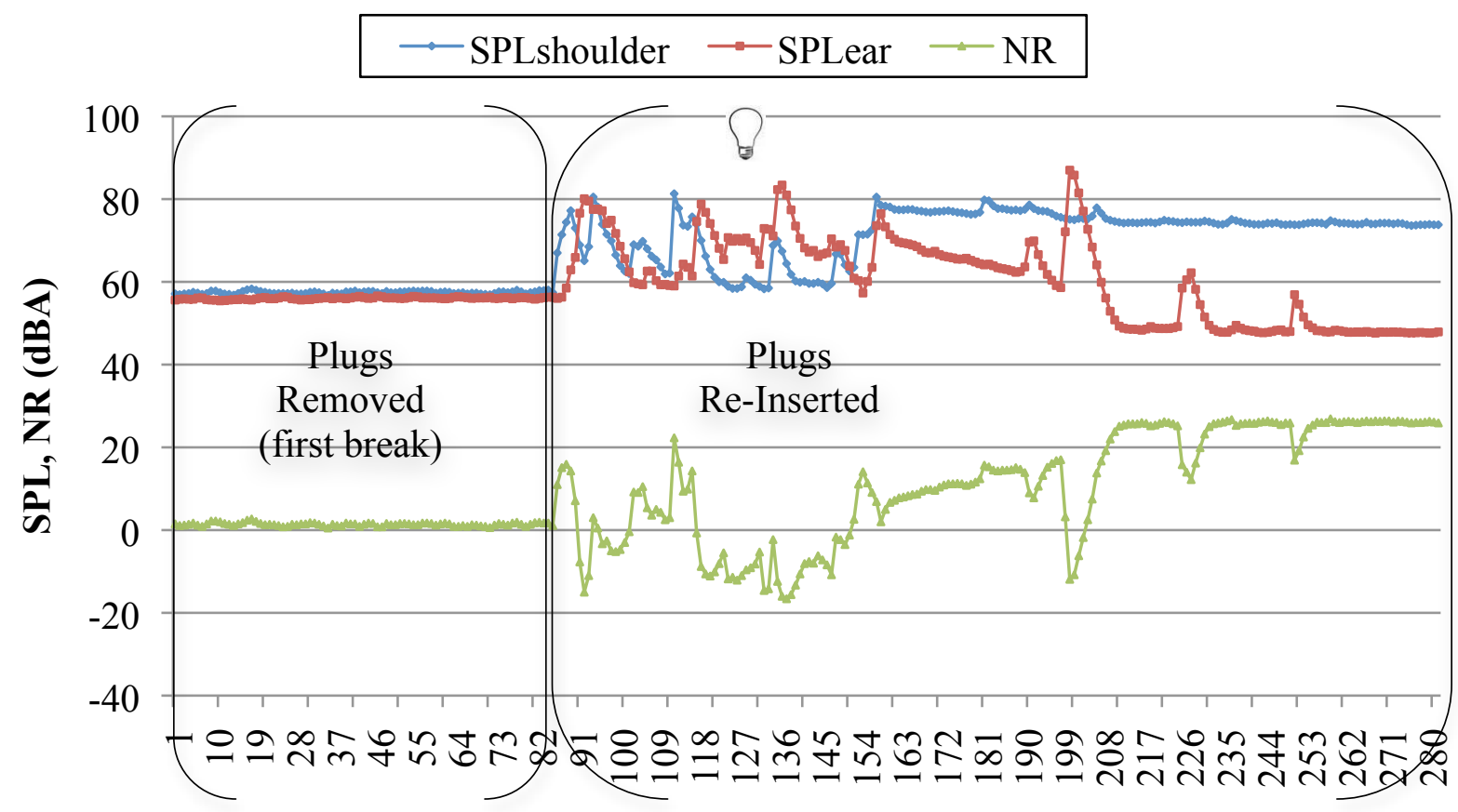

Duration (seconds)

Figure 24. Second-by-second results for Subject 6 during first break 
It is possible that viewing second-by-second time series would reveal details not observable with the minute-by-minute results. The second-by-second results for Subject 6 at the end of his first and second break are shown in Figures 24 and 25. Looking at the NR results in those figures reveals sharp SPL inclines and declines that suggest the earplug was being re-inserted or influenced at that instance. One would expect changes in NR to occur over many seconds due to the time required for the foam earplugs to fully expand after insertion. This phenomenon may explain the roughly 80 seconds required to reach a plateau after Subject 6 inserted his earplugs. The investigator found that at least 40 seconds were required to fully seat inside the ear canal.

Note, also, the instances where $\mathrm{SPL}_{\text {ear }}$ values were greater than $\mathrm{SPL}_{\mathrm{sh}}$ values during the reinsertion period. Although the investigator was unable to confirm this from observations for Subject 6, the sharp spikes in $\mathrm{SPL}_{\text {ear }}$ above $\mathrm{SPL}_{\mathrm{sh}}$ values may be due to the subject seating the earplug with his finger from time to time. This event was observed with other subjects and explained further in section 7.3.

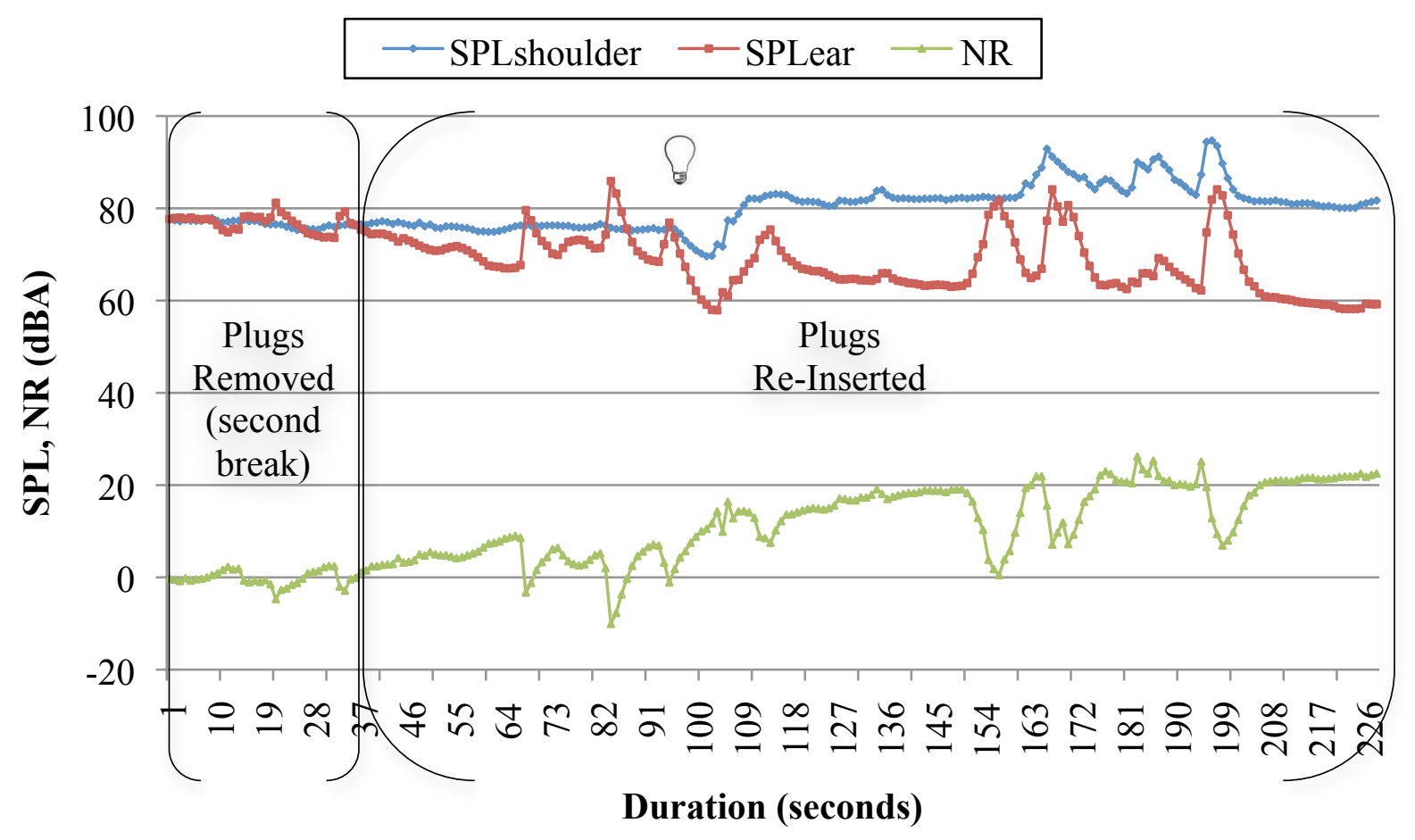

Figure 25. Second-by-second results for Subject 6 during second break 
This study investigated the real time improvement in experienced protection due to using a signaling light to indicate when HPDs fail to adequately protect subjects. The working assumption was that workers would put HPDs back on or attempt to improve the fit of HPDs when a blinking light lets them know that at least one of their ears was overexposed. Table 10 shows NR mean results for each subject during periods of Light Deactivation and Light Activation.

Table 10. Descriptive statistics of NR mean by light status

\begin{tabular}{|c|c|c|c|c|c|c|c|c|c|}
\hline \multirow{2}{*}{ Subject } & \multicolumn{4}{|c|}{$\begin{array}{l}\text { Light Deactivated } \\
\qquad(\mathrm{dBA})\end{array}$} & \multicolumn{4}{|c|}{$\begin{array}{l}\text { Light Activated } \\
\qquad(\mathrm{dBA})\end{array}$} & \multirow{2}{*}{$\Delta \mathrm{NR}$} \\
\hline & $\mathrm{N}$ & $\begin{array}{l}\text { NR } \\
\text { Mean }\end{array}$ & $\begin{array}{l}\text { NR Std } \\
\text { Dev }\end{array}$ & $\begin{array}{c}\text { NR } \\
\text { Median }\end{array}$ & $\mathrm{N}$ & $\begin{array}{c}\text { NR } \\
\text { Mean }\end{array}$ & $\begin{array}{l}\text { NR Std } \\
\text { Dev }\end{array}$ & $\begin{array}{c}\text { NR } \\
\text { Median }\end{array}$ & \\
\hline $2^{* *}$ & 3 & 0.2 & 1.9 & -0.2 & 3 & 7.2 & 3.5 & 5.2 & 6.9 \\
\hline 3 & 3 & 8.6 & 0.3 & 8.5 & 3 & 7.6 & 1.1 & 7.9 & -1.0 \\
\hline 4 & 3 & 4.6 & 0.8 & 4.3 & 3 & 6.2 & 0.8 & 6.3 & 1.6 \\
\hline $5^{*}$ & 3 & 18.7 & 6.7 & 21.3 & 3 & 20.4 & 4.8 & 20.3 & 1.6 \\
\hline $6^{*}$ & 3 & 21.5 & 0.3 & 21.5 & 3 & 21.8 & 0.1 & 21.8 & 0.3 \\
\hline $7^{* *}$ & 3 & 2.1 & 1.6 & 2.6 & 3 & 2.2 & 0.6 & 2.3 & 0.1 \\
\hline 8 & 3 & 10.3 & 8.9 & 10.8 & 3 & 17.4 & 3.8 & 18.4 & 7.1 \\
\hline $9^{*}$ & 3 & 20.7 & 3.5 & 20.2 & 3 & 20.6 & 2.9 & 20.6 & -0.1 \\
\hline $11^{* *}$ & 3 & 0.8 & 0.5 & 1.0 & 3 & 2.8 & 4.1 & 0.9 & 2.0 \\
\hline $12^{* *}$ & 3 & 1.5 & 4.5 & -0.6 & 3 & 1.5 & 1.8 & 1.1 & 0.0 \\
\hline 13 & 3 & 14.2 & 4.4 & 13.1 & 3 & 13.1 & 4.1 & 11.1 & -1.1 \\
\hline $14^{* *}$ & 3 & 0.6 & 2.8 & 0.9 & 3 & 2.5 & 3.4 & 2.0 & 1.9 \\
\hline 15 & 3 & 12.6 & 1.0 & 12.5 & 3 & 11.6 & 5.4 & 13.1 & -1.0 \\
\hline 16 & 3 & 5.9 & 9.4 & 0.6 & 3 & 5.2 & 2.5 & 4.7 & -0.7 \\
\hline 17 & 3 & 6.8 & 5.0 & 9.3 & 3 & 14.8 & 1.6 & 15.3 & 7.9 \\
\hline 18 & 3 & 11.6 & 7.9 & 15.6 & 3 & 15.1 & 5.2 & 17.9 & 3.6 \\
\hline $19^{* *}$ & 3 & 2.9 & 3.7 & 1.3 & 3 & 5.3 & 3.1 & 6.6 & 2.4 \\
\hline 20 & 3 & 11.5 & 1.4 & 11.4 & 3 & 14.2 & 3.3 & 15.8 & 2.7 \\
\hline $21^{* *}$ & 3 & -1.7 & 0.6 & -1.7 & 3 & 5.9 & 5.2 & 3.9 & 7.6 \\
\hline $22^{*}$ & 3 & 14.0 & 2.5 & 13.5 & 3 & 16.1 & 2.8 & 15.6 & 2.1 \\
\hline Overall & 60 & 8.4 & 3.4 & 8.3 & 60 & 10.6 & 3.0 & 10.5 & 2.2 \\
\hline
\end{tabular}


There were five negative $\Delta \mathrm{NR}$ values, indicating that the light may have led to lower NR values during periods of activation than were experienced during periods of no activation. However, those five subjects experienced $\Delta \mathrm{NR}$ values (highest $=-1.1 \mathrm{dBA}$ ), suggesting that the negative values could have been due to random errors due to the imprecision of the dosimeters.

In this study the terms "computed NR" and earplug "fit" are used as if they meant the same thing. One could certainly define a "good fit" as one that produces a high NR, but it is doubtful that visual observations of the apparent quality of fit can precisely predict NR. However, the study assumed that worker attempts to improve the sensations they associated with a better fit would lead to higher NR for a given individual and earplug. Hence, the study implicitly assumed that worker attempts to improve "fit" (or to stop the light from blinking) would be successful, if attempted. That turned out not to be true for some subjects.

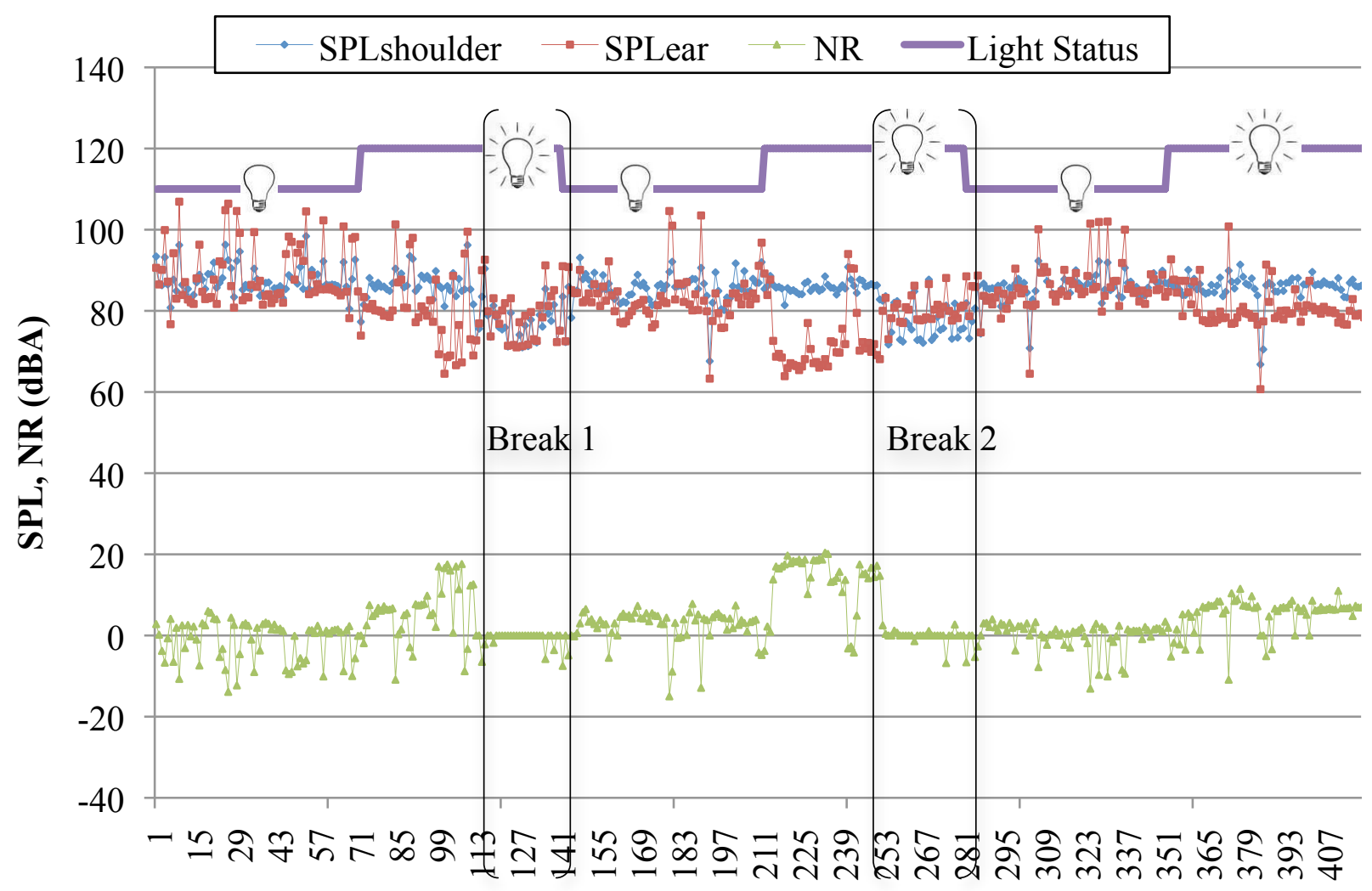

Duration (minutes)

Figure 26. Minute-by-minute results for Subject $2($ Mean NR $=3.7 \mathrm{dBA}, \mathrm{SD}=4.6 \mathrm{dBA})$ 
Subject 2 is one of seven subjects with a NR mean $<5 \mathrm{dBA}$. Note the negative NR values in Figure 26. A negative NR value would literally mean that there was a small amount of amplification inside the ear canal. His earplugs actually increased his exposures. These negative values are something that has appeared in a previous study $(\mathrm{Wu}, 2010)$. Despite a large potential and opportunity for improvement, Subject 2 failed to improve his NR when the light was activated. As will be discussed in more detail later, Subject 2 and other subjects with consistently low NR values may have been unable to improve their fits even with persistent effort. For Subject 2 the SPL $\mathrm{sh}_{\text {sh }}$ values were generally well above $80 \mathrm{dBA}$ except during breaks. Thus, since his NR values were extremely low (see Figure 26), his light would have blinked frequently during periods of Light Activation.

Again, because the subject's initial NR was very low, the potential for improvement when using the light as a prompt during periods of Light Activation was high. Nevertheless, the achieved NR by the subject was extremely low $(\Delta N R=6.9)$, suggesting that he was either unable or unwilling to improve his fit (see Table 10).

In this case, Subject 2 appeared to be highly diligent. The investigator observed Subject 2 attempting to insert his earplugs several times throughout the shift. During one apparently diligent effort to insert the earplug, the subject stated with evident frustration that he could not "get the light to stop blinking." The poor NR (NR mean $=3.7 \mathrm{dBA})$ obtained by this subject may be explained by his previous ear canal surgery. Therefore, if a worker has had ear surgery, workplaces may need to take extraordinary care in evaluating a candidate's ear protection ultimately relying on earmuffs. Clearly, there may be many other circumstances that limit potential effectiveness for other subjects. 


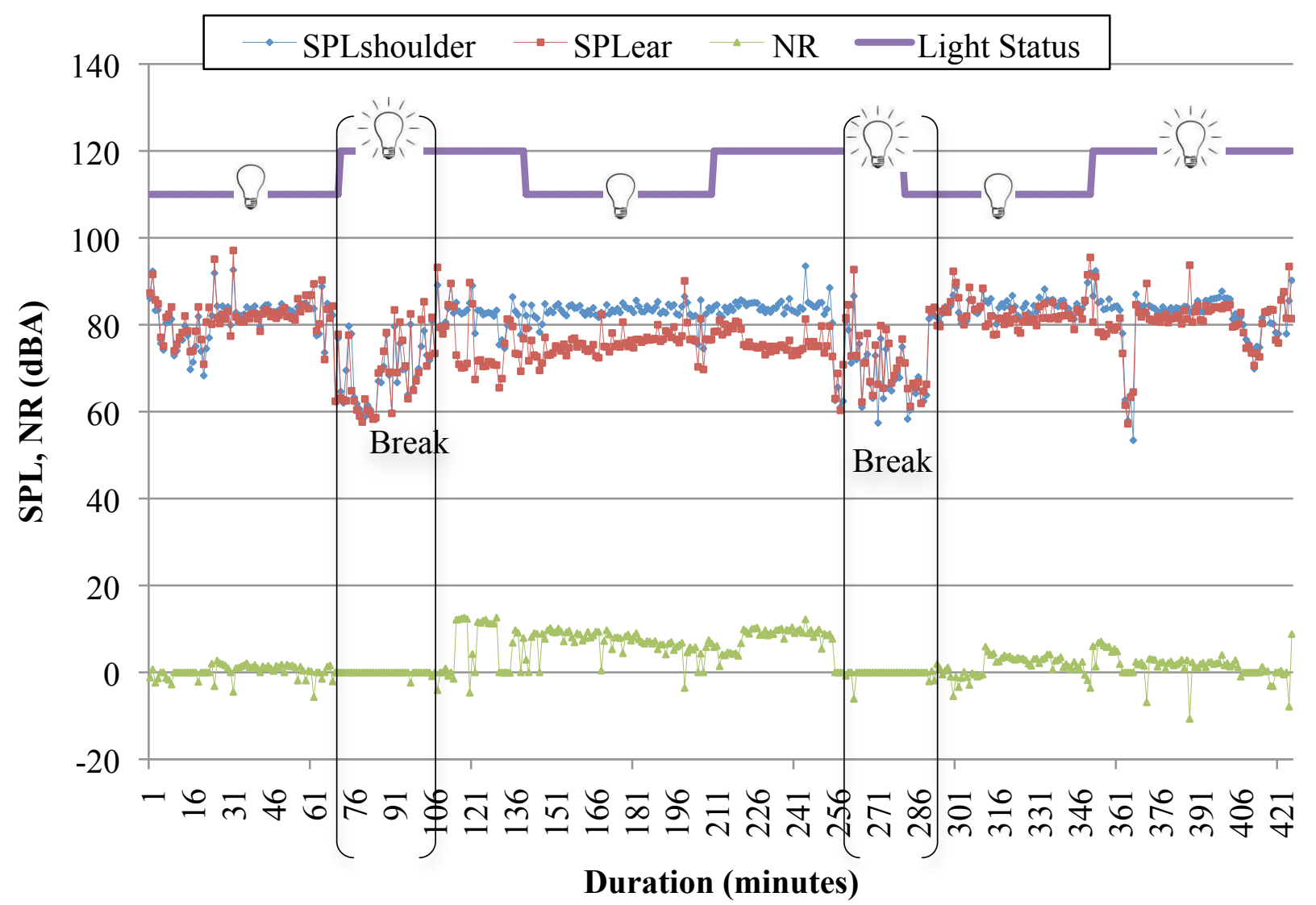

Figure 27. Minute-by-minute results for Subject $19(\mathrm{NR}$ Mean $=4.1 \mathrm{dBA}, \mathrm{SD}=3.3 \mathrm{dBA})$

Like Subject 2, Subject 19 also had a low mean NR and high variability (NR mean $=4.1$, SD =3.3). Note the improvement $(\Delta \mathrm{NR}=4.6 \mathrm{~dB})$ from period one (Light Deactivated) to period 2 (Light Activated). It is possible that the improvement was due to changes in behavior prompted by the light (see Figure 27). 


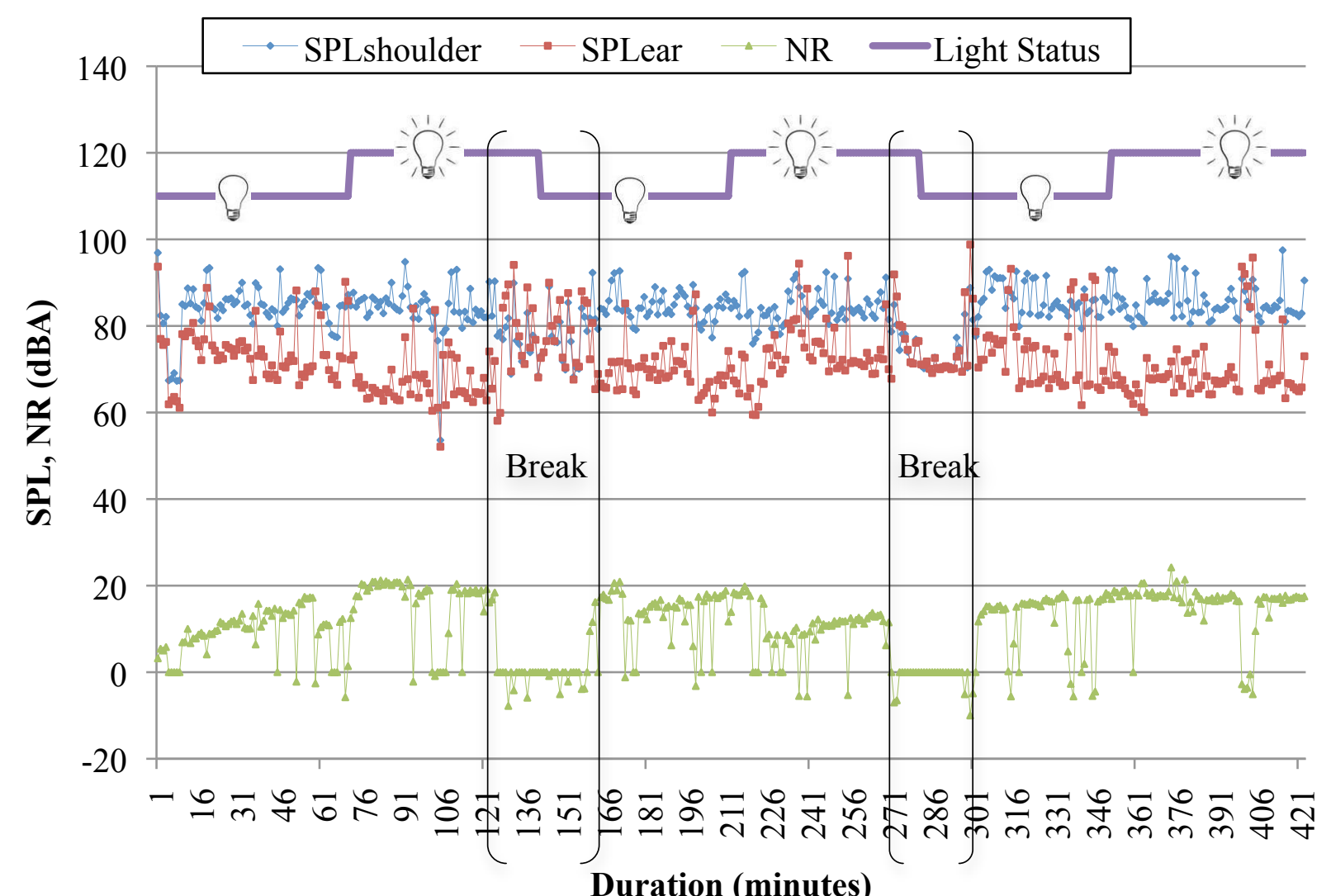

Figure 28. Minute-by-minute results for Subject $20($ Mean NR $=12.8 \mathrm{dBA}, \mathrm{SD}=2.7 \mathrm{dBA})$

Subjects with moderate initial NR values (i.e., 5 to $15 \mathrm{dBA}$ ) may have had the best opportunities to improve fit. Two of five subjects with moderate first period NR values showed a measureable improvement when the light was activated during the second period. For example, Subject 20 (see Figure 28) showed a substantial improvement in NR $(\Delta \mathrm{NR}=6.2 \mathrm{dBA})$ from the first Light Deactivated period to the first Light Activated period. Subject 20's NR improvement was mostly sustained during subsequent light periods, regardless of whether the light was activated. He appeared to attempt to wear his earplugs when required. 


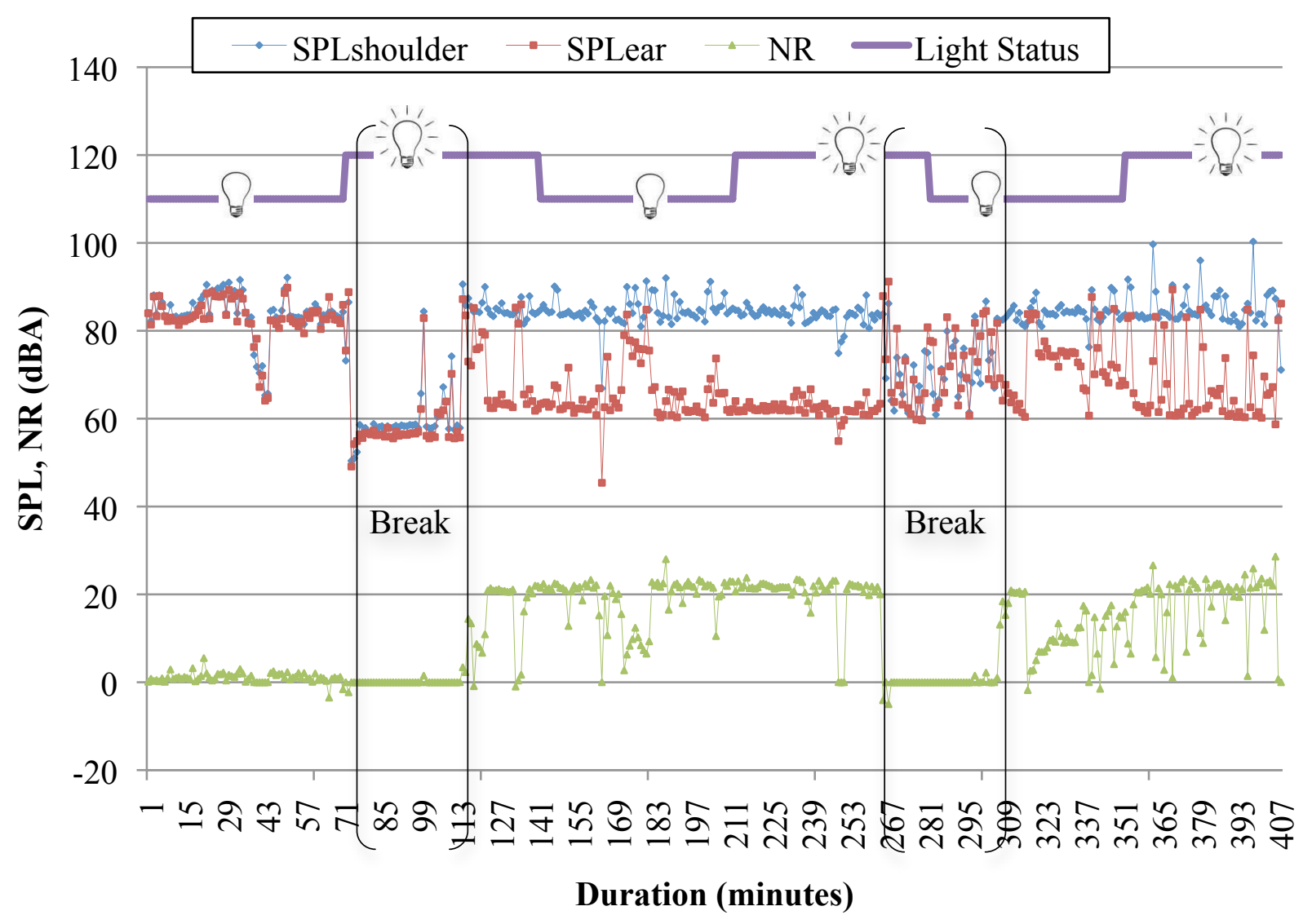

Figure 29. Minute-by-minute results for Subject $8($ Mean NR $=13.9 \mathrm{dBA}, \mathrm{SD}=7.3 \mathrm{dBA})$ 


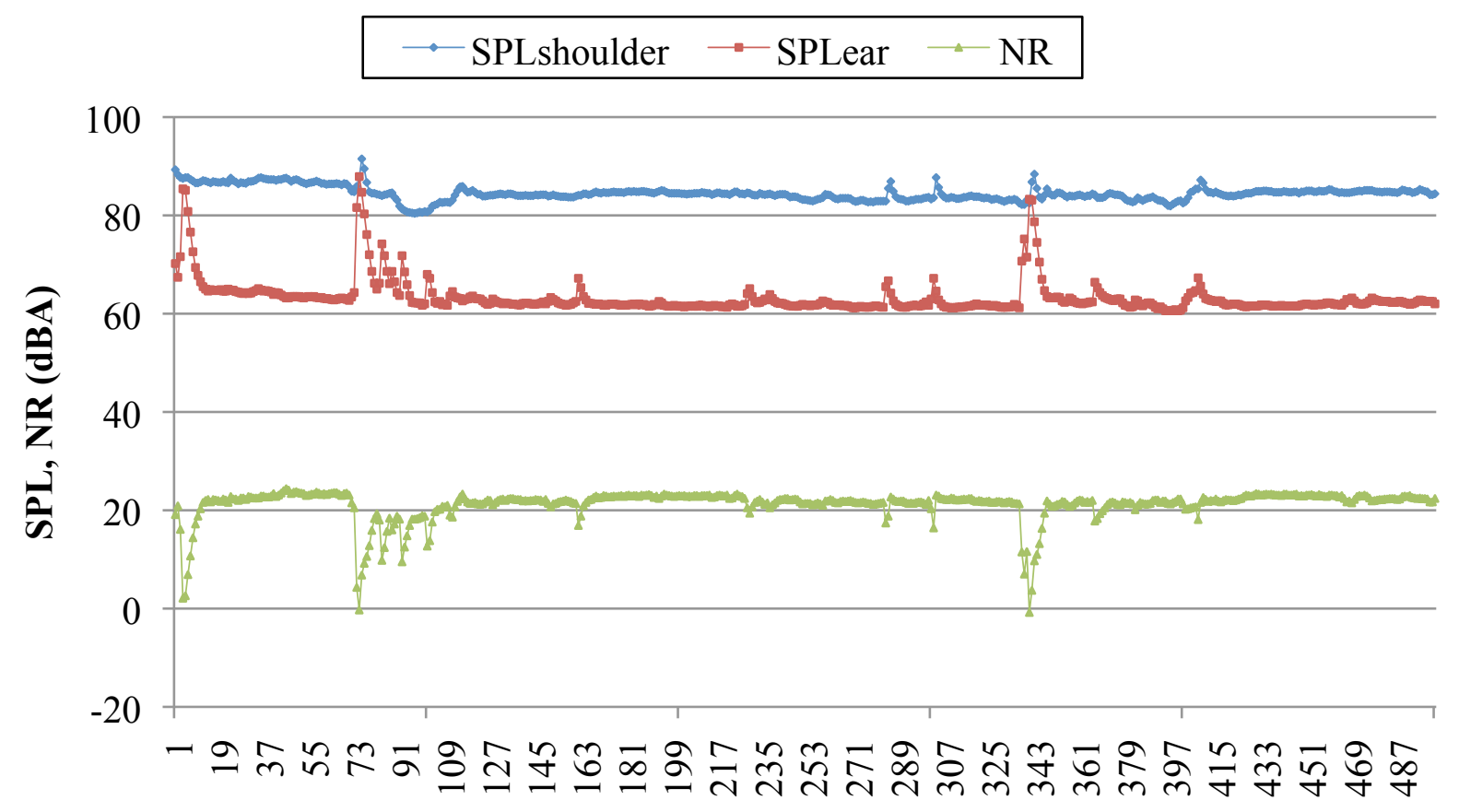

Duration (seconds)

Figure 30. Second-by-second results for Subject 8 between first and second break

Examination of the minute-by-minute results for Subject 8 showed episodes of low or negative NR values and high variability even for workers who had overall high NR values (see Figure 29). Closer examination of the same information may reveal trends useful to those considering developing new HPDs. In this regard, note the period after the second break had a NR mean of $16.2 \mathrm{dBA}$ and a very high variability $(\mathrm{SD}=7.3)$. Finding the cause of such periods of high variability also may reveal why plugs sometimes work so poorly for some subjects. For example, within the time period between the first and second break for Subject 8 (see Figure 30), the NR mean appears to be higher than $20 \mathrm{dBA}$. Closer examination of the second-by-second results (see Figure 30) indicates that the actual value was 18.5 $\mathrm{dBA}(\mathrm{SD}=6.5)$ between the first and second break because of unexplained periodic drops. Observation of the same subject and same earplug during a period shortly thereafter shows that the NR was higher in variability and therefore the maximal level was not obtained as much of the time. Therefore, even if the plug was capable of producing a high level of protection for some workers all of the time and for all workers for several minutes at a time the plug may prove ineffective or highly variable for some 
workers over a work shift even when the worker is trained and diligent and there is no evident explanation for the protector's failure or changes in performance.

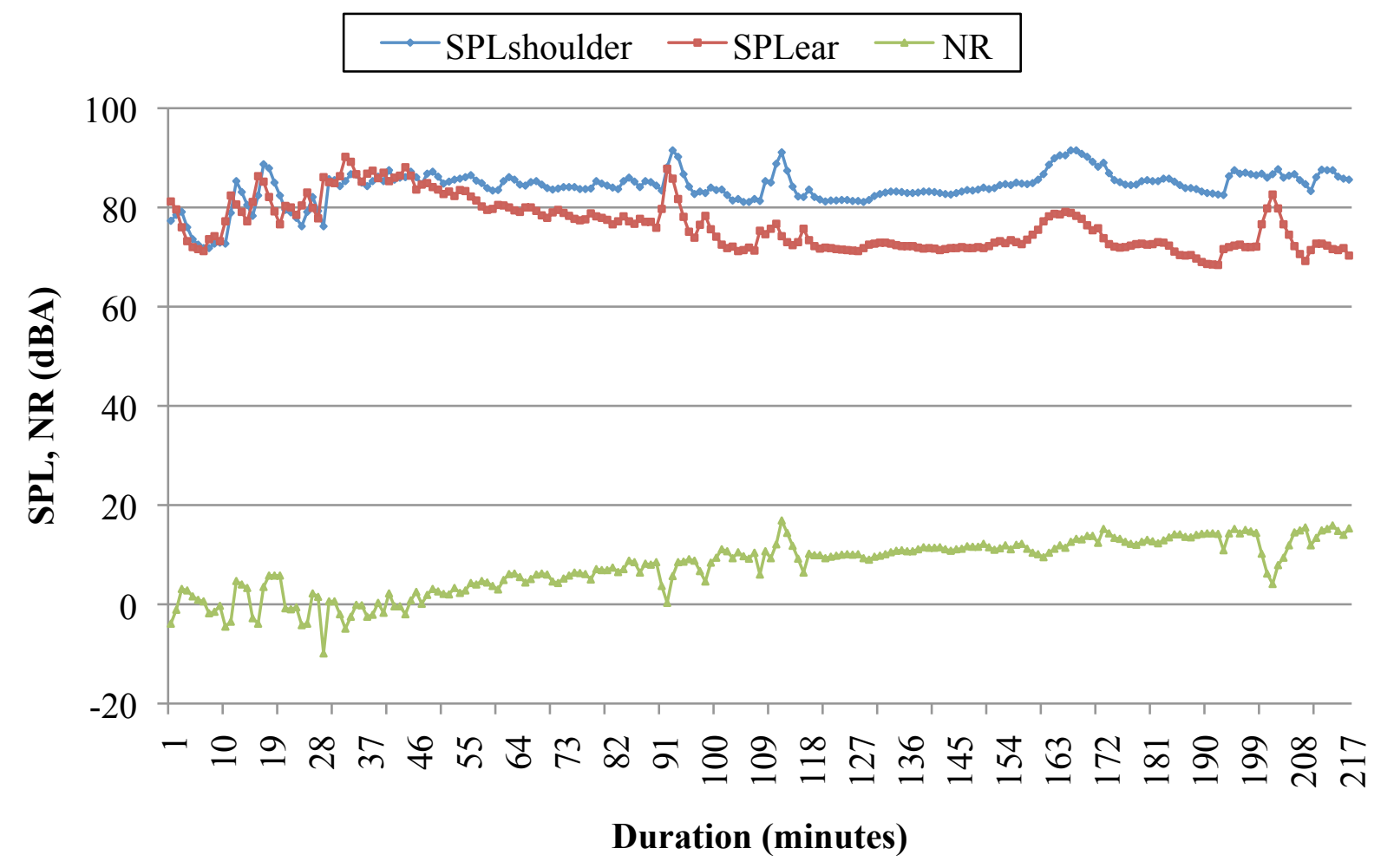

Figure 31. Second-by-second results for Subject 8 after first break

Closer examination of the second by second results for Subject 8 just after his first break indicate that the time for the earplug to reach a plateau of NR after re-insertion was just under 80 seconds (see Figure 31), the same as with Subject 6. 


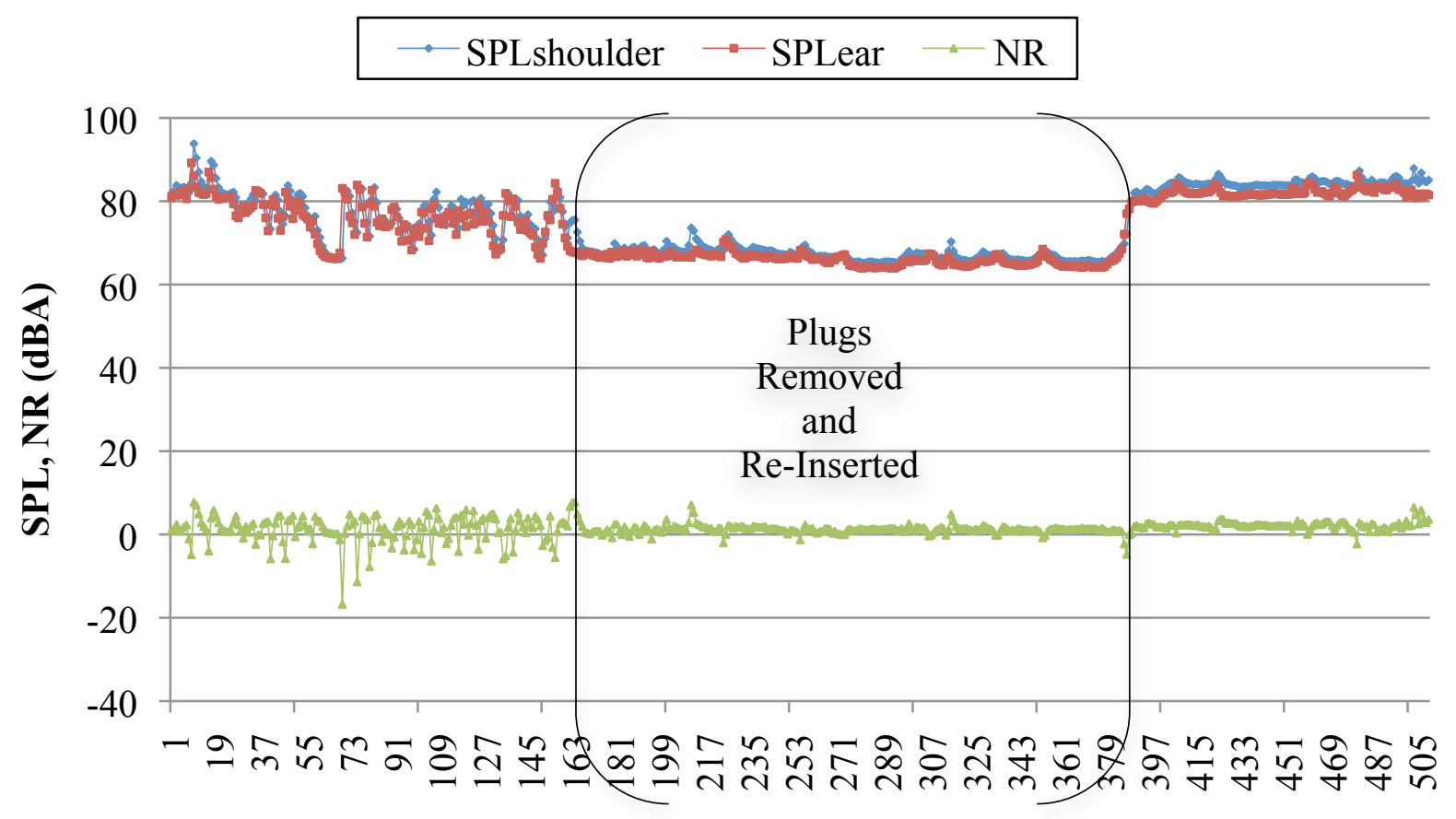

\section{Duration (seconds)}

Figure 32. Second-by-second results for Subject 8 (Mean NR=13.8 dBA, SD=9.2 dBA)

Even high variability was not consistent. Figure 32 shows the NR results for Subject 8 before and after removing and inserting his earplugs. Note that the NR prior to earplug removal was highly variable but became more constant after reinserting the earplugs. However, in both time periods, the NR was always near zero, while the ambient $\mathrm{SPL}_{\text {sh }}$ was highly variable. The assumption was that the NR values should not be affected by SPL $\mathrm{sh}_{\text {sh }}$ values, and therefore conceptually, if true it would not matter how variable $\mathrm{SPL}_{\mathrm{sh}}$ was, the NR should stay constant. Therefore, one would expect to see a continuous and steady NR with perhaps sharp increases and decreases due to refitting or plug loosing over time. 


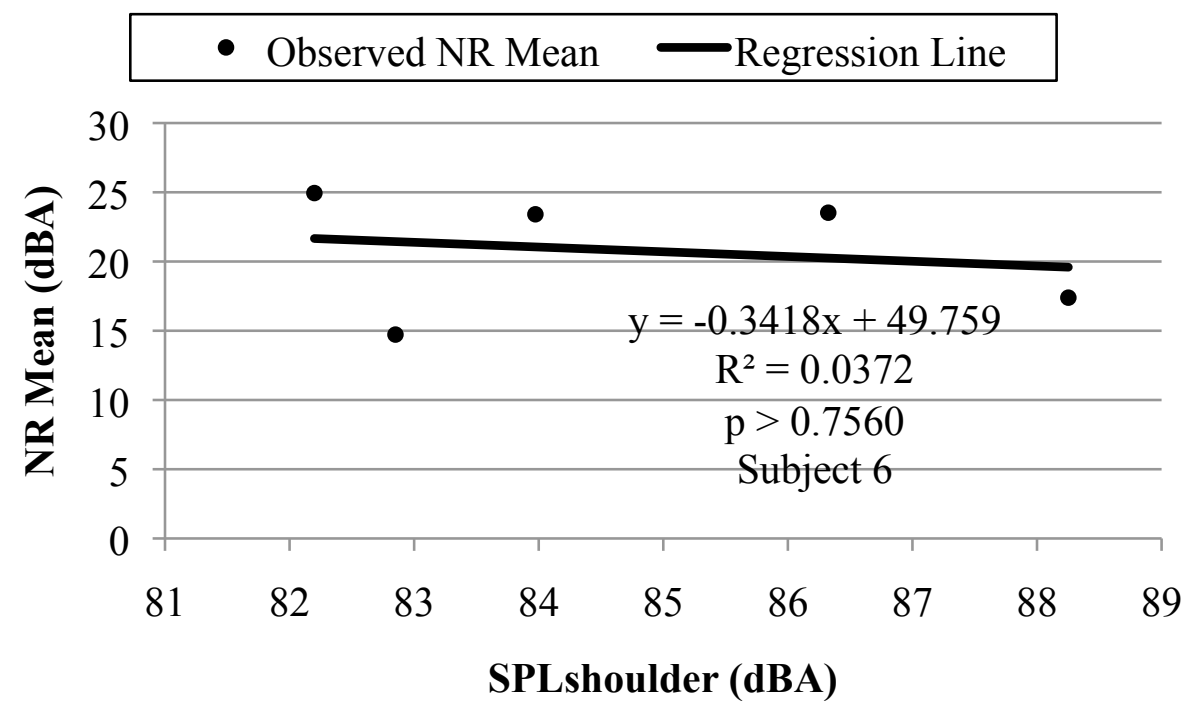

Figure 33. Second-by-second $\mathrm{SPL}_{\mathrm{sh}}$ mean versus NR mean for Subject $6(\mathrm{~N}=5)$

To test the assumption that computed NR values remain steady during times when $\mathrm{SPL}_{\mathrm{sh}}$ values fluctuate, five periods (120 seconds for each period) for Subject 6 were as randomly as possible selected from his second-by-second results. These "snapshots" were used to plot second-by-second $\mathrm{SPL}_{\mathrm{sh}}$ values against NR mean values. As can be seen in Figure 33, all of the evidence from this study shows that NR values do not remain steady as SPL $\mathrm{L}_{\text {sh }}$ values fluctuate $\left(\mathrm{R}^{2}=0.0372\right)$.

The results of the linear regression analysis between $\mathrm{SPL}_{\mathrm{sh}}$ and NR mean for Subject 6 are shown in Figure 33. The slope (-0.3418) of the regression line shown in Figure 33 was not significantly different from zero ( $p>0.7560$ ), and the coefficient of determination $\mathrm{R}^{2}$ was 0.0372 . 


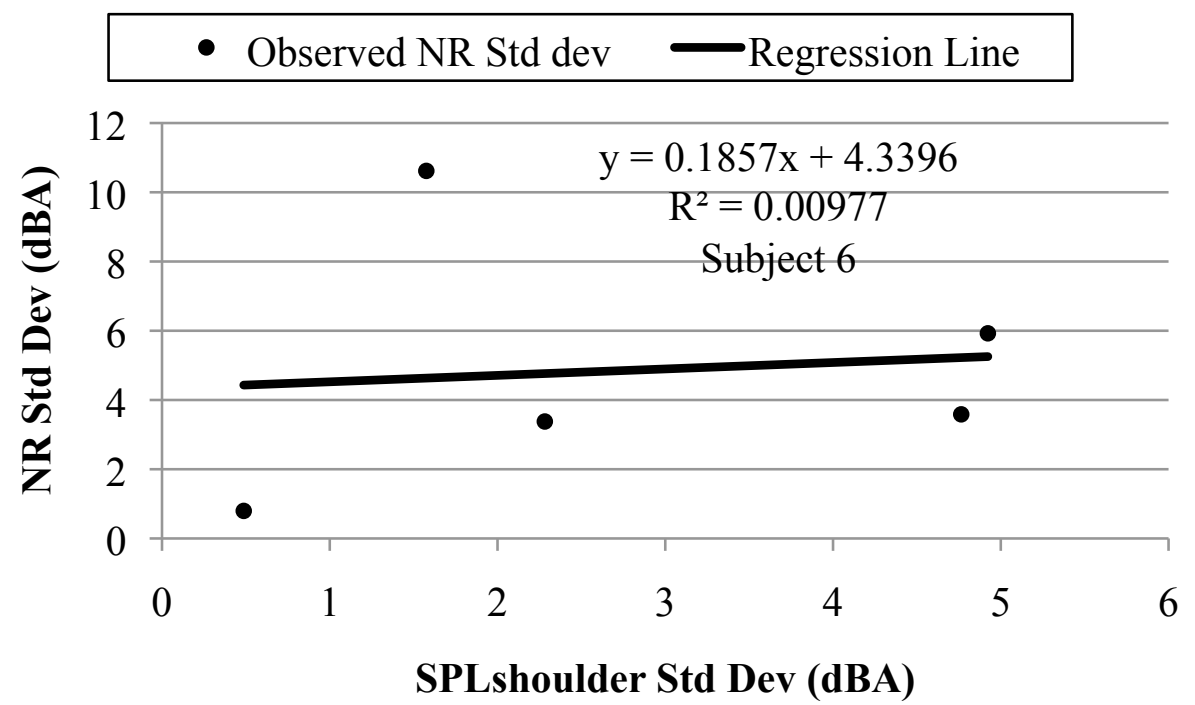

Figure 34. Second-by-second $\mathrm{SPL}_{\mathrm{sh}} \operatorname{Std}$ Dev versus NR Std Dev (N=5)

As shown in Figure 34, the NR SD was plotted against $\mathrm{SPL}_{\mathrm{sh}} \mathrm{SD}$ for Subject 6 second-bysecond results. Again, all of the evidence from this study shows that NR values do not remain steady as $\mathrm{SPL}_{\mathrm{sh}}$ values fluctuate $\left(\mathrm{R}^{2}=0.00977\right)$. 


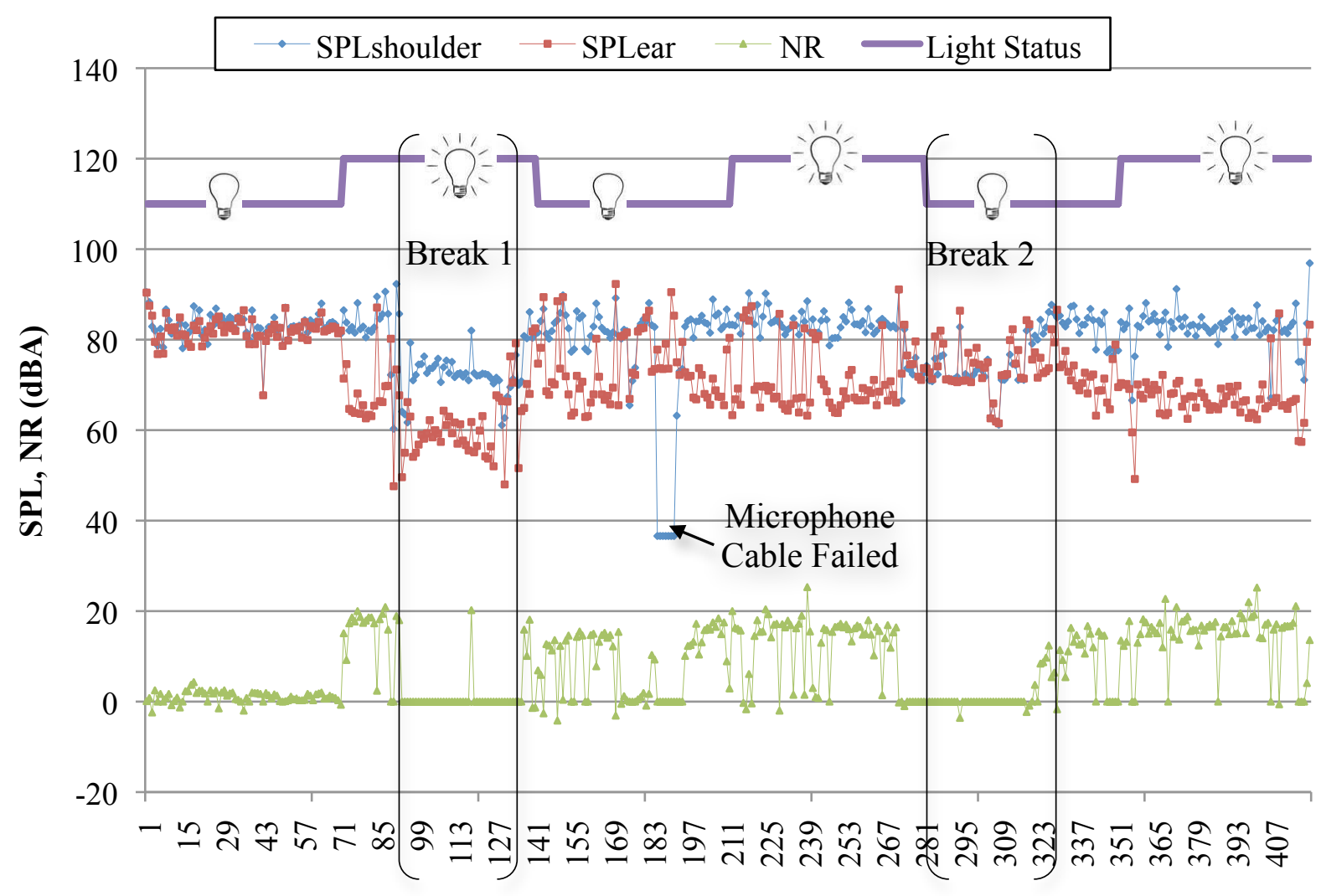

Duration (minutes)

Figure 35. Minute-by-minute results for Subject $17($ Mean NR $=10.8 \mathrm{dBA}, \mathrm{SD}=5.5 \mathrm{dBA})$

Subject 17 also showed a moderate improvement in NR between periods of Light Activation and Light Deactivation. As shown in Figure 35, Subject 17 appears to have altered behavior because her NR values during periods of Light Activation appears to be higher than during periods of Light Deactivation $(\triangle \mathrm{NR}=7.9 \mathrm{dBA})$. The logged data for Subject 17 illustrates another phenomenon. During the shift Subject 17 alerted the investigator that her microphone cable was damaged. Presumably, the damaged cable failed for a short period. The investigator replaced the cable, recalibrated equipment and continued data collection. The data from the suspicious period was omitted from all data analyses and descriptive statistics. 


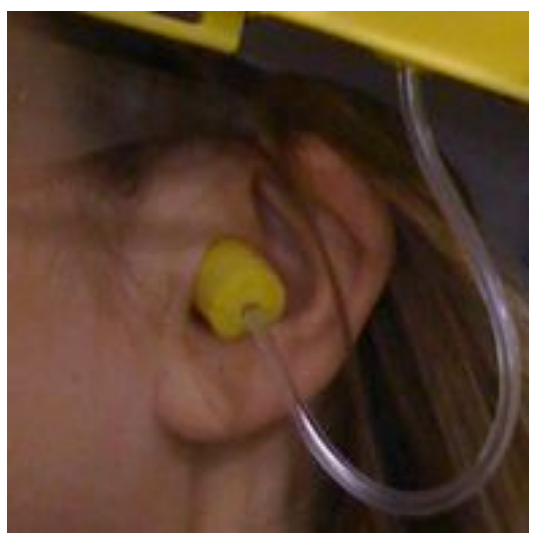

Figure 36a. Subject 17 observed earplug fit

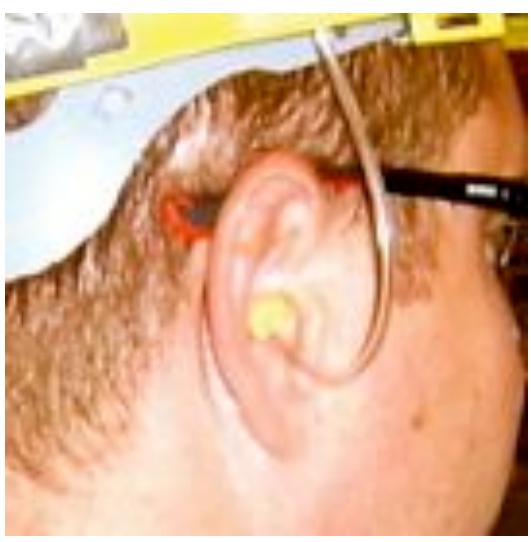

Figure 36b. Subject 2 observed earplug fit

During closer examination of Figure 35, the $\mathrm{SPL}_{\mathrm{sh}}$ values appear to be more constant or less variable than $\mathrm{SPL}_{\text {ear }}$ values. Note that one cannot observe the minute-by-minute NR values and determine whether light was activated or deactivated. It appears that the NR values were

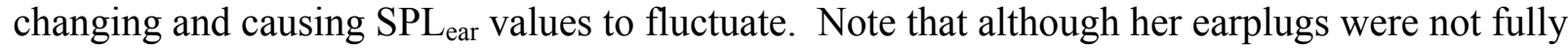
inserted and visually extended outside the ear canal (i.e., shallow insertion), Subject 17 still managed to achieve a reasonable NR during those periods and at no point did the investigator observe the earplugs fully inserted into the ear (see Figure 36a). In another example, Figure 36b shows Subject 2 with his earplugs inserted deeply into the ear canal. One would expect that a deeply inserted earplug would provide a high NR. However, this was not the case, as Subject 2 achieved one of the lowest mean NR values $(\mathrm{NR}$ mean $=3.7 \mathrm{dBA})$. It was also noted that the apparatus could have influenced the fitting and produced small movements of the earplug relative to the ear. 


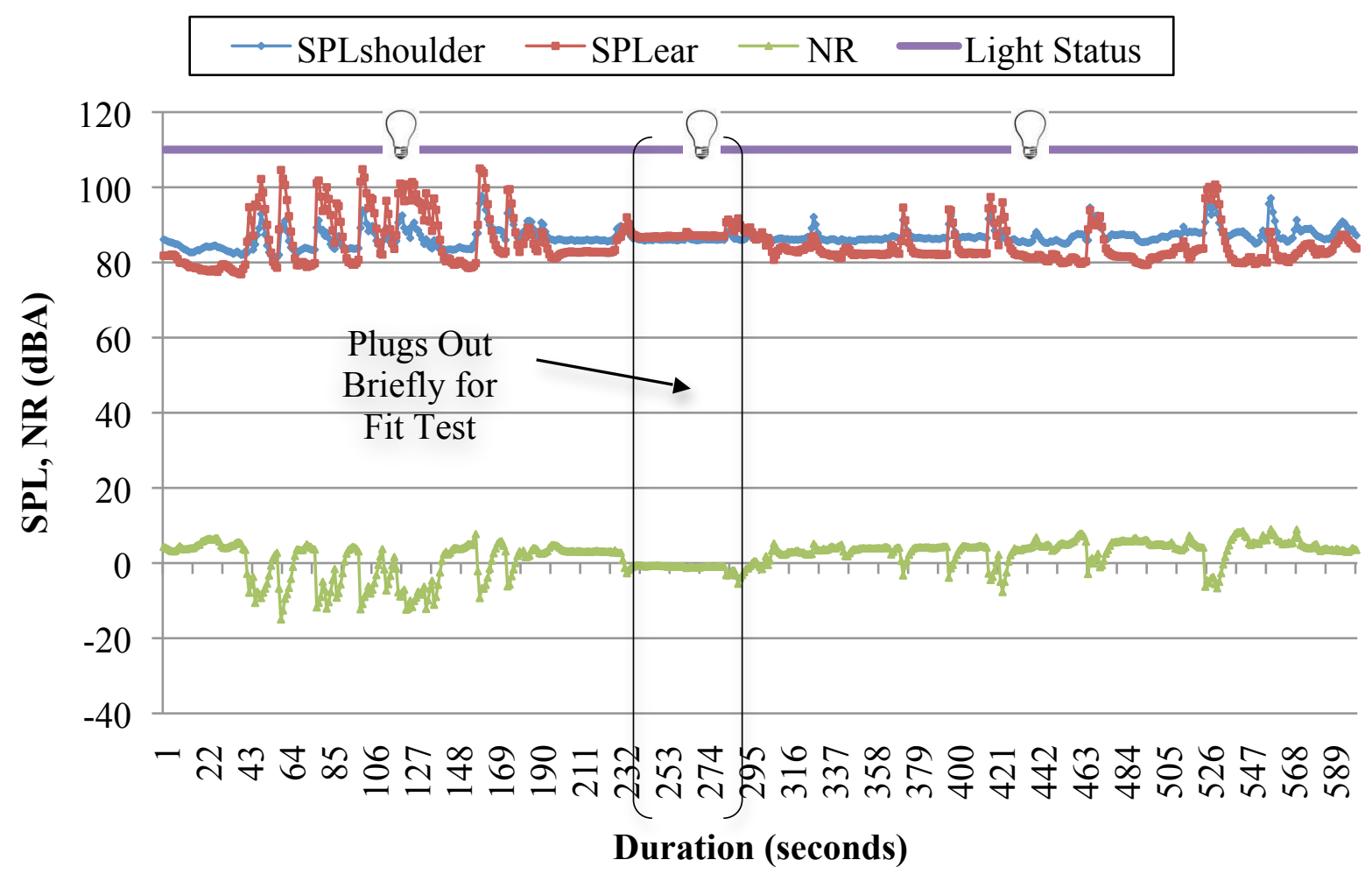

Figure 37. Second-by-second results for Subject 2

Review of the minute-by-minute results showed a high degree of variability. One would expect if the results were examined based on integrated values of each second instead of integrated values of each minute the results would show higher variability.

The variability of minute-by-minute results showed there was some process going on that causes the fit to change. If examined second-by-second one would observe even more variability because changes appear to occur in seconds. This suggests, whatever phenomenon was producing the changes was very fast $(<1$ second). For example, movement of the jaw, chewing gum, or talking may cause changes in HPD fit. Note the investigator did not observe the fluctuating variability in the reverberation chamber.

Results showed that second-by-second computed NR values fluctuated widely during tested work shifts. For example, (see Figure 37) the second-by-second recorded SPLs and computed 
NR plotted against time during an observed fit-test show that the magnitudes of the NR values do not appear to be associated with higher $\mathrm{SPL}_{\text {sh }}$ values, as one might expect.

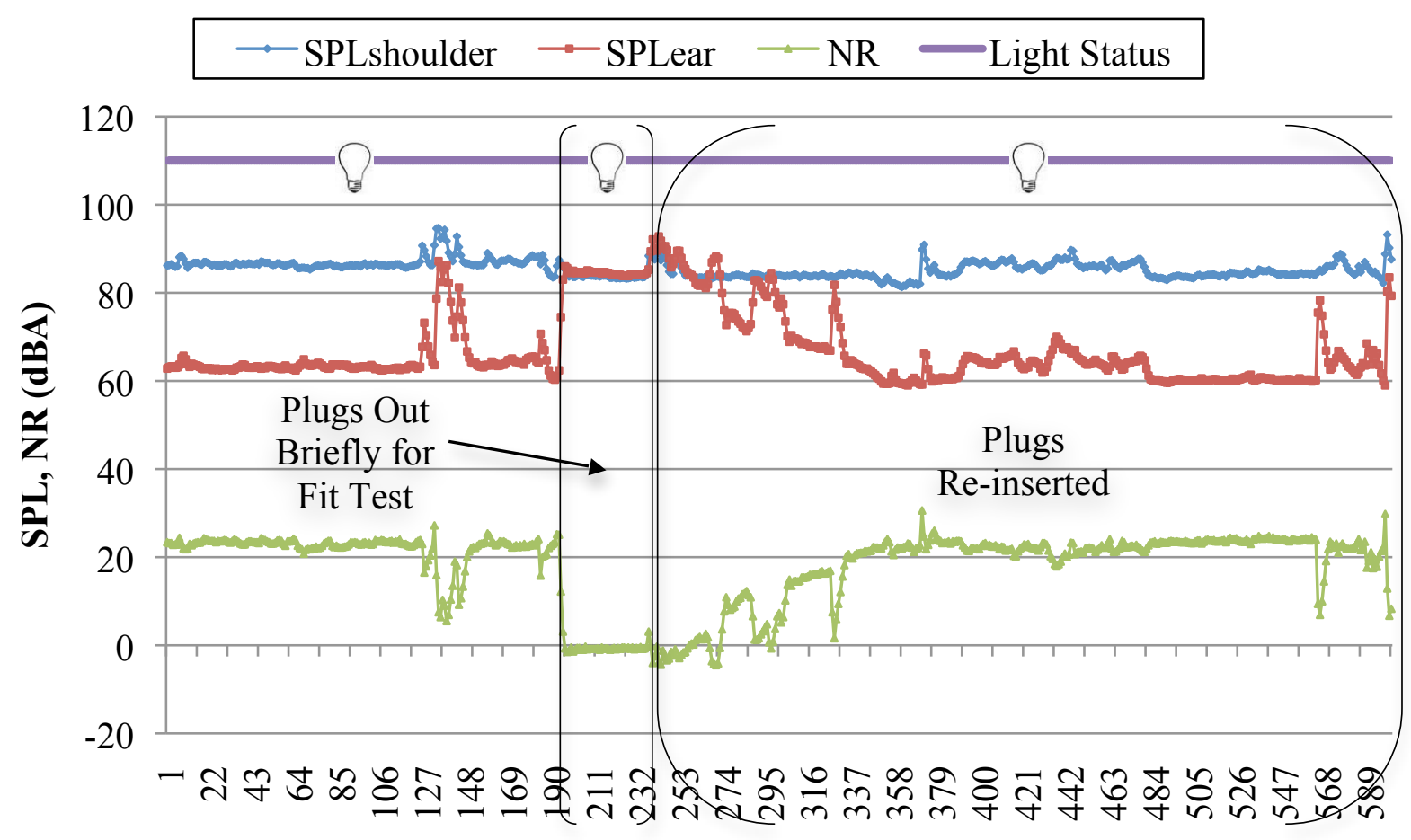

Duration (seconds)

Figure 38. Second-by-second results for Subject 6

On the opposite extreme was Subject 6 who had the least variability and the highest NR values. The second-by-second recorded SPLs and computed NR plotted against time during an observed fit-test for Subject 6 is shown in Figure 38. Again, the magnitudes of the NR values do not appear to be associated with changes in $\mathrm{SPL}_{\mathrm{sh}}$ values, as one might expect. Despite the fact that one has a far better fit than the other they still are similar in having high variability.

One might expect that, especially with a foam earplug, the NR would change only gradually with time, if at all, or perhaps would change every time a subject removed and re-inserted, but otherwise would stay constant. For these subjects, that proved not be the case at all. In fact, 
looking at this minute-by-minute data, one can observe that NR varies with the appearance of randomness.

\subsection{Effects of Known Events on Second-by-Second Results}

The overall purpose of this study was to determine if a light that blinked when sound levels were excessively high at the ear would prompt a change in behavior that would lead to an improved NR. The assumption was that attempts to improve fit would be successful and therefore produce measureable changes in NR. However, as will be discussed many subjects had very little change in NR, yet the investigator observed those same subjects making repeated attempts to refit their hearing protection.

Those experienced in conducting sound surveys may wonder how episodic events affect the overall noise dose. Such events include, talking, tapping earplug and chewing gum during sound surveys. As shown in Figures 39 through 52, the investigator observed the effect of some known events on second-by-second results.

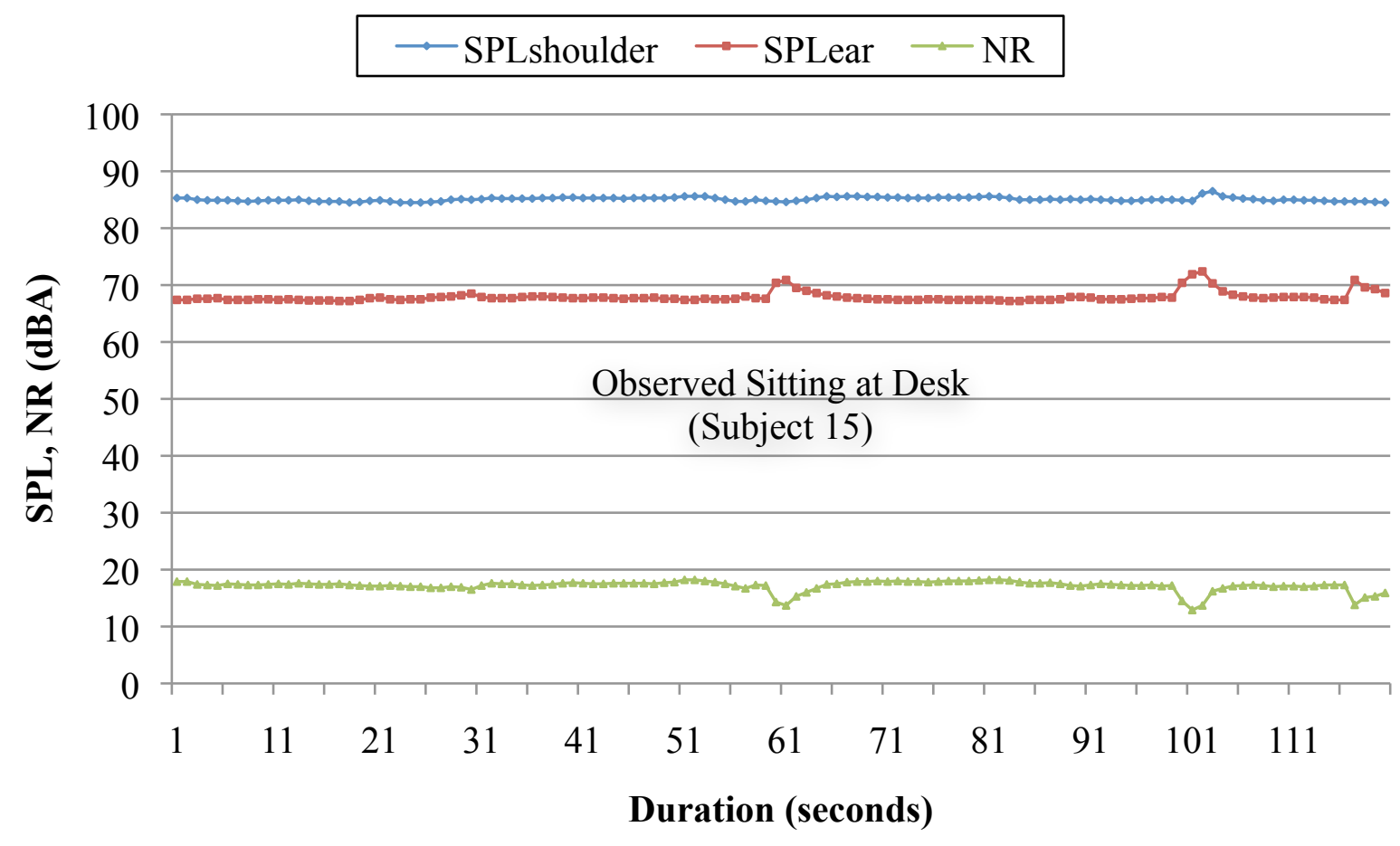

Figure 39. Observed second-by-second results 
Figure 39 shows the second-by-second time series during which Subject 15 was observed by the investigator to be sitting at a workstation desk with his earplugs inserted. As can be seen, the $\mathrm{SPL}_{\text {sh }}$ values were mostly constant and roughly $85 \mathrm{dBA}$. Likewise, the SPL ear values also appear to be constant at approximately $68 \mathrm{dBA}$. Therefore, as expected, the computed NR values were constant at approximately $17 \mathrm{dBA}$. The investigator prior to the field study expected SPL and NR values would be constant. On the other hand, there were three short time periods during

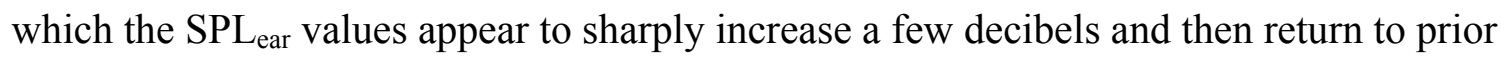
constant values. One would speculate that these three episodes represented movements of facial muscles (e.g., jaw tightening).

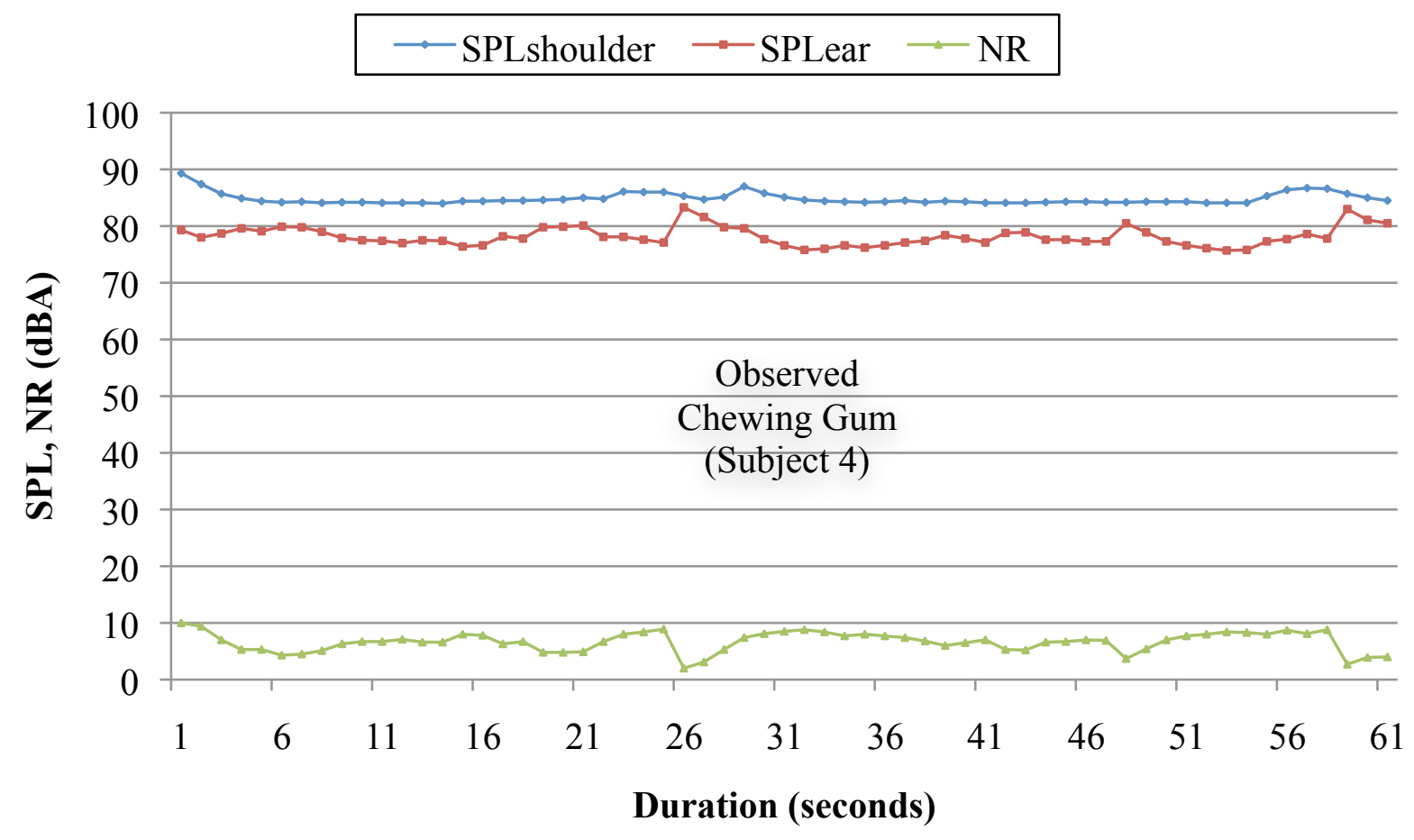

Figure 40. Observed second-by-second results 


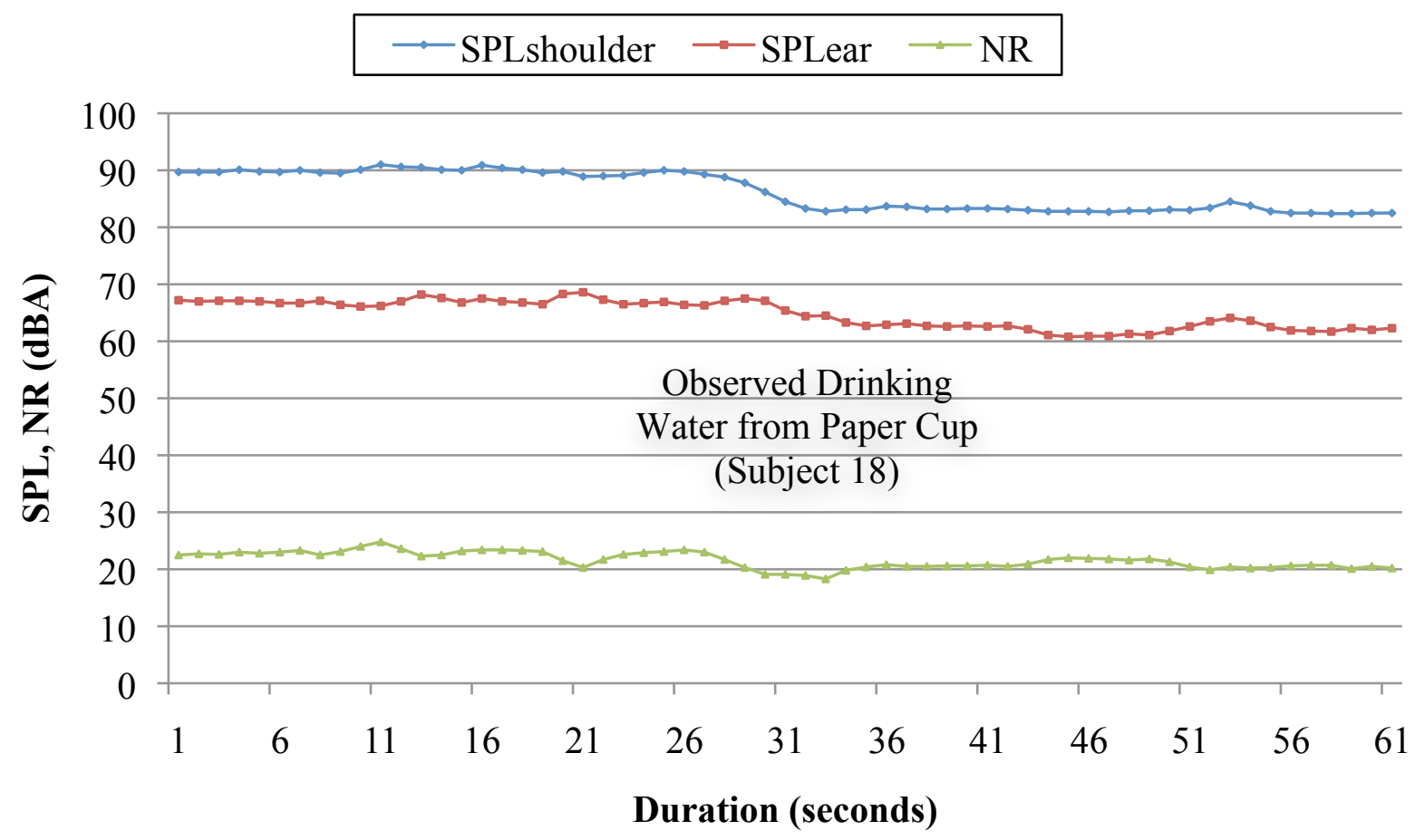

Figure 41. Observed second-by-second results

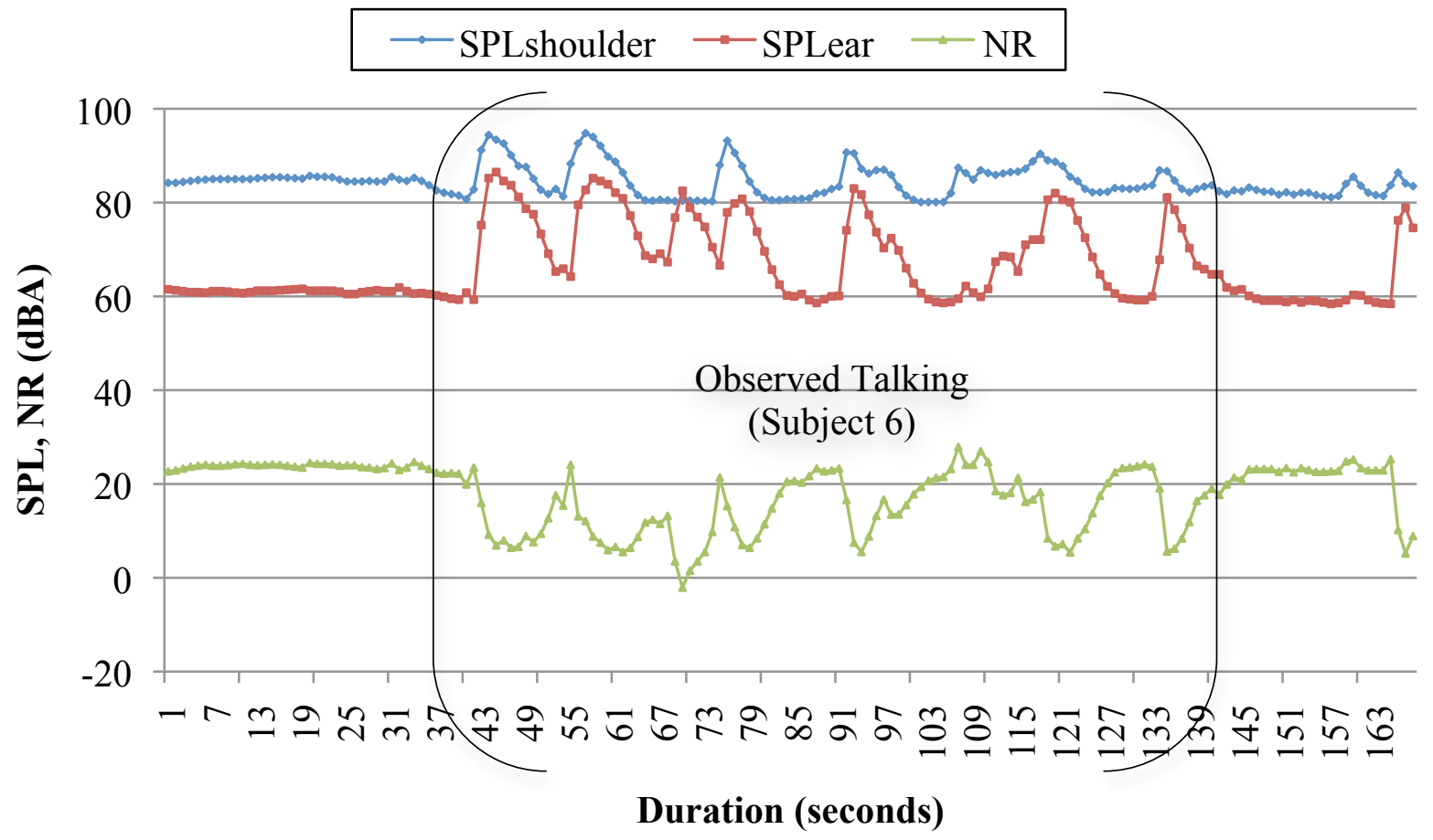

Figure 42. Observed second-by-second results 


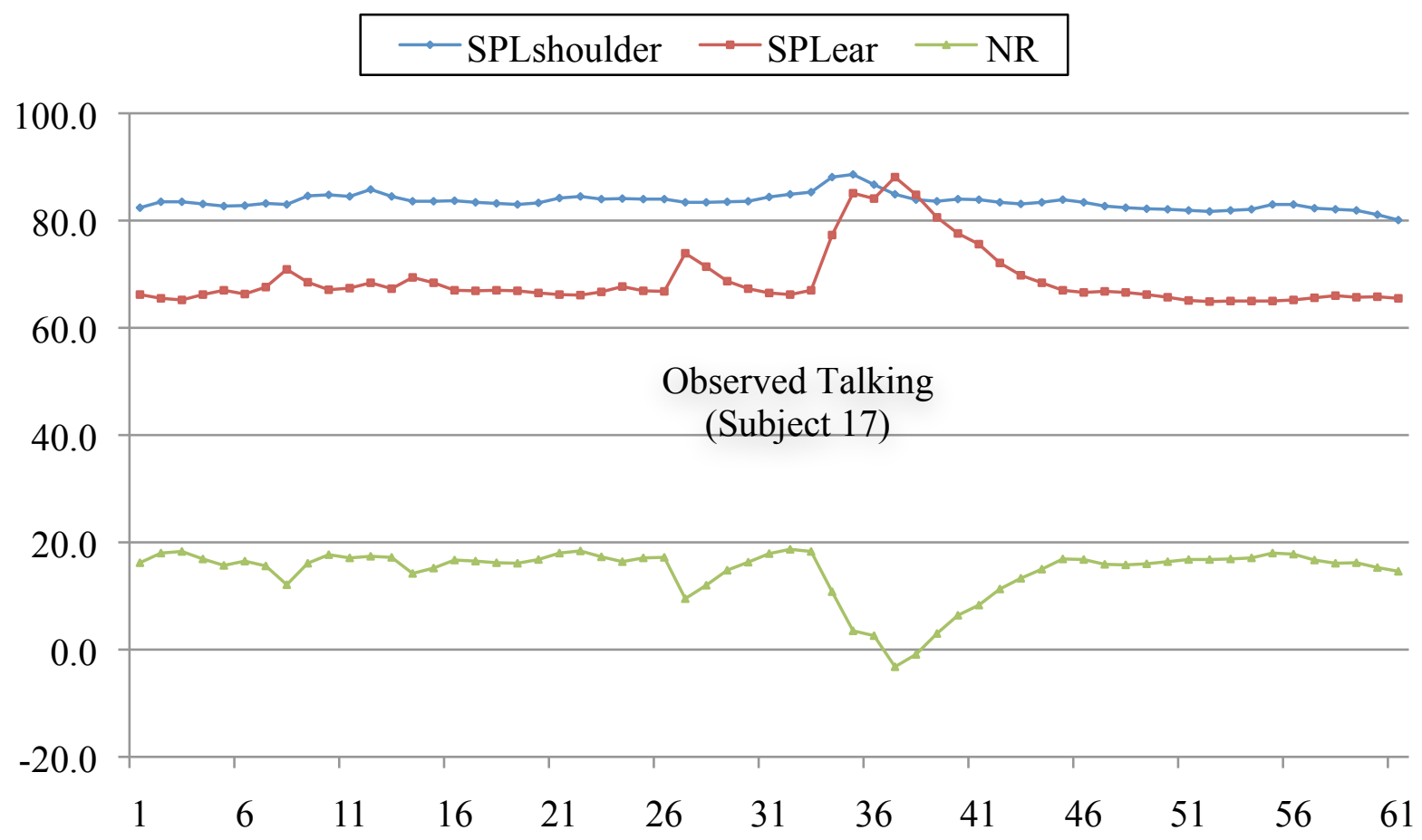

Figure 43. Observed second-by-second results

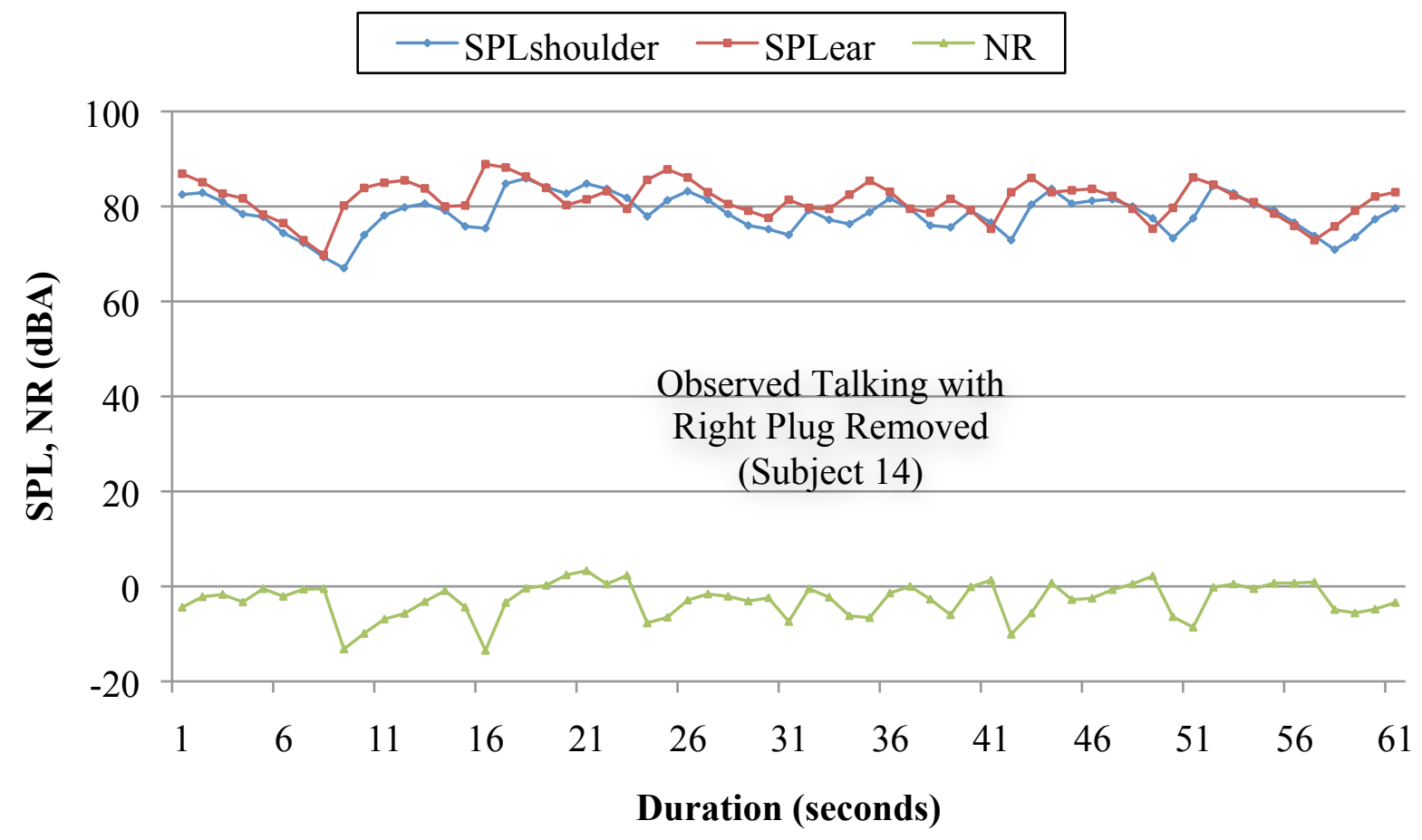

Figure 44. Observed second-by-second results 


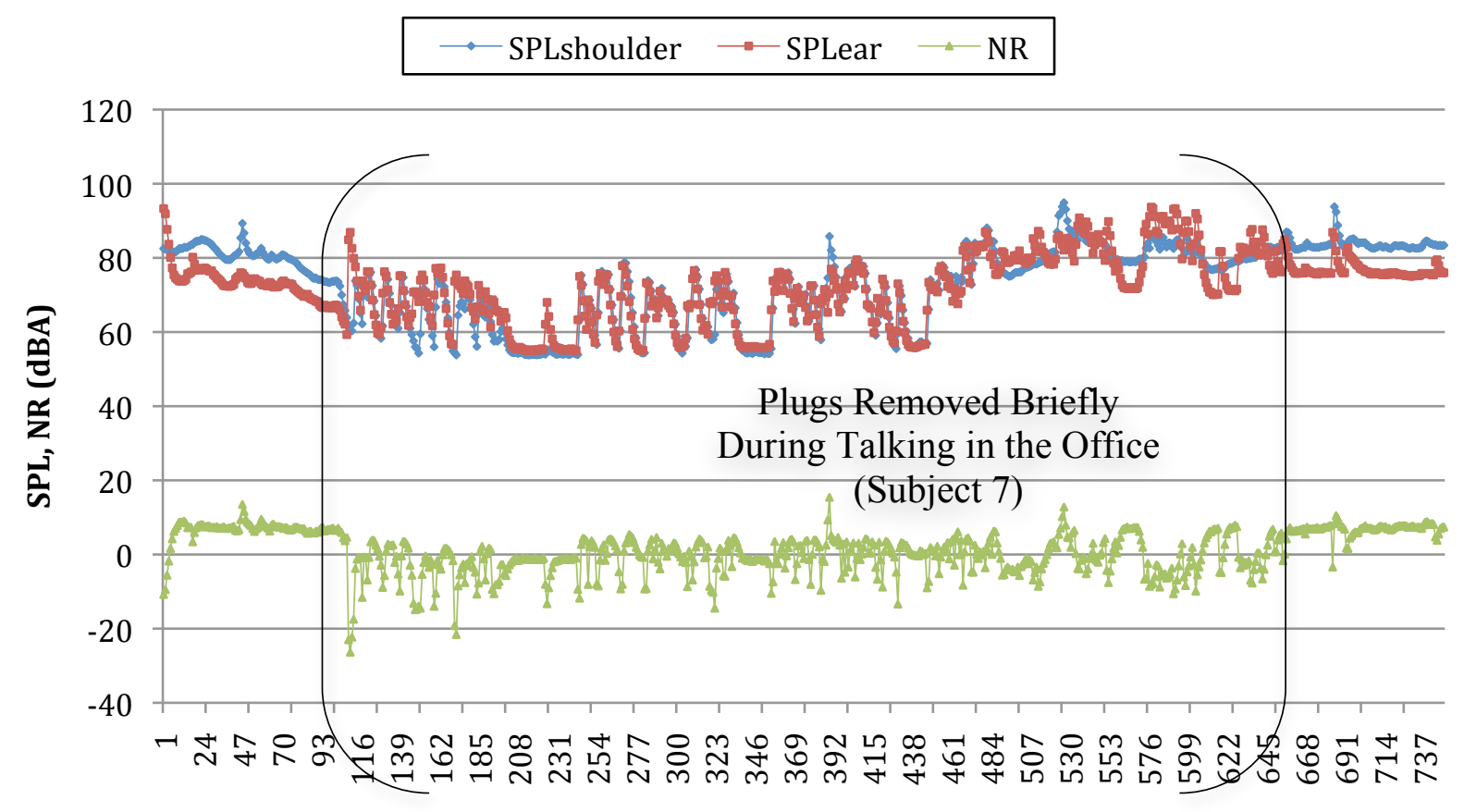

\section{Duration (seconds)}

Figure 45. Observed second-by-second results

Figures 40 through 45 show the second-by-second time series during which subjects were observed by the investigator to make muscle movements in the face while their earplugs were inserted (i.e., chewing gum, drinking water from cup, and talking). Figures 42 through 43 show the observed effect of talking during times when earplugs were inserted. Figures 44 and 45 show the observed effect of talking during times when one or both earplugs were removed. 


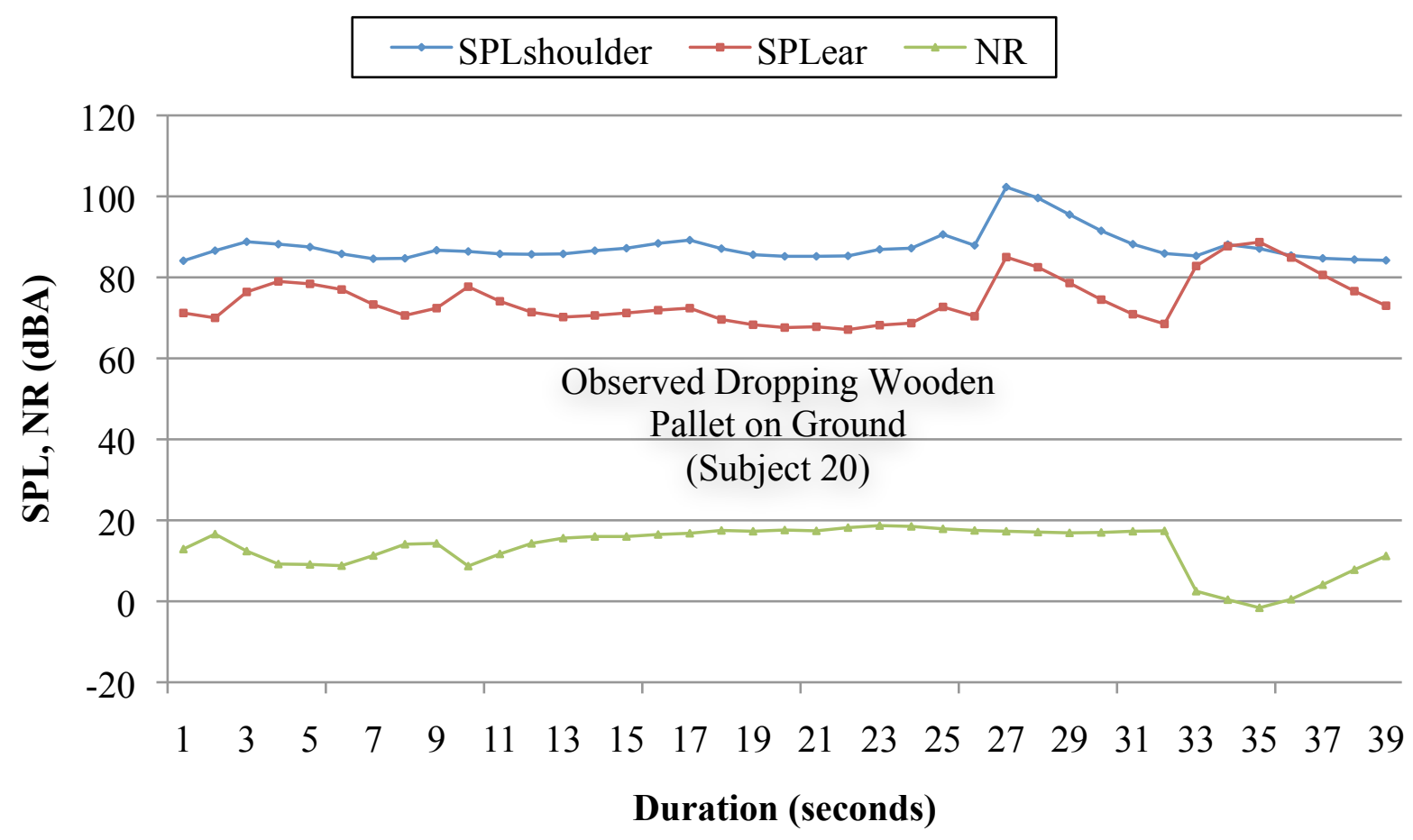

Figure 46. Observed second-by-second results

As shown in Figure 46, the investigator observed Subject 20 drop a wooden pallet on the floor. Note the period of time where NR was nearly zero. If facial muscles produced changes in $\mathrm{NR}$, this should be an occasion for it, but it was not. Indeed, NR dropped to nearly zero and remained low for several seconds. 


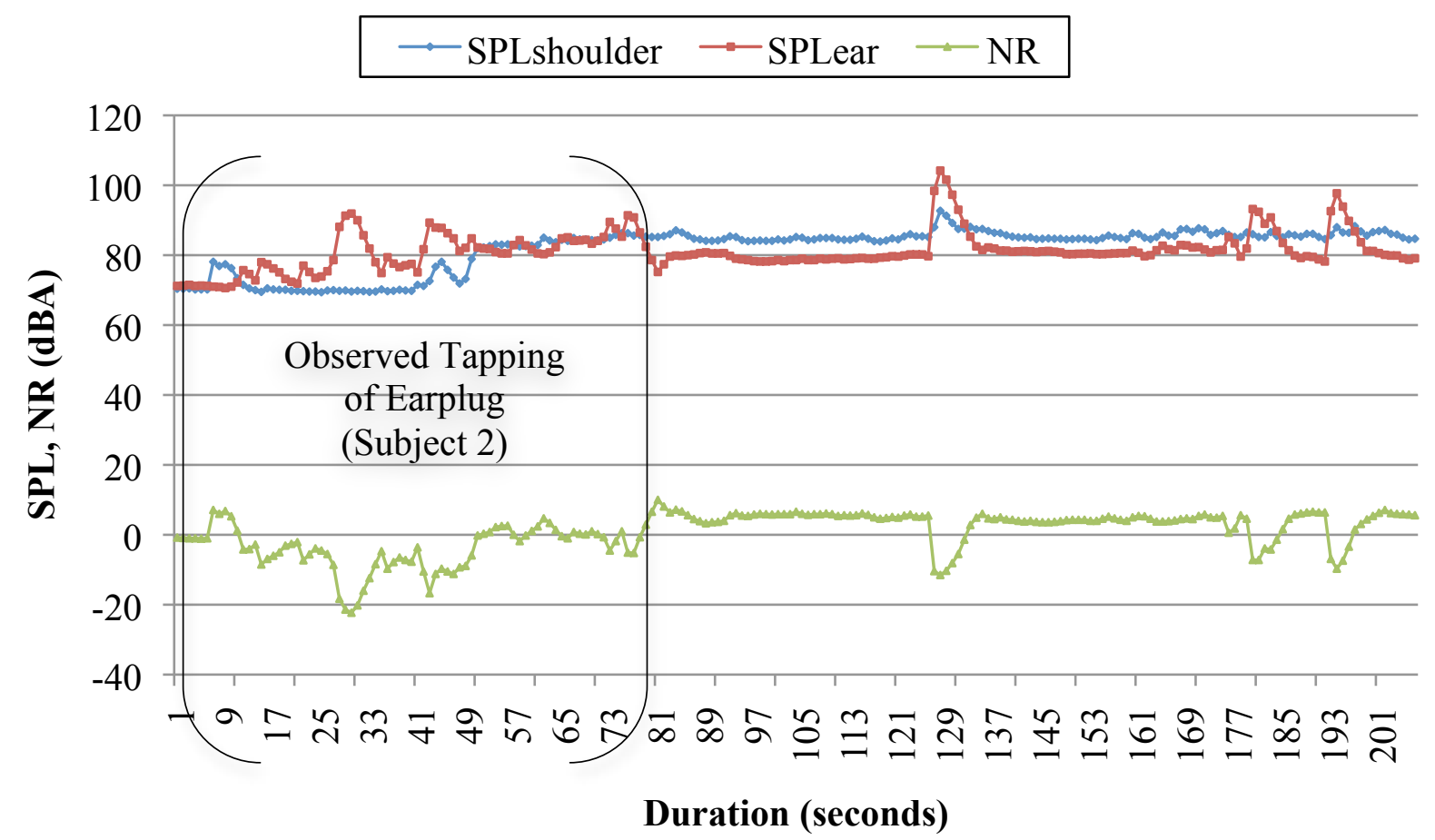

Figure 47. Observed second-by-second results

Figure 47 shows a second-by-second time series during which Subject 2 was observed by the investigator to tap his inserted earplugs. As can be seen, the SPLear values sharply increased and decreased during each apparent tap of the HPD, while the SPL $\mathrm{S}_{\text {sh }}$ values remained mostly steady. As expected, the computed NR values fluctuate widely and fell mostly below zero, indicating that the SPL levels inside the ear canal increased above ambient $\mathrm{SPL}_{\text {sh }}$ values. 


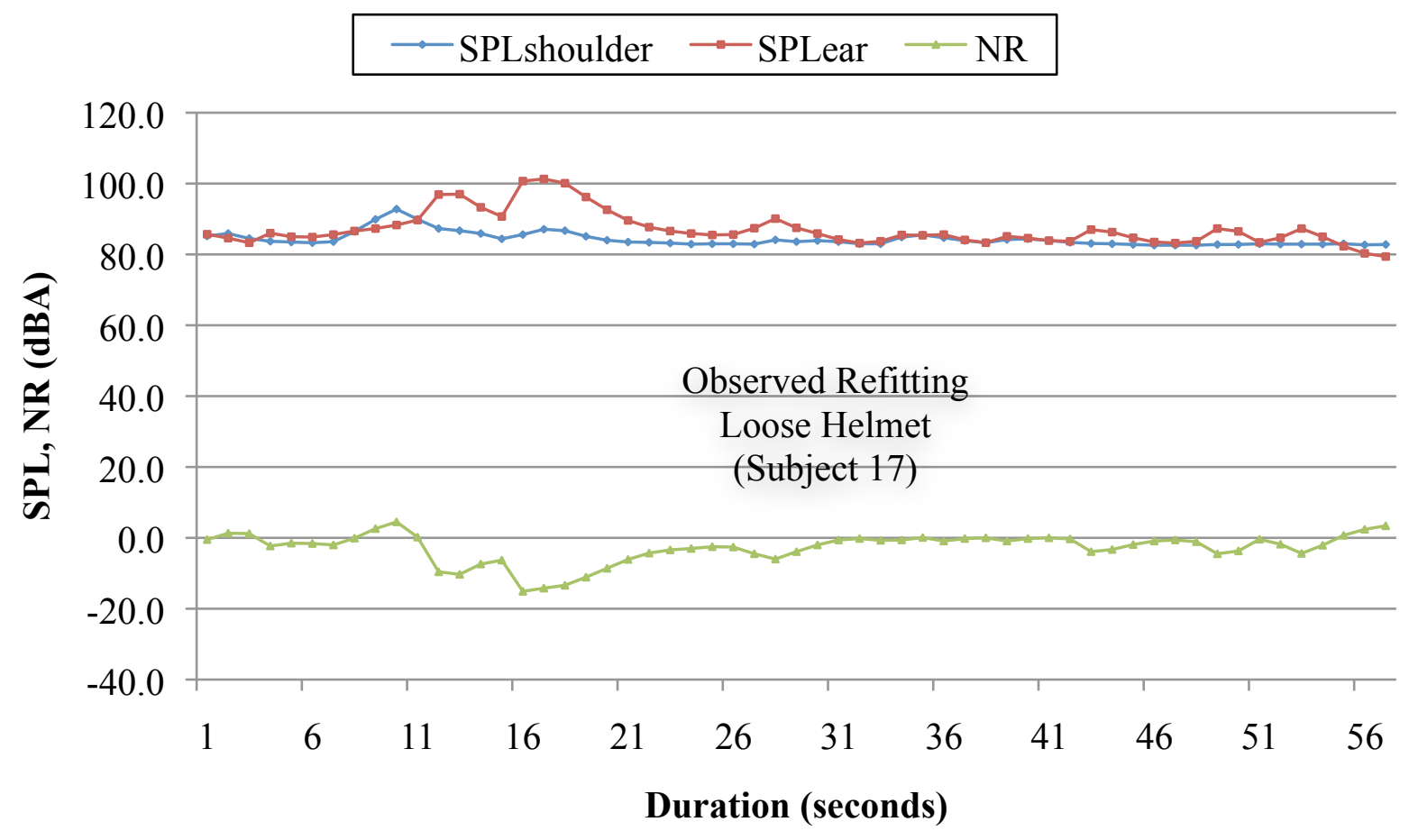

Figure 48. Observed second-by-second results

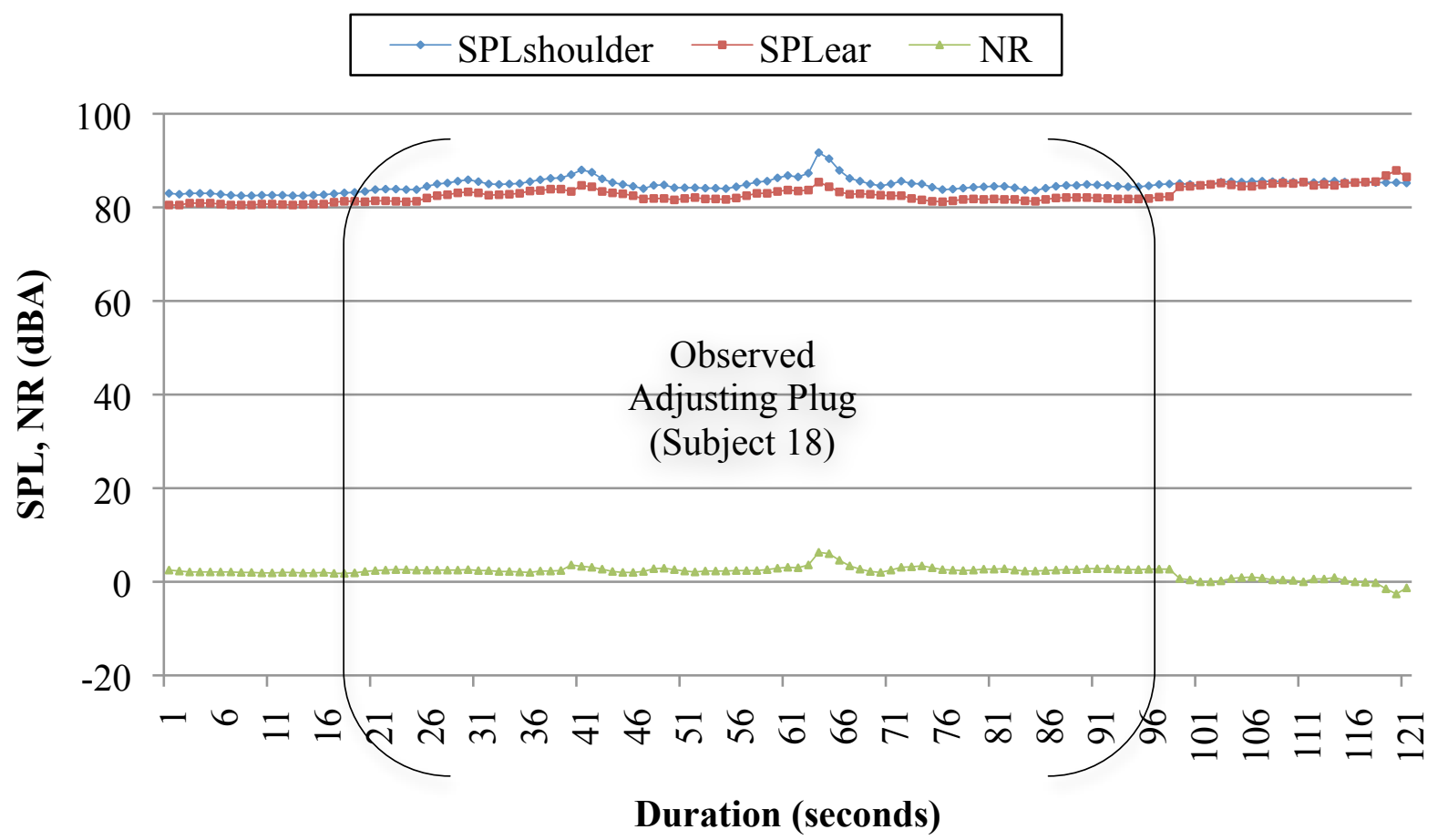

Figure 49. Observed second-by-second results 


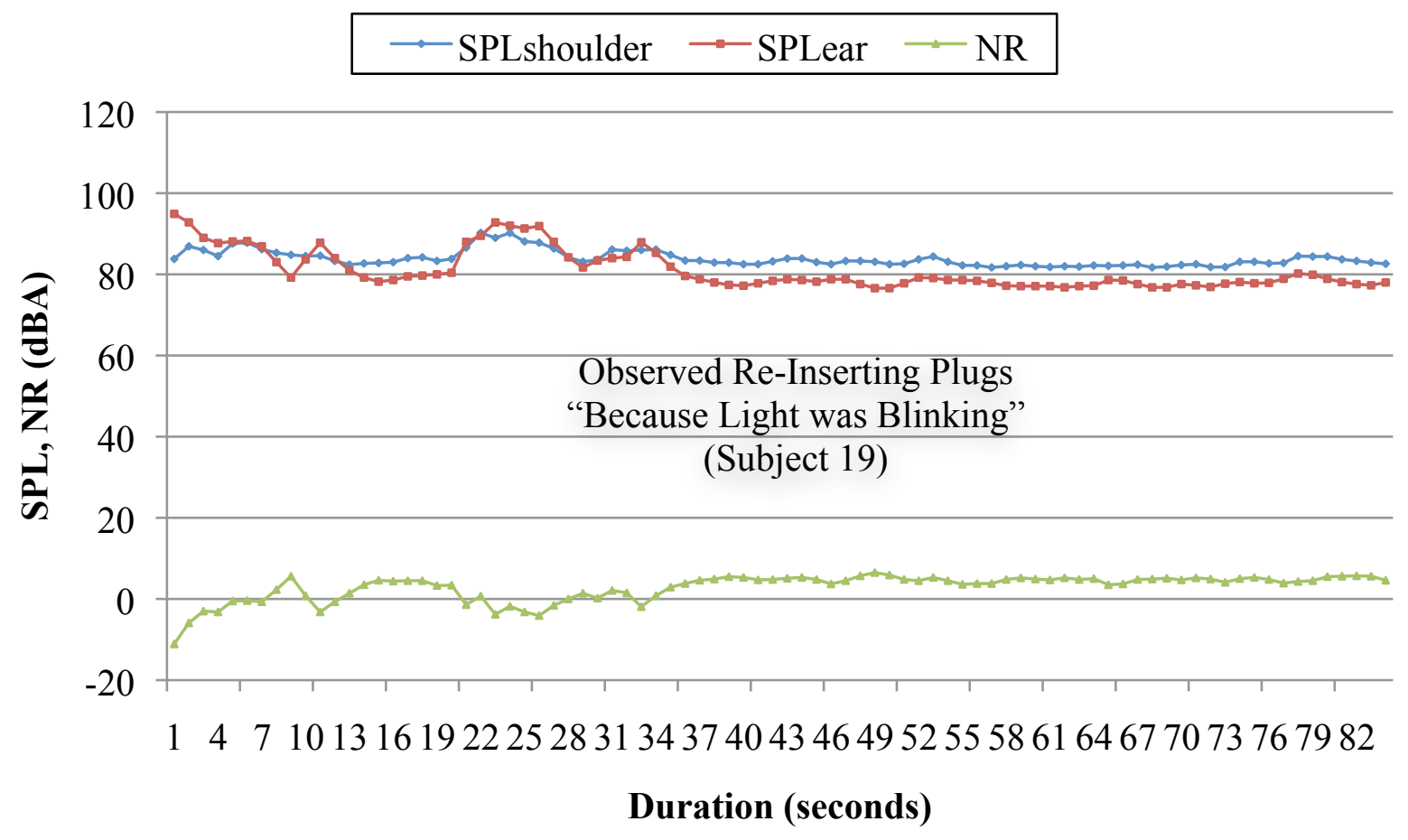

Figure 50. Observed second-by-second results

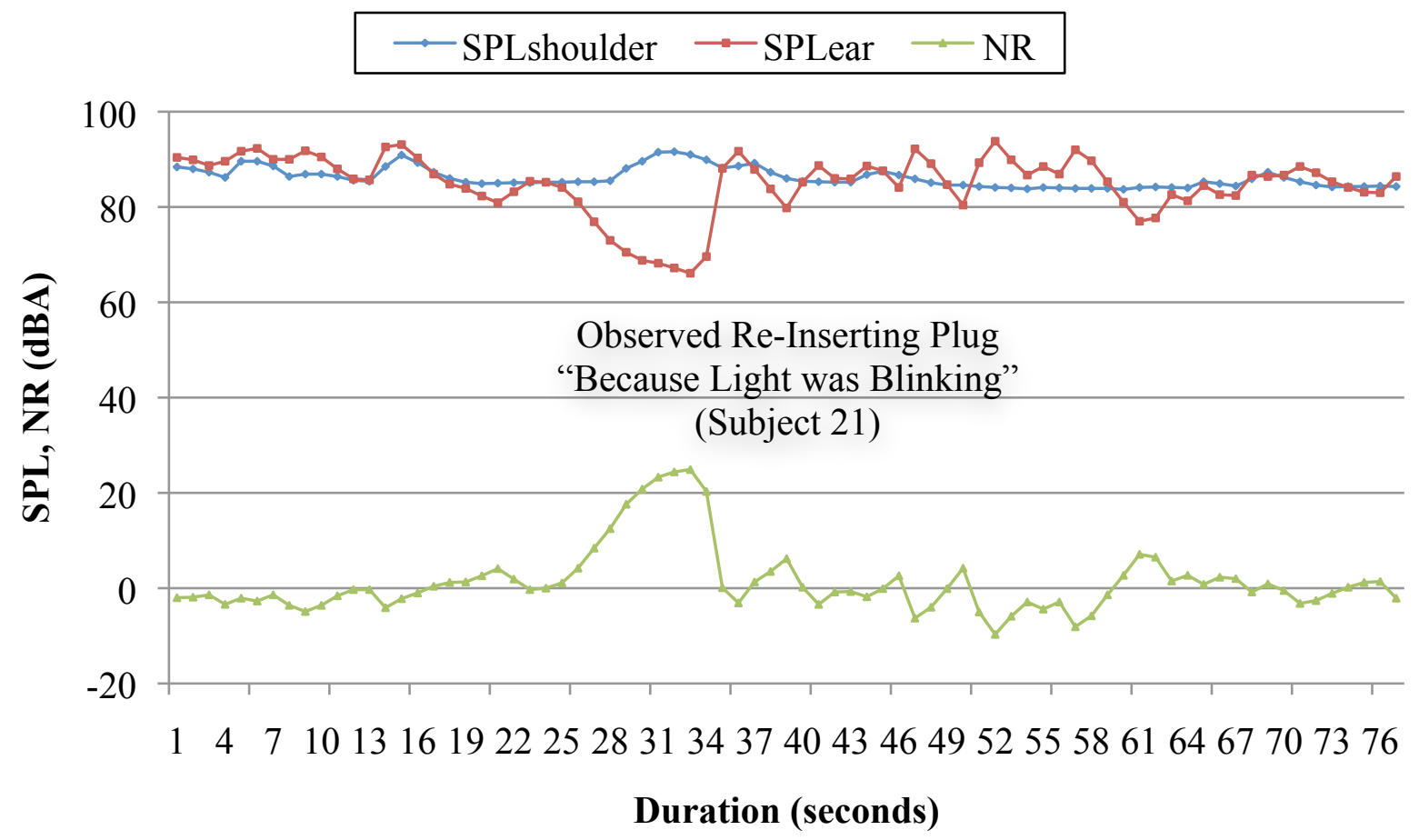

Figure 51. Observed second-by-second results 


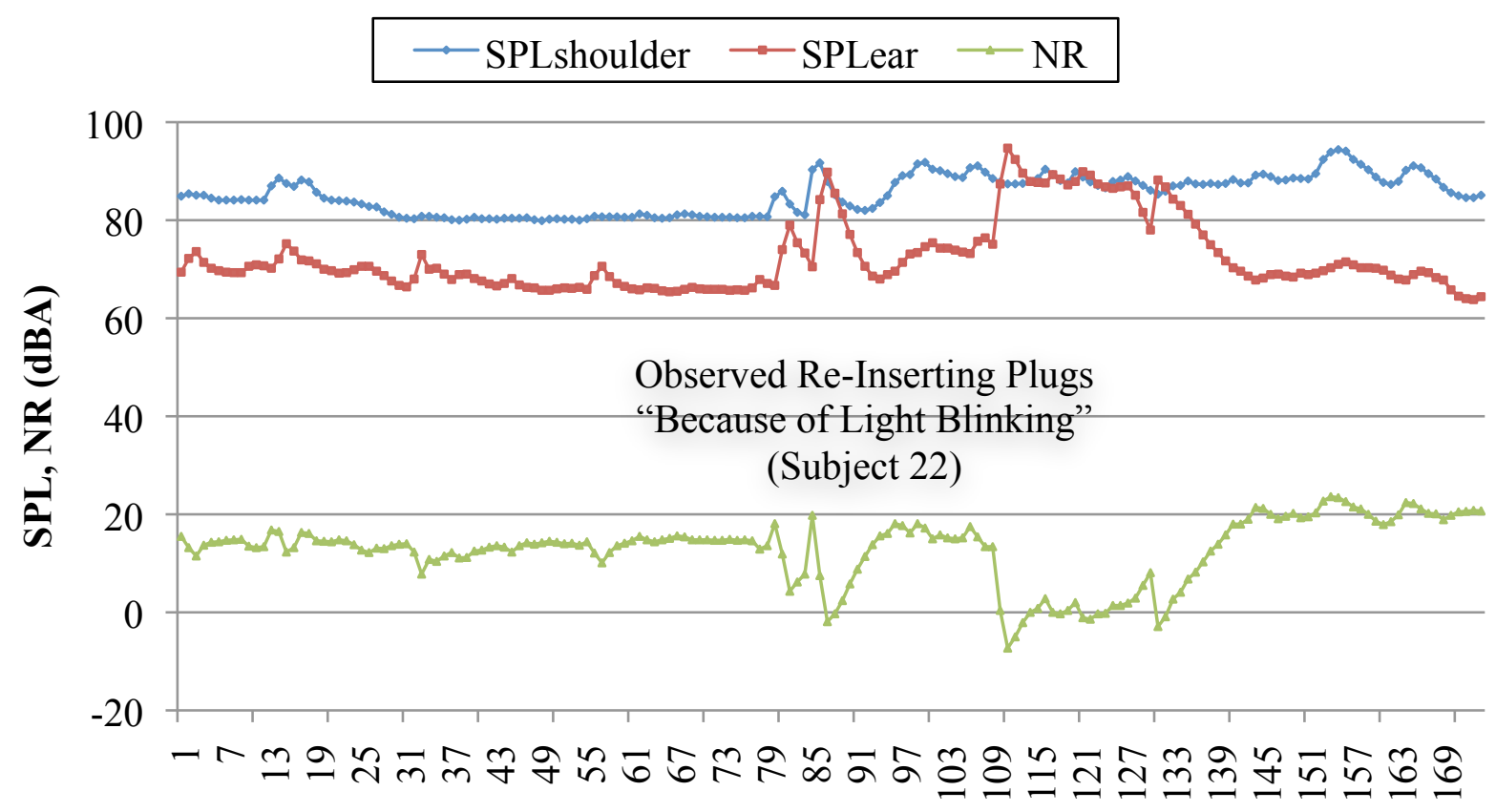

Duration (seconds)

Figure 52. Observed second-by-second results

Figures 48 through 52 each show one of five subjects observed by the investigator during times when they were attempting to re-insert their hearing protection after having removed it. Three of the five were apparently prompted by the light blinking during periods of Light Activation. In all three of those cases, subjects commented that they were re-inserting their HPDs "because the light was blinking." As can be seen, all three cases were similar in that the SPL $_{\text {ear }}$ values fluctuated widely during the re-insertion of the earplugs with an observed increased NR shortly after the re-insertion period. 


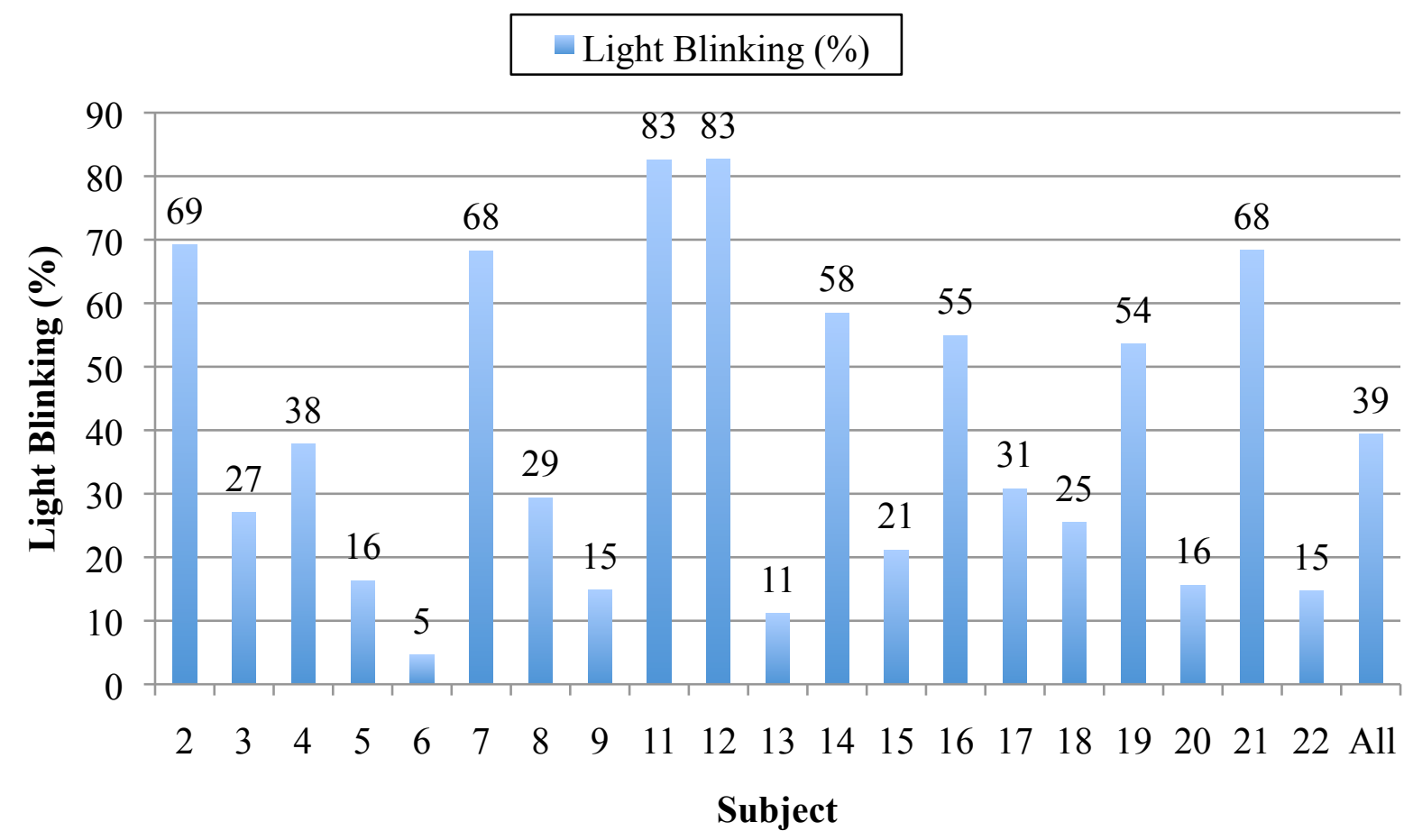

Figure 53. Percent of eligible times that light should be blinking ( $\left.\mathrm{SPL}_{\text {ear }}>80 \mathrm{dBA}\right)$

\subsection{Effects of Light Activation During Shifts}

The expectation was that subjects would respond to the signal light by successfully adjusting their earplugs to obtain a better fit and would therefore achieve a higher NR. Ideally, the subjects would learn during the first period of Light Activation so that NR would improve throughout all periods or improve after the first period and be sustained through subsequent period whether the light system was activated or not.

In this experiment the light was set to blink if the noise level exceeded the threshold for 3 seconds if the light system was active. Each time the light blinked was a prompt to the subject to adjust their earplugs. Therefore, each blink was a chance to improve NR. One might suppose that if the light threshold ( $\mathrm{SPL}_{\mathrm{ear}}=80 \mathrm{dBA}$ ) was not met or exceeded during the shift, subjects would be unaware that they have a poor fit and would have no reason to adjust to a better fit. Logically, this would mean that the "light effect" would not be observed. 
As shown in Figure 53 and Table 11, the percent of eligible times (i.e., SPLsh $\geq 80 \mathrm{dBA}$ and system activated) that the light should be blinking varied from 5 to $83 \%$ for different subjects. Hence, subjects with very poor NR mean values had the light blinking a large percentage of time thereby giving them the most prompts to improve their fit. Thus, one would expect the greatest improvements in those with the worst initial NR values. For example, Subjects two, seven, eleven, twelve, and 21 had NR mean values of 3.7, 2.1, 1.8, 1.5, and 2.1 dBA, respectively, and the light should have blinked greater than $68 \%$ of their tested shift. Far from showing the greatest increase in NR they showed very little improvement. As shown in Figure 53, and as one would expect, the lower the NR mean the more SPL $\mathrm{ear}_{\text {exceed }} 80 \mathrm{dBA}$ and therefore the light should be blinking a larger amount of time. The subjects who could not obtain even modest protection (i.e., $\mathrm{NR}>5 \mathrm{dBA}$ ) all reported being unable to get the light to stop blinking, making it clear that the earplugs were ineffective whether due to the subjects' poor technique or the inability of that earplug to be effective even when worn properly. Hence, a subject with a very high NR in cycle one, before any intervention had occurred, had far less potential for improvement regardless of the level of motivation and competence. Likewise, a subject who has an extremely poor NR may simply be unable to improve their fit regardless of attempts at intervention.

On the other hand, some subjects had little opportunity for improvement because their high NR allowed few blinks, giving them few prompts to improve their fits. An example was Subject 6, who had relatively few prompts to adjust his protector because his percent light blinking was only $3 \%$. Of course the reason he had such few prompts was because he had the highest NR mean $(\mathrm{NR}$ mean $=20.3 \mathrm{dBA})$. Therefore, two things that are at work: first was the high NR mean (assumed good fit) and second was his $\mathrm{SPL}_{\mathrm{sh}}$ value was low $\left(\mathrm{SPL}_{\mathrm{sh}}=86 \mathrm{dBA}\right)$. Because Subject 6 achieved a high NR and given that his average ambient noise exposure was within six decibels of the light threshold, it may have been that the light did not activate because he already achieved a good fit and therefore prompt further improvement. It is possible that if the light threshold was reduced to 65 decibels this subject would have been able to achieve an even higher NR with prompting from the light. 
Table 11. Percent of eligible times that light should be blinking ( $\left.\mathrm{SPL}_{\text {ear }}>80 \mathrm{dBA}\right)$

\begin{tabular}{ccccc}
\hline Subject & $\begin{array}{c}\text { NR Mean } \\
(\mathrm{dBA})\end{array}$ & $\begin{array}{c}\mathrm{SPL}_{\text {sh }} \geq 80 \\
(\text { seconds })\end{array}$ & $\begin{array}{c}\mathrm{SPL}_{\text {ear }} \geq 80 \\
(\text { seconds })\end{array}$ & $\begin{array}{c}\text { Light Blinking* } \\
(\%)\end{array}$ \\
\hline 2 & 3.7 & 21825 & 15107 & 69 \\
3 & 8.1 & 22453 & 6068 & 27 \\
4 & 5.4 & 22085 & 8357 & 38 \\
5 & 19.6 & 22346 & 3648 & 16 \\
6 & 21.6 & 20594 & 943 & 5 \\
7 & 2.1 & 21535 & 14705 & 68 \\
8 & 13.9 & 19263 & 5657 & 29 \\
9 & 20.7 & 16422 & 2435 & 15 \\
11 & 1.8 & 14859 & 12273 & 83 \\
12 & 1.5 & 18223 & 15068 & 83 \\
13 & 13.6 & 19490 & 2173 & 11 \\
14 & 1.5 & 21733 & 12707 & 58 \\
15 & 12.1 & 21060 & 4450 & 21 \\
16 & 5.6 & 19472 & 10698 & 55 \\
17 & 10.8 & 17395 & 5358 & 31 \\
18 & 13.3 & 20935 & 5336 & 25 \\
19 & 4.1 & 18695 & 10013 & 54 \\
20 & 12.8 & 20624 & 3214 & 16 \\
21 & 2.1 & 21792 & 14895 & 68 \\
22 & 15.0 & 19017 & 2796 & 15 \\
Overall & 9.4 & 399818 & 155901 & 39 \\
\hline
\end{tabular}

${ }^{*}$ Light Blinking $=\left(\right.$ Seconds $\mathrm{SPL}_{\text {ear }} \geq 80 /$ Seconds $\left.\mathrm{SPL}_{\mathrm{sh}} \geq 80\right) \times 100 \%$ 


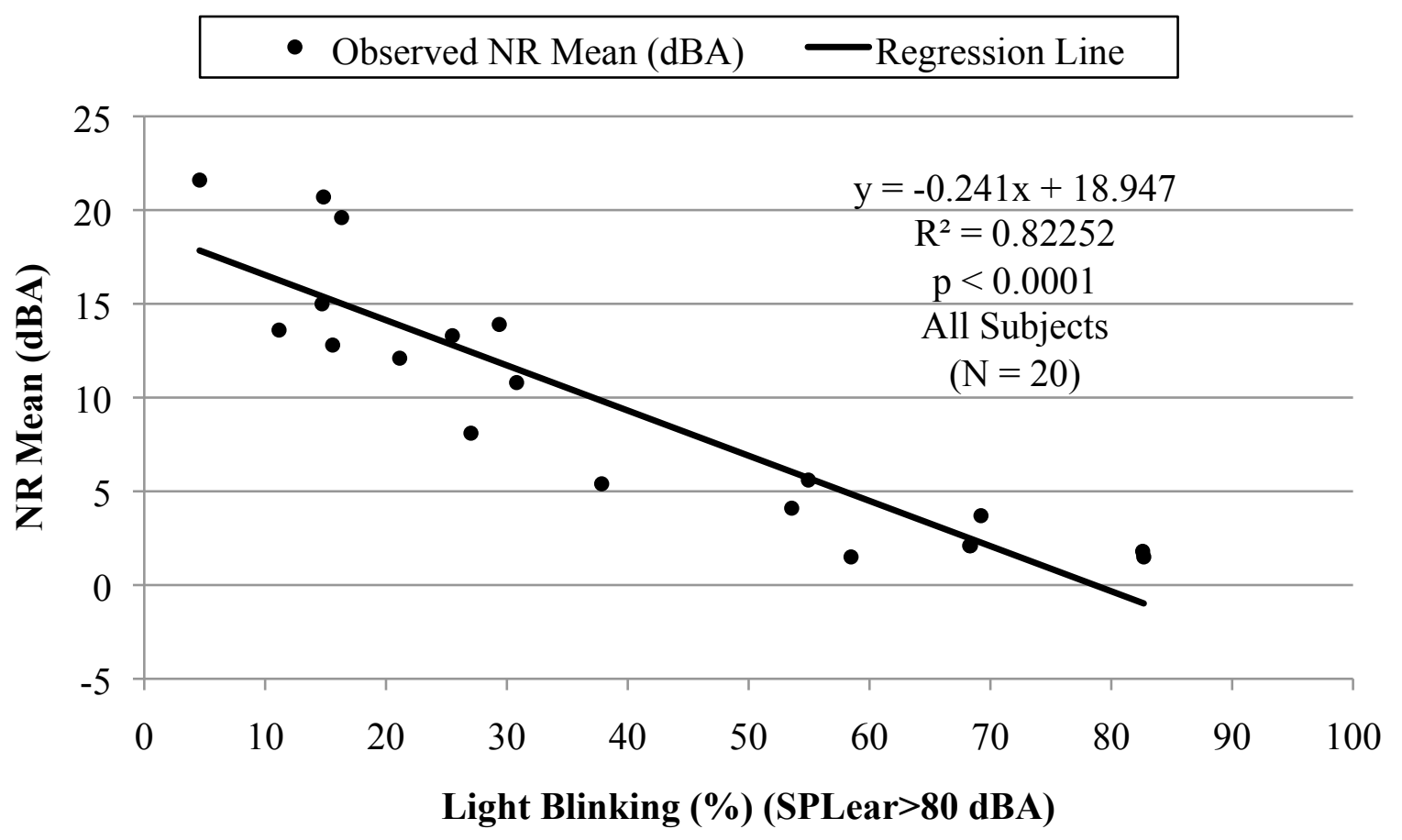

Figure 54. Light blinking versus overall NR mean

Figure 54 shows fraction of the time light was blinking plotted against NR mean for all subjects. As expected the light blinked less for subjects with higher NR mean values than for subjects with poor NR mean values. Thus, the worse protection a worker has the more light blinks during periods of activation and therefore the more observed prompts and the more opportunity for improvement. The finding also indicates that the light may be most useful for notifying supervisors that a worker's HPD is not working.

It is possible that if ambient noise levels were greatly higher one might observe higher NR mean values, including subjects who achieved a poor fit (NR mean $<5 \mathrm{dBA}$ ). On the other hand, it was possible one would not observe higher NR mean values, especially for subjects unable to improve their fits.

Figure 54 shows the results of the linear regression analysis between times when the light should be blinking and NR mean for all subjects. The slope (-0.241) of the regression line shown in Figure 53 was significantly different from zero $(\mathrm{p}<0.0001)$, and the coefficient of 
determination $\mathrm{R}^{2}$ was 0.82252 . The latter indicates that the prediction relationship was moderately strong with only $18 \%$ of the variability not explained.

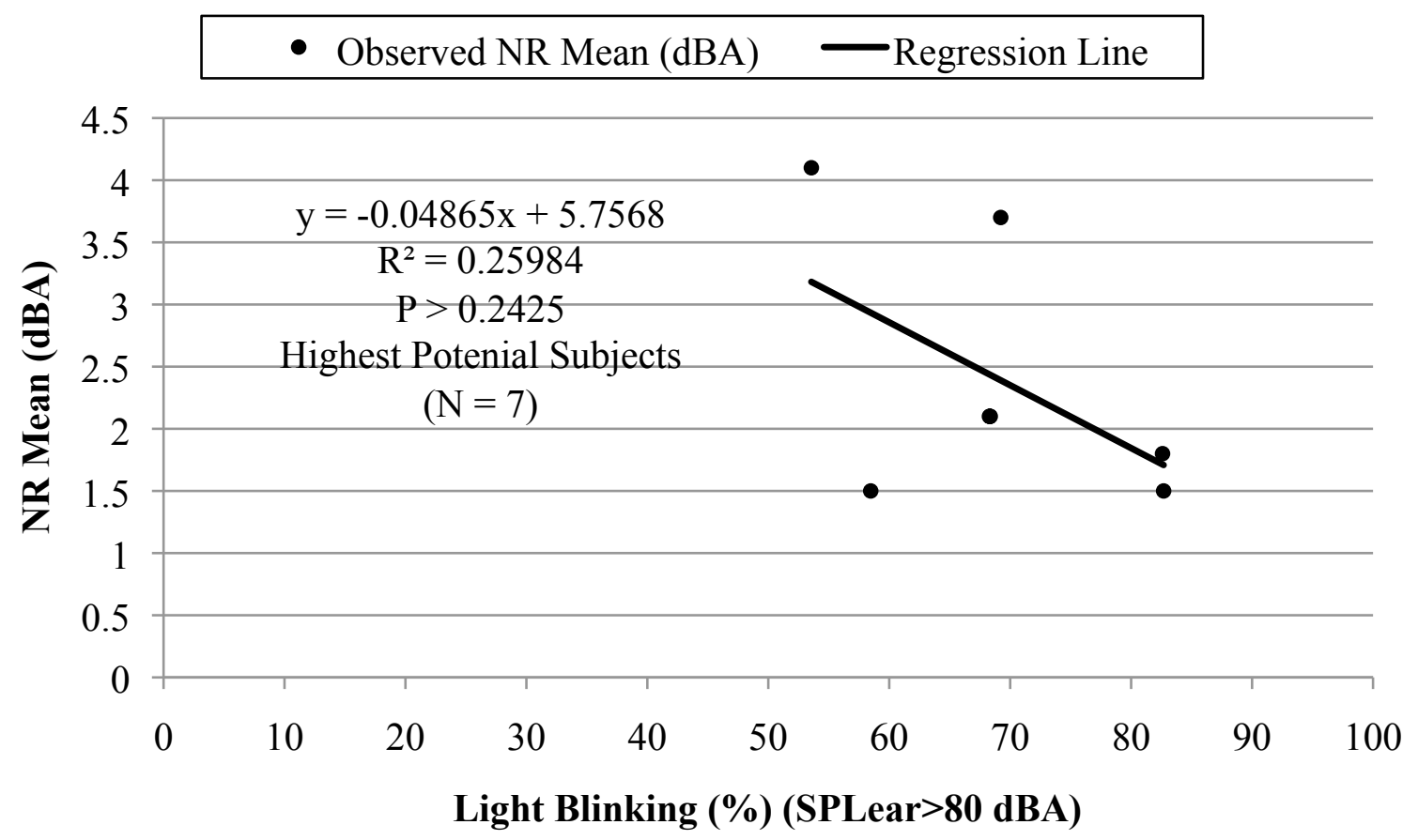

Figure 55. Light blinking versus overall NR Mean

Figure 55 shows the relationship times when the light should be blinking and NR for all subjects. The modest slope (-0.049) of the regression line shown in Figure 55 was not significantly different from zero $(p>0.243)$. The coefficient of determination $R^{2}$ was 0.260 . 


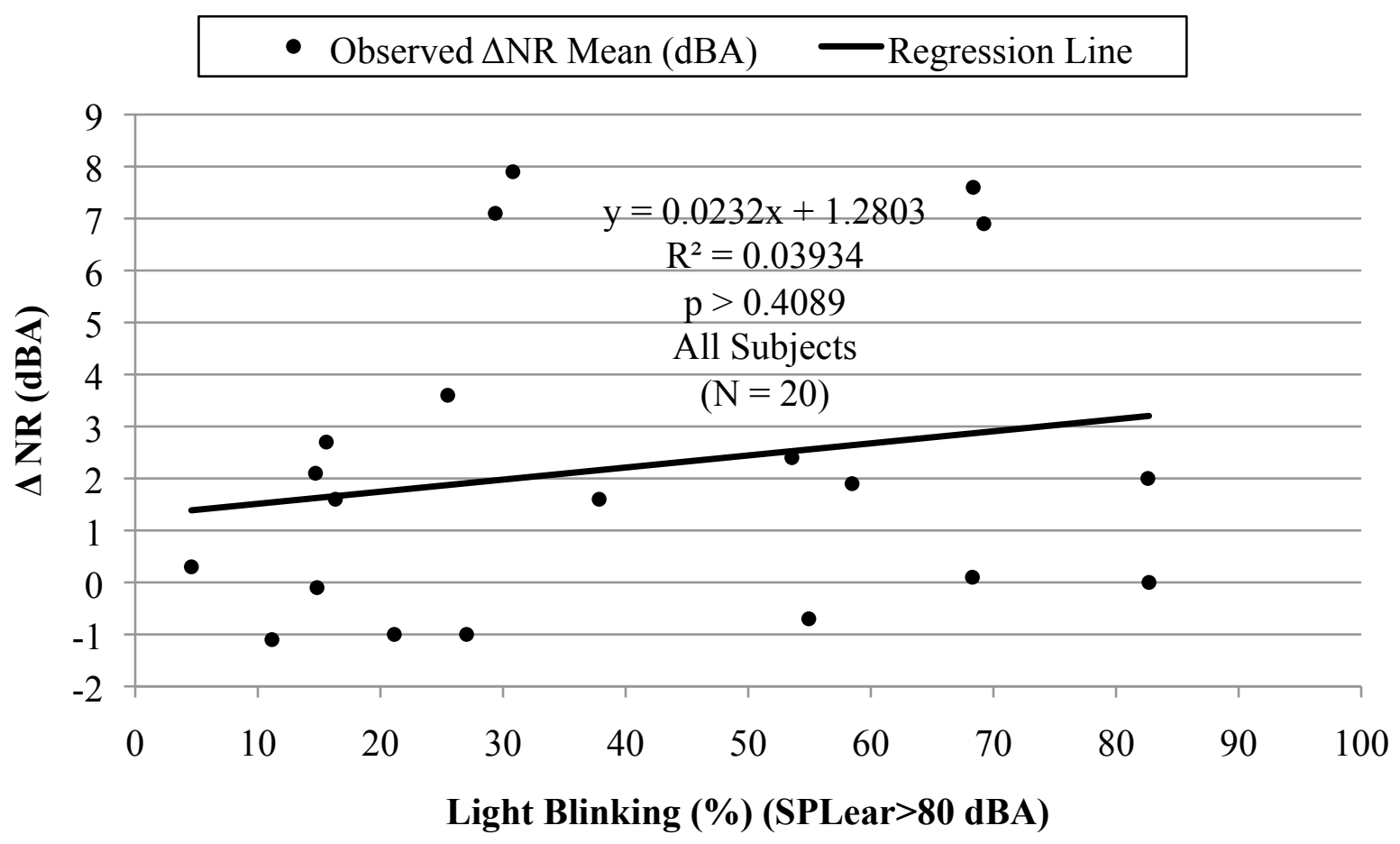

Figure 56. Light blinking versus $\Delta$ NR Mean

Figure 56 shows the results of the times when the light should be blinking and $\Delta \mathrm{NR}$ for all subjects. The negligible slope (0.023) of the regression line was not significantly different from zero ( $p>0.4089$ ), and the coefficient of determination $R^{2}$ was 0.039 indicating no relationship. 


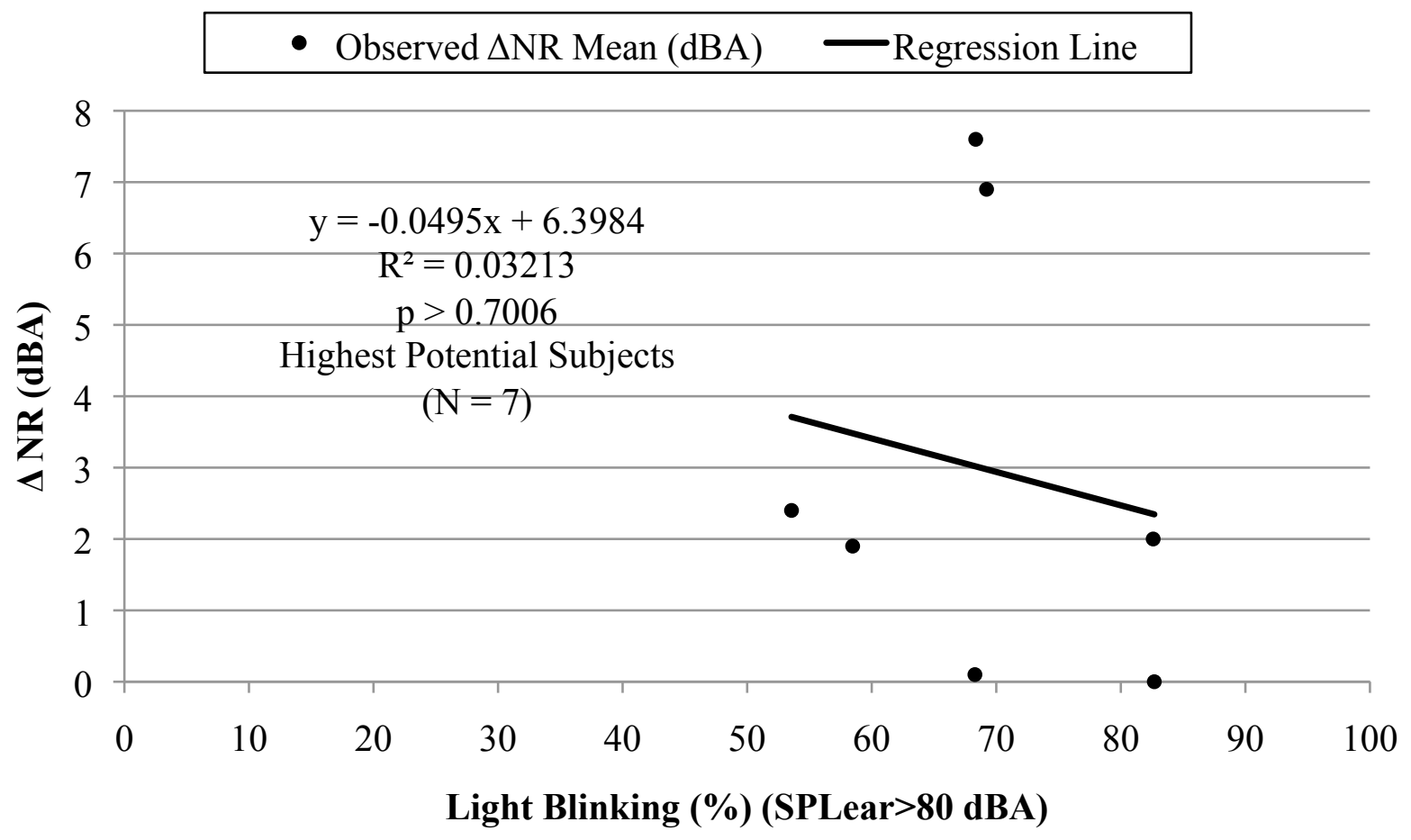

Figure 57. Light blinking versus $\Delta$ NR Mean

Some subjects could not improve their NR due to starting with high NR or being unable to improve poor fits despite diligent efforts. Hence, including them dilutes the effectiveness of the light for those who could potentially improve their fits. Figure 57 shows the results of the relationship between times when the light should be blinking and $\Delta \mathrm{NR}$ for subjects with $\mathrm{NR}<5$ and NR $>15$ excluded. The slope (-0.050) of the regression line shown in Figure 57 was not significantly different from zero $(\mathrm{p}>0.701)$, and the coefficient of determination $\mathrm{R}^{2}$ was negligible at 0.032 . Hence, even for those with the greatest potential for improvement, more blinks did not improve performance. 


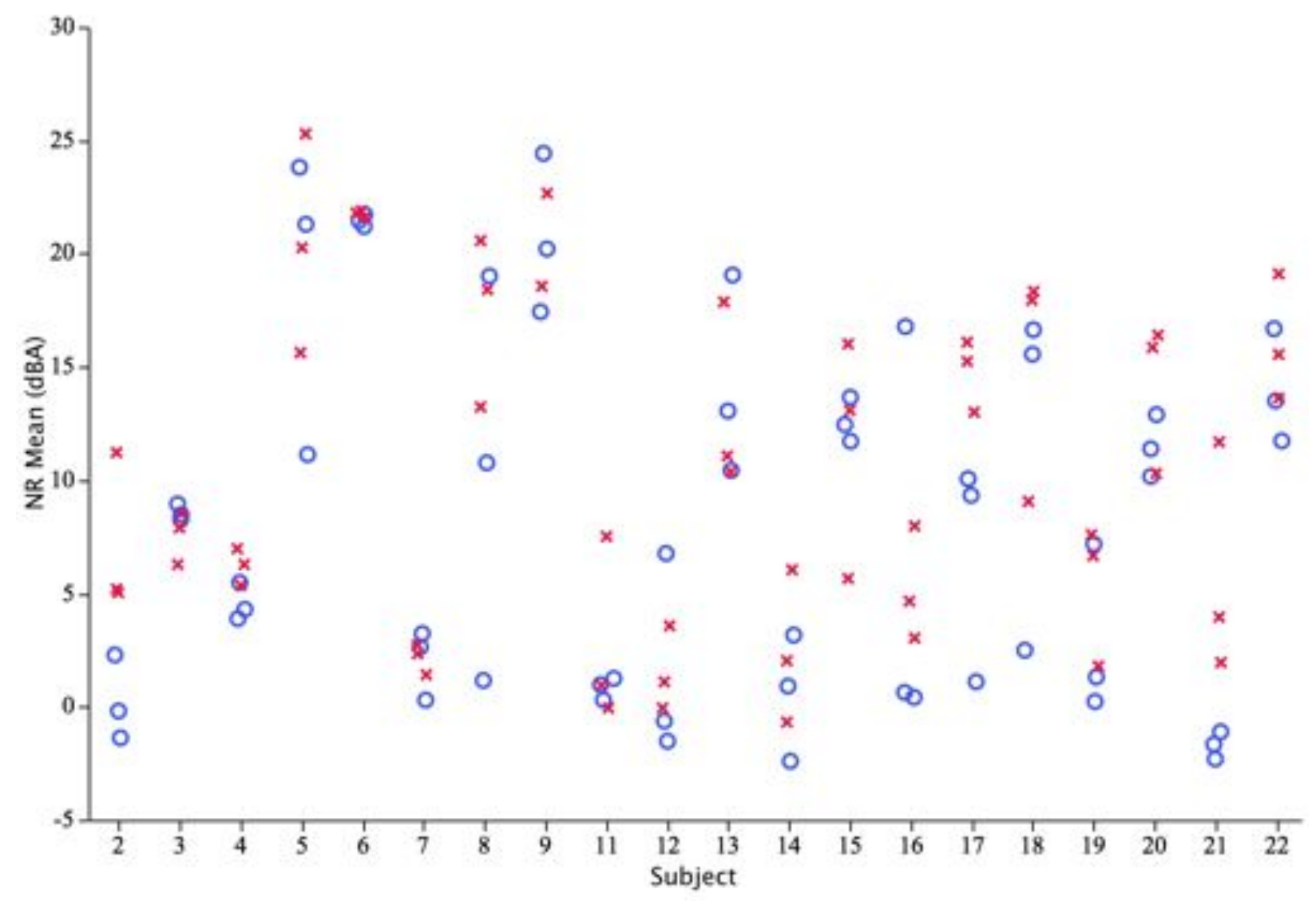

Figure 58. NR mean versus light status $(\mathrm{N}=20)$

\subsection{Effect of Light Status}

As shown in Figure 58 and Table 9, the high degree of overlap between Light Deactivation and Light Activation suggests weak effects, at best. This is shown quantitatively by the modest differences in NR mean values for light activated and light deactivated (8.4 dBA and 10.6 dBA, respectively). An improvement of just over $2 \mathrm{dBA}$ is a small reward for such an intrusive intervention. 


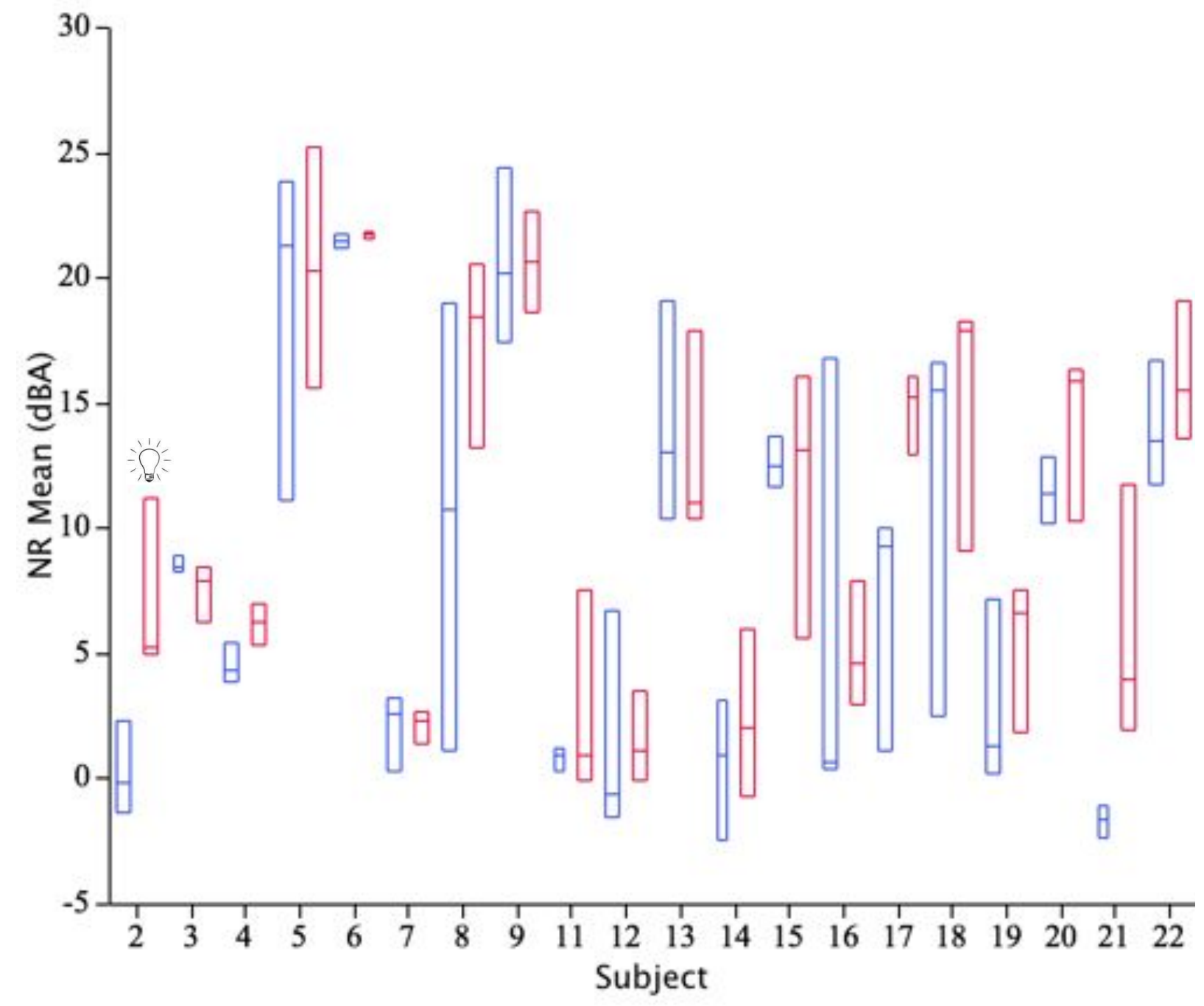

Figure 59. NR mean versus subject by light status

As can be seen in Figure 59 and Table 9, there were substantial differences among subjects. The between subject standard deviation for NR was $3.5 \mathrm{dBA}$. The results appear to indicate that subjects were the most important variable, as is often the case with studies involving human subjects. The distribution for all subjects during light deactivation and light activation are shown in Figures 60a and 60b. 


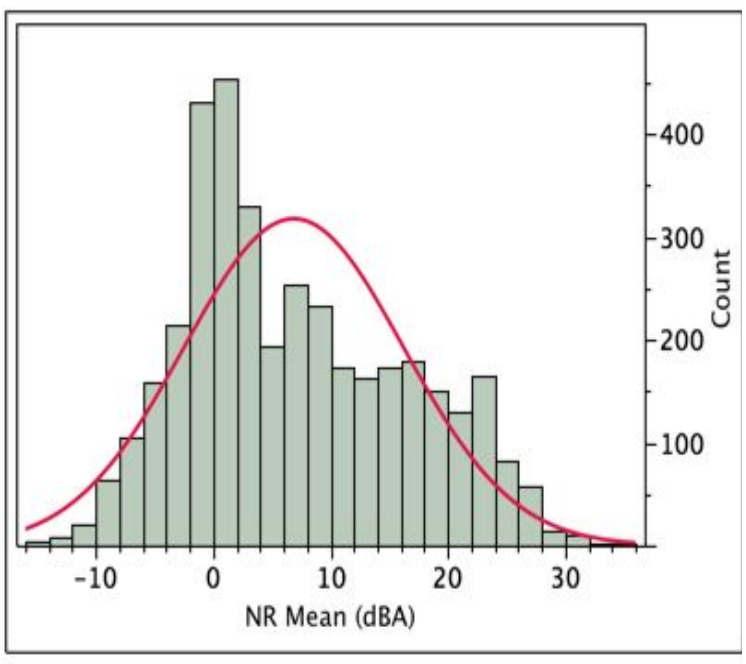

Figure 60a. Distribution for all subjects during periods of Light Deactivation

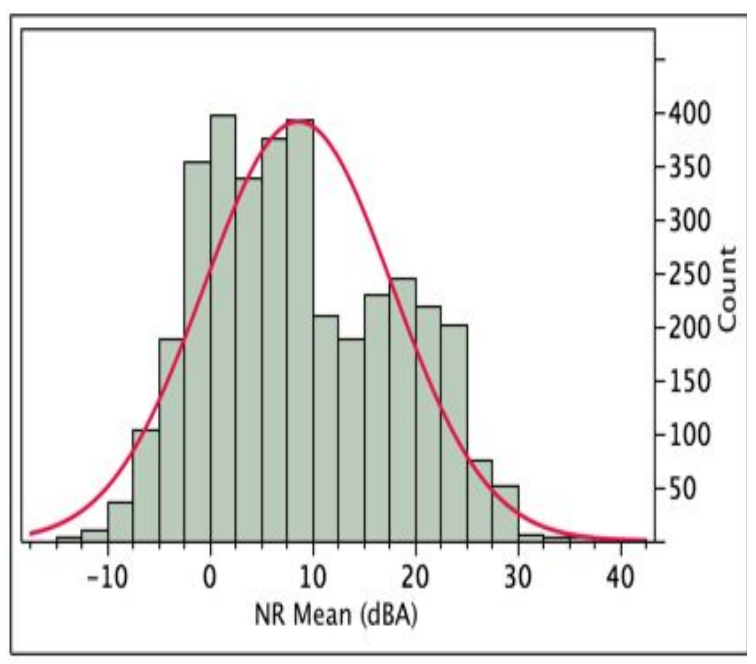

Figure $60 \mathrm{~b}$. Distribution for all subjects during periods of Light Activation 


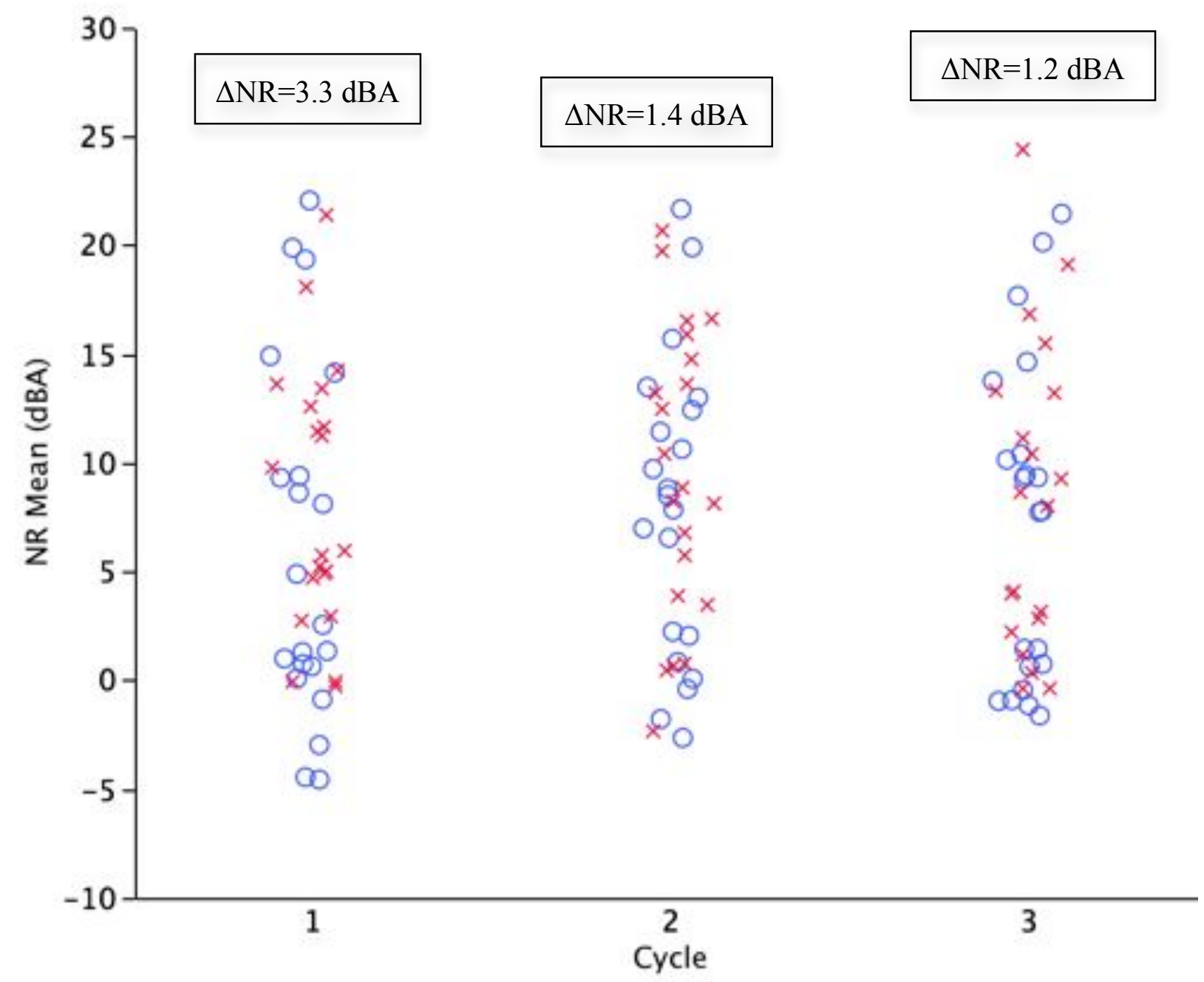

Figure 61. NR mean versus cycle by light status $(\mathrm{O}=$ light deactivated, $\mathrm{X}=$ light activated $)$

\subsection{Effect of Cycle}

As shown in Figure 61 and Table 11, it appears that cycle two had the highest NR mean (10.4 dBA) both with and without light signaling. Cycle differences appear to be weak, though the difference between Light Activation and Light Deactivation was greatest in the first cycle and diminished afterwards (see Figure 61). 
Table 12. Descriptive statistics of NR mean (dBA) by cycle and light status for all subjects $(\mathrm{N}=120)$

\begin{tabular}{ccccc}
\hline Cycle & Light Status & \multicolumn{3}{c}{ NR Mean (dBA) } \\
& Mean & Std Dev & Median \\
\hline 1 & Deactivated & 7.0 & 8.2 & 4.1 \\
& Activated & 10.3 & 6.1 & 8.3 \\
& Overall & 8.6 & 7.2 & 6.2 \\
2 & & & & \\
& Deactivated & 9.7 & 7.8 & 10.6 \\
& Activated & 11.1 & 7.5 & 10.7 \\
& Overall & 10.4 & 7.7 & 10.6 \\
3 & & & & 7.8 \\
& Deactivated & 7.2 & 7.4 & 8.3 \\
& Activated & 8.4 & 7.1 & 8.9 \\
& Overall & 7.8 & 7.2 & 8.5 \\
All Cycles & Deactivated & 8.4 & 7.8 & 8.7 \\
& Activated & 9.9 & 7.8 & \\
& Overall & 9.1 & 7.8 & \\
\hline
\end{tabular}

As shown in Figure 60 and Table 12, the high degree of overlap between cycles suggests that cycle is not an important variable $(\mathrm{p}>0.12)$. There are several plausible expectations regarding the high degree of overlap between cycles. The first was that there would be no sustained effect from having Light Activated from a previous time period. If that is true, there would be no difference between cycles. The second expectation was that there would be a learning effect, but it would be learned in the first period and sustained throughout the rest with little additional learning. If true, the first period would be the highest, and the remaining periods would be no trend. In other words, the NR mean values would increase to a higher level and stay there for the remainder of the tested shift. The third expectation would be that it was nonpersistent. If true, each time during Light Activation subjects would achieve an improved NR and during periods of Light Deactivation subjects would do poorly.

The fact that there was no apparent learning effect suggests that one could effectively use the exposure-indicating light for training unless the exposure-indicating light was coupled with refitting earplugs, in which case it would be really training on how to use earplugs, not 
necessarily how to improve fit with a given pair. It is true that one could be trained by using the flashing light, and could learn how HPDs feel inside the ear canal. However, the variability of the NR makes it more difficult to learn from the light in the field. If the NR was constant, a worker may learn how to fit the HPD since a poor fit would continually generate a signal until the fit were improved. Likewise, a good fit would persist. Therefore it is suggested that the erratic NR obscured learning. Assuming variability cannot be reduced, it is possible that within a static fit test the results would be less variable and a worker may learn how to adjust their HPD because of higher quality feedback. Therefore the problem was not the light; the issue was the earplug NR was too erratic, which affects the effectiveness of light during training.

There was no observed effect of pattern of order, because there was no great effect overall. One reason a pattern was not observed was because the light effect was modest. If the effect of the light being activated was more substantial than when deactivated, one might be able to observe an order effect. The difference between Light Activated and Light Deactivated was modest, so any possible pattern would be difficult to observe. 


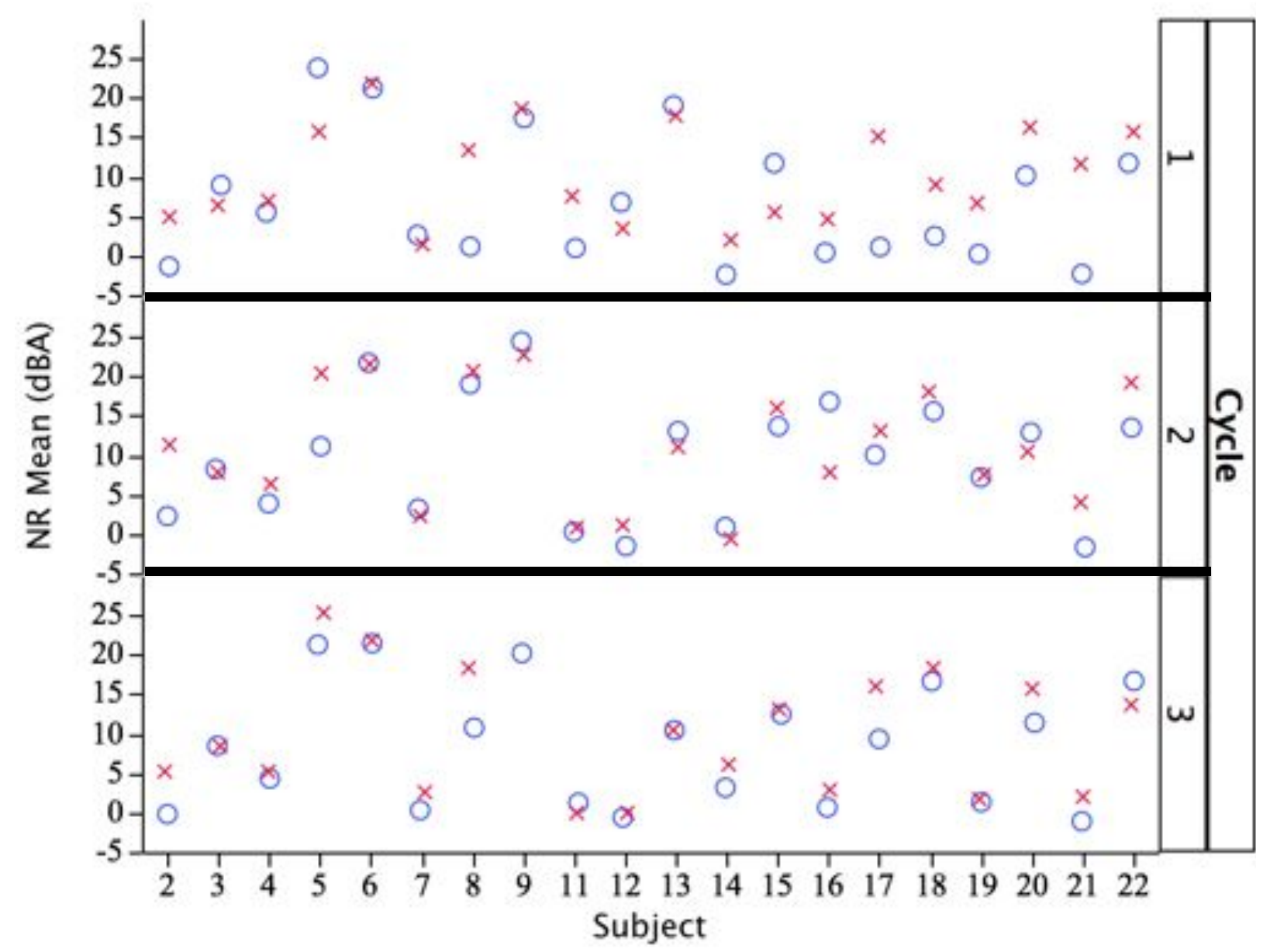

Figure 62. NR Mean (dBA) versus subject by cycle and light status $(\mathrm{O}=$ light deactivated, $\mathrm{X}=$ light activated $)$

Figure 62 shows subject NR mean by cycle. Note the Light Deactivated average NR during cycle 1 for all subjects (NR mean $=7.0 \mathrm{dBA}$ ). Cycle one; Light Deactivated was a baseline NR mean value for each subject because the light was deactivated with no prior subject exposure to the light. During cycle one; Light Activated NR mean for all subjects was $10.3 \mathrm{~dB}(\Delta \mathrm{NR}=3.3$ dBA). The improvement during cycle one suggests a behavior change towards NR when the light was activated. Table 28 (see Appendix) shows descriptive statistics for NR mean by cycle for each subject. Note that there was little improvement during cycles $2(\Delta \mathrm{NR}=1.4 \mathrm{dBA})$ and 
cycle $3(\triangle \mathrm{NR}=1.5 \mathrm{dBA})$ indicating that the improvement in NR occurred only when the light was activated and did not appear to persist. It may suggest a signaling effect rather than a learning effect.

Figures 63a-u show individual subject and overall results by period. 


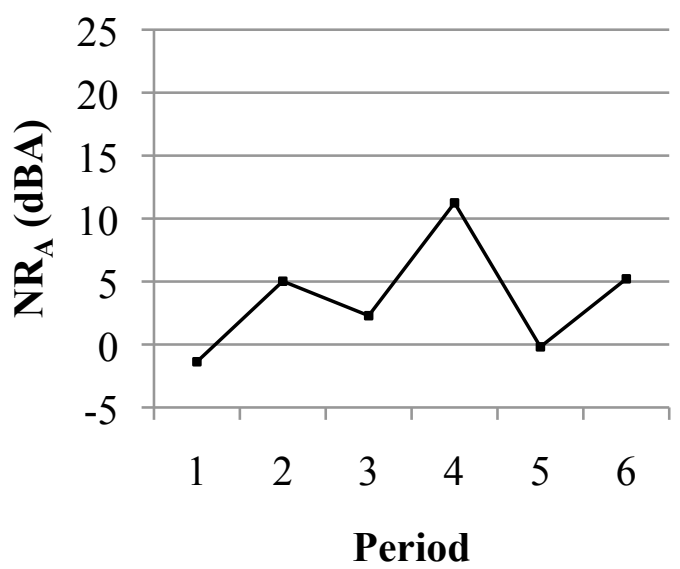

Figure 63a. Subject 2

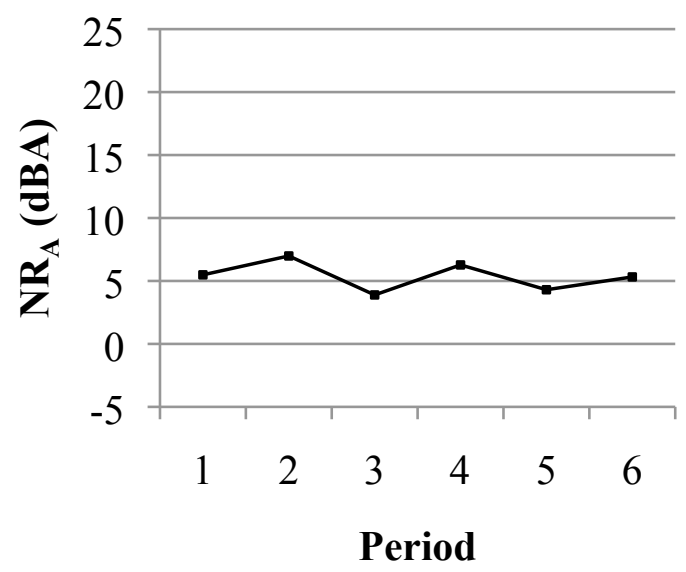

Figure 63c. Subject 4

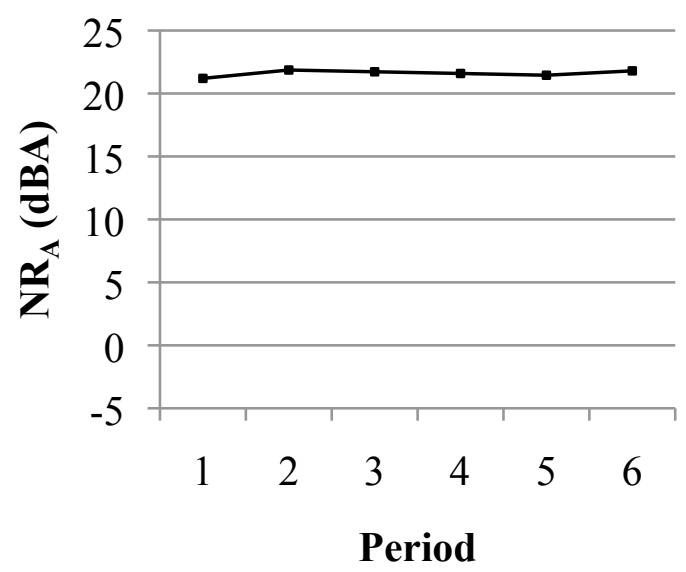

Figure 63e. Subject 6

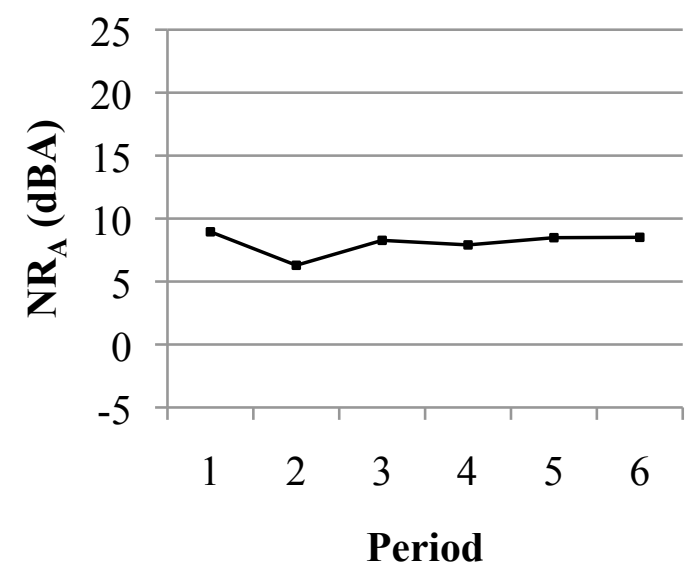

Figure 63b. Subject 3

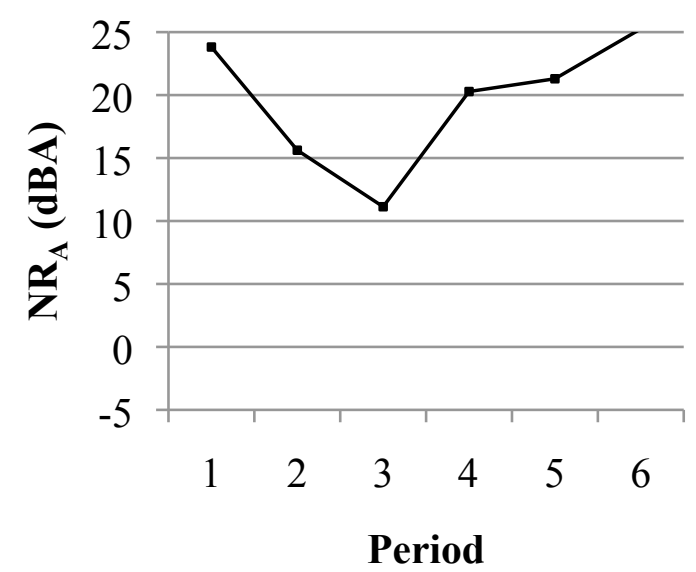

Figure 63d. Subject 5

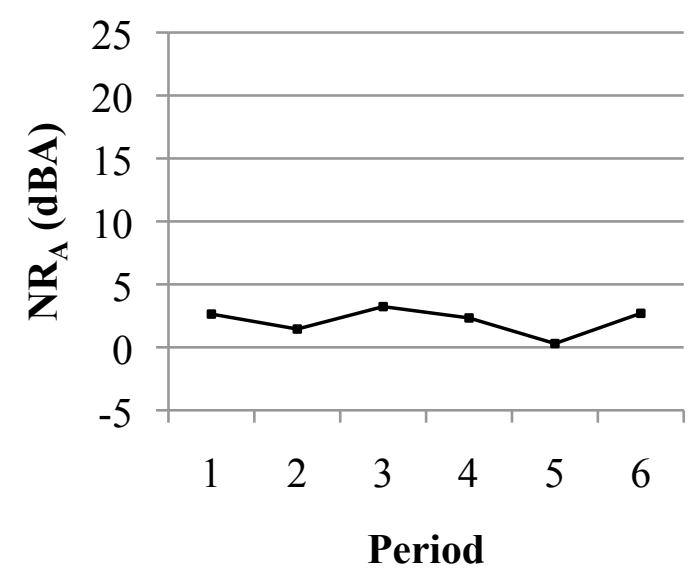

Figure 63f. Subject 7 


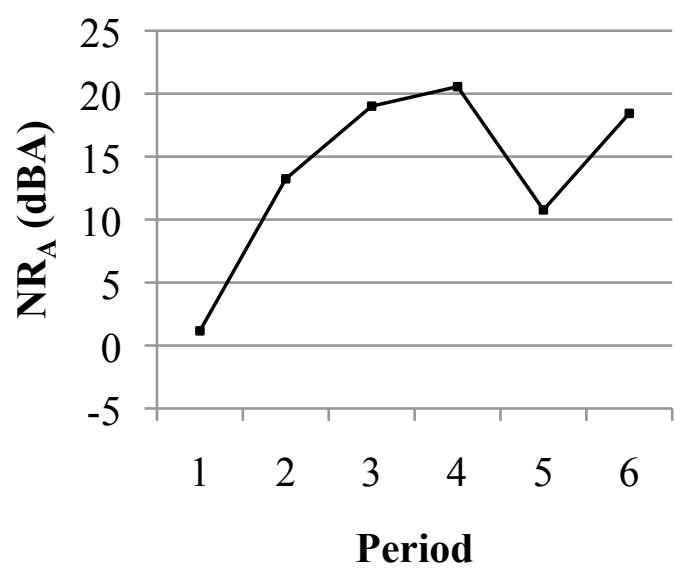

Figure 63g. Subject 8

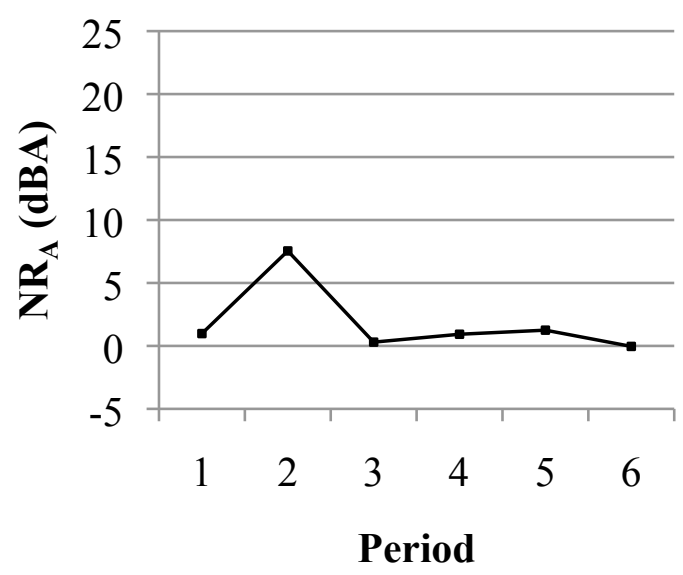

Figure 63i. Subject 11

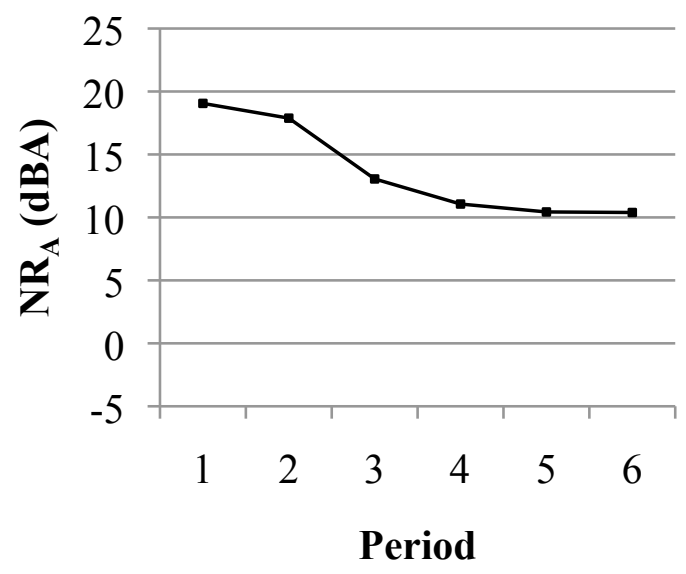

Figure 63k. Subject 13

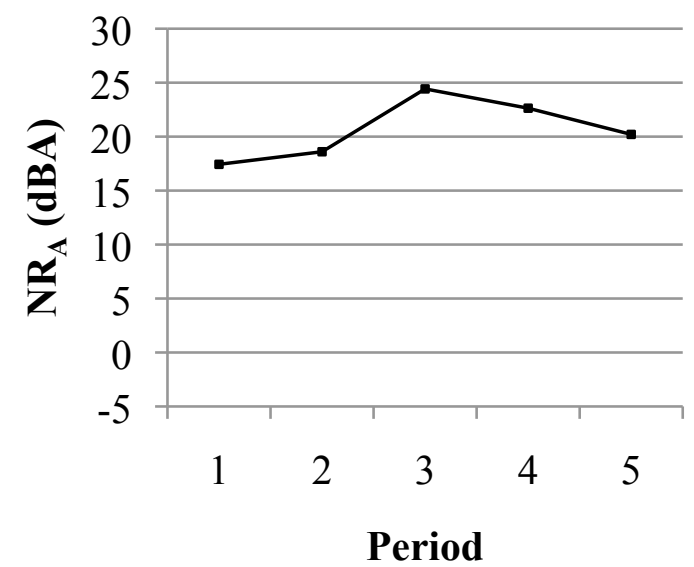

Figure $63 \mathrm{~h}$. Subject 9

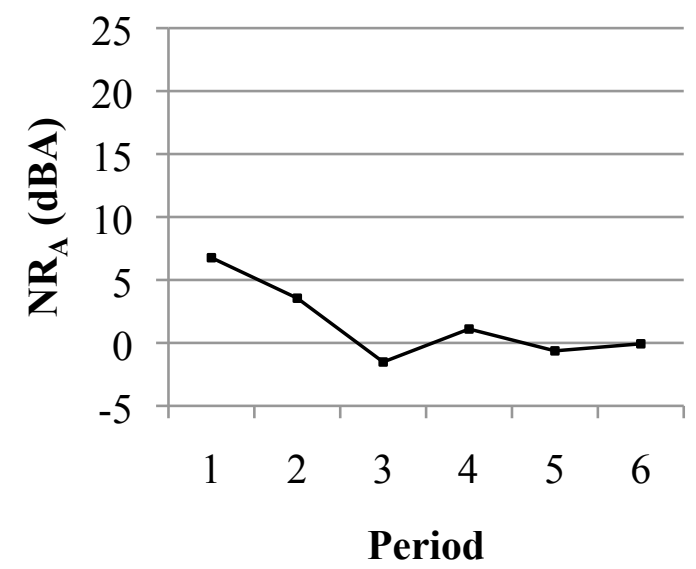

Figure 63j. Subject 12

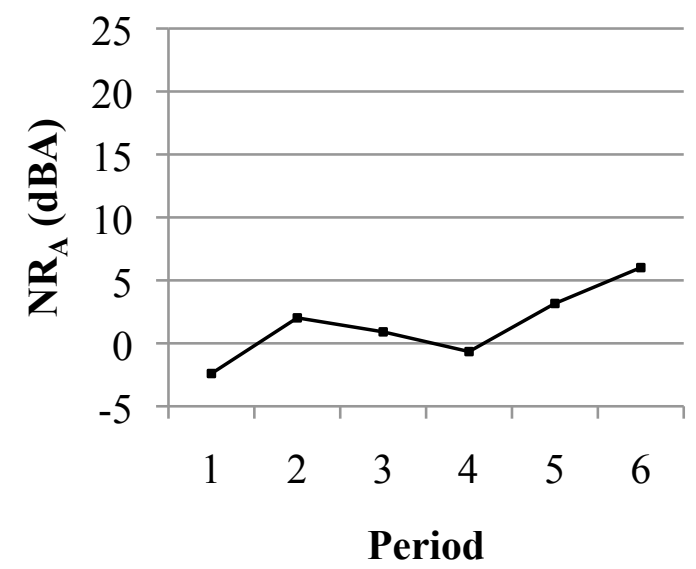

Figure 631. Subject 14 


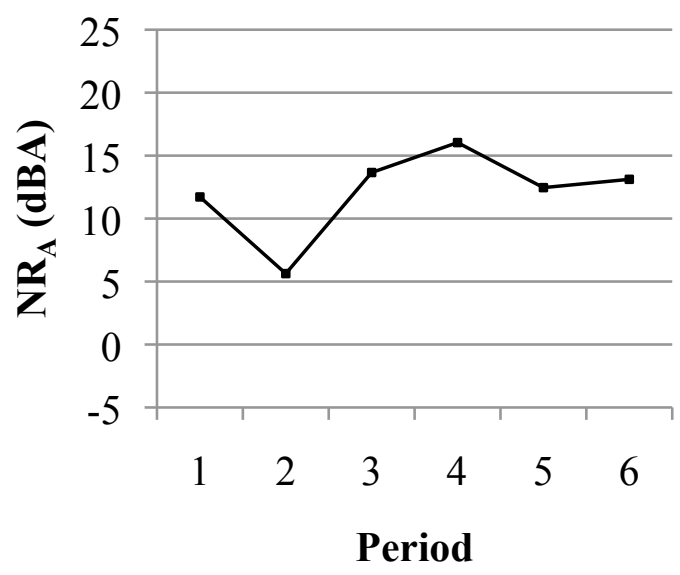

Figure 63m. Subject 15

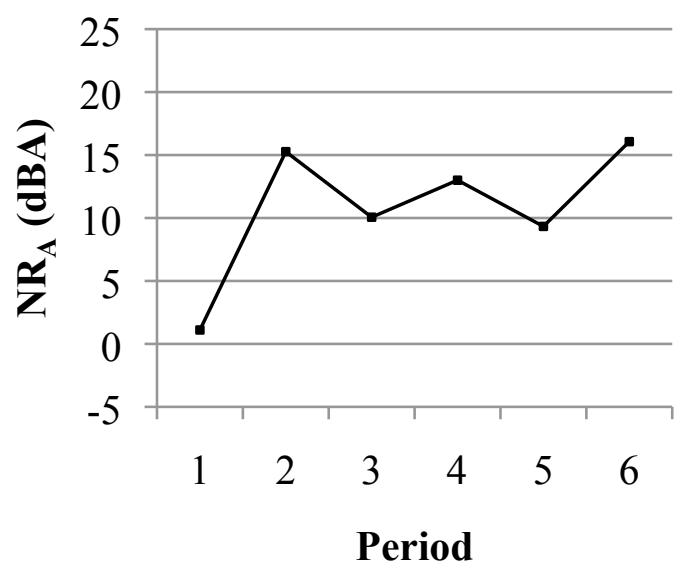

Figure 63o. Subject 17

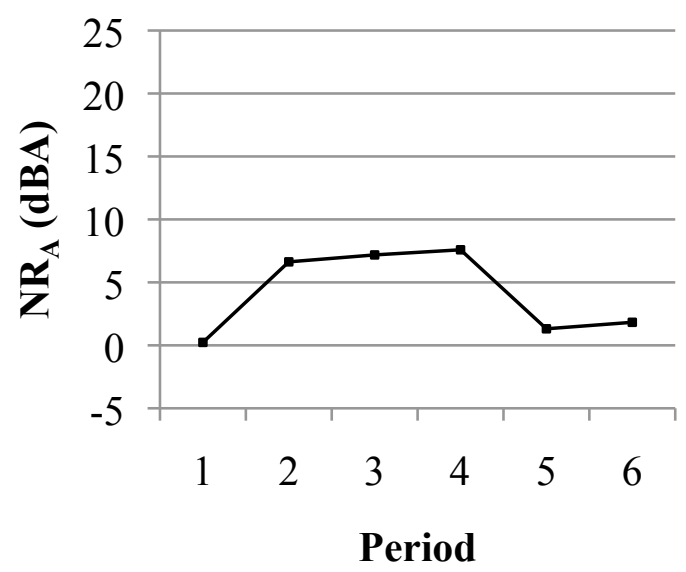

Figure 63q. Subject 19

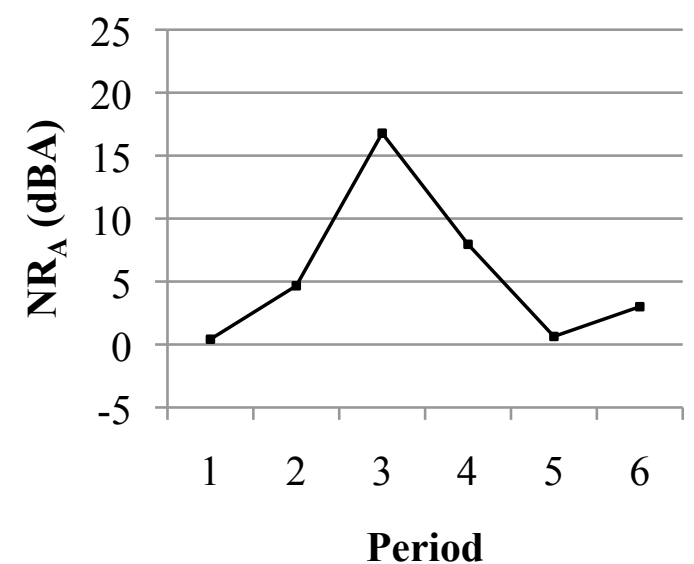

Figure 63n. Subject 16

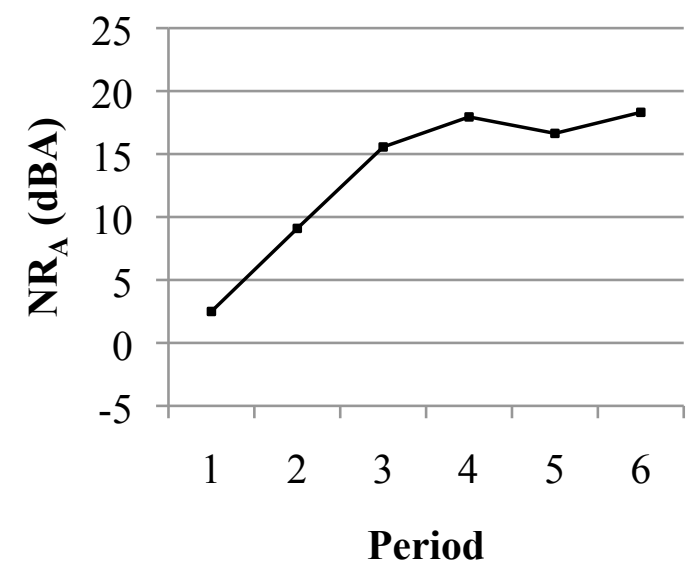

Figure 63p. Subject 18

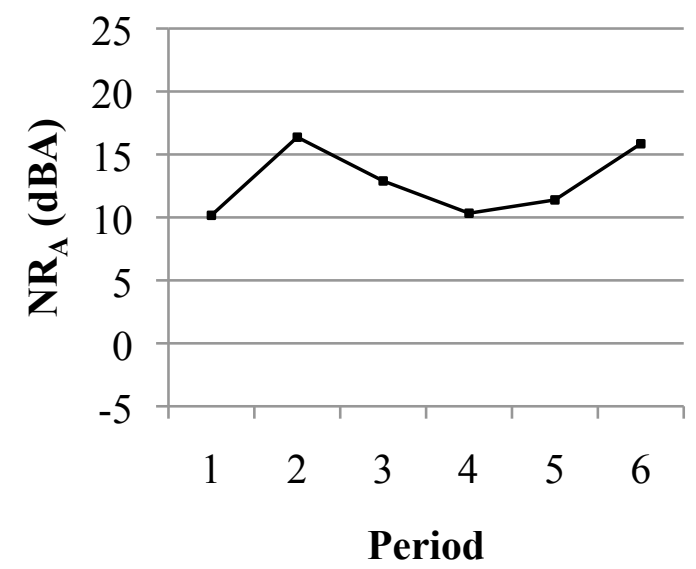

Figure 63r. Subject 20 


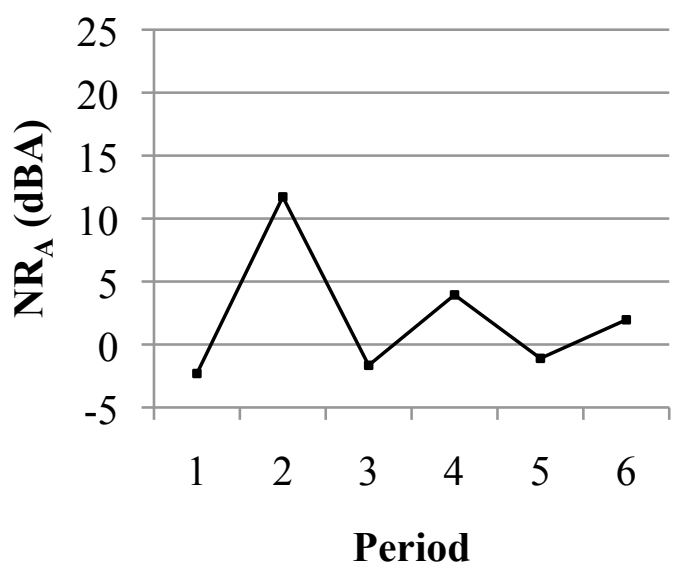

Figure 63s. Subject 21

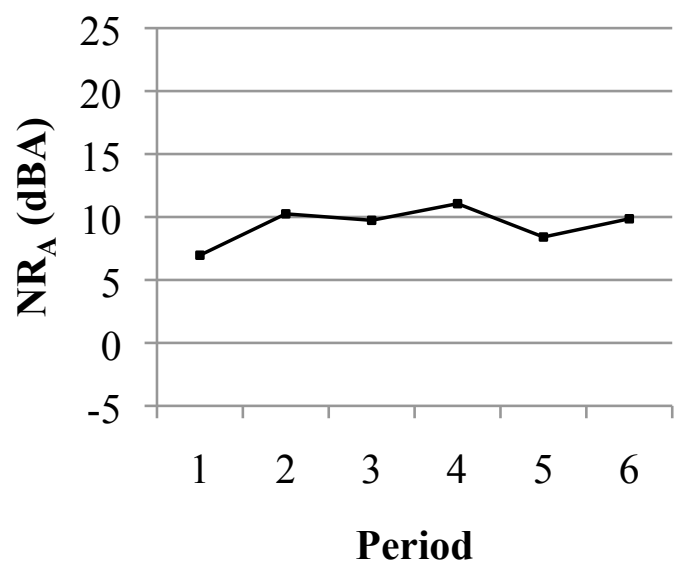

Figure 63u. Overall

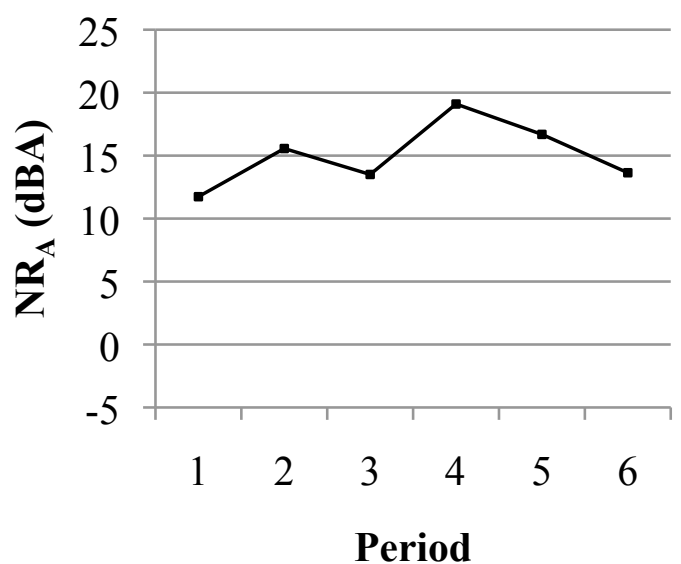

Figure 63t. Subject 22

The NR mean results of six tests per subject are shown Figures 63a-u. As can be seen, there was no consistent pattern for change in NR over the six periods. 


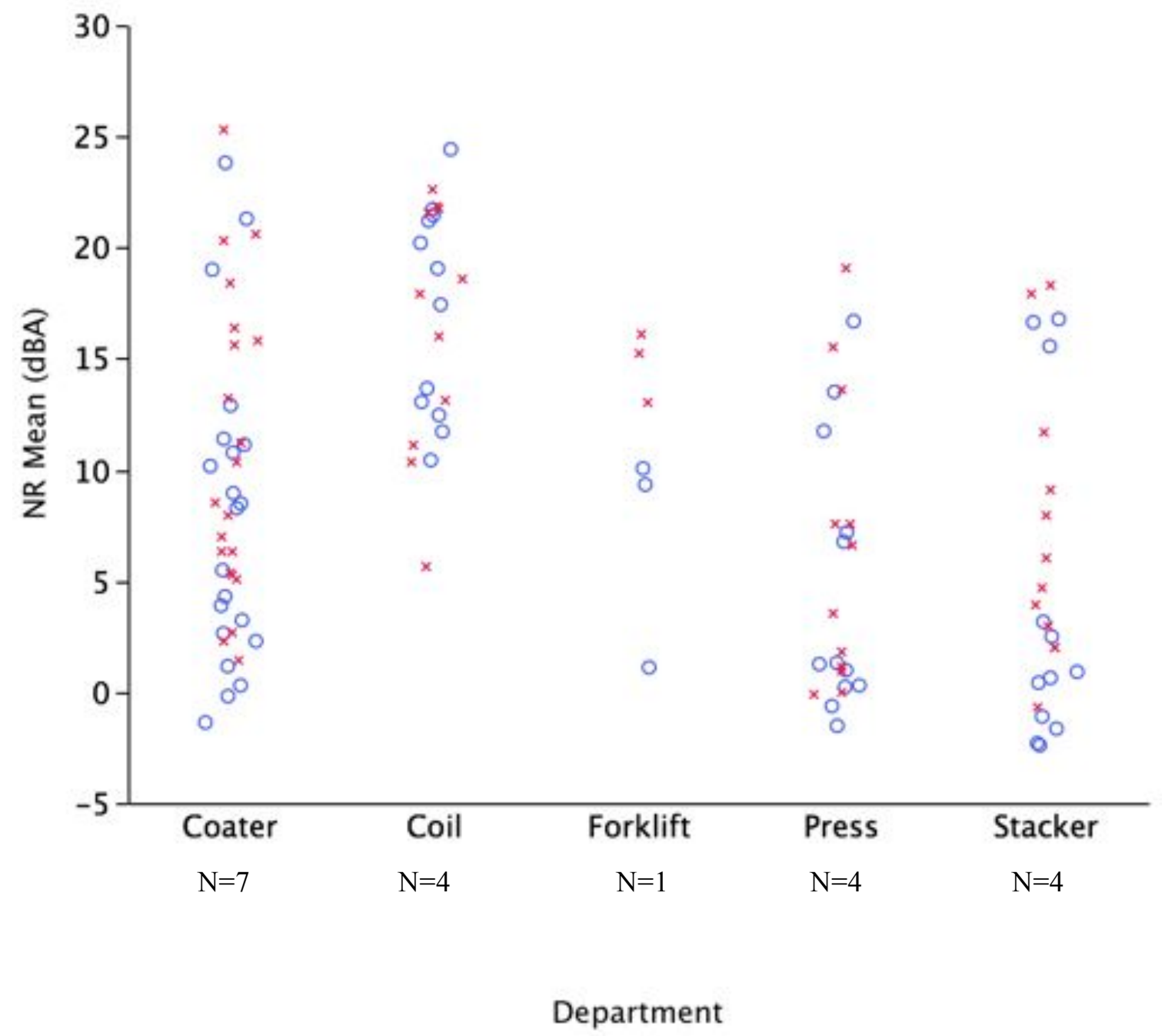

Figure 64. NR Mean versus department by light status (blue circle $=$ Light Deactivated, red X $=$ Light Activated)

\subsection{Effect of Department}

Figure 64 and Table 13 show NR mean for each department by light status. Four of five departments appear to show an increased NR during periods of Light Activation compared to periods of Light Deactivation. Note the forklift department appears to have the highest $\Delta \mathrm{NR}$ mean $(8.0 \mathrm{dBA})$. 
Table 13. Mean NR by department during periods of light deactivated and light activated

\begin{tabular}{ccccc}
\hline & \multicolumn{1}{c}{$\begin{array}{c}\text { Light } \\
\text { Deactivated } \\
\text { Department }\end{array}$} & $\mathrm{N}$ & $\begin{array}{c}\text { Light } \\
\text { Activated }\end{array}$ & $\Delta \mathrm{NR}$ \\
& & NR Mean (dBA) & NR Mean (dBA) & \\
\hline Coater & 21 & 8.0 & 10.7 & 2.7 \\
Coil & 12 & 17.2 & 16.4 & -0.8 \\
Forklift & 3 & 6.8 & 14.8 & 8.0 \\
Press & 12 & 4.8 & 6.4 & 1.6 \\
Stacker & 12 & 4.1 & 7.2 & 3.1 \\
All & 60 & 8.2 & 11.1 & 2.9 \\
& & $(\mathrm{SD}=5.3)$ & $(\mathrm{SD}=4.5)$ & \\
\hline
\end{tabular}

As suggested by observation of the high degree of overlap between different departments during periods of Light Activation and Light Deactivation, department was not an important factor with the exception of the forklift department (see Figure 64). Because the individual differences are also very important and there was only one individual in the forklift department, it was spurious to state a departmental difference when it could be an individual difference, as it was meaningless to assign one subject to a department. When the forklift department was removed from the statistical analysis there was no difference between departments during periods of Light Activated and Light Deactivated $(\mathrm{p}<0.1037)$. Therefore the contribution of Subject 17 to the variance will show up in the subject contribution, which is extremely high. Of course if you had more subjects per department, there may be a difference. However, with this limited data it was not found to be an important factor.

\subsection{Effects of Personal Characteristics}

As previously mentioned, the subjects recruited for the field study were diverse by age and duration of employment, and were predominately males. The following sections show NR mean by self-reported personal characteristics (age, gender and duration of employment). 


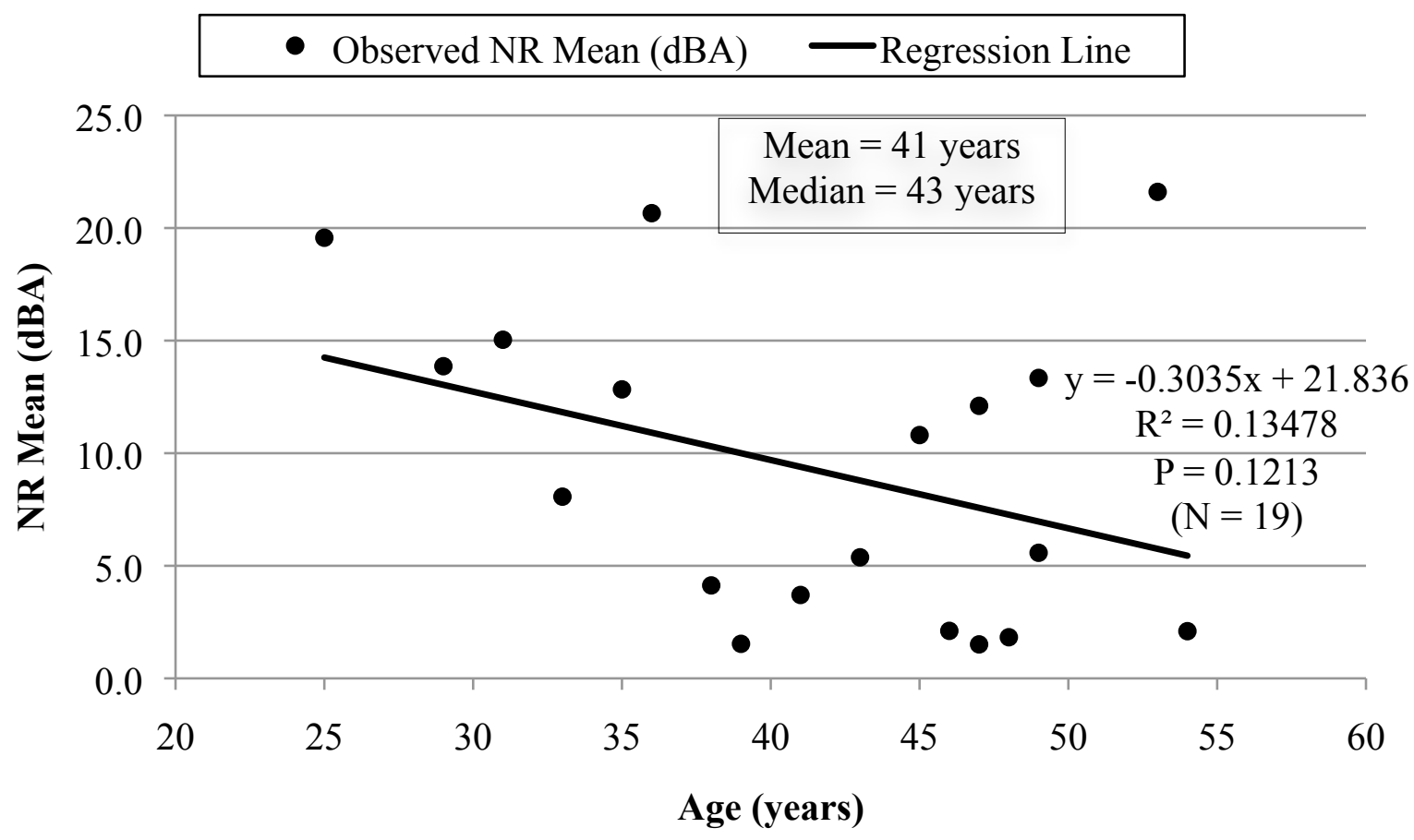

Figure 65. Age plotted against NR mean values

\subsubsection{Effect of Subject Age}

One might suppose that older subjects would experience greater mean NR than younger subjects because the older workers are likely to have more experience wearing hearing protectors and their maturity may induce better compliance in wearing protectors. However, there appears to be no systematic differences in $\mathrm{NR}_{\mathrm{A}}$ based on age for tested subjects (see Figure 65 and Table 14). Note the average subject age was 41 years $(\mathrm{SD}=8.3)$ with a median of 43 years.

The results of the linear regression analysis between age and NR mean are shown in Figure 65. The slope (-0.304) of the regression line on Figure 65 was not significantly different from zero ( $\mathrm{p}>0.12$ ), and the coefficient of determination $\mathrm{R}^{2}$ was 0.135 . 


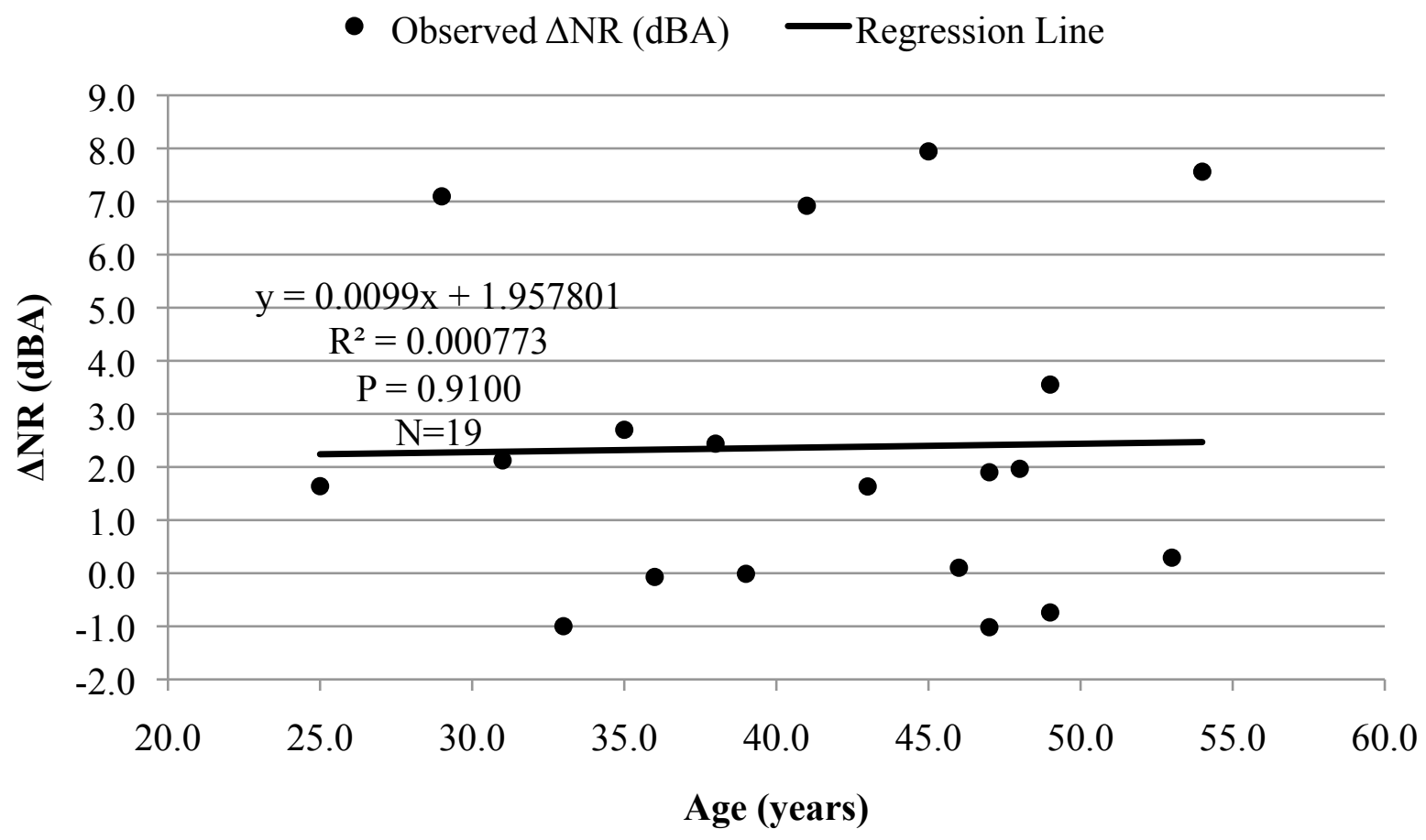

Figure 66. Age plotted against $\Delta \mathrm{NR}$ values

The results of the linear regression analysis between age and $\Delta$ NR are shown in Figure 66. The slope (-0.0099) of the regression line on Figure 66 was not significantly different from zero ( $\mathrm{p}>0.91$ ), and the coefficient of determination $\mathrm{R}^{2}$ was 0.00077 . 
Table 14. Descriptive statistics by personal characteristics

\begin{tabular}{ccccc}
\hline Subject & $\begin{array}{c}\text { Age } \\
\text { (years) }\end{array}$ & $\begin{array}{c}\text { Duration of } \\
\text { Experience } \\
\text { (years) }\end{array}$ & Gender & $\begin{array}{c}\text { NR Mean } \\
(\mathrm{dBA})\end{array}$ \\
\hline 2 & 41 & 17 & Male & 3.7 \\
3 & 33 & 4 & Male & 8.1 \\
4 & 43 & 5 & Male & 5.4 \\
5 & 25 & 5 & Male & 19.6 \\
6 & 53 & 12 & Male & 21.6 \\
7 & 46 & 9 & Male & 2.1 \\
8 & 29 & 1 & Male & 13.9 \\
9 & 36 & 11 & Male & 20.7 \\
11 & 48 & 11 & Female & 1.8 \\
12 & $39 *$ & Female & 1.5 \\
13 & $\mathrm{n} / \mathrm{a}$ & 12 & Male & 13.6 \\
14 & 47 & 13 & Male & 1.5 \\
15 & 47 & 19 & Male & 12.1 \\
16 & 49 & 6 & Male & 5.6 \\
17 & 45 & 12 & Female & 10.8 \\
18 & 49 & 10 & Male & 13.3 \\
19 & 38 & 10 & Female & 4.1 \\
20 & 35 & 11 & Male & 12.8 \\
21 & 54 & 4.5 & Female & 2.1 \\
22 & 31 & 4.5 & Male & 15.0 \\
& & & & \\
Overall & 41 & 9 & Male $=15$ & 9.5 \\
& $(\mathrm{SD}=8.3)$ & $(\mathrm{SD}=4.7)$ & Female $=5$ & \\
\hline
\end{tabular}

${ }^{*}$ Value not self reported by subject

Table 15. Descriptive statistics of NR Mean for male versus female

\begin{tabular}{cccccc}
\hline Subject Sex & $\mathrm{N}$ & $\begin{array}{c}\text { NR Mean } \\
(\mathrm{dBA})\end{array}$ & $\begin{array}{c}\text { NR Median } \\
(\mathrm{dBA})\end{array}$ & $\begin{array}{c}\text { NR Std Dev } \\
(\mathrm{dBA})\end{array}$ & $\begin{array}{c}\Delta \text { NR Mean } \\
(\mathrm{dBA})\end{array}$ \\
\hline $\mathrm{F}$ & 5 & 4.1 & 2.1 & 3.9 & 4.0 \\
$\mathrm{M}$ & 15 & 11.3 & 12.8 & 6.6 & 1.4 \\
Overall & 20 & 7.7 & 7.5 & 5.3 & \\
\hline
\end{tabular}




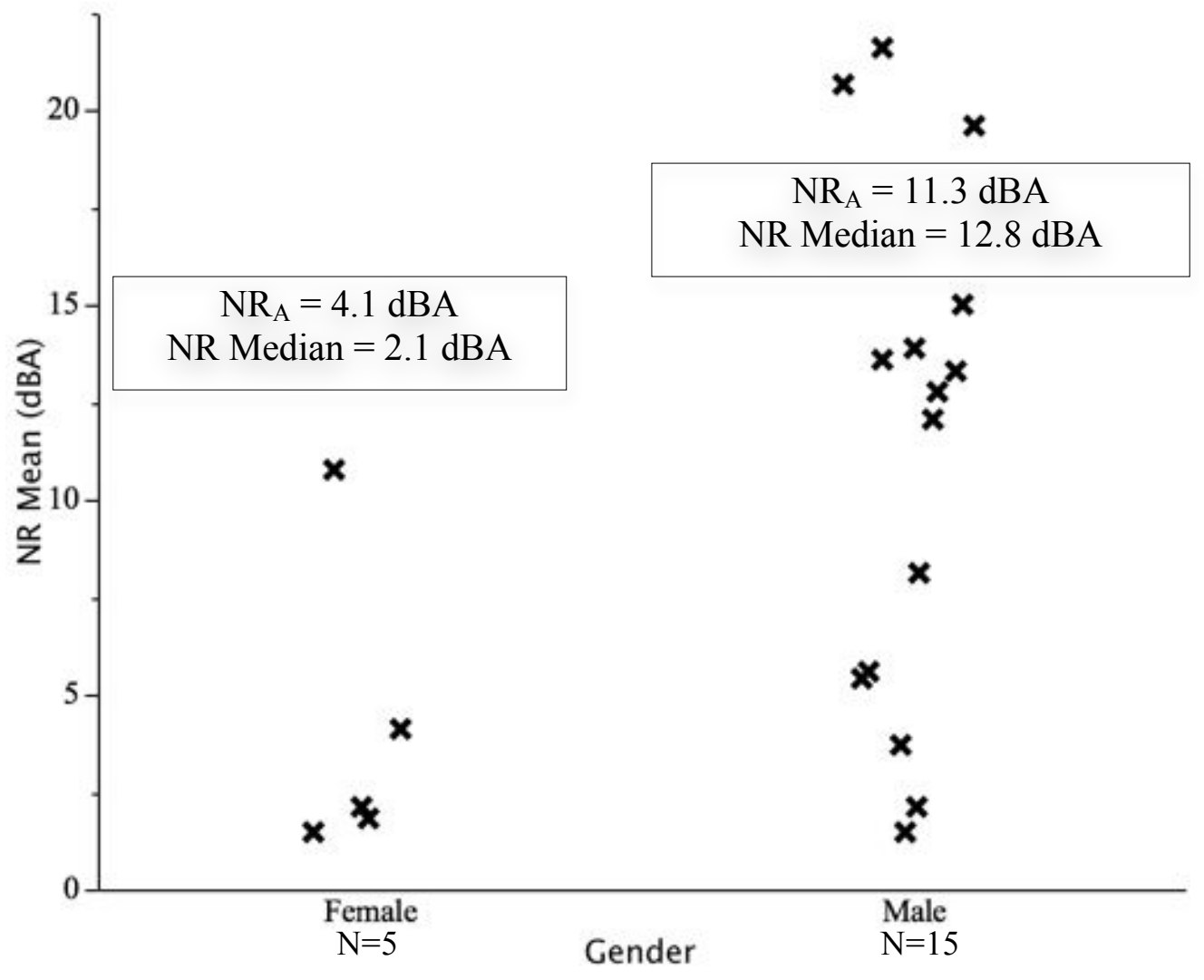

Figure 67. Gender plotted against NR Mean values

\subsubsection{Effect of Subject Gender}

It was expected that the 5 female subjects would experience greater NR than the 15 male subjects, because females tend to be more rule-abiding than males (Portillo and DeHart-Davis, 2009). However, results of the 6 tests per subject (see Figure 67 and Table 15) indicate that NR was higher for males than females. Hence, females had great room for improvement. However, when $\Delta \mathrm{NR}$ is compared for males and females it appears that females have higher $\Delta \mathrm{NR}$, but still have low mean NRs overall (NR mean $=4.1 \mathrm{dBA})$. In other words, while the men may have had a higher overall mean noise reduction, the women displayed a greater change (though still modest) in NR pre- and post- treatment (see Figure 67). According to Abel, et. al. (1990), women typically have smaller ear canals than men, resulting in a poorer seal of the HPD to the 
ear canal. Therefore, an alternative explanation could be that the tested HPDs were one size and fit females poorly.

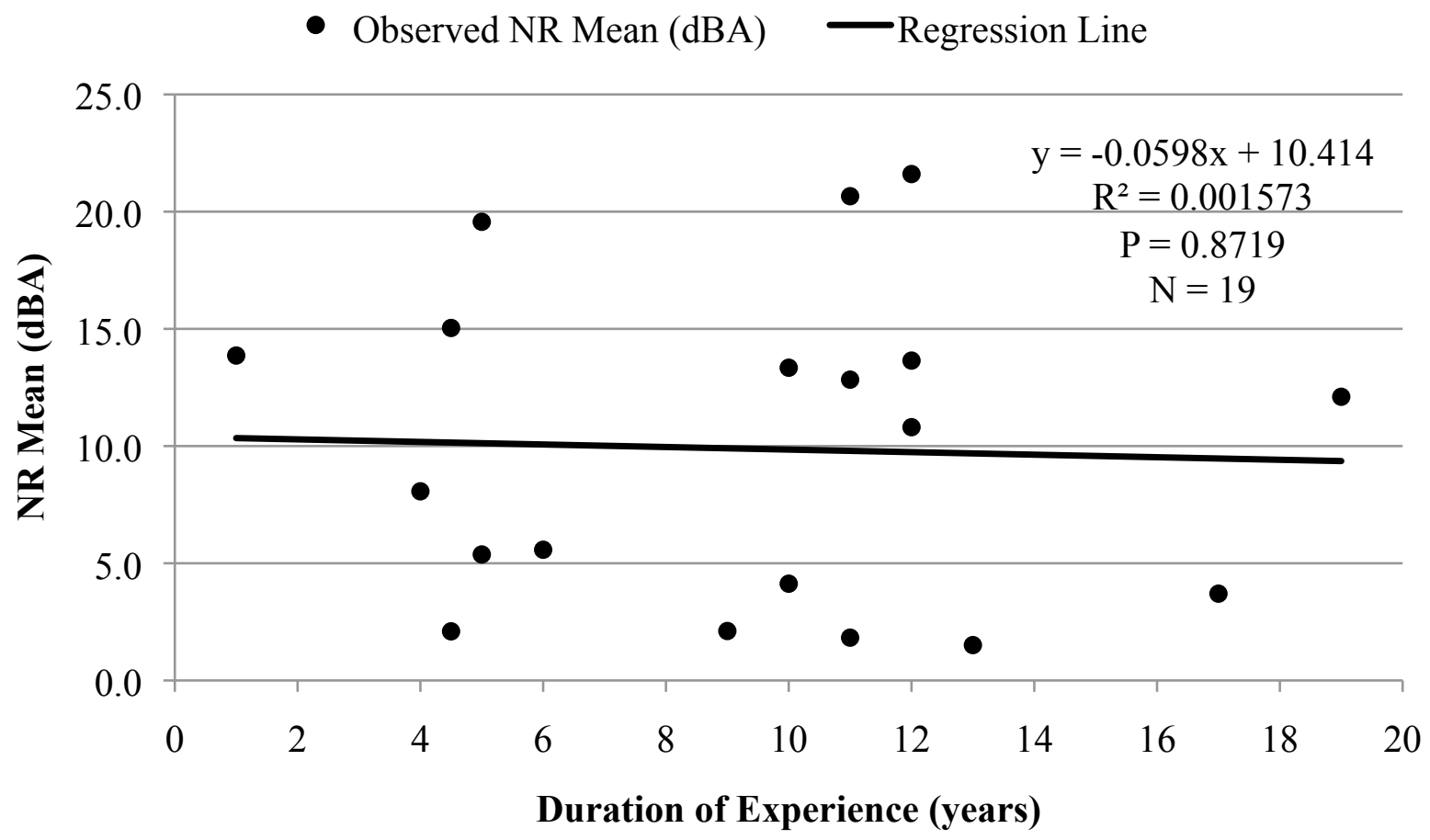

Figure 68. Duration of Employment plotted against NR Mean values

\subsubsection{Effect of Subject Duration of Employment}

One might expect that because the facility had a zero tolerance policy for failure to wear HPDs, that the longer a worker was employed at the facility, the greater the NR value would be, if only because non-compliant employees would be "weeded out" over time. As can be seen in Figure 68 and shown quantitatively in Table 13, duration of employment does not appear to have had a consistent effect on NR for this group of subjects. Note the average subject experience at the metal products facility was 9 years $(\mathrm{SD}=4.7)$ with a median of 10 years.

As listed in Figure 68, the slope (-0.060) of the regression line was not significantly different from zero $(\mathrm{p}=0.872)$, and the coefficient of determination $\mathrm{R}^{2}$ was 0.002 . 


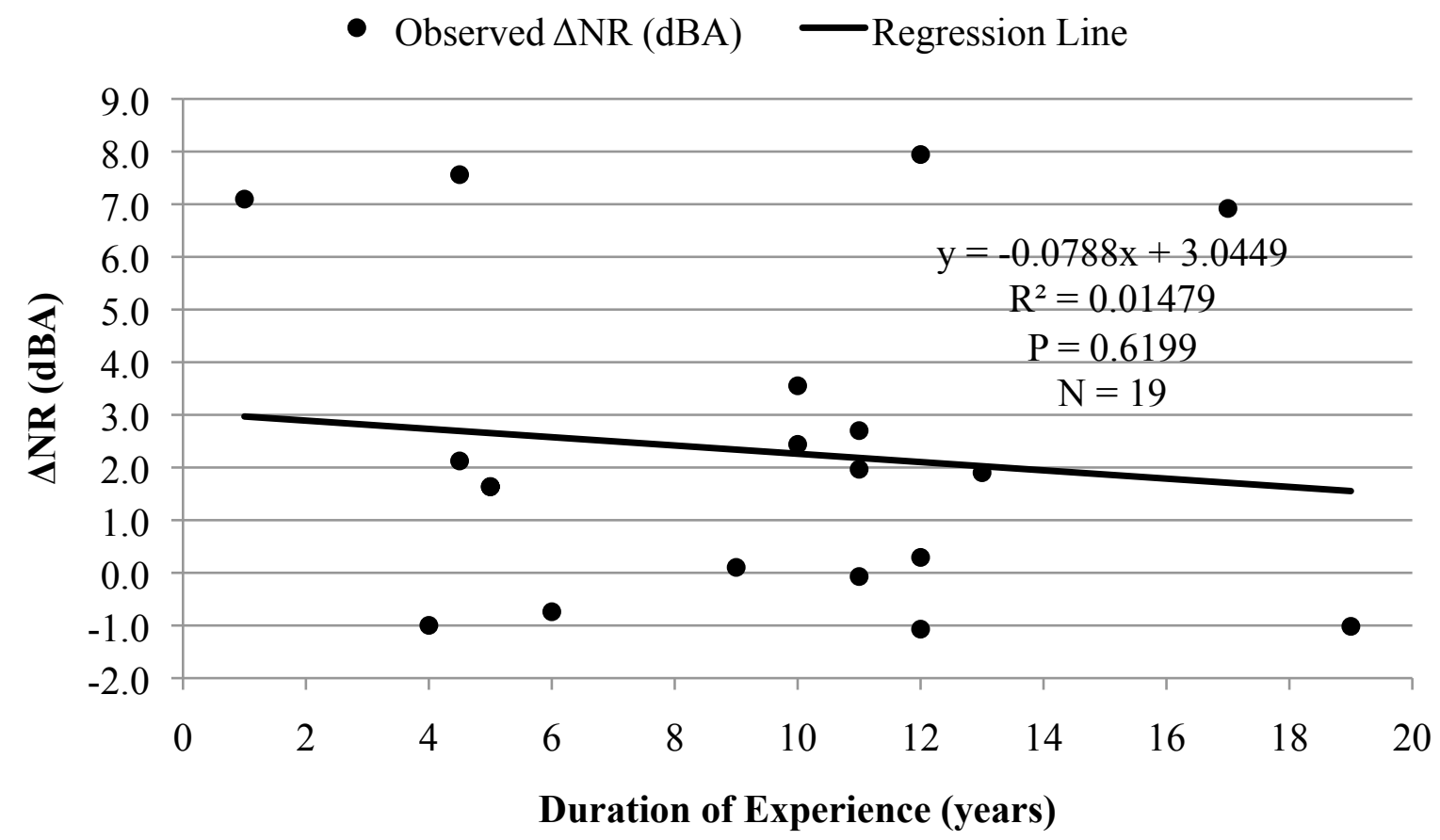

Figure 69. Duration of Employment plotted against $\Delta$ NR Mean values

The results of the linear regression analysis between duration of employment and $\Delta \mathrm{NR}$ are shown in Figure 69. The slope (-0.079) of the regression line on Figure 69 was not significantly different from zero $(\mathrm{p}=0.620)$, and the coefficient of determination $\mathrm{R}^{2}$ was 0.015 . 


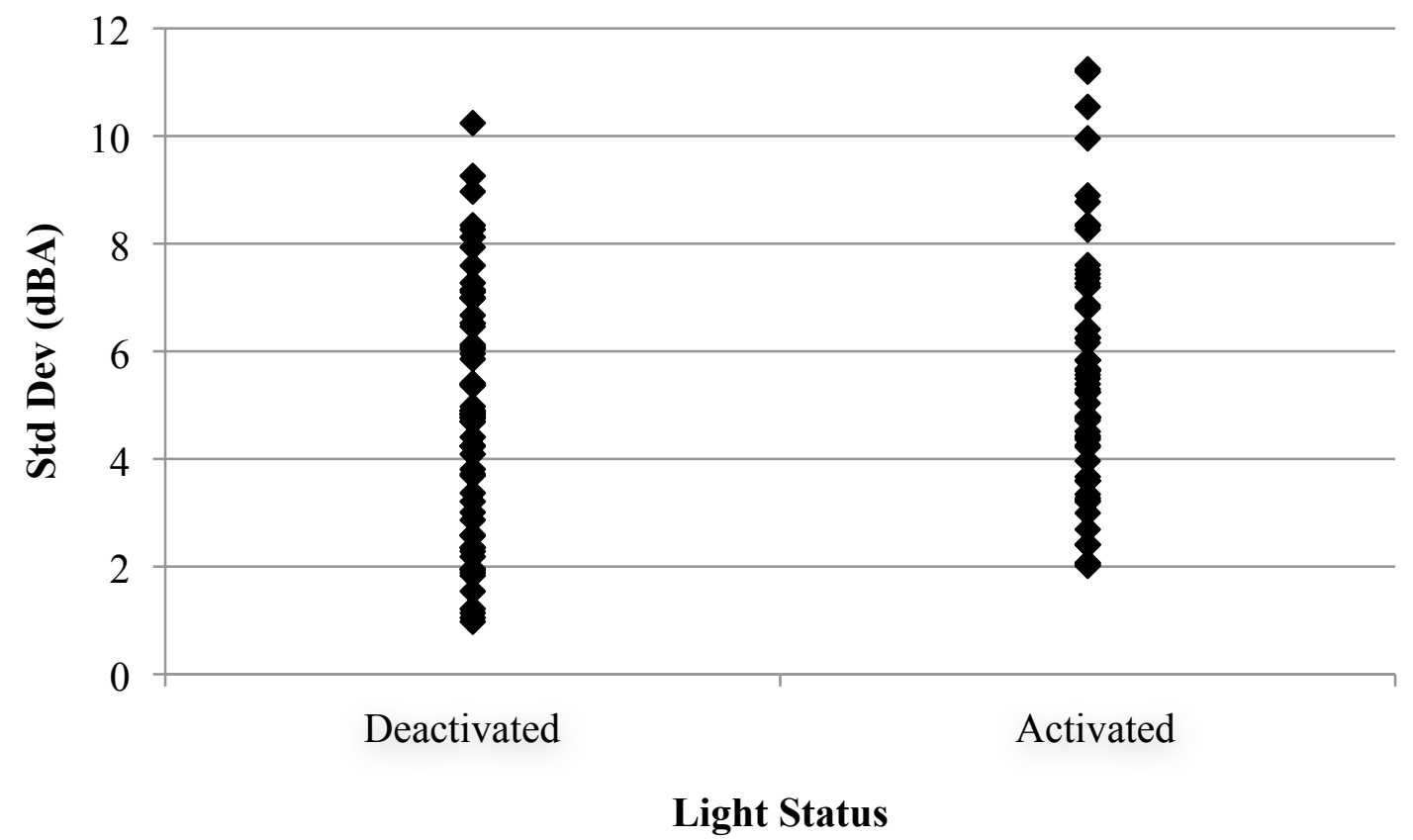

Figure 70. Standard deviation plotted against light status

\subsection{Light Deactivated SD compared to Light Activated SD}

As can be seen in Figure 70 and Table 16, the Light Deactivated SD (4.8 dBA) appears to be slightly different from the Light Activated SD (5.6 dBA). F-Test showed that the difference was not significant at $\alpha=5 \%(\mathrm{p}=0.0598)$. 
Table 16. Standard deviation $\left(\mathrm{SPL}_{\text {sh }}>80\right)$ plotted by light status

\begin{tabular}{cccc}
\hline Light Status & $\mathrm{N}$ & $\begin{array}{c}\text { Mean } \\
(\mathrm{dBA})\end{array}$ & $\begin{array}{c}\text { Std Dev } \\
(\mathrm{dBA})\end{array}$ \\
\hline Deactivated & 60 & 4.8 & 2.3 \\
Activated & 60 & 5.6 & 2.3 \\
\hline
\end{tabular}

Figure 17 shows the ANOVA of light status on NR standard deviation.

Table 17. ANOVA of light status on NR Std Dev

\begin{tabular}{cccccc}
\hline Source & df & $\begin{array}{c}\text { Sums of } \\
\text { Squares }\end{array}$ & $\begin{array}{c}\text { Mean } \\
\text { Square }\end{array}$ & F-Ratio & Prob \\
\hline Constant & 1 & 18.89 & 18.89 & 3.62 & 0.0598 \\
Light Status & 1 & 18.89 & 5.23 & 3.62 & 0.0598 \\
Error & 117 & 611.89 & & & \\
Total & 118 & 630.78 & & & \\
\hline
\end{tabular}




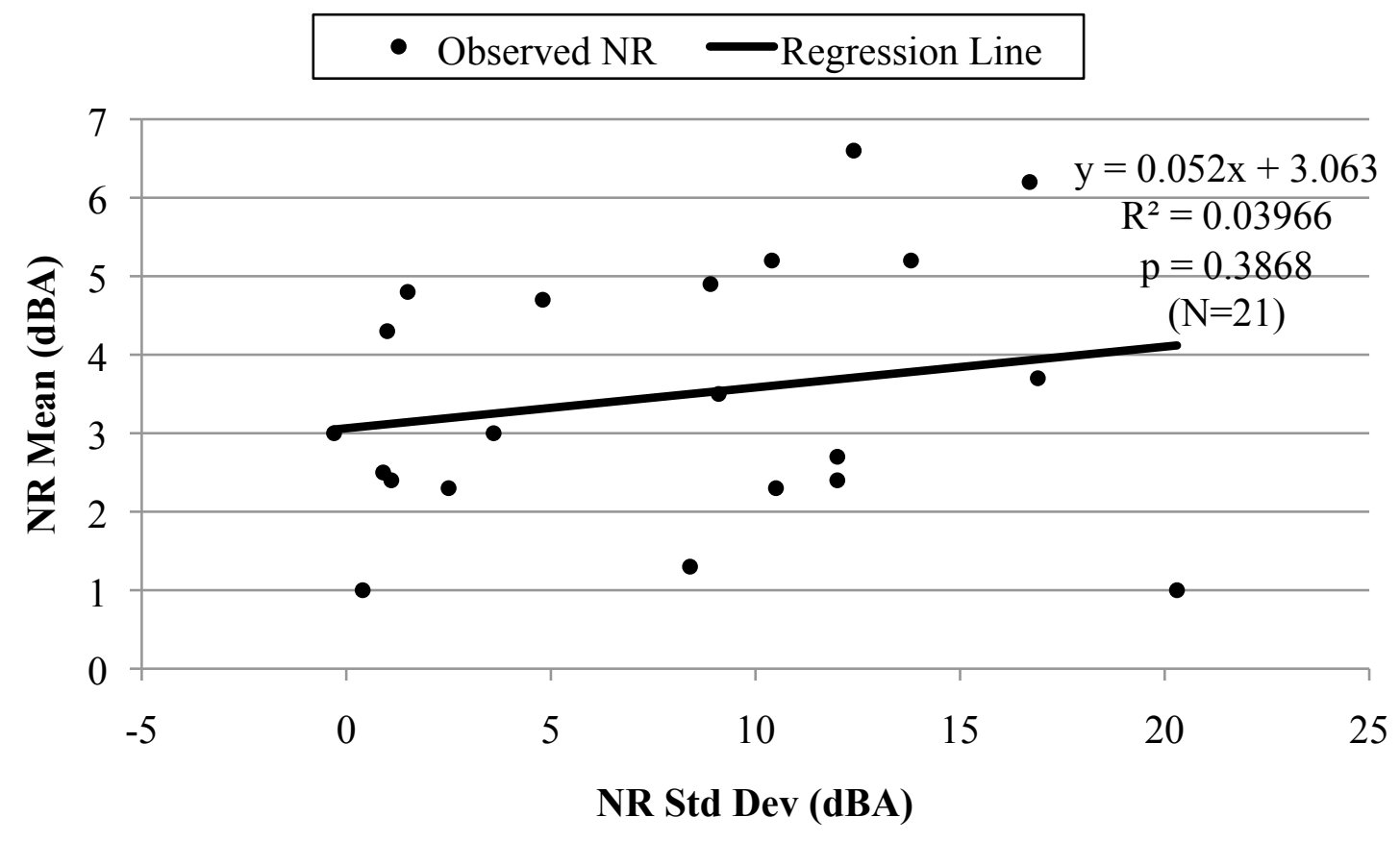

Figure 71. NR std dev plotted against NR mean

It was expected that the higher the NR mean, the lower the standard deviation. However, as can be seen in Figure 71, the slope (0.052) of the regression line was not significantly different from zero ( $\mathrm{p}>0.387$ ), and the coefficient of determination $\mathrm{R}^{2}$ was 0.040 . 
The ANOVA of light status, subject, cycle and interactions results from the field study are displayed in Table 18.

Table 18. ANOVA of light status, subject, cycle and interactions on NR mean

\begin{tabular}{cccccc}
\hline Source & df & $\begin{array}{c}\text { Sums of } \\
\text { Squares }\end{array}$ & $\begin{array}{c}\text { Mean } \\
\text { Square }\end{array}$ & F-Ratio & Prob \\
\hline Constant & 1 & 10460.7 & 10460.7 & 702.54 & 0.0001 \\
Subject & 19 & 5087.22 & 267.748 & 17.982 & 0.0001 \\
Cycle & 2 & 64.1305 & 32.0653 & 2.1535 & 0.1218 \\
Light Status & 1 & 146.147 & 146.147 & 9.8152 & 0.0023 \\
Cycle * Light Status & 2 & 19.7145 & 9.85724 & 0.66201 & 0.5182 \\
Error & 94 & 1399.65 & 14.8898 & & \\
Total & 118 & 6700.73 & & & \\
\hline
\end{tabular}

As is often the case with studies involving human subjects, subject differences were the most important variable $(\mathrm{p}=0.0001)$. As expected, cycle was not an important variable in this study ( $\mathrm{p}=0.1218)$. Table 19 and 20 show ANOVA of all periods and period (one). Both are significant, possibly because representing effects of light.

Table 19. ANOVA of all periods on NR mean

\begin{tabular}{cccccc}
\hline Source & df & $\begin{array}{c}\text { Sums of } \\
\text { Squares }\end{array}$ & $\begin{array}{c}\text { Mean } \\
\text { Square }\end{array}$ & F-Ratio & Prob \\
\hline Constant & 1 & 10460.7 & 10460.7 & 702.5 & 0.0001 \\
Subject & 19 & 5087.2 & 267.7 & 18.0 & 0.0001 \\
All Periods & 5 & 230.4 & 46.1 & 3.1 & 0.0125 \\
Error & 94 & 1399.7 & 14.9 & & \\
Total & 118 & 6700.7 & & & \\
\hline
\end{tabular}


Table 20. ANOVA of period $(=1)$ on NR mean

\begin{tabular}{cccccc}
\hline Source & df & $\begin{array}{c}\text { Sums of } \\
\text { Squares }\end{array}$ & $\begin{array}{c}\text { Mean } \\
\text { Square }\end{array}$ & F-Ratio & Prob \\
\hline Constant & 1 & 10460.7 & 10460.7 & 693.1 & 0.0001 \\
Subject & 19 & 5081.9 & 267.5 & 17.7 & 0.0001 \\
Period $=1$ & 1 & 150.9 & 150.9 & 10.0 & 0.0021 \\
Error & 98 & 1479.2 & 15.1 & & \\
Total & 118 & 6700.7 & & & \\
\hline
\end{tabular}

One might expect that providing quantitative feedback would help individual workers recognize that their HPD is either not properly seated or is not in place when needed. The expectation was that workers would wear their HPDs a larger fraction of the time when noise levels in their ears exceeded $80 \mathrm{dBA}$. Likewise, it was expected that a worker whose HPD was on but not properly seated would be induced to re-position or otherwise re-fit the HPD if the light came on. Therefore, the anticipated changes in behavior due to signaling were expected to produce effectively higher $\mathrm{NR}_{\mathrm{A}}$ values than would occur when no signaling was activated. The results of the field study indicated that changes in behavior due to signaling produced moderately higher NR mean values ( $\triangle \mathrm{NR}=2.2 \mathrm{dBA})$ than occurred when no signaling was activated, suggesting that the signal light moderately increased the average NR for workers when activated and therefore may reduce noise induced hearing loss $(\mathrm{p}=0.0023)$.

Any behavioral intervention based on the assumption that motivation is both the problem and the answer could fall short if the poor fits experienced by many of these workers is representative of what is achieved elsewhere. It is important to note that the investigator observed individual workers repeatedly and obviously trying to obtain a better fit, yet their NR were still dismal throughout. This could be due to poor technique, suggesting additional training may be effective but it certainly makes it clear to this investigator that motivation was not the problem and therefore not the solution. 


\section{CHAPTER 8: COMPARING NR MEAN FOR FIT-TEST TO NR MEAN DURING PERIODS OF LIGHT ACTIVATION}

\subsection{Purpose}

This study tested the overall effect of fit-testing workers while they stood in place at their workstation during otherwise normal work at a metal products manufacturing facility. The expectation was that NR mean values from the fit-test would be equal to or higher than NR mean values during periods of Light Activation. Furthermore, the variability of the NR mean values during the fit-test were expected to be lower than during periods of Light Activation because subjects were standing mostly still during the fit-test.

\subsection{Background}

Berger (2007), Hager (2007) and Neitzel et. al. (2005) suggests that a personal fit-test is a better indicator of hearing protection than relying on the published NRR during field use. If fittesting workers at their workstation accurately represented their NR mean during periods of Light Activation, one could predict a workers best NR with this short duration fit-test.

\subsection{Apparatus}

This study used the same apparatus used in the main field study (see Chapters 3).

\subsection{Methods}

During times that were as randomly selected as possible, the investigator carried out a fittest on 18 subjects during their normal work shift. The fit-test required subjects while standing in place at their workstation to remove and drape both earplugs at their shoulders and on the investigator's signal (30 seconds later), insert them back into their ears as they normally would. The investigator recorded the start time of each fit-test. Due to constraints outside the investigator's control, fit-test times varied by subject.

The fit-test NR mean values were compared to NR mean values achieved by subjects during periods of Light Activation (i.e., periods 2, 4, 6). The NR mean values during periods of Light Activation were used as a comparison because the field values were assumed to be the subject's 
best achieved fit. Because the investigator did not have the planned period of time of at least 30 seconds for each subject standing still, the effect of fit-test was analyzed using three subjective

rules: 20 second NR mean, maximum flat NR, and the 60 second NR mean. Each subjective rule will be discussed further below.

\subsubsection{Step-By-Step Procedures for 20 Second NR Mean Rule}

An example of the 20 second NR mean rule being applied to Subject 5 is shown in Table 21. Using the 20 second NR mean rule, the following steps were applied to 18 subjects:

1. Using the recorded fit-test start time by the investigator, the second-by-second NR values were observed by the investigator in consecutive order until a NR value $\geq 3$ $\mathrm{dBA}$ was identified. Noise reduction values during times of plugs out varied by 2 $\mathrm{dBA}$ and therefore the assumption was that the value of $<3 \mathrm{dBA}$ indicated that the hearing protection was inserted into the workers ear canal.

2. After 60 seconds (allowing the foam earplug to expand completely) from the identified value in step 1, the average of the next 20 second consecutive interval was calculated and recorded as the NR mean value for the fit test.

3. If more than one fit test was carried out on a subject, the average of both 20 second NR mean results would be used as the NR mean value.

Subject 21 was excluded from the 20 second NR mean analysis because NR values $\geq 3 \mathrm{dBA}$ were not achieved after the fit-test. 
Table 21. Example of calculating the 60 second NR rule for Subject $5(\cdots=$ hidden rows $)$

\begin{tabular}{|c|c|c|c|c|c|}
\hline Subject & $\begin{array}{c}\text { Time } \\
\text { (second ) }\end{array}$ & $\begin{array}{l}\mathrm{SPL}_{\mathrm{sh}} \\
(\mathrm{dBA})\end{array}$ & $\begin{array}{l}\mathrm{SPL}_{\text {ear }} \\
(\mathrm{dBA})\end{array}$ & $\mathrm{NR}(\mathrm{dB})$ & 60 Second Rule \\
\hline 5 & $17: 13: 23$ & 87.1 & 60.1 & 27 & Pre Fit Test \\
\hline 5 & $17: 13: 24$ & 86.5 & 62.7 & 23.8 & Pre Fit Test \\
\hline 5 & $17: 13: 25$ & 85.4 & 84 & 1.4 & Fit Test \\
\hline 5 & $17: 13: 26$ & 84.9 & 87 & -2.1 & Fit Test \\
\hline 5 & $17: 13: 27$ & 85.2 & 85.6 & -0.4 & Fit Test \\
\hline 5 & & $\cdots$ & $\cdots$ & $\cdots$ & $\cdots$ \\
\hline 5 & 17:14:09 & 85.7 & 83.8 & 1.9 & Fit Test \\
\hline 5 & $17: 14: 10$ & 88.5 & 86.5 & 2 & Fit Test \\
\hline 5 & $17: 14: 11$ & 87.8 & 88 & -0.2 & Fit Test \\
\hline 5 & $17: 14: 12$ & 90.2 & 87 & 3.2 & Value $\geq 3 \mathrm{~dB}$ \\
\hline 5 & $17: 14: 13$ & 90.1 & 88.4 & 1.7 & second 2 \\
\hline 5 & $17: 14: 14$ & 89.6 & 87.6 & 2 & second 3 \\
\hline 5 & $17: 14: 15$ & 87.9 & 86.6 & 1.3 & second 4 \\
\hline 5 & & $\ldots$ & $\ldots$ & $\ldots$ & \\
\hline 5 & $17: 15: 09$ & 84.9 & 59.6 & 25.3 & second 58 \\
\hline 5 & $17: 15: 10$ & 85.1 & 59.6 & 25.5 & second 59 \\
\hline 5 & $17: 15: 11$ & 85.2 & 59.9 & 25.3 & second 60 \\
\hline 5 & $17: 15: 12$ & 85.2 & 60 & 25.2 & Average \\
\hline 5 & $17: 15: 13$ & 85.6 & 59.8 & 25.8 & Average \\
\hline 5 & $17: 15: 14$ & 86 & 59.9 & 26.1 & Average \\
\hline 5 & $17: 15: 15$ & 85.9 & 59.7 & 26.2 & Average \\
\hline 5 & $17: 15: 16$ & 88.1 & 59.6 & 28.5 & Average \\
\hline 5 & $17: 15: 17$ & 88.8 & 60.9 & 27.9 & Average \\
\hline 5 & $17: 15: 18$ & 87.5 & 61.6 & 25.9 & Average \\
\hline 5 & $17: 15: 19$ & 87.5 & 60.4 & 27.1 & Average \\
\hline 5 & $17: 15: 20$ & 88 & 61.5 & 26.5 & Average \\
\hline 5 & $17: 15: 21$ & 87.7 & 61.9 & 25.8 & Average \\
\hline 5 & $17: 15: 22$ & 87.4 & 61.9 & 25.5 & Average \\
\hline 5 & $17: 15: 23$ & 87 & 61.7 & 25.3 & Average \\
\hline 5 & $17: 15: 24$ & 87.4 & 60.9 & 26.5 & Average \\
\hline 5 & $17: 15: 25$ & 88.2 & 60.4 & 27.8 & Average \\
\hline 5 & $17: 15: 26$ & 87.3 & 60.9 & 26.4 & Average \\
\hline 5 & $17: 15: 27$ & 86.3 & 60.3 & 26 & Average \\
\hline 5 & $17: 15: 28$ & 86.4 & 59.9 & 26.5 & Average \\
\hline 5 & $17: 15: 29$ & 86.5 & 60.3 & 26.2 & Average \\
\hline 5 & $17: 15: 30$ & 85.9 & 59.8 & 26.1 & Average \\
\hline 5 & $17: 15: 31$ & 87.2 & 58.6 & 28.6 & Average \\
\hline 5 & $17: 15: 32$ & 89.5 & 59.5 & 30 & Post Fit Test \\
\hline 5 & $17: 15: 33$ & 92.4 & 60.7 & 31.7 & Post Fit Test \\
\hline
\end{tabular}




\subsubsection{Step-by-step procedures for Maximum Flat NR Rule}

The second rule used to analyze the fit-test results was the maximum flat NR. For this rule, the following steps were applied to 18 subjects:

1. Using recorded start time of the fit test, the computed second-by-second NR values were observed by the investigator until an observed maximum plateau was identified.

2. The maximum NR value identified by the investigator in step 1 was used as the fittest NR mean.

Note the maximum value during the observed flat period was expected to be the subject's best NR value.

\subsubsection{Step-by-step procedures for 60 Second $N_{A}$ Rule}

For the 60 second NR mean rule, the following steps were applied to 18 subjects:

1. Using the investigator's recorded start time of fit-test, the second-by-second NR values were observed by the investigator until the 60 second value was identified.

2. Using the identified value in step 1 , the average of the next 60 second consecutive interval was calculated and recorded as the NR mean for the fit-test. 


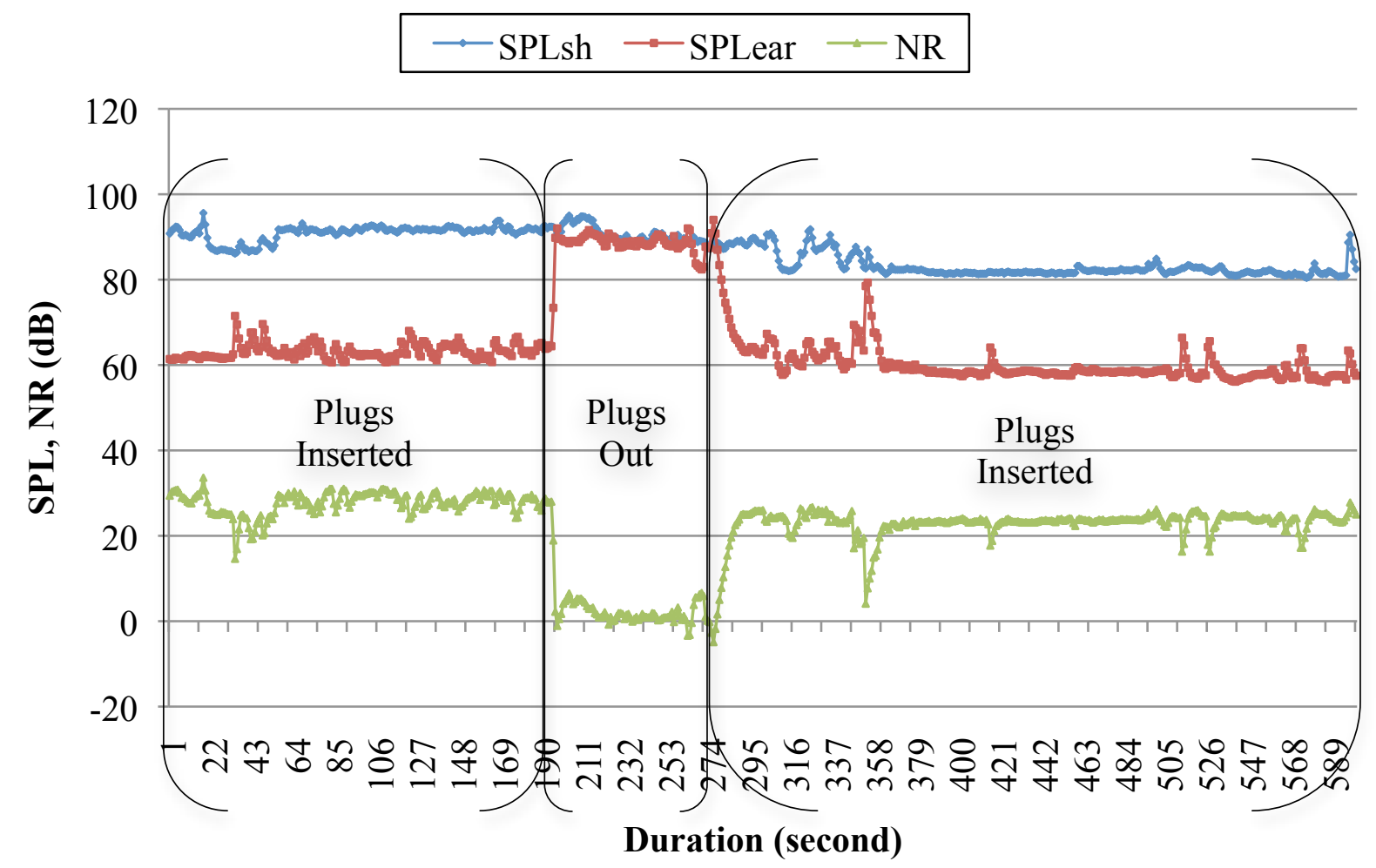

Figure 72. Second-by-second results for Subject 9

\subsection{Results}

As shown in Figure 72, the computed NR was observed to decrease to near zero during the earplugs out period and rapidly increase after reinsertion of earplugs. Subject 9 illustrates a pattern where NR values appear to show less variability during the period after earplug reinsertion than prior to the removal of earplugs. 


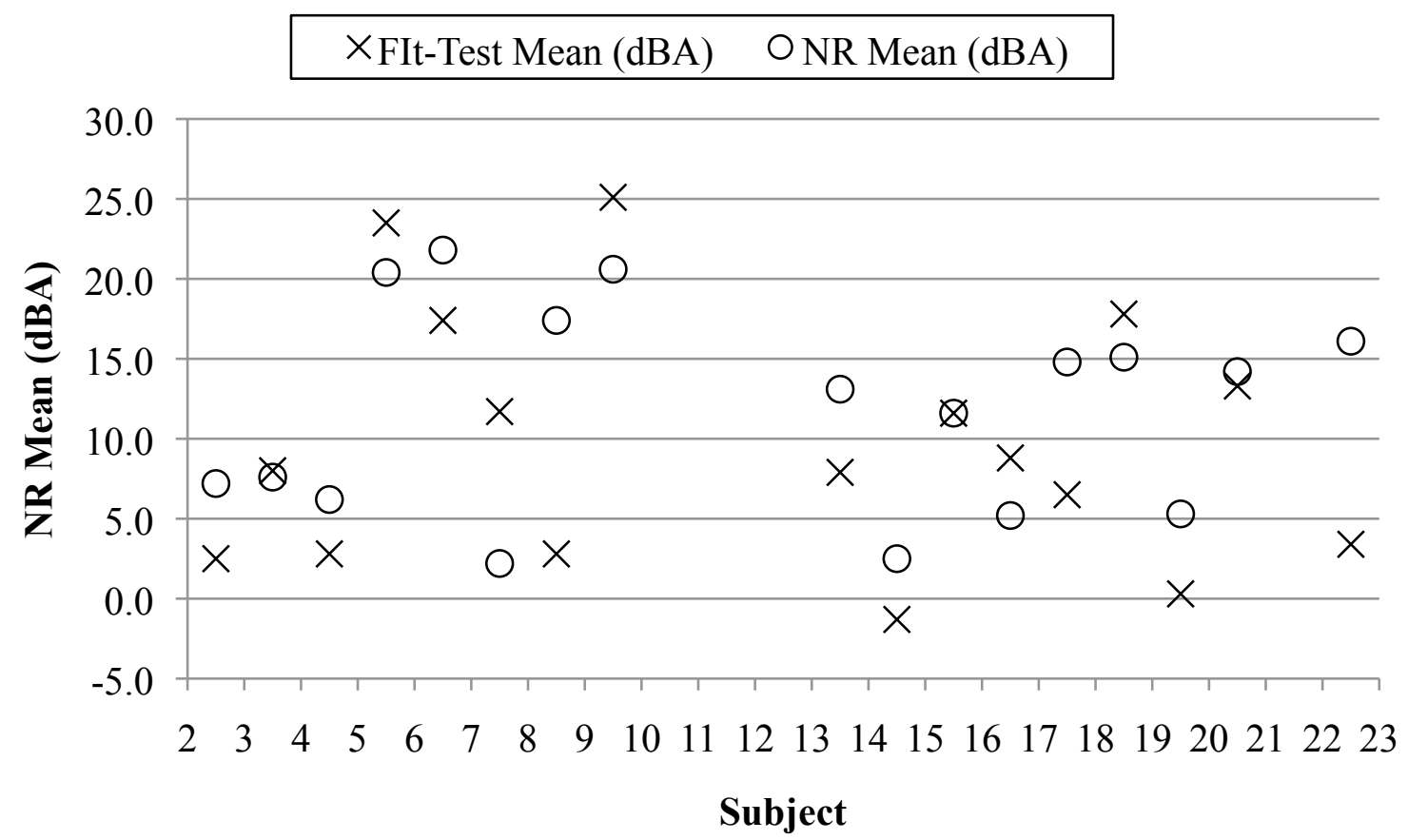

Figure 73. NR mean versus fit test mean 
Table 22. NR mean "20 second" fit-test compared to NR mean during periods of light Activation ( $\mathrm{N}=17)$

\begin{tabular}{|c|c|c|c|}
\hline Subject & $\begin{array}{c}\text { NR Mean Field } \\
\text { Fit Test } \\
20 \text { Second NR Mean Rule } \\
(\mathrm{dBA})\end{array}$ & $\begin{array}{l}\text { NR Mean Light Activation } \\
\text { (dBA) }\end{array}$ & $\Delta \mathrm{NR}$ Mean \\
\hline 2 & 2.5 & 7.2 & -4.7 \\
\hline 3 & 8.0 & 7.6 & 0.4 \\
\hline 4 & 2.8 & 6.2 & -3.4 \\
\hline 5 & 23.5 & 20.4 & 3.1 \\
\hline 6 & 17.4 & 21.8 & -4.4 \\
\hline 7 & 11.7 & 2.2 & 9.5 \\
\hline 8 & 2.8 & 17.4 & -14.6 \\
\hline 9 & 25.1 & 20.6 & 4.5 \\
\hline 13 & 7.9 & 13.1 & -5.2 \\
\hline 14 & -1.3 & 2.5 & -3.8 \\
\hline 15 & 11.6 & 11.6 & 0 \\
\hline 16 & 8.8 & 5.2 & 3.6 \\
\hline 17 & 6.5 & 14.8 & -8.3 \\
\hline 18 & 17.8 & 15.1 & 2.7 \\
\hline 19 & 0.3 & 5.3 & -5 \\
\hline 20 & 13.3 & 14.2 & -0.9 \\
\hline 22 & 3.4 & 16.1 & -12.7 \\
\hline All & $\begin{array}{c}9.5 \\
(\mathrm{SD}=7.8)\end{array}$ & $\begin{array}{c}11.8 \\
(\mathrm{SD}=6.4)\end{array}$ & -2.3 \\
\hline
\end{tabular}




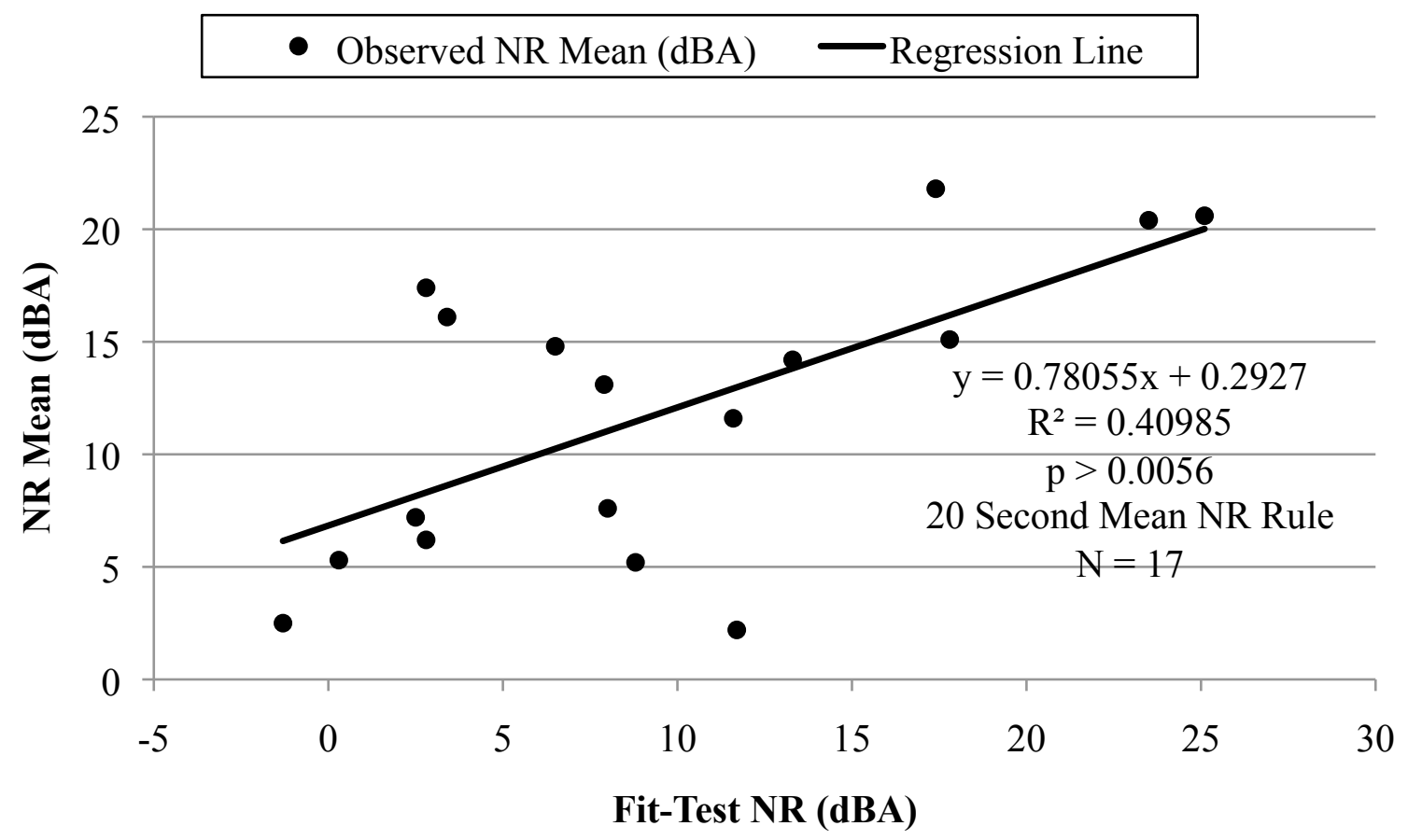

Figure 74. Comparison of NR Mean during fit test and during periods of Light Activated

\subsubsection{Second NR Mean Rule}

As shown in Figures 73, 74 and Table 22, fit-test NR mean values appear to be associated with NR mean Light Activation values when applying the 60 second NR rule.

The results of the linear regression analysis between age and $\Delta \mathrm{NR}$ are shown in Figure 74. The slope (0.781) of the regression line on Figure 74 was significantly different from zero ( $p>$ 0.0056 at $\alpha=5 \%$ ), and the coefficient of determination $R^{2}$ was 0.40985 . 


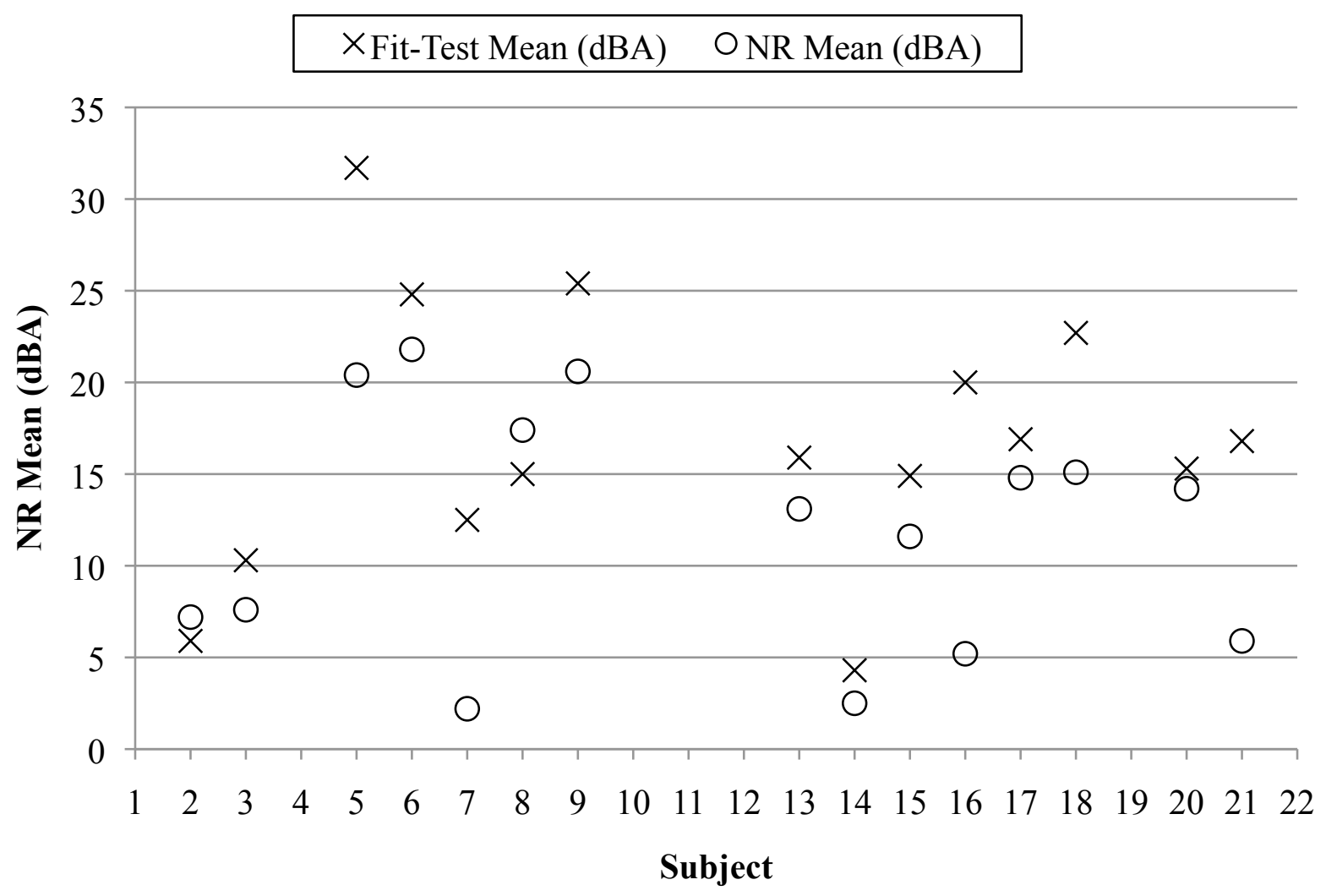

Figure 75. NR mean versus fit test mean 
Table 23. NR mean "maximum flat NR fit-test compared to NR mean during periods of light activation $(\mathrm{N}=15)$

\begin{tabular}{|c|c|c|c|}
\hline Subject & $\begin{array}{c}\text { NR Mean Field } \\
\text { Fit Test } \\
\text { Maximum Flat NR Rule } \\
(\mathrm{dBA})\end{array}$ & $\begin{array}{l}\text { NR Mean Light } \\
\text { Activation (dBA) }\end{array}$ & $\Delta$ NR Mean \\
\hline 2 & 5.9 & 7.2 & -1.3 \\
\hline 3 & 10.3 & 7.6 & 2.7 \\
\hline 5 & 31.7 & 20.4 & 11.3 \\
\hline 6 & 24.8 & 21.8 & 3 \\
\hline 7 & 12.5 & 2.2 & 10.3 \\
\hline 8 & 15.0 & 17.4 & -2.4 \\
\hline 9 & 25.4 & 20.6 & 4.8 \\
\hline 13 & 15.9 & 13.1 & 2.8 \\
\hline 14 & 4.3 & 2.5 & 1.8 \\
\hline 15 & 14.9 & 11.6 & 3.3 \\
\hline 16 & 20.0 & 5.2 & 14.8 \\
\hline 17 & 16.9 & 14.8 & 2.1 \\
\hline 18 & 22.7 & 15.1 & 7.6 \\
\hline 20 & 15.3 & 14.2 & 1.1 \\
\hline 21 & 16.8 & 5.9 & 10.9 \\
\hline All & $\begin{array}{c}16.8 \\
(\mathrm{SD}=7.3)\end{array}$ & $\begin{array}{c}12.0 \\
(\mathrm{SD}=6.6)\end{array}$ & 4.9 \\
\hline
\end{tabular}




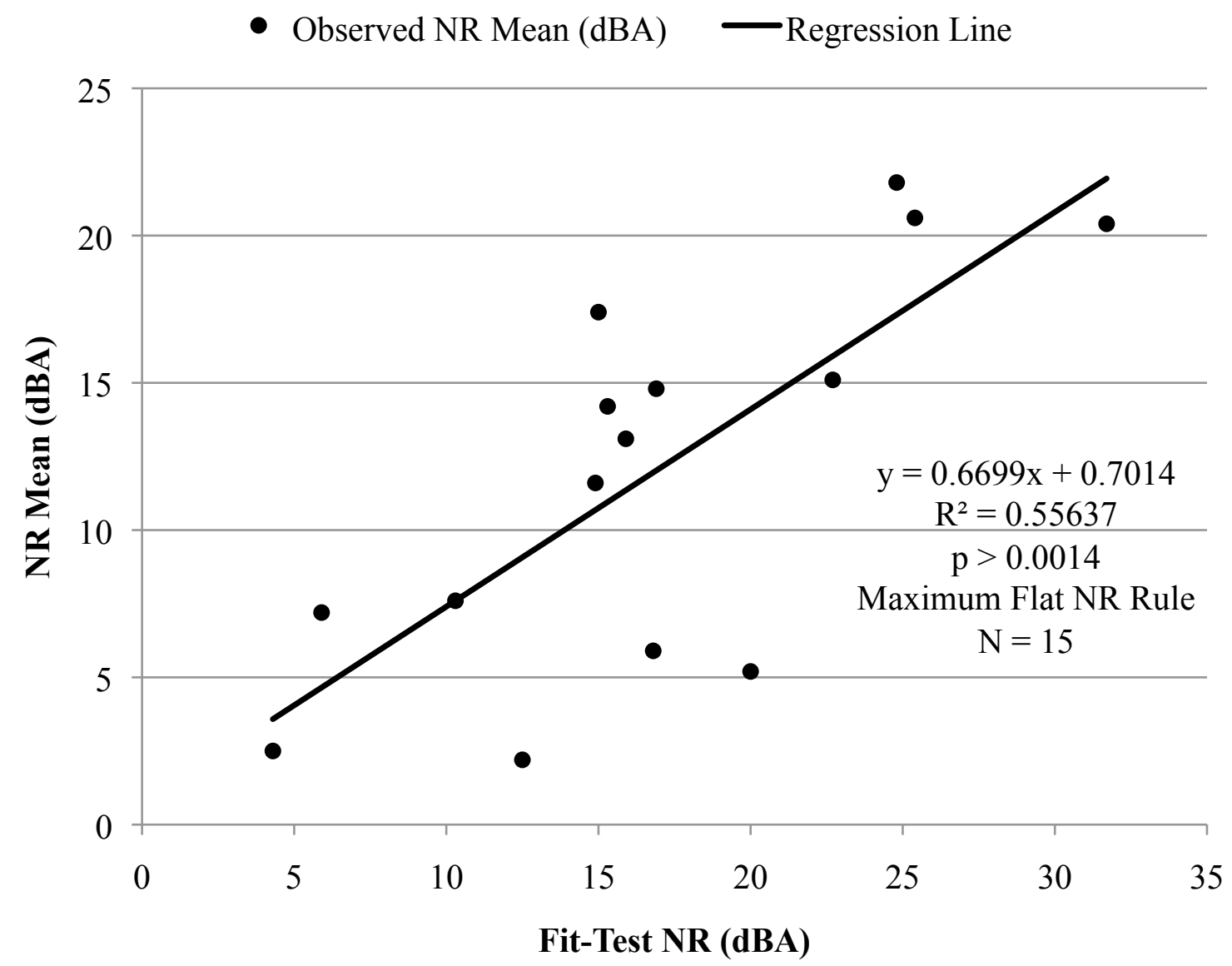

Figure 76. Comparison of NR Mean during fit test and during periods of Light Activation

\subsubsection{Maximum Flat NR Rule}

The results of the linear regression analysis between fit test and NR mean values are shown in Figures 75, 76 and Table 23. The slope (0.670) of the regression line on Figure 76 was significantly different from zero ( $p>0.0014$ at $\alpha=5 \%$ ), and the coefficient of determination $\mathrm{R}^{2}$ was 0.55637 . 


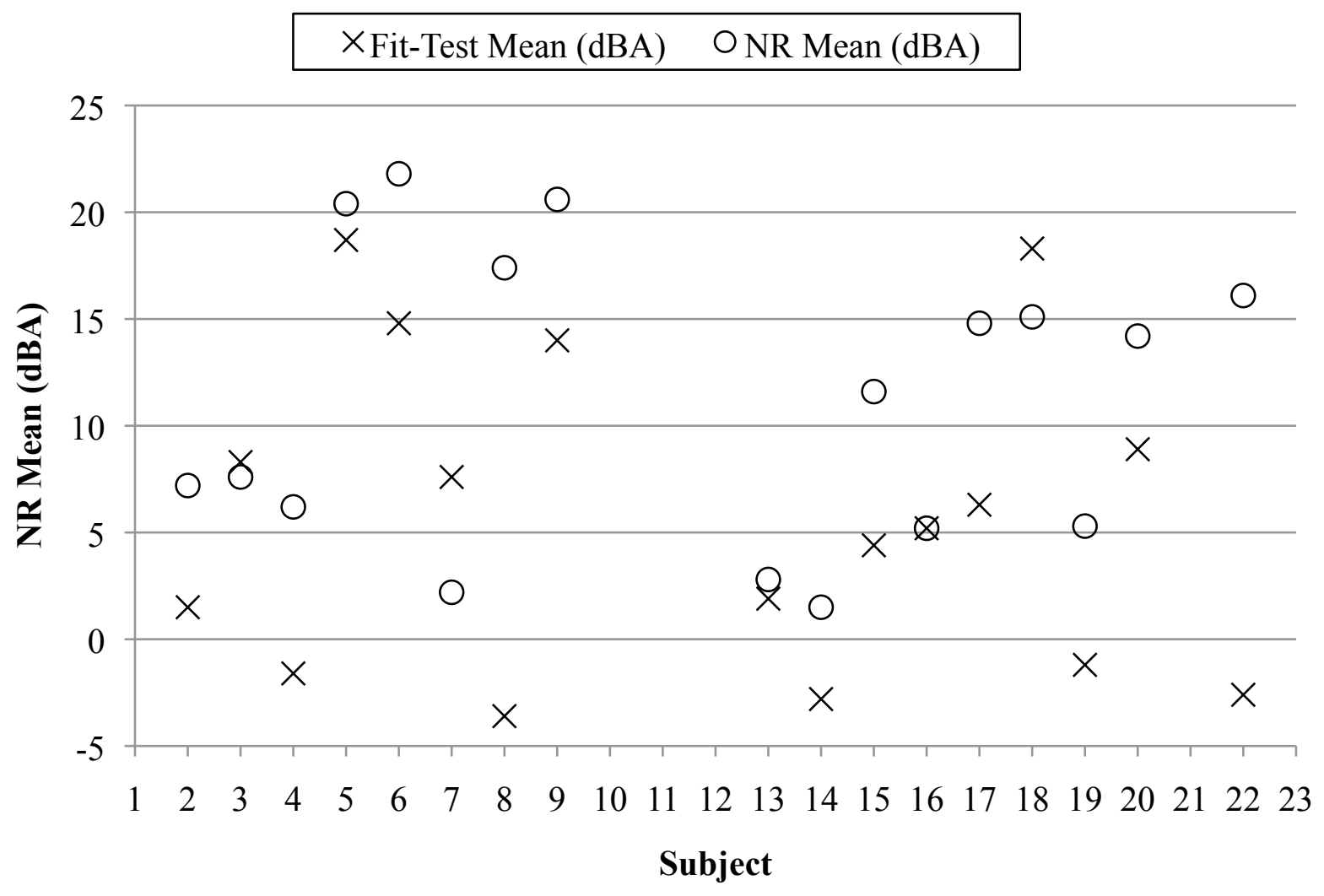

Figure 77. NR mean versus fit test mean 
Table 24. NR mean "60 second" fit-test compared to NR mean during periods of light Activation ( $\mathrm{N}=17)$

\begin{tabular}{|c|c|c|c|}
\hline Subject & $\begin{array}{c}\text { NR Mean Field } \\
\text { Fit Test } \\
60 \text { Second NR Mean Rule } \\
(\mathrm{dBA})\end{array}$ & $\begin{array}{l}\text { NR Mean Light } \\
\text { Activation (dBA) }\end{array}$ & $\Delta \mathrm{NR}$ Mean \\
\hline 2 & 1.5 & 7.2 & -5.7 \\
\hline 3 & 8.3 & 7.6 & 0.7 \\
\hline 4 & -1.6 & 6.2 & -7.8 \\
\hline 5 & 18.7 & 20.4 & -1.7 \\
\hline 6 & 14.8 & 21.8 & -7 \\
\hline 7 & 7.6 & 2.2 & 5.4 \\
\hline 8 & -3.6 & 17.4 & -21 \\
\hline 9 & 14.0 & 20.6 & -6.6 \\
\hline 13 & 1.9 & 2.8 & -0.9 \\
\hline 14 & -2.8 & 1.5 & -4.3 \\
\hline 15 & 4.4 & 11.6 & -7.2 \\
\hline 16 & 5.2 & 5.2 & 0 \\
\hline 17 & 6.3 & 14.8 & -8.5 \\
\hline 18 & 18.3 & 15.1 & 3.2 \\
\hline 19 & -1.2 & 5.3 & -6.5 \\
\hline 20 & 8.9 & 14.2 & -5.3 \\
\hline 22 & -2.6 & 16.1 & -18.7 \\
\hline All & $\begin{array}{c}5.8 \\
(\mathrm{SD}=7.3)\end{array}$ & $\begin{array}{c}11.2 \\
(\mathrm{SD}=6.9)\end{array}$ & -5.4 \\
\hline
\end{tabular}




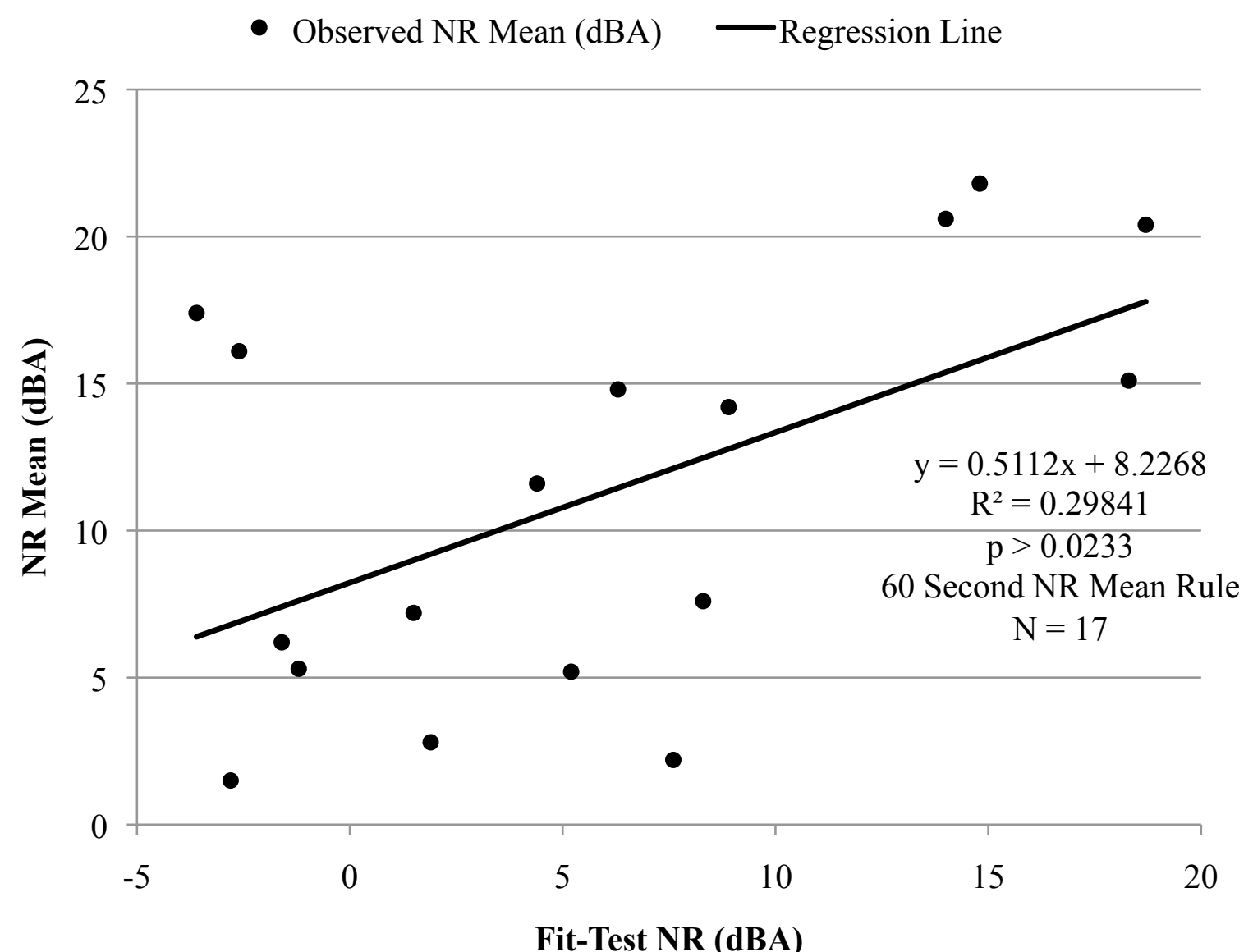

Figure 78. Comparison of NR Mean during fit test and during periods of Light Activation

\subsubsection{Second NR Mean Rule}

The results of the linear regression analysis between fit-test NR mean and NR mean values are shown in Figures 77, 78 and Table 24. The slope (0.511) of the regression line on Figure 78 was significantly different from zero ( $p>0.0233$ at $\alpha=5 \%$ ), and the coefficient of determination $\mathrm{R}^{2}$ was 0.29841 . 


\subsection{Discussion}

According to a study conducted in the mining industry, personal fit-tests may not always predict workers' actual “working” NR values (Wu, 2010). In fact, even the average of multiple fit-tests has a poor predictive power of "working" NR. The results of this subjective study indicate that "working" fit-test might prove to be useful and future research is warranted.

\subsection{Conclusion}

In comparing the three subjective rules applied to field fit-tests, fit-test NR mean values appear to be associated with NR mean Light Activation values. Three subjective rules were applied, all showing significant differences; however, less than $50 \%$ of the variation was accounted for in the models. 


\section{CHAPTER 9: CONCLUSIONS, CAVEATS, AND RECOMMENDATIONS}

This research indicated that signaling can produce modest improved protection for workers who do not already have outstanding compliance in wearing HPDs but are willing and able to adjust their fits when prompted to improve their protection.

Analysis of the data from these subjects produced the following conclusions:

1. Observed noise reductions experienced by subjects were on average less than one fourth of the rated NRR value, with the highest one being less than three quarters of the rated NRR value.

2. Subject differences were the most important variable, as is most often the case with human subjects $(\mathrm{p}=0.0001)$.

3. The improvement found occurred only when the light was activated and did not persist when the light was deactivated and did not improve from cycle to cycle. There was not a learning effect, but only a signaling effect.

4. The intervention was found to be of marginal utility when averaged over all subjects $(\triangle \mathrm{NR}<2.2 \mathrm{dBA})$.

5. The intervention identified 4 of 21 subjects who had high initial NR values and could not improve them.

6. Although the overall improvement in noise reduction was modest, real time NR identified 7 of 21 workers who apparently could not get a good fit despite previous company training and obviously diligent efforts. One had had ear surgery.

7. Cycle was not significant $(\mathrm{p}=0.1218)$.

8. Age, duration of employment, and gender did not significantly affect NR values ( $p>$ $5 \%$ ).

9. Period was significant ( $p=0.0125$ ), possibly only because of the effects of light signaling. 
Caveats include:

1. Subjects tested in a different workplace may experience different results.

2. Utility of the light may have been reduced because subjects often could not easily use their hands to re-adjust HPD fit because of the work task.

3. The light helmet and protruding tubing may have caused movements of the earplug, thereby producing noise exposure artifacts.

4. The study only took place in a single shift. If it had been extended over multiple shifts the subjects may have come to ignore the blinking light.

5. The noise levels for the subjects were generally in the range of 80-90 dBA, which may be too low for some workers to take hearing protection seriously.

Recommendations for future research include:

1. It would be beneficial to fit-test with several brands of earplugs prior to the full shift tests. This would allow comparison of in-office fit-testing to worktime NR values. Furthermore, it would allow testing subjects only with HPD with which they could achieve $\mathrm{NR}=20 \mathrm{dBA}$ or better. It would also provide a more valid comparison of the NR achieved while working to the NR achieved under ideal fit-testing conditions.

2. Test the light signaling effect in an environment with $\mathrm{SPL}_{\mathrm{sh}}$ well above $90 \mathrm{dBA}$.

3. Test different feedback mechanisms (e.g., vibrating signal) to alert workers when noise in the ear is excessive. 


\section{CHAPTER 10: NOISE CONTROL RECOMMENDATIONS}

\subsection{Purpose}

Although the 8-hour TWA noise exposure was not above the OSHA PEL for any of the tested subjects, they were consistently over the OSHA AL (see Tables 12-16). In 1997, NIOSH found that there is approximately $25 \%$ excess risk of hearing loss even if a workforce is protected to the PEL criteria. Therefore, workers protected at the PEL may still experience hearing loss. Hence, it is worthwhile to reduce noise exposures to less than the PEL and AL, if feasible. Noise exposure can be reduced by altering or enclosing equipment to reduce noise generation at the source, by using sound-absorbing materials, by administrative and work practice changes and by personal hearing protection.

This chapter discusses methods to reduce noise exposure at this metal products facility.

\subsection{Overall Plant Process}

Most of the facility is on a single level. However, an upper-level area (lunch, training and rest rooms) exists above a portion of the main level along the left side of the facility. The building contains areas for production and production-support operations, maintenance, parts and materials supply and storage, shipping and receiving, testing laboratories, offices and a lunchroom.

The first step in the mostly automated production process at the metal products facility is to unroll a large steel coil. The process takes place in the coil department and involves unrolling thin gauge steel, cutting to length and stacking the pre-cut sheets onto wooden pallets. The next step in the production process is to coat the pre-cut steel sheets with a proprietary coating in the coating department. End of line operators, called stackers, palletize coated steel sheets in the stacker department to be transferred to the press department. Next, the press department uses presses to form lids to be packed into paper sleeves. Lastly, the finished product, metal lids, are packed and shipped as needed. 


\subsection{Overall Sound Map}

A preliminary step for providing abatement controls was to characterize the noise exposure throughout the facility. This characterization was done by using a SLM to measure SPLs at predetermined locations throughout the facility. For convenience, support beams were used as reference locations. In addition, $\mathrm{SPL}_{\text {sh }}$ measurements were used from the main field study.

A sound map of the metal products facility is shown in Figure 79. All operations take place in one large, open space, as there are no permanent divisions separating departments. As can be seen in Table 25, mean $\mathrm{SPL}_{\mathrm{sh}}$ values from the field study ranged from $85 \mathrm{dBA}$ to $87 \mathrm{dBA}$ with coater and press having the highest and lowest mean SPLs, respectively.

Table 25. Descriptive $\mathrm{SPL}_{\text {sh }}(\mathrm{dBA})$ values by department $\left(\mathrm{SPL}_{\mathrm{sh}}>80\right)$

\begin{tabular}{cccc}
\hline Department & Mean & Median & Range \\
\hline Coater & 87 & 86 & 23 \\
Coil & 86 & 85 & 21 \\
Press & 85 & 84 & 21 \\
Stacker & 86 & 85 & 31 \\
\hline
\end{tabular}




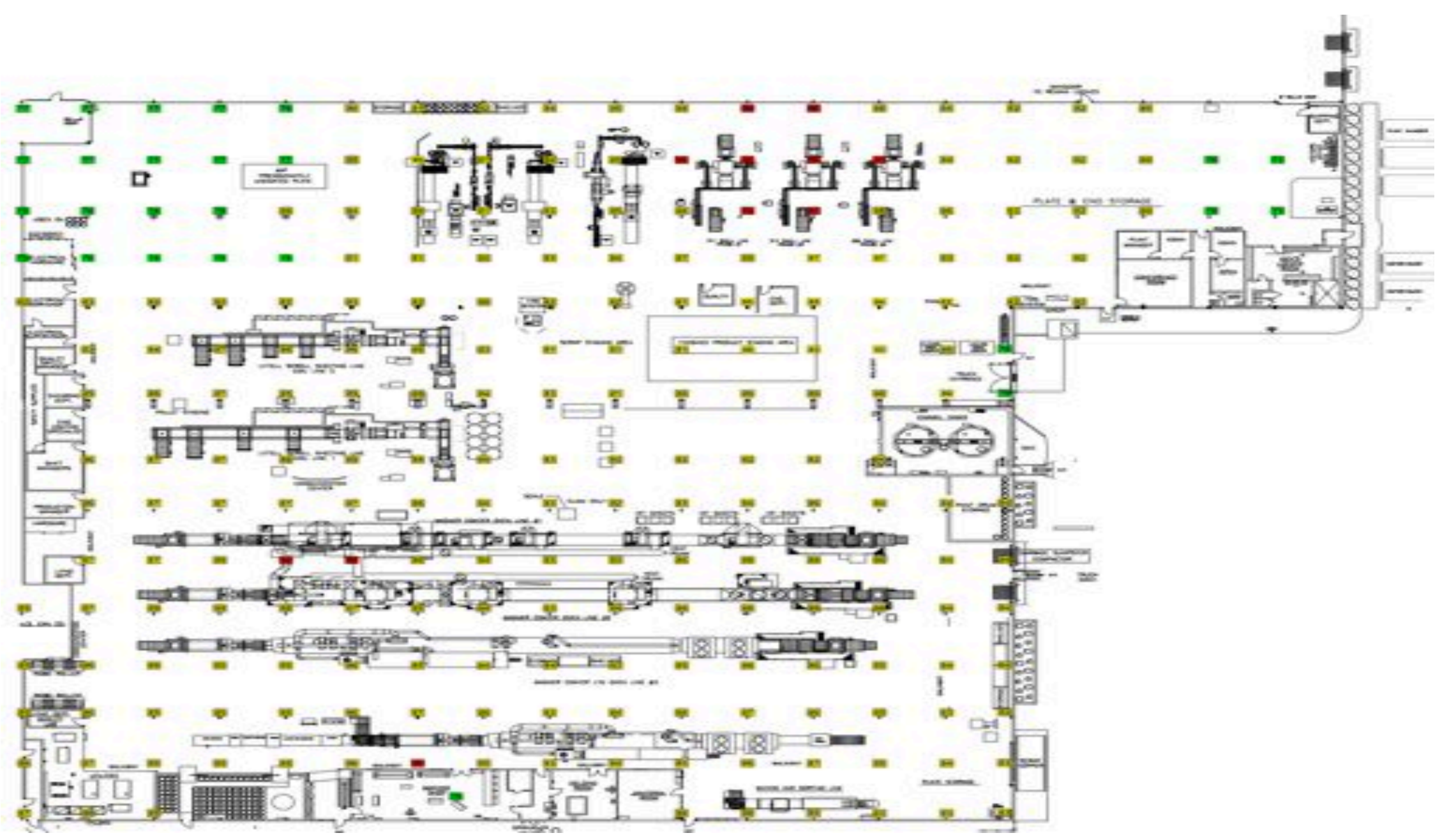

Figure 79. Sound map of metal products facility 


\subsection{Production Noise Sources and Control Measures by Department}

Four departments were evaluated for noise because they were perceived to have the highest levels in the facility. The four departments are coil, coating, stacker and press. Process overview, sources of noise, controls and recommendations will be discussed for these four departments.

Walls, floor and ceiling are constructed from materials that create hard surfaces, namely metal and concrete. This type of construction creates diffuse noise environments for workers. Therefore, abatement controls for diffuse environments will be further discussed in the recommended control measures for each department.

\subsubsection{Coil Department Process Overview}

The main mission of the coil department is to unroll large steel coils, and cut the steel using a shear. The department consists of two different coil lines located adjacent to each other in numerical order, with two workers per line. The workers are primarily responsible for monitoring the automated unrolling and shearing operations. Duties also include changing blades, loading and unloading wooden pallets, visual quality checks and maintaining operations. Workers retreat to quiet areas (lunchroom or personal vehicle) during two 15-minute breaks and one 30-minute lunch break per 8-hour shift. It is normal to have both coil lines operating per shift. 


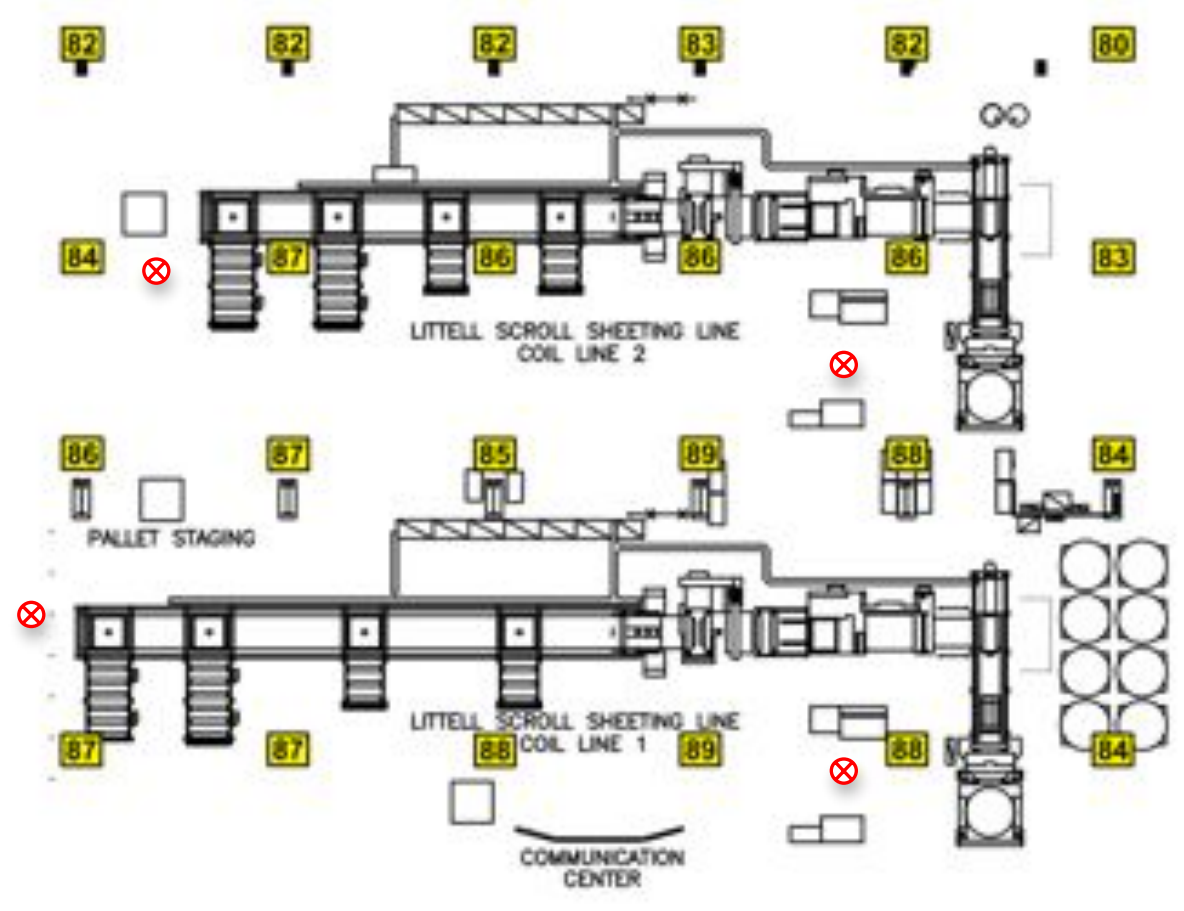

Figure 80. Sound map of the coil department showing SPL (dBA) (operator locations $=$ red circle with $\mathrm{x}$ )

\subsubsection{Sources of Noise}

As shown in Figure 80 and Table 25, the sound map of the coil department indicates ambient noise levels ranging from 80 to $89 \mathrm{dBA}$ with an average of $86 \mathrm{dBA}$ and a median of 85 dBA. 


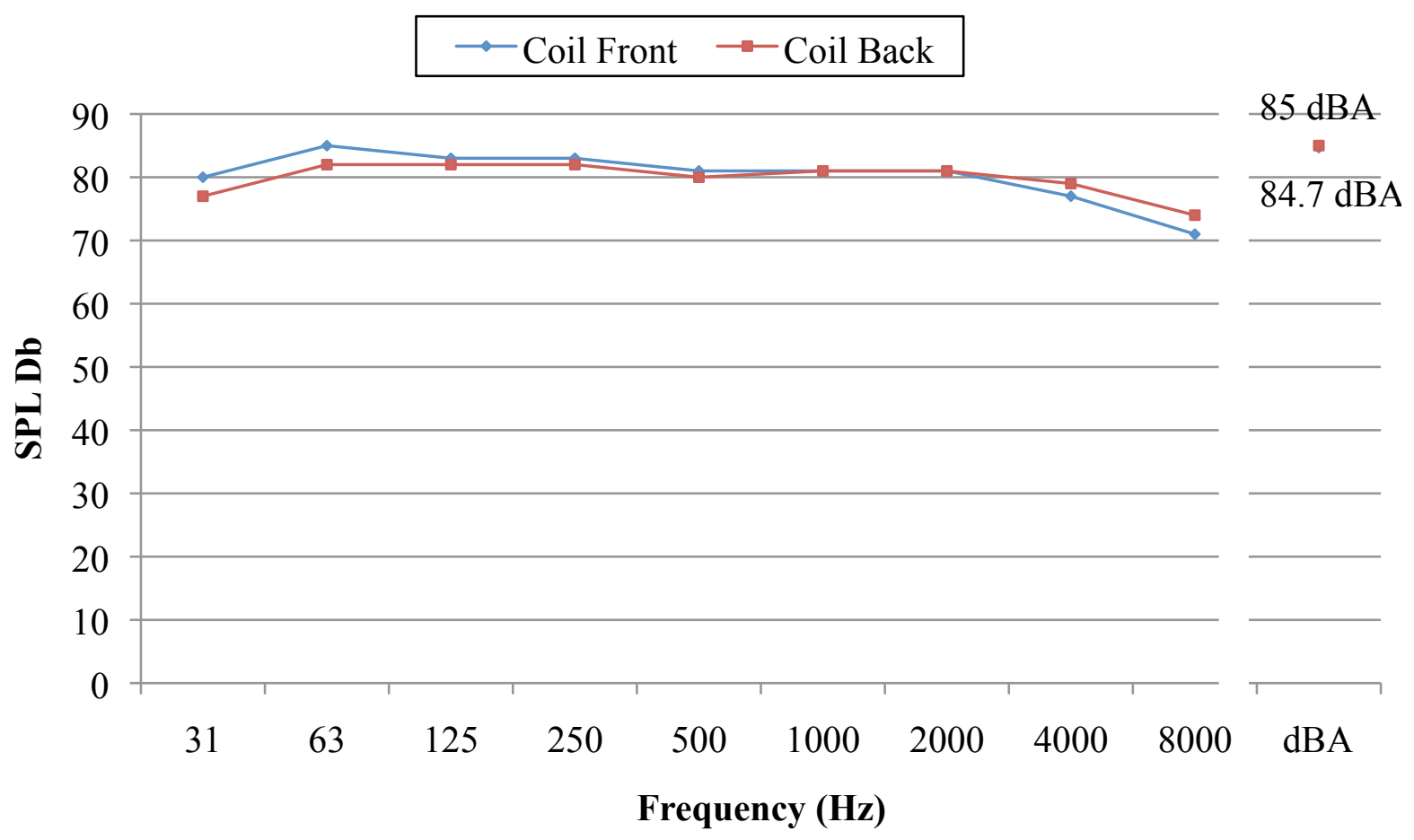

Figure 81. Frequency band measurements for coil department

Sources of noise in the coil department included: shear, lapping belt and diffuse noise.

Figure 81 shows the frequency spectra for the front and back workstations in the coil department. The trivial difference is probably due to the combination of all noise sources, as workstations had similar, relatively flat spectra.

\subsubsection{Control and Recommendations}

$\underline{\text { Shear }}$

The shearing operation continuously exposed a single worker to noise levels above $86 \mathrm{dBA}$ (see Table 25). Because the shear is not dominated by low frequencies, an enclosure of the shear with noise insulation could be highly effective, if feasible. Custom equipment enclosures can provide an IL of 20-40 dBA according to Berger, et. al. (2003). However, the need for frequent access due to equipment jams, frequent blade changes and quality checks make enclosing the shear the least feasible option. It is common for workers to reject or defeat enclosures because 
acoustical enclosures can (1) restrict visibility and physical access, (2) cause heat buildup, (3) result in internal surface contamination, and (4) incur damage due to routine maintenance (Berger, et. al. (2003).

Another source treatment, modifying the mechanical impacts of the shear, should be further investigated. For example, reducing the driving force and distance between the blade and steel can provide noise reduction (Berger, et. al. 2003).

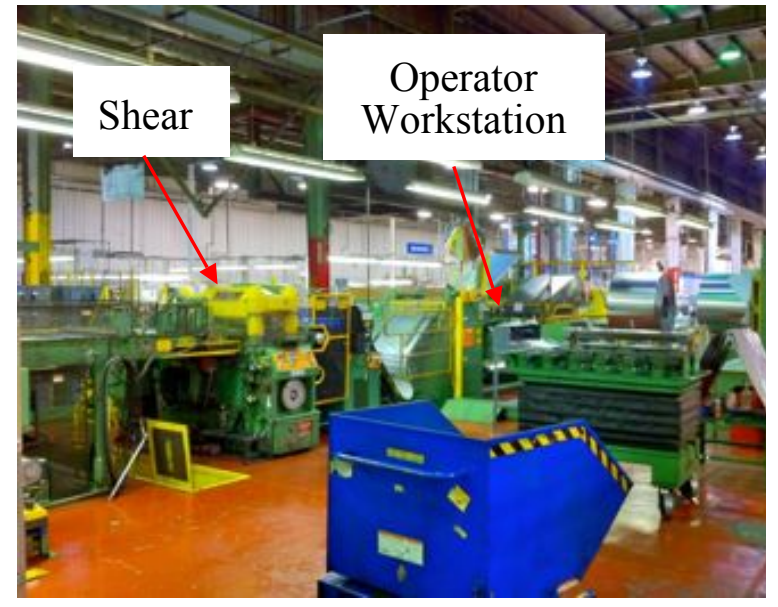

Figure $82 \mathrm{a}$. Front of coil line showing shear

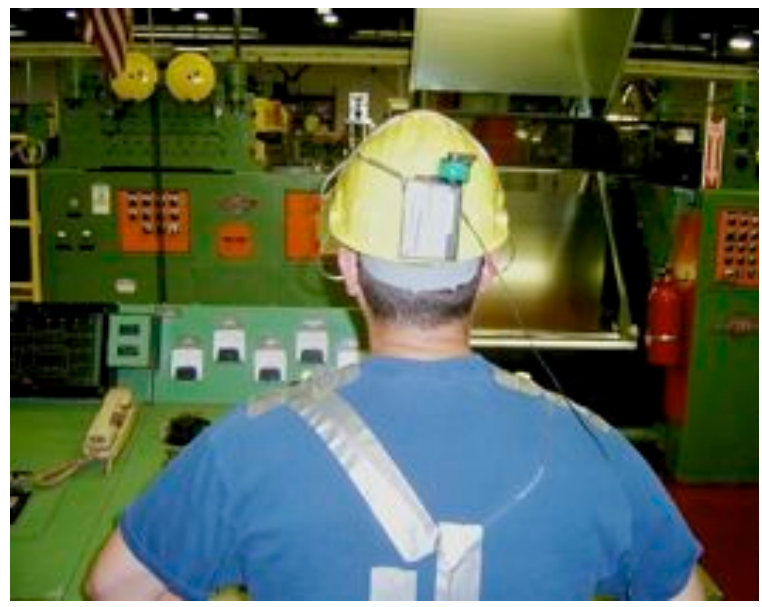

Figure $82 \mathrm{~b}$. Operator observing front of coil line from workstation

Figure $82 \mathrm{a}$ shows the shear in relation to the front operator workstation. Because noise exposure cannot be eliminated by enclosing the shear, engineering controls to intercept the sound as it travels from the shear to the operator should be studied. Building an enclosure with noise insulation around the operator may be useful in reducing noise exposure. An operator enclosure booth would allow continuous monitoring of the shearing operation while isolating the operator from excessive noise levels (see Figure 82b). An added benefit of installing an enclosure for the worker would be temperature control, as temperatures in the summer are frequently above 100 degrees. Treating the coil line operator by an acoustical enclosure would be practical in the coil department because worker movement is confined to a relatively small area during the shift. On 
the other hand, building an enclosure with temperature control and lighting would be costly and may not be warranted by a worker exposure below the PEL.

Because working from an enclosure may not be the most feasible option due to reasons discussed above, an alternative would be to relocate the primary workstation further from the noise source. However, due to the highly reflective noise environment relocating the worker further from the shear may not be the best option.

In terms of feasibility, an acoustical barrier inserted between the shear and operator may be the best option for the coil department. The barrier treatment would be beneficial because the operator is located in the direct field. To maximize the potential IL, the barrier should be located as close to the worker as possible and should include visual access to the shear (Berger, et. al. (2003).

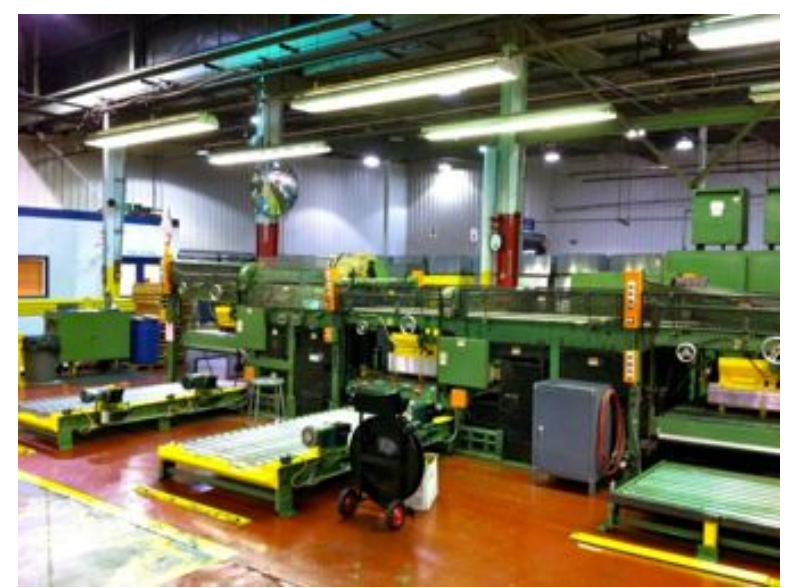

Figure 83a. Back of coil line

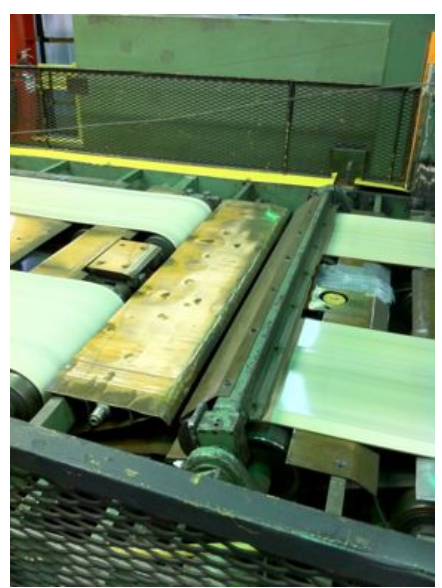

Figure 83b. Lapping belt

\section{Lapping Belt}

The purpose of the lapping belt is to allow the coil line to run faster with fewer product jams by overlapping steel sheets. 
At the end of the coil line, a worker stands and monitors the automated stacking of steel sheets onto wooden pallets. As steel sheets move down the conveyor (see Figure 83a), there are gaps in the conveyor that must be passed. These gaps are passed by the use of a lapping belt (see Figure $83 \mathrm{~b}$ ). A lapping belt creates a powerful jet of air to lift the steel sheet over the gap to the next conveyor by overlapping one sheet onto the next. At the next conveyor, a powerful magnet pulls the sheet tight to the line, which causes an impact noise. Note that the front coil line operator is located near the lapping belt. Because the conveyor needs this powerful jet of air to move the steel sheet it is not feasible to reduce the air noise by reducing the air velocity.

Therefore, the only way to reduce this noise is to have a different mechanism. The lapping belt design will need to be re-engineered so the gap is not necessary or so there is some other method to pass the conveyor gap.

Note further investigation is needed to separate the lapping belt air noise and conveyor sheet impact noise, as this measurement was not possible during the facility inspection.

\section{$\underline{\text { Diffuse Noise }}$}

The walls, floor and ceiling are constructed from materials that create hard metal and concrete surfaces. As a result, there may be some benefit to sound insulation applied to walls and ceiling. The sound insulation may benefit workers not exposed to near field sources. These workers may be supervisors, maintenance workers, forklift operators and custodial staff.

\subsubsection{Coating Department Process Overview}

The main mission of the coating department is to evenly spray pre-cut sheets of steel with a proprietary coating. The automated process consists of three coating lines located adjacent to each other in numerical order, with one worker per coating line. After the coating is applied, the coated sheets continue down the process line through an enclosed oven. The purpose of the oven is to bake the coating onto the sheets of steel. The worker is primarily responsible for batch feeding wooden pallets of uncoated steel sheets into the front end of the coating line. Duties also include routine adjustments, unloading empty wooden pallets, adding chemicals and maintaining operations. Workers retreat to quiet areas (lunchroom or personal vehicle) during two 15-minute 
breaks and one 30-minute lunch break per 8-hour shift. It is normal to have 2 to 3 coater lines operating per shift.

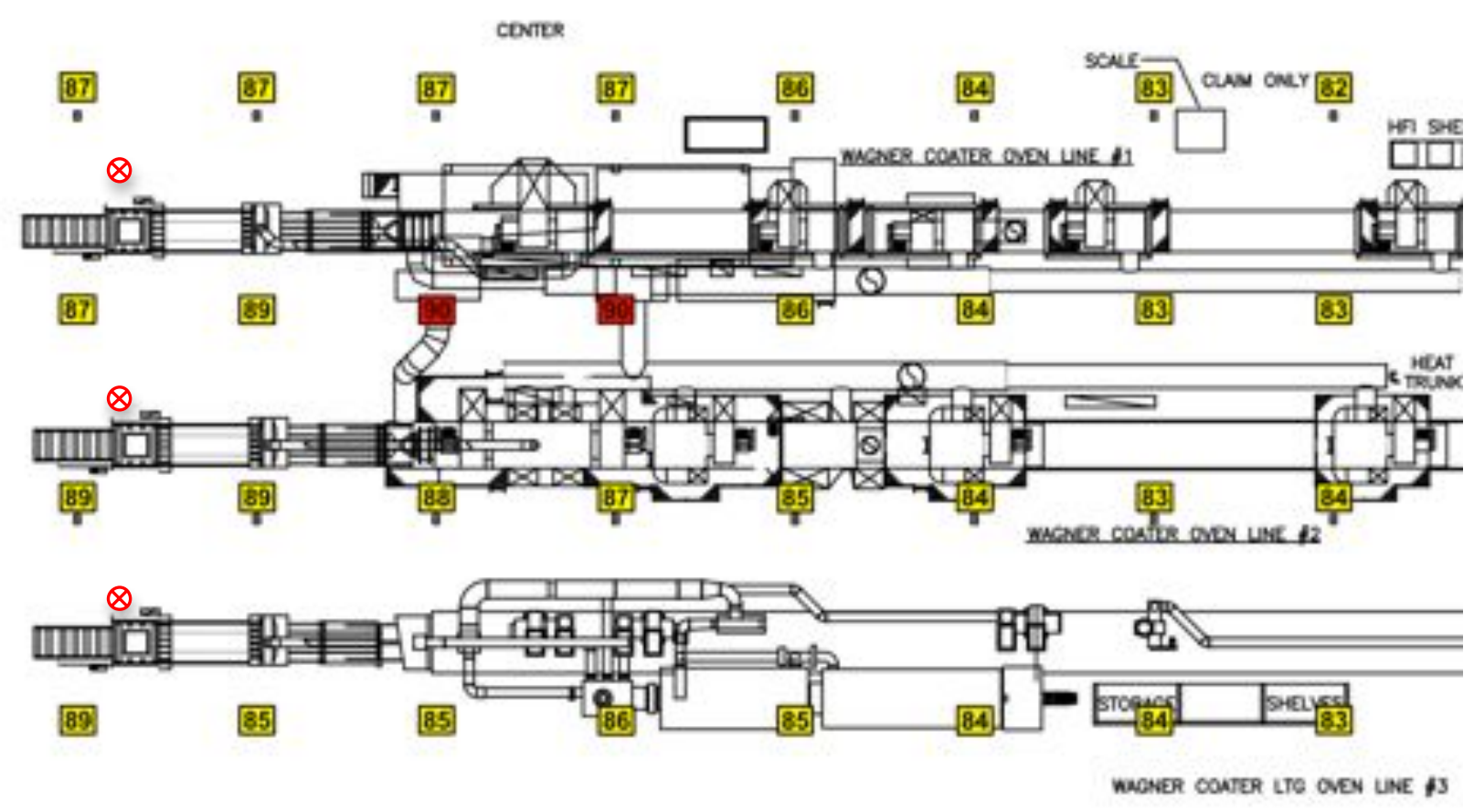

Figure 84. Sound map of the coating department SPL (dB)

(operator locations $=$ red circle with $\mathrm{x}$ )

\subsubsection{Sources of Noise}

As shown in Figure 84 and Table 25, the sound map of the coating department indicates ambient noise levels ranging from 82 to $90 \mathrm{dBA}$ with an average of $87 \mathrm{dBA}$ and a median of 86 dBA. 


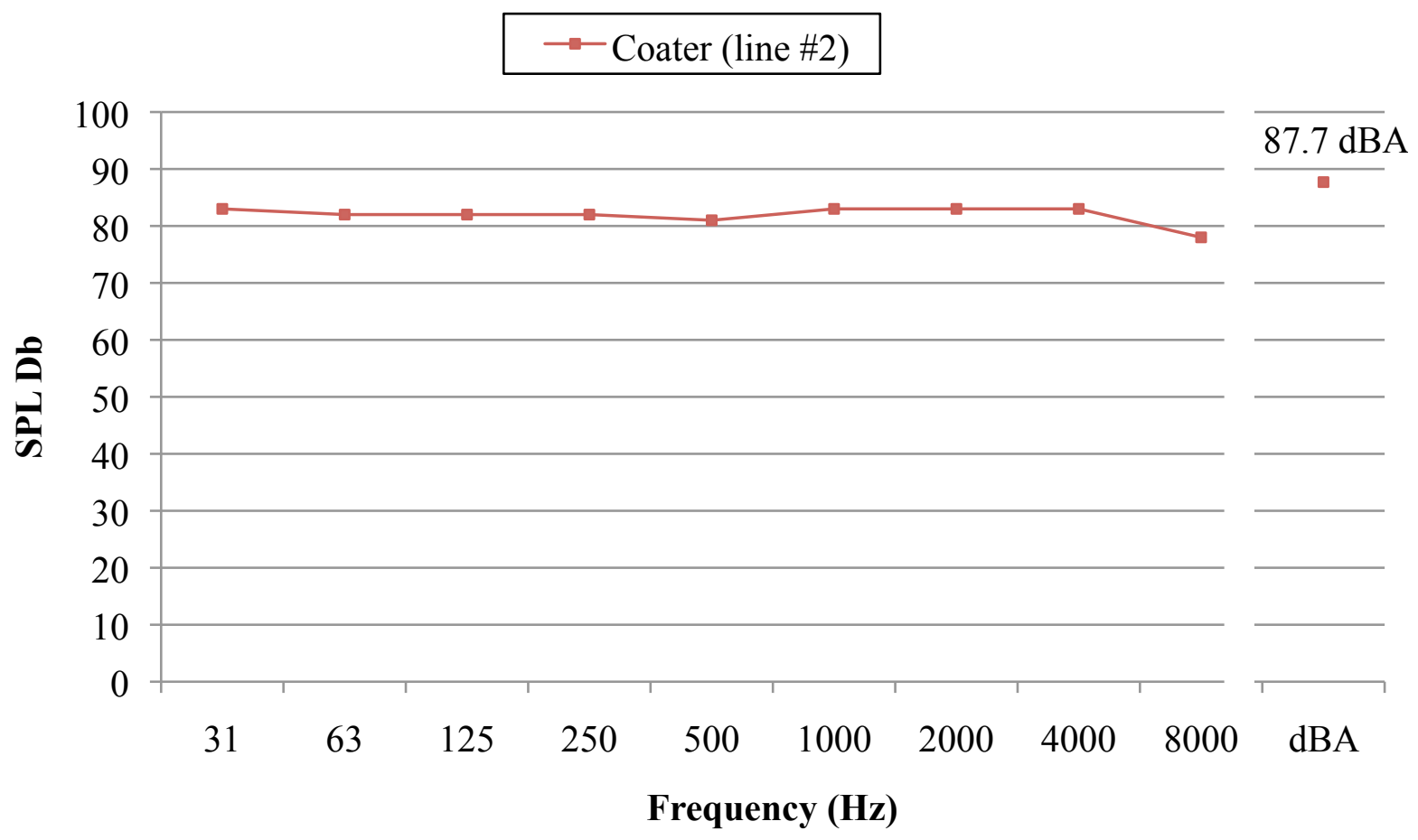

Figure 85. Frequency band measurements for coating department

Sources of noise in the coating department included: coater, access doors, impact and diffuse noise. Figure 85 shows the frequency spectrum for the coating department. Coater \#2 had a relatively flat spectrum. 


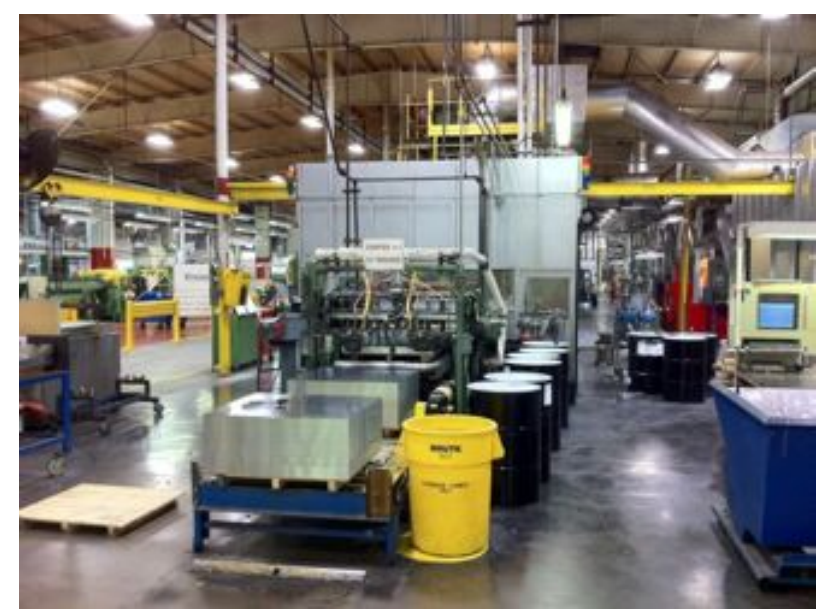

Figure 86. Coating department equipment

\subsubsection{Controls and Recommendations}

\section{$\underline{\text { Coater }}$}

The coating department operation is not dominated by low frequency sound (see Figure 86). Because of the need for frequent access and to adjust, inspect and maintain the coater, enclosing the operation appears to be impractical. However, the worker may benefit from a personal acoustical enclosure with noise insulation. The operator enclosure booth would allow continuous monitoring of the coating operation and provide relief from excessive noise levels. As with the coil department, an added benefit of installing an enclosure for the worker would be temperature control, as temperatures in the summer are frequently above 100 degrees. 


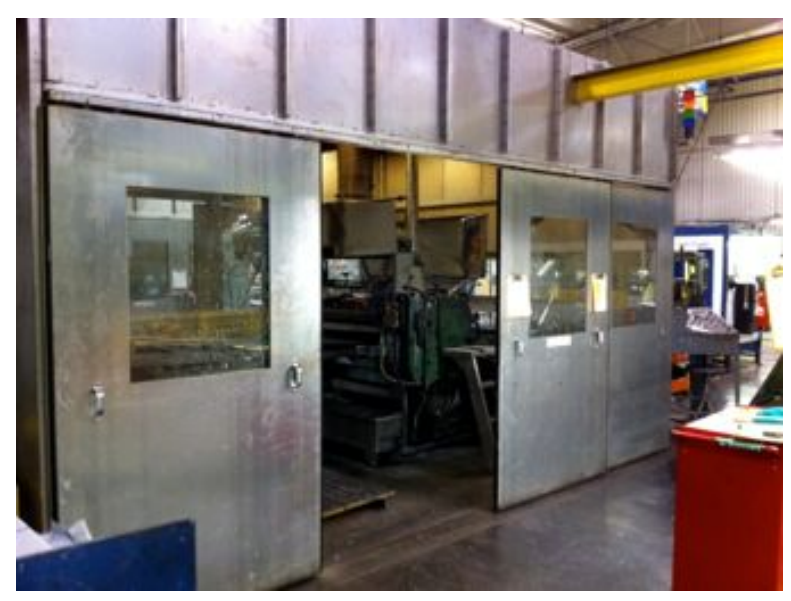

Figure 87. Door left open on enclosed coating operation

\section{$\underline{\text { Access Doors }}$}

The spray coating operation had previously been enclosed with noise insulation. However, side access doors were often kept open by workers for the sake of convenience (see Figure 87). According to Berger, et. al. (2003) it is common for workers to reject and defeat enclosures which constrain production. The open doors allow noise to escape and may increase exposure to workers outside the enclosure. Installing interlocks on doors may improve the effectiveness of the enclosure, by requiring the doors to be shut during production. Note the access doors are opened to make routine equipment adjustments and workers do not work inside the enclosure for extended periods of time.

\section{$\underline{\text { Impact }}$}

Magnetic conveyors moving precut steel sheets from wooden pallets to the coating line have multiple impact sites. The installation of noise deadening bumpers (wood, Teflon ${ }^{\circledR}$ ) to reduce impacts may benefit workers exposed to near field noise. For example, the impact spot of steel sheets onto metal conveyors would benefit from this control. 


\section{Diffuse Noise}

The walls, floor and ceiling are constructed from metal and concrete. Hence, there may be some benefit from sound insulation on walls and the ceiling, especially for workers away from the near field, including supervisors, maintenance workers, forklift operators, and custodial staff.

\subsubsection{Stacker Department Process Overview}

The main mission of the stacking department is to stack cured coated steel sheets arriving from the coater operation. The automated process consists of three stackers located adjacent to each, with one worker per stacker line. After the proprietary coating is cured, the dry steel sheets are automatically stacked one-by-one onto a wooden pallet. After the sheets are stacked, the full pallet is inverted onto a second wooden pallet. The worker is responsible for monitoring the stacking operation. Duties also include routine adjustments, replacing wooden pallets, inverting full pallets, visual quality checks and metal banding to secure stacked metal. Workers retreat to quiet areas (lunchroom or personal vehicle) during two 15-minute breaks and one 30-minute lunch break per 8-hour shift. It is normal to have 2 to 3 stackers operating per shift. 


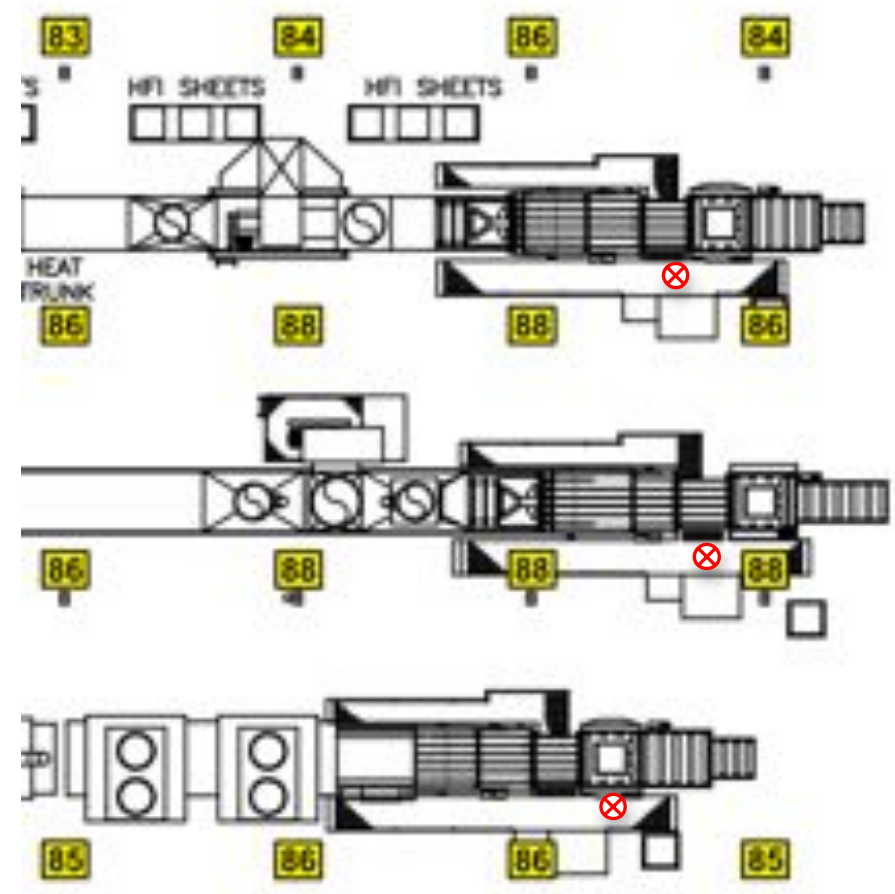

Figure 88. Sound map of the stacker department SPL (dB)

(operator locations $=$ red circle with $\mathrm{x}$ )

\subsubsection{Sources of Noise}

As shown in Figure 88 and Table 25, the sound map of the stacker department indicates ambient noise levels ranging from 85 to $88 \mathrm{dBA}$ with an average of $86 \mathrm{dBA}$ and a median of 85 dBA. 


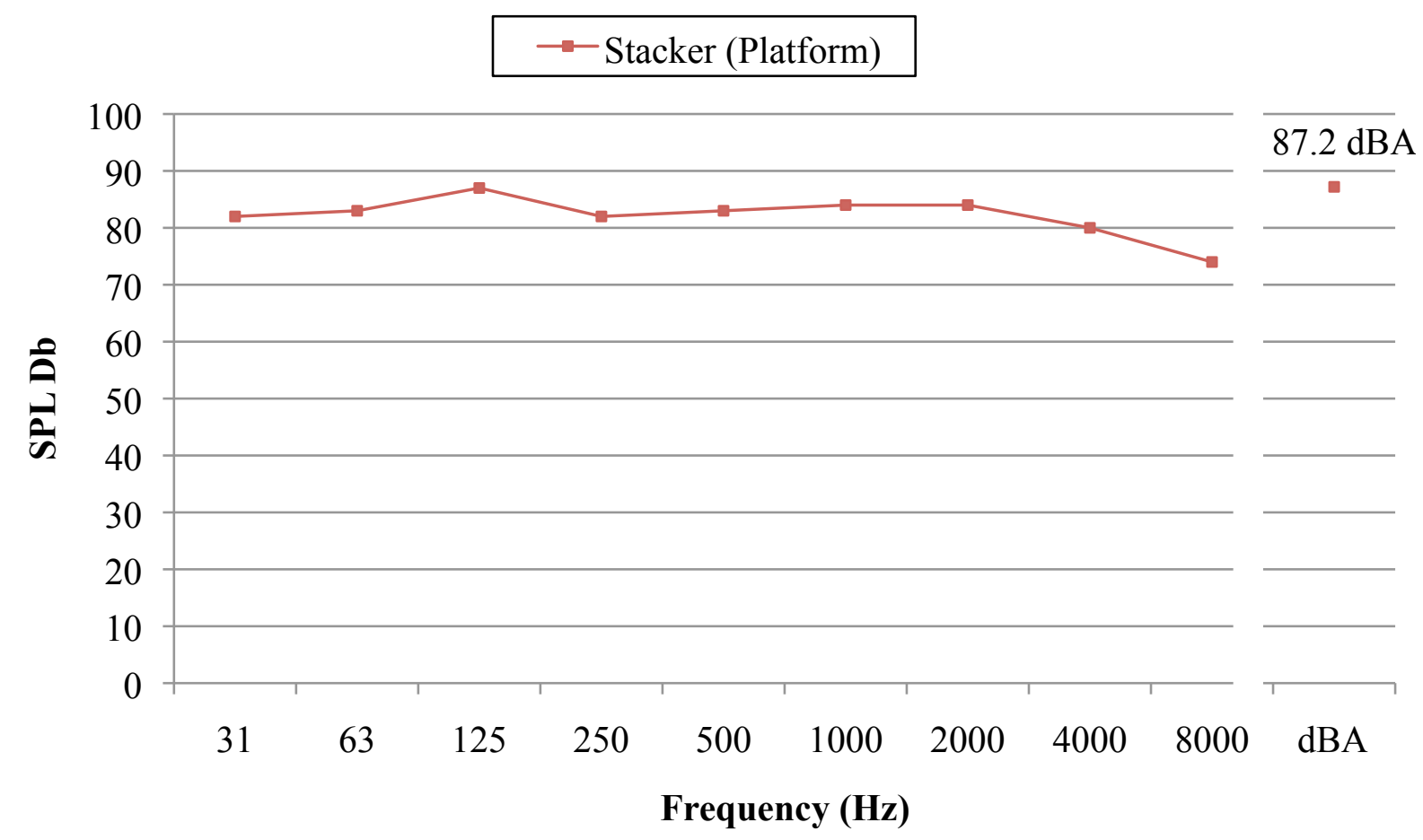

Figure 89. Frequency band measurements for stacker department

Sources of noise in the stacker department included: stacker, oven exhaust fan and diffuse noise. Figure 89 shows the frequency spectrum for the stacker equipment. It appears the stacker had a relatively flat spectrum with a modest spike at $125 \mathrm{~Hz}$. 


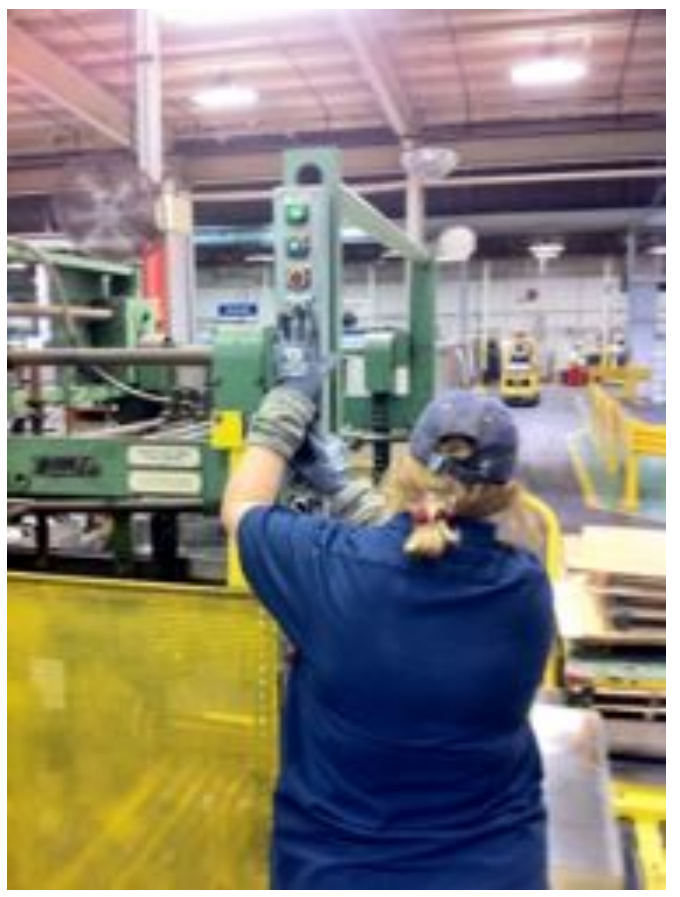

Figure 90. Worker at stacker workstation

\subsubsection{Controls and Recommendations}

\section{$\underline{\text { Stacker }}$}

Due to the work process and need for access, the stacker operation cannot be enclosed with noise insulation or shielded from the worker (see Figure 90). Furthermore, the worker cannot be stationed inside a personal enclosure because of the limited space. 


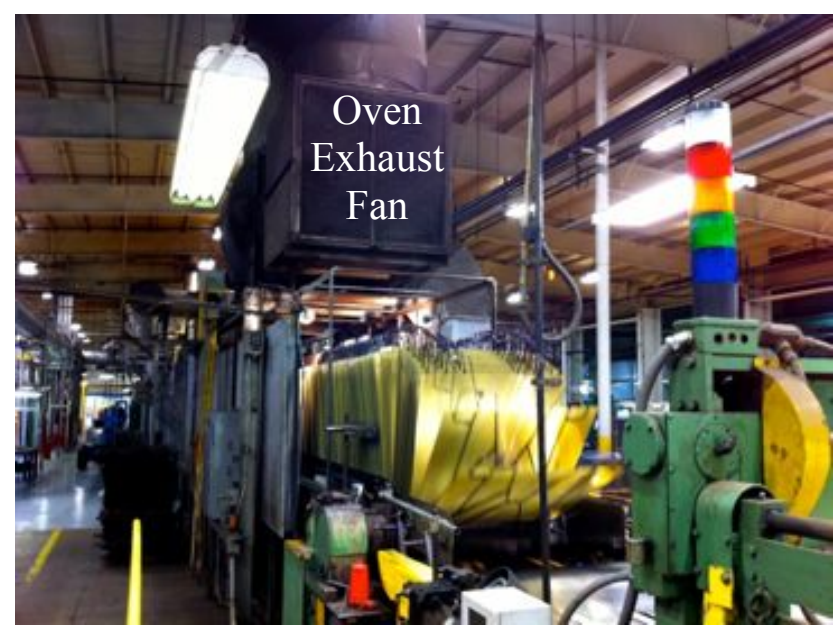

Figure 91. Oven exhaust fan at stacker

\section{Oven Exhaust Fan}

One source of noise that may increase the stacker's noise exposure is the oven exhaust fan (see Figure 91). The exhaust fan design will need to be re-engineered so the air intake and exhaust ducting is further from the worker. Another option would be to shield the exhaust fan noise from the worker. However, this is beyond the investigators' ability and would take intensive study and effort by someone who has access to the machine and exhaust ventilation.

\section{Diffuse Noise}

Similar to other departments, the walls, floor and ceiling are constructed from metal and concrete. Hence, there may be some benefit from sound insulation on walls and the ceiling, especially for workers away from the near field, including supervisors, maintenance workers, forklift operators, and custodial staff.

\subsubsection{Press Department Process Overview}

The main mission of the press department is to press metal lids of various sizes out of coated steel sheets. The nearly automated process consists of six different presses located adjacent to each other in numerical order, with one worker per press. The worker is primarily responsible for packing a stack of lids into paper sleeves and placing sleeves onto wooden pallets. Duties 
also include changing dies, visual quality checks and maintaining operations, as lids commonly cause equipment jams on conveyors and at liner equipment. Workers retreat to quiet areas (lunchroom or personal vehicle) during two 15-minute breaks and one 30-minute lunch break per 8 -hour shift. It is normal to have only 1 to 2 presses operating per shift.

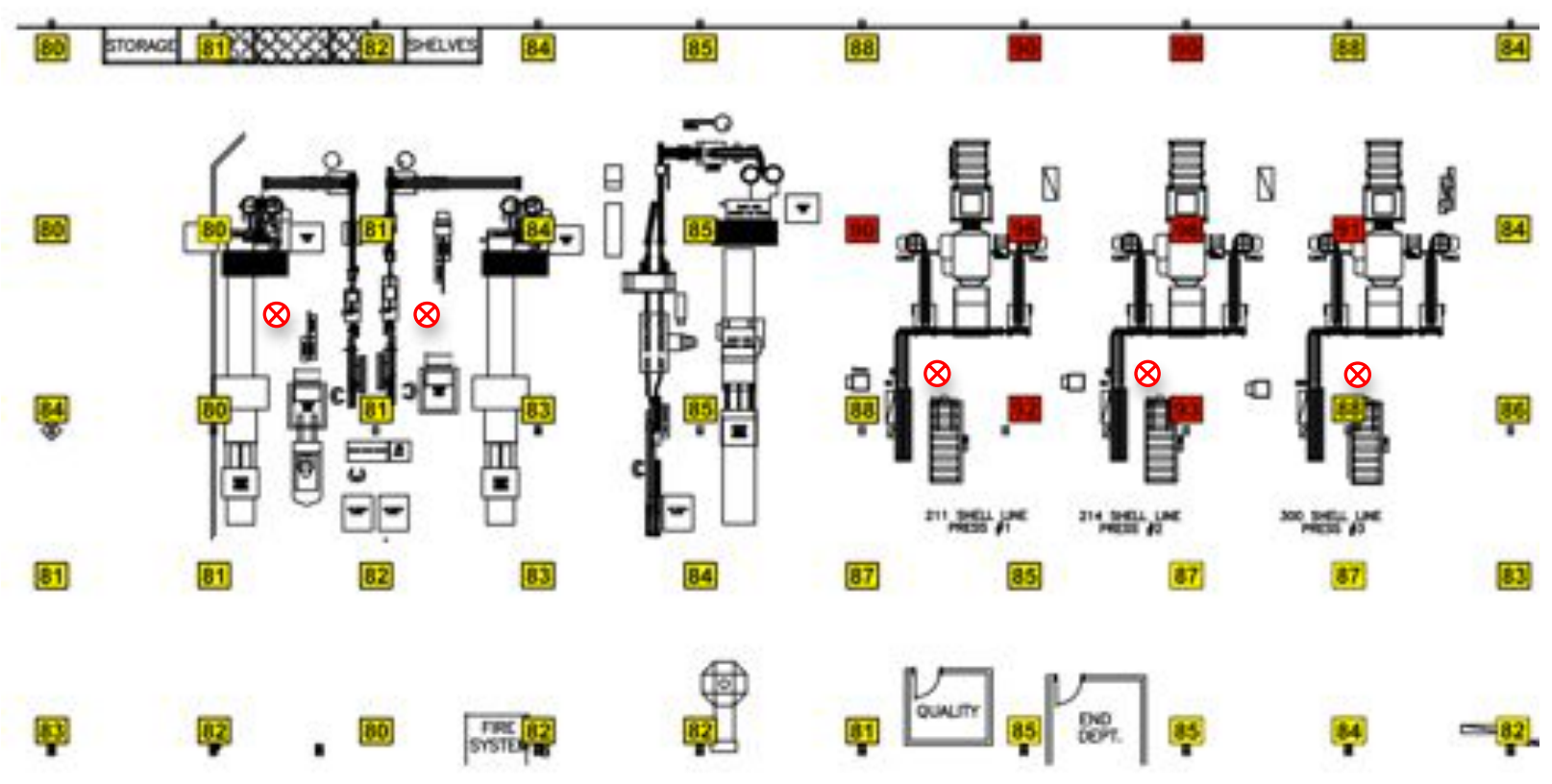

Figure 92. Sound map of the press department SPL (dB)

(operator locations $=$ red circle with $\mathrm{x}$ )

\subsubsection{Sources of Noise}

As shown in Figure 92 and Table 25, the sound map of the press department indicates ambient noise levels ranging from 80 to $98 \mathrm{dBA}$ with an average of $85 \mathrm{dBA}$ and a median of 84 dBA. 


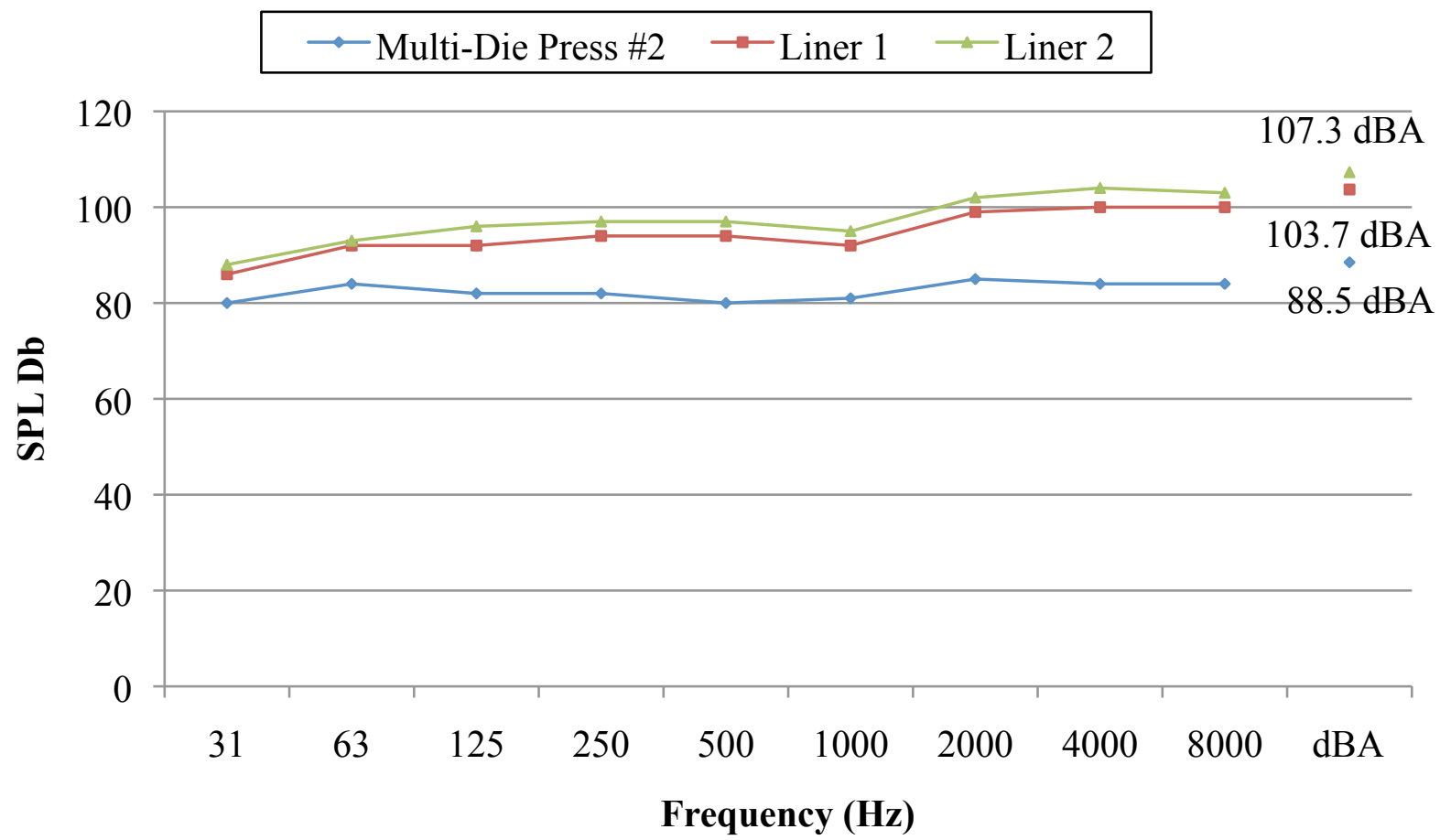

Figure 93. Frequency band measurements for press area

Sources of noise in the press department included: press, liner, metal conveyors, air driven equipment, impact and diffuse noise. Figure 93 shows frequency spectra for press and both liners at the multi-die \#2 press. The difference between the multi-die press \#2 and both liners was due to sound generation, as liner 1 and 2 (103.7 dBA and 107.3 dBA, respectively) generated higher exposures than the multi-die press \#2 (88.5 dBA). Note the trivial difference between liner 1 and liner 2 is probably due to a combination of all noise sources. As can be seen in Figure 93, equipment had similar, relatively flat spectra. Hence the overall levels were not dominated by low frequency sound. 


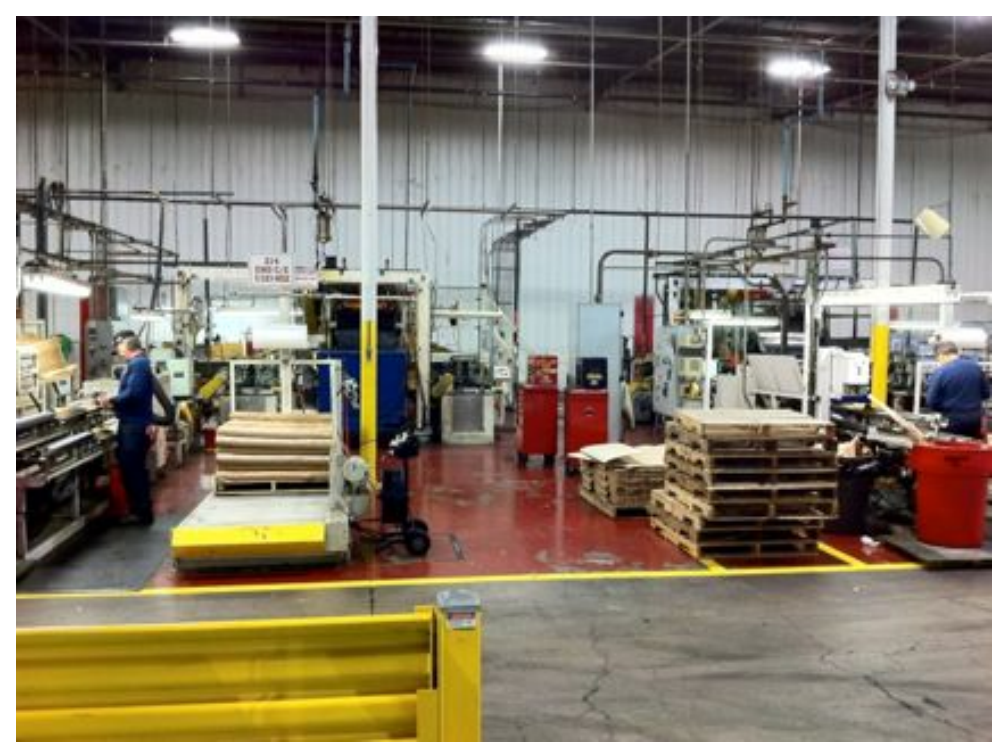

Figure 94. Press department

\subsubsection{Controls and Recommendations}

\section{$\underline{\text { Press }}$}

The press (see Figure 94) was bolted directly to concrete flooring and may benefit from the use of machine mounts and pads that reduce noise from vibration.

The use of compressed air may create unnecessary noise exposures; therefore, installing silencers or mufflers for use on compressed air systems may help to reduce exhaust noise from air driven equipment. Other options include reducing air pressure if higher than necessary and investigate moving waste air exhaust further away from the worker. 


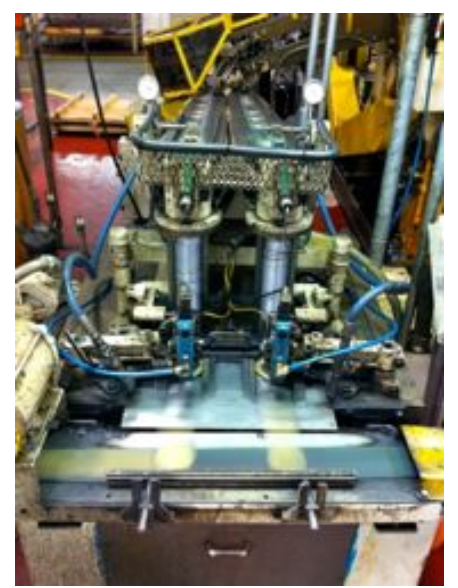

Figure 95a. Continuous feed liner

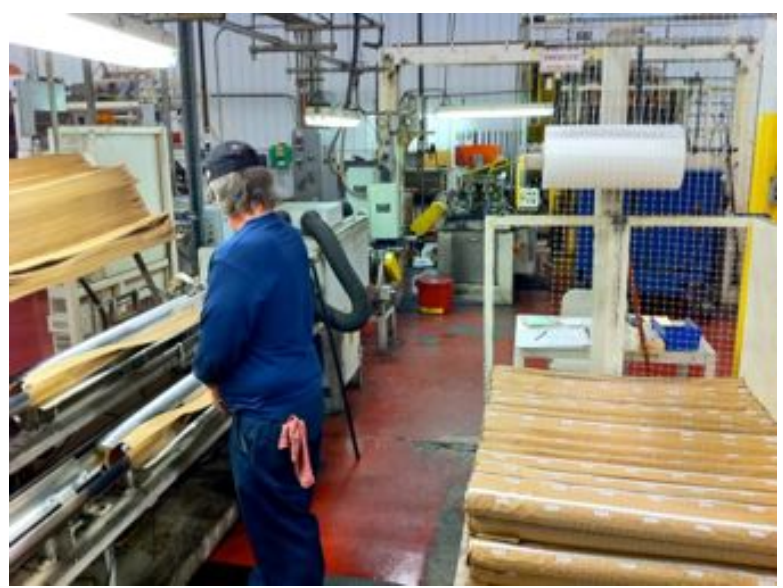

Figure 95b. Worker visually inspecting liner from the packing workstation

$\underline{\text { Liner }}$

There are two liners per press (see Figure 95a). The SPL of each liner was measured at 107 dBA directly at the source. Each worker is required to be in close visual proximity to liners because of frequent equipment jams (see Figure 95b). Because the liner is not dominated by very low frequencies (see Figure 93), enclosures with noise insulation could be highly effective. However in this case the need for access is so great that the liners cannot be meaningfully enclosed. Therefore, use of modular reinforced, limp vinyl panels may help to block or shield the worker from the direct sound path of the liners. Additionally, the panels would allow visual contact of liners and act as a movable barrier between liner equipment and sleeve packing areas.

Further investigation in designing the partial barrier would require additional noise measurement to be certain the worker is located within the near field and not in the reverberant field. This is beyond the investigators' ability and would take intensive study and effort by someone who has access to the machine.

\section{$\underline{\text { Conveyors }}$}

Magnetic conveyors moving steel lids from press to liners to packing station have multiple impact sites. The installation of noise deadening bumpers (wood, Teflon ${ }^{\circledR}$ ) to reduce impacts may benefit workers tied to near field noise. For example, the impact spot of steel lids ejected 
from the liner is directly onto metal conveyors. This operational step in the process would benefit from this control method.

\section{Diffuse Noise}

The walls, floor and ceiling are constructed from materials that create hard surfaces, namely metal and concrete. As a result, there may be some benefit of noise insulation, especially for workers who are not exposed to a near field noise sources. These workers may be supervisors, maintenance workers, forklift operators and custodial staff.

\subsection{Summary of Noise Sources and Control Recommendations by Department}

There is potential excessive noise exposure (above the OSHA AL) to employees at the metal products facility. Although none of the values measured in the field study (see Table 25) exceeded the OSHA PEL, there are recommended noise abatement controls that can further reduce noise exposure at this facility.

Note this limited survey attempts to provide practical noise abatement controls using available data collected during the field study. Further investigation should consider conducting a task analysis for each workstation. The task analysis would identify the contributions of each noise source to the exposure of each worker. The analysis would allow interventions for each specific noise source to be considered by feasibility, cost and effectiveness.

In conclusion, Table 26 summarizes noise sources and recommended controls by department to further reduced employee noise exposure at this facility. 
Table 26. Summary of noise sources and control recommendations by department

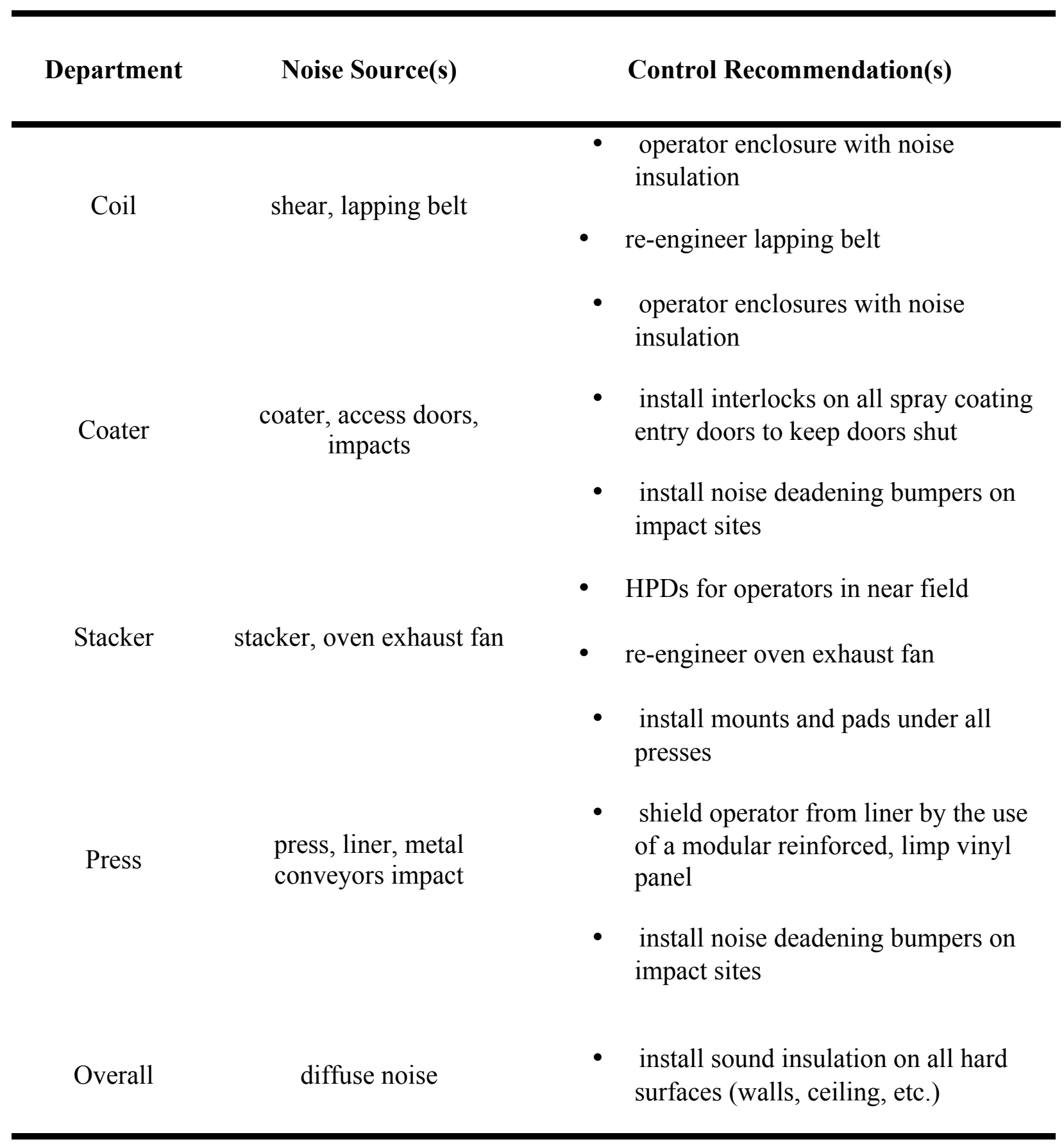




\section{BIBLIOGRAPHY}

Abel, S. M., Rockley, T., Goldfarb, D., Hawke, M. (1990). Outer ear canal shape and its relation to the effectiveness of sound attenuating earplugs. Journal of Otolaryngology, 19(2):91-95.

American National Standards Institute (1974). American National Standard for the Measurement of Real-Ear Hearing Protectors and Physical Attenuation of Earmuffs. ANSIS3.19-1974, New York, NY.

American National Standards Institute (1995). Microphone-in-Real-Ear and Acoustic Test Fixture Methods for the Measurement of Insertion Loss of Circumaural Hearing Protection Devices. S12.42-1995, New York, NY.

Berger, E. H. (1980). Hearing protector performance: How they work - and - what goes wrong in the real world. Sound and Vibration. 14(10), 14-17.

Berger, E. H., and Kerivan, J.E. (1983). Influence of physiological noise and the occlusion effect on the measurement of real-ear attenuation at threshold. Journal of the Acoustical Society of America 74, 81-94.

Berger, E. H. (1986). Review and tutorial: Methods of measuring the attenuation of hearing protection devices. The Journal of the Acoustical Society of America, 79(6), 175- 182.

Berger E. H., and Killion M.C. (1989). Comparison of noise attenuation of three audiometric earphones, with additional data on masking near threshold. Journal of the Acoustical Society of America 86, 1392-1403.

Berger, E. H. (1993). The naked truth about NRRs. Aearo Company, Retrieved February 19, 2011 from http://www.e-a-r.com/pdf/hearingcons/earlog20.pdf.

Berger, E. H., Franks, JR., and Lindgren, F. (1996). International review of field studies of hearing protector attenuation. Scientific basis of noise-induced hearing loss (pp. 361-77). New York, NY.

Berger, E. H. (2003). Hearing protector devices. In E. H. Berger, L. H. Royster, J. D. Royster, D. P. Driscoll, and M. Layne (Eds.), Noise Manual, 5th Edition (pp. 379-455). Fairfax, VA: American Hygiene Association.

Berger, E. H. (2005). Preferred methods for measuring hearing protector attenuation, Paper presented at the Proceedings of Inter-Noise 05, Noise Control Foundation, Poughkeepsie, NY.

Burks, J. A. and Michael, K. L. (2003). A new best practice for hearing conservation: the Exposure Smart Protector (ESP), Paper presented at Proceedings of Noise-Con 2003, Washington, DC. 
Casali, J. G., Mauney, D. W., \& Burks, J. A. (1995). Physical versus psychophysical measurement of hearing protector attenuation - a.k.a. MIRE vs. REAT. Sound and Vibration, 29(7), 20-27.

Goncalves, Cláudia Giglio de Oliveira; Couto, Christiane Marques do; Carraro, Juliana Malteze and Leonelli, Bianca Santos. Evaluation of hearing-protector insertion in groups with and without training. Rev. CEFAC [online]. 2009, vol.11, n.2 [cited 2010-08-15], pp. 345-352 . Available from: $<$ http://www.scielo.br/scielo.php?script $=$ sci_arttext\&pid=S1516$18462009000200021 \& \operatorname{lng}=\mathrm{en} \& n r m=$ iso $>$. ISSN 1516-1846. doi: 10.1590/S151618462009000200021.

Earshen, J. J. (2003). Sound measurement: instrumentation and noise descriptors. In E. H. Berger, L. H. Royster, J. D. Royster, D. P. Driscoll, and M. Layne (Eds.), Noise Manual, 5th Edition (pp. 52-55). Fairfax, VA: American Hygiene Association.

El Dib, R. P., Atallah, A. N., Andriolo, R. B., Soares, B. G., and Verbeek, J. (2007). A systematic review of the interventions to promote the wearing of hearing protection. São Paulo Medical Journal, 125, 362-9.

Environmental Protection Agency (1979). Noise labeling requirements for hearing Protectors, 40CFR, 44(190), Part 211, 56130- 56147.

Ewigman, B. G., Kivlahan, C. H., Hosokawa, M. C., and Horman, D. (1990). Efficacy of an intervention to promote use of hearing protection devices by firefighters. Public Health Reports, $105,53-59$.

Hager, L. D. (2007). Hearing protection devices: current standards and pending development. Retrieved January 8, 2008 from http:/www.hearingreview.com/issues/articles/200703_04.asp?mode.

Hong, O. S., Ronis, D. L., Lusk, S. L., and Kee, G. S. (2006). Efficacy of a computer-based hearing test and tailored hearing protection intervention. International Journal of Behavioral Medicine, 13, 304-314.

Janssen, L., and Bidwell, J. (2007). Performance of a full facepiece, air-purifying respirator against lead aerosols in a workplace environment, Journal of Occupational and Environmental Hygiene, 4(2), $123-128$.

Lempert, B. L., and Edwards, R. G. (1983). Field investigations of noise reduction afforded by insert-type hearing protectors. Journal of American Industrial Hygiene Association. 44:894902.

Lusk, S. L., Ronis, D. L., and Kerr, M. J. (1995). Predictors of hearing protection use among workers: implications for training programs. Human Factors, 37, 635-640. 
Lusk, S. L., Hong, O. S., Ronis, D. L., Eakin, B. L., Kerr, M. J., and Early, M. R. (1999). Effectiveness of an intervention to increase construction workers' use of hearing protection. Human Factors, 41, 487-494.

Lusk, S. L., Kerr, M. J., Ronis, D. L., and Eakin, B. L. (1999). Applying the health promotion model to development of a work site intervention. American Journal of Health Promotion, 13, 219-227.

Lusk, S. L., Ronis, D. L., Kazanis, A. S., Eakin, B. L., Hong, O. S., and Raymond, D. M. (2003). Effectiveness of a tailored intervention to increase factory workers' use of hearing protection. Nursing Research, 52, 289-295.

Lusk, S. L., Eakin, B. L., Kazanis, A. S., and McCullagh, M. C. (2004). Effects of booster interventions on factory workers' use of hearing protection. Nursing Research, 53, 53-58.

Kerr, M. J., Savik, K., Monsen, K. A., and Lusk, S. L. (2007). Effectiveness of computer-based tailoring versus targeting to promote use of hearing protection. Canadian Journal of Nursing Research, 39, 80-97.

Neitzel, R., and Seixas, N. (2005). The effectiveness of hearing protection among construction workers. The Journal of Occupational and Environmental Hygiene, 2(4), 227-238.

Neitzel, R., Somers, S., and Seixas, N. (2006). Variability of real-world hearing protector attenuation measurements. Annals of Occupational Hygiene, 2 (6), 1-13.

Neitzel, R., Meischke, H., Daniell, W. E., Trabeau, M., Somers, S. and Seixas, N. S. (2008), Development and pilot test of hearing conservation training for construction workers. American Journal of Industrial Medicine, 51: 120-129. doi: 10.1002/ajim.20531.

National Institute for Occupational Safety and Health (NIOSH). (1996). "Preventing occupational hearing loss - a practical guide," Franks, J., Stephenson, M.R., and Merry, C.J., eds., National Institute for Occupational Safety and Health, Cincinnati, Ohio, DHHS (NIOSH) Publication No. 96-110, 91.

National Institute for Occupational Safety and Health (NIOSH). (1998). Occupational noise exposure: revised criteria 1998. National Institute for Occupational Safety and Health, Cincinnati, Ohio, DHHS (NIOSH) Publication No. 98-126, 20.

National Institute for Occupational Safety and Health (NIOSH). (2010). Method for calculating and using the noise reduction rating-NRR. Retrieved February 27, 2011 from http://www2.cdc.gov/hp-devices/pdfs/calculation.pdf.

Occupational Safety and Health Administration. (1983). Occupational noise exposure: Hearing conservation amendment; final rule. 48 (46), 9738-9785. 
Occupational Safety and Health Administration. (2010). Interpretation of OSHA's Provisions for Feasible Administrative or Engineering Controls of Occupational Noise. Retrieved December 28, 2010 from

http://www.osha.gov/pls/oshaweb/owadisp.show_document?p_table=FEDERAL_REGISTER\& p_id=21773.

Pender, N. (1987). Health promotion in nursing practice. ( $2^{\text {nd }}$ ed.). Norwalk, CT: Appleton and Lange.

Portillo, S. and DeHart-Davis, L. (2009), Gender and Organizational Rule Abidance. Public Administration Review, 69: 339-347.

Royster, L. H., and Royster, J. D. (1984). "Hearing protection utilization: survey results across the USA. Journal of Acoustical Society of America, 1, 76, S43.

Stephenson, M. T., Witte, K., Vaught, C., Quick, B. L., Booth-Butterfield, S., Patel, D., and Zuckerman, C. (2005). Using persuasive messages to encourage voluntary hearing protection among coal miners. Journal of Safety Research, 36, 9-17.

Tsukada, T., and Sakakibara, H. (2008). A trail of individual education for hearing protection with an instrument that measures the noise attenuation effect of wearing earplugs. Industrial Health, 46, 393-396.

Verbeek, J. H., Kateman, E., Morata, T. C., Dreschler, W., and Sorgdrager, B. (2009). Interventions to prevent occupational noise induced hearing loss. Cochrane Database Syst Rev. 2009 Jul 8;3.

Witt, B. (2007). Earmuffs: a primer. Occupational Hearing Conservation. Retrieved January 7, 2008 from http://www.hearingreview.com/issues/articles/2007-03_03.asp?mode.

Wu, M. (2010). Comparison of noise reduction results for fit-testing and continuous observations during coal mining for selected earplug and earmuff. Diss. West Virginia University.

Zohar, D., Cohen, A., and Azar, N. (1980). Promoting increased use of ear protectors in noise through information feedback. Human Factors, 22, 69-79.

Zohar, D., and Fussfeld, N. (1981). Modifying earplug wearing behavior by behavior modification techniques: an empirical evaluation. Journal of Organizational Behavior Management, 3, 41-52. 


\title{
EFFECT OF AN EXPOSURE-INDICATING LIGHT ON \\ NOISE REDUCTION EXPERIENCED DURING \\ WORK AT A FACTORY
}

\author{
John A. Frazer \\ Dissertation submitted to the \\ College of Engineering and Mineral Resources \\ at West Virginia University \\ in partial fulfillment of the requirements \\ for the degree of \\ Doctor of Philosophy \\ in \\ Occupational Safety and Health
}

Department of Industrial and Management Systems Engineering

Approval of the Examining Committee

Steven E. Guffey, Ph.D., CIH, Chair

Ronald C. Althouse, Ph.D.

Michael J. Klishis, Ph.D., CSHM

Kevin L. Michael, Ph.D.

Warren R. Myers, Ph.D., MPH, CIH

Date 


\section{APPENDIX}


Table 27. Raw data (SPL, dB) by subject for each replication

\begin{tabular}{|c|c|c|c|c|c|c|c|c|c|c|c|c|c|c|c|}
\hline \multirow[b]{2}{*}{ Subject } & \multicolumn{8}{|c|}{ Open Ear Threshold by Frequency Band (dB SPL) } & \multicolumn{7}{|c|}{ Room Level by Frequency Band (dB SPL) } \\
\hline & Trial & 125 & 250 & 500 & 1000 & 2000 & 4000 & 8000 & 125 & 250 & 500 & 1000 & 2000 & 4000 & 8000 \\
\hline \multirow[t]{2}{*}{1} & 1 & -3.3 & -2.2 & 3.6 & 6.9 & 0.1 & 6.6 & 4.7 & 35.0 & 26.8 & 37.8 & 42.6 & 38.9 & 55.3 & 53.9 \\
\hline & 2 & -2.9 & -0.5 & 4.1 & 6.1 & -0.7 & 2.3 & 3.8 & 32.5 & 27.9 & 37.8 & 40.6 & 37.4 & 49.2 & 55.0 \\
\hline \multirow[t]{2}{*}{2} & 1 & 4.6 & 4.2 & 5.4 & -0.8 & -2.5 & 5.7 & 0.7 & 42.3 & 34.6 & 38.4 & 38.1 & 36.9 & 46.5 & 40.5 \\
\hline & 2 & 5.3 & 4.8 & 3.5 & -0.5 & -3.8 & 0.1 & 4.1 & 42.5 & 33.6 & 34.1 & 38.9 & 29.4 & 41.9 & 44.6 \\
\hline \multirow[t]{2}{*}{3} & 1 & -1.7 & -4.8 & -4.8 & -3.1 & -4.7 & -0.2 & 5.7 & 30.4 & 25.8 & 30.1 & 29.7 & 35.5 & 43.8 & 49.9 \\
\hline & 2 & 1 & -4.3 & -2.9 & -1.9 & -4.5 & -1.3 & 6.2 & 36.1 & 26.3 & 31.6 & 29.2 & 35.1 & 42.0 & 52.6 \\
\hline \multirow[t]{2}{*}{4} & 1 & -1.7 & 2.5 & 0.7 & 2.6 & 0.4 & 10.8 & 14.5 & 23.5 & 24.6 & 27.8 & 30.7 & 35.4 & 50.6 & 57.2 \\
\hline & 2 & 1 & 2.4 & -0.9 & -0.4 & 1.3 & 10 & 15.9 & 25.4 & 26.2 & 27.5 & 28.3 & 33.9 & 51.7 & 59.4 \\
\hline \multirow[t]{2}{*}{5} & 1 & -4.2 & -3.2 & -4.8 & -4.2 & -0.1 & -2.5 & 5.6 & 21.5 & 23.0 & 25.9 & 27.4 & 31.2 & 44.8 & 51.5 \\
\hline & 2 & -4.7 & -3.4 & -4.9 & -4.9 & -0.6 & -4.3 & 4.7 & 17.6 & 20.3 & 24.0 & 27.6 & 31.8 & 43.3 & 51.8 \\
\hline \multirow[t]{2}{*}{6} & 1 & -4.5 & -4.8 & -3 & -0.8 & -4 & -4.6 & -3.7 & 34.0 & 25.8 & 34.7 & 38.3 & 36.7 & 36.3 & 48.7 \\
\hline & 2 & -4.8 & -3.9 & -3.8 & -2.8 & -4.5 & -4.8 & -4.1 & 35.6 & 28.7 & 34.2 & 35.0 & 34.1 & 43.1 & 46.1 \\
\hline \multirow[t]{2}{*}{7} & 1 & 1.9 & 5.7 & 9.9 & 6.3 & 5.7 & -1.5 & -4.1 & 35.4 & 28.8 & 42.4 & 37.8 & 39.0 & 45.1 & 41.4 \\
\hline & 2 & -0.2 & 4.8 & 9.7 & 5.4 & 6.4 & -2.2 & -3.7 & 34.6 & 30.2 & 38.1 & 37.7 & 36.2 & 46.2 & 41.2 \\
\hline \multirow[t]{2}{*}{8} & 1 & -3.1 & 0.5 & 7.6 & 9 & 3.3 & 3.4 & 8 & 36.6 & 35.2 & 52.7 & 46.1 & 46.1 & 44.4 & 51.9 \\
\hline & 2 & -3.4 & 2.3 & 5.1 & 10.3 & 3.5 & 4.5 & 8.4 & 34.8 & 36.9 & 46.2 & 47.4 & 43.7 & 46.0 & 52.8 \\
\hline \multirow[t]{2}{*}{9} & 1 & -3.6 & -0.8 & 1.9 & -2.9 & 3.3 & 0.4 & 2.8 & 36.4 & 32.7 & 38.5 & 34.5 & 38.6 & 45.6 & 54.7 \\
\hline & 2 & 2.1 & 0.3 & 3.9 & -4 & 4.7 & -1.2 & 1.1 & 39.0 & 35.9 & 41.1 & 33.4 & 40.3 & 43.0 & 53.9 \\
\hline \multirow[t]{2}{*}{10} & 1 & -3.4 & 1.9 & 1.4 & 0.3 & 5.4 & 1.3 & 8.1 & 29.4 & 33.3 & 37.1 & 33.1 & 39.2 & 39.5 & 56.4 \\
\hline & 2 & 2.2 & 0 & 3 & 0.8 & 7 & 2.5 & 5.1 & 40.6 & 35.3 & 40.1 & 34.9 & 42.6 & 47.5 & 56.3 \\
\hline \multirow[t]{2}{*}{11} & 1 & -1.7 & 0.5 & 1 & 0.6 & 1.3 & 4.3 & 2.3 & 23.3 & 24.0 & 29.3 & 27.8 & 35.9 & 45.0 & 44.5 \\
\hline & 2 & -1.6 & 0.3 & 2.1 & -0.2 & -1.6 & 2.1 & 1.8 & 27.4 & 25.3 & 30.3 & 27.6 & 35.1 & 40.5 & 43.6 \\
\hline \multirow[t]{2}{*}{12} & 1 & -1.7 & -0.5 & 0.1 & -2 & 2.2 & -0.2 & 1 & 31.9 & 24.1 & 30.0 & 29.6 & 38.0 & 47.6 & 47.5 \\
\hline & 2 & -1.7 & -0.1 & 1.3 & -0.7 & 0.6 & -1.3 & 0.5 & 33.8 & 28.6 & 35.8 & 38.4 & 41.3 & 48.5 & 47.6 \\
\hline \multirow[t]{2}{*}{13} & 1 & 0.9 & 3.2 & 6.5 & 6.6 & 4.6 & 7.6 & 8.3 & 26.6 & 22.5 & 32.2 & 29.8 & 37.0 & 45.1 & 39.5 \\
\hline & 2 & 0.9 & 4.3 & 5.7 & 4.4 & 2.9 & 7.6 & 6.1 & 32.1 & 27.9 & 34.7 & 32.4 & 35.4 & 49.9 & 45.5 \\
\hline \multirow[t]{2}{*}{14} & 1 & 2.2 & 0.9 & 1.2 & -0.1 & -4.1 & -0.4 & -3.2 & 31.9 & 26.6 & 27.7 & 28.8 & 33.3 & 44.9 & 46.2 \\
\hline & 2 & 0.2 & -0.1 & 0.1 & -2.3 & -4.2 & -0.7 & -2 & 29.0 & 26.8 & 31.4 & 30.6 & 32.1 & 44.2 & 45.6 \\
\hline \multirow[t]{2}{*}{15} & 1 & -3.1 & 1.8 & 2.7 & -1.4 & -4 & 5.8 & -1.3 & 23.5 & 25.7 & 30.2 & 27.9 & 37.4 & 48.1 & 45.9 \\
\hline & 2 & -2.8 & 1.6 & 0.3 & -3.1 & -1.9 & 3.9 & -4.8 & 32.5 & 30.1 & 33.5 & 30.4 & 39.2 & 46.7 & 44.3 \\
\hline \multirow[t]{2}{*}{16} & 1 & 4.2 & 7.2 & 12.1 & 9.4 & 5.8 & 9 & 3 & 30.9 & 28.4 & 38.1 & 35.7 & 43.3 & 53.3 & 46.9 \\
\hline & 2 & 2.8 & 8.6 & 11.8 & 10.8 & 6.7 & 10.2 & 4.8 & 26.6 & 29.0 & 39.2 & 37.9 & 43.0 & 52.3 & 47.7 \\
\hline \multirow[t]{2}{*}{17} & 1 & 6.8 & 8.6 & 8.6 & 10.8 & 9.9 & 5.4 & 2.9 & 32.5 & 34.1 & 30.7 & 41.6 & 48.7 & 43.1 & 44.7 \\
\hline & 2 & 8.8 & 9.2 & 9.8 & 12.1 & 11.4 & 2.9 & 2.1 & 38.0 & 32.6 & 36.2 & 43.8 & 52.2 & 43.1 & 44.1 \\
\hline 18 & 1 & -0.9 & 3.8 & 6.3 & 13.1 & 1.9 & 2.4 & -3.9 & 30.7 & 29.1 & 34.7 & 44.7 & 41.0 & 48.0 & 44.0 \\
\hline & 2 & -1.4 & 4.6 & 6.3 & 10.3 & 2.9 & 1.3 & -3.2 & 28.5 & 26.3 & 34.2 & 40.7 & 39.5 & 47.1 & 45.2 \\
\hline 19 & 1 & -1.6 & -2 & 2.7 & 1.4 & -3.1 & 1 & 3.4 & 25.6 & 18.0 & 28.4 & 28.5 & 31.8 & 38.0 & 35.8 \\
\hline & 2 & -0.5 & -1.8 & 2 & 0.1 & -2.4 & 2.1 & 3.7 & 31.0 & 19.1 & 27.2 & 28.6 & 32.7 & 41.4 & 41.1 \\
\hline 20 & 1 & 3 & 2.4 & 2.7 & 4.3 & 14.5 & 13.9 & 14.2 & 30.4 & 29.5 & 43.4 & 39.6 & 51.0 & 61.4 & 57.7 \\
\hline & 2 & -0.8 & -0.4 & 1.7 & 3.7 & 10.6 & 13.6 & 12.1 & 34.5 & 32.6 & 43.7 & 36.6 & 46.9 & 61.0 & 55.6 \\
\hline
\end{tabular}


Table 28. Aggregate results by important variables

\begin{tabular}{|c|c|c|c|c|c|c|c|c|}
\hline Subject & Light & Period & Cycle & Department & $\mathrm{N}$ & NR Mean & NR Std Dev & $\begin{array}{c}\text { NR } \\
\text { Median }\end{array}$ \\
\hline 2 & 0 & 1 & 1 & Coater & 71 & -1.4 & 5.0 & 0.8 \\
\hline 2 & 0 & 3 & 2 & Coater & 70 & 2.3 & 4.4 & 3.7 \\
\hline 2 & 0 & 5 & 3 & Coater & 70 & -0.2 & 3.7 & 1.2 \\
\hline 2 & 1 & 2 & 1 & Coater & 70 & 5.0 & 7.4 & 5.8 \\
\hline 2 & 1 & 4 & 2 & Coater & 70 & 11.2 & 8.3 & 14.4 \\
\hline 2 & 1 & 6 & 3 & Coater & 69 & 5.2 & 4.3 & 6.7 \\
\hline 3 & 0 & 1 & 1 & Coater & 71 & 9.0 & 2.6 & 8.2 \\
\hline 3 & 0 & 3 & 2 & Coater & 70 & 8.3 & 2.2 & 8.1 \\
\hline 3 & 0 & 5 & 3 & Coater & 70 & 8.5 & 2.6 & 8.3 \\
\hline 3 & 1 & 2 & 1 & Coater & 70 & 6.3 & 4.0 & 7.3 \\
\hline 3 & 1 & 4 & 2 & Coater & 70 & 7.9 & 2.4 & 7.9 \\
\hline 3 & 1 & 6 & 3 & Coater & 74 & 8.5 & 2.0 & 7.9 \\
\hline 4 & 0 & 1 & 1 & Coater & 71 & 5.5 & 8.1 & 8.9 \\
\hline 4 & 0 & 3 & 2 & Coater & 70 & 3.9 & 4.8 & 4.1 \\
\hline 4 & 0 & 5 & 3 & Coater & 70 & 4.3 & 5.4 & 6.0 \\
\hline 4 & 1 & 2 & 1 & Coater & 70 & 7.0 & 4.5 & 8.2 \\
\hline 4 & 1 & 4 & 2 & Coater & 70 & 6.3 & 5.7 & 7.9 \\
\hline 4 & 1 & 6 & 3 & Coater & 74 & 5.3 & 4.8 & 6.4 \\
\hline 5 & 0 & 1 & 1 & Coater & 71 & 23.8 & 4.8 & 25.6 \\
\hline 5 & 0 & 3 & 2 & Coater & 70 & 11.1 & 9.0 & 7.7 \\
\hline 5 & 0 & 5 & 3 & Coater & 70 & 21.3 & 9.3 & 26.6 \\
\hline 5 & 1 & 2 & 1 & Coater & 70 & 15.6 & 11.2 & 19.7 \\
\hline 5 & 1 & 4 & 2 & Coater & 70 & 20.3 & 10.5 & 25.6 \\
\hline 5 & 1 & 6 & 3 & Coater & 58 & 25.3 & 5.5 & 26.9 \\
\hline 6 & 0 & 1 & 1 & Coil & 71 & 21.2 & 4.7 & 23.5 \\
\hline 6 & 0 & 3 & 2 & Coil & 70 & 21.7 & 6.1 & 23.6 \\
\hline 6 & 0 & 5 & 3 & Coil & 70 & 21.5 & 5.4 & 23.2 \\
\hline 6 & 1 & 2 & 1 & Coil & 70 & 21.9 & 5.4 & 23.2 \\
\hline 6 & 1 & 4 & 2 & Coil & 70 & 21.6 & 4.8 & 23.2 \\
\hline 6 & 1 & 6 & 3 & Coil & 62 & 21.8 & 3.6 & 22.6 \\
\hline 7 & 0 & 1 & 1 & Coater & 71 & 2.6 & 7.3 & 5.8 \\
\hline 7 & 0 & 3 & 2 & Coater & 70 & 3.2 & 4.9 & 2.0 \\
\hline 7 & 0 & 5 & 3 & Coater & 70 & 0.3 & 4.8 & 1.6 \\
\hline 7 & 1 & 2 & 1 & Coater & 70 & 1.5 & 5.3 & 1.8 \\
\hline 7 & 1 & 4 & 2 & Coater & 70 & 2.3 & 5.8 & 3.6 \\
\hline 7 & 1 & 6 & 3 & Coater & 58 & 2.7 & 4.4 & 2.4 \\
\hline 8 & 0 & 1 & 1 & Coater & 71 & 1.2 & 1.1 & 1.0 \\
\hline
\end{tabular}


Table 28 (cont.). Aggregate results by important variables

\begin{tabular}{|c|c|c|c|c|c|c|c|c|}
\hline Subject & Light & Period & Cycle & Department & $\mathrm{N}$ & NR Mean & NR Std Dev & $\begin{array}{c}\text { NR } \\
\text { Median }\end{array}$ \\
\hline 8 & 0 & 3 & 2 & Coater & 70 & 19.0 & 5.4 & 21.5 \\
\hline 8 & 0 & 5 & 3 & Coater & 70 & 10.8 & 6.5 & 10.4 \\
\hline 8 & 1 & 2 & 1 & Coater & 70 & 13.2 & 8.9 & 17.7 \\
\hline 8 & 1 & 4 & 2 & Coater & 70 & 20.6 & 5.2 & 21.7 \\
\hline 8 & 1 & 6 & 3 & Coater & 57 & 18.4 & 6.9 & 21.3 \\
\hline 9 & 0 & 1 & 1 & Coil & 71 & 17.4 & 10.2 & 20.8 \\
\hline 9 & 0 & 3 & 2 & Coil & 70 & 24.4 & 4.2 & 24.6 \\
\hline 9 & 0 & 5 & 3 & Coil & 70 & 20.2 & 7.6 & 22.6 \\
\hline 9 & 1 & 2 & 1 & Coil & 70 & 18.6 & 11.2 & 23.3 \\
\hline 9 & 1 & 4 & 2 & Coil & 70 & 22.6 & 10.0 & 25.1 \\
\hline 9 & 1 & 6 & 3 & Coil & 60 & $\mathrm{n} / \mathrm{a}$ & $\mathrm{n} / \mathrm{a}$ & $\mathrm{n} / \mathrm{a}$ \\
\hline 11 & 0 & 1 & 1 & Press & 26 & 1.0 & 3.7 & -0.5 \\
\hline 11 & 0 & 3 & 2 & Press & 70 & 0.3 & 2.0 & 0.2 \\
\hline 11 & 0 & 5 & 3 & Press & 70 & 1.3 & 3.4 & 0.5 \\
\hline 11 & 1 & 2 & 1 & Press & 45 & 7.5 & 3.3 & 8.6 \\
\hline 11 & 1 & 4 & 2 & Press & 70 & 0.9 & 2.0 & 1.1 \\
\hline 11 & 1 & 6 & 3 & Press & 72 & 0.0 & 2.1 & -0.4 \\
\hline 12 & 0 & 1 & 1 & Press & 21 & 6.8 & 4.1 & 7.7 \\
\hline 12 & 0 & 3 & 2 & Press & 70 & -1.5 & 2.9 & -0.9 \\
\hline 12 & 0 & 5 & 3 & Press & 70 & -0.6 & 1.0 & -0.5 \\
\hline 12 & 1 & 2 & 1 & Press & 70 & 3.6 & 6.3 & 1.9 \\
\hline 12 & 1 & 4 & 2 & Press & 70 & 1.1 & 3.0 & 1.2 \\
\hline 12 & 1 & 6 & 3 & Press & 68 & -0.1 & 2.4 & -0.2 \\
\hline 13 & 0 & 1 & 1 & Coil & 71 & 19.1 & 5.9 & 21.4 \\
\hline 13 & 0 & 3 & 2 & Coil & 70 & 13.1 & 7.0 & 14.8 \\
\hline 13 & 0 & 5 & 3 & Coil & 70 & 10.4 & 6.1 & 13.8 \\
\hline 13 & 1 & 2 & 1 & Coil & 70 & 17.9 & 7.5 & 19.9 \\
\hline 13 & 1 & 4 & 2 & Coil & 70 & 11.1 & 5.3 & 11.0 \\
\hline 13 & 1 & 6 & 3 & Coil & 73 & 10.4 & 4.4 & 11.7 \\
\hline 14 & 0 & 1 & 1 & Stacker & 71 & -2.4 & 4.8 & -0.4 \\
\hline 14 & 0 & 3 & 2 & Stacker & 70 & 0.9 & 3.8 & 1.0 \\
\hline 14 & 0 & 5 & 3 & Stacker & 70 & 3.2 & 4.8 & 5.2 \\
\hline 14 & 1 & 2 & 1 & Stacker & 70 & 2.0 & 7.6 & 3.4 \\
\hline 14 & 1 & 4 & 2 & Stacker & 70 & -0.7 & 5.6 & 1.3 \\
\hline 14 & 1 & 6 & 3 & Stacker & 79 & 6.0 & 4.4 & 7.8 \\
\hline 15 & 0 & 1 & 1 & Coil & 71 & 11.7 & 8.3 & 15.8 \\
\hline 15 & 0 & 3 & 2 & Coil & 70 & 13.7 & 7.1 & 17.1 \\
\hline
\end{tabular}


Table 28 (cont.). Aggregate results by important variables

\begin{tabular}{|c|c|c|c|c|c|c|c|c|}
\hline Subject & Light & Period & Cycle & Department & $\mathrm{N}$ & NR Mean & NR Std Dev & $\begin{array}{c}\text { NR } \\
\text { Median }\end{array}$ \\
\hline 15 & 0 & 5 & 3 & Coil & 70 & 12.5 & 7.9 & 16.1 \\
\hline 15 & 1 & 2 & 1 & Coil & 70 & 5.6 & 8.8 & 4.9 \\
\hline 15 & 1 & 4 & 2 & Coil & 70 & 16.0 & 5.0 & 17.9 \\
\hline 15 & 1 & 6 & 3 & Coil & 76 & 13.1 & 4.7 & 14.9 \\
\hline 16 & 0 & 1 & 1 & Stacker & 71 & 0.4 & 1.0 & 0.2 \\
\hline 16 & 0 & 3 & 2 & Stacker & 69 & 16.8 & 3.0 & 17.2 \\
\hline 16 & 0 & 5 & 3 & Stacker & 70 & 0.6 & 1.9 & -0.1 \\
\hline 16 & 1 & 2 & 1 & Stacker & 70 & 4.7 & 4.8 & 5.3 \\
\hline 16 & 1 & 4 & 2 & Stacker & 71 & 8.0 & 5.6 & 5.2 \\
\hline 16 & 1 & 6 & 3 & Stacker & 80 & 3.0 & 2.7 & 2.1 \\
\hline 17 & 0 & 1 & 1 & Forklift & 71 & 1.1 & 1.2 & 1.3 \\
\hline 17 & 0 & 3 & 2 & Forklift & 70 & 10.1 & 6.5 & 12.5 \\
\hline 17 & 0 & 5 & 3 & Forklift & 70 & 9.3 & 6.0 & 11.1 \\
\hline 17 & 1 & 2 & 1 & Forklift & 70 & 15.3 & 6.4 & 17.9 \\
\hline 17 & 1 & 4 & 2 & Forklift & 70 & 13.0 & 6.8 & 15.8 \\
\hline 17 & 1 & 6 & 3 & Forklift & 69 & 16.1 & 3.7 & 16.5 \\
\hline 18 & 0 & 1 & 1 & Stacker & 71 & 2.5 & 3.2 & 1.7 \\
\hline 18 & 0 & 3 & 2 & Stacker & 70 & 15.6 & 6.7 & 18.7 \\
\hline 18 & 0 & 5 & 3 & Stacker & 70 & 16.6 & 7.1 & 19.3 \\
\hline 18 & 1 & 2 & 1 & Stacker & 70 & 9.1 & 7.2 & 8.5 \\
\hline 18 & 1 & 4 & 2 & Stacker & 70 & 17.9 & 7.4 & 21.1 \\
\hline 18 & 1 & 6 & 3 & Stacker & 72 & 18.3 & 4.8 & 19.7 \\
\hline 19 & 0 & 1 & 1 & Press & 71 & 0.2 & 1.9 & 1.0 \\
\hline 19 & 0 & 3 & 2 & Press & 70 & 7.2 & 2.3 & 7.4 \\
\hline 19 & 0 & 5 & 3 & Press & 70 & 1.3 & 2.4 & 1.9 \\
\hline 19 & 1 & 2 & 1 & Press & 69 & 6.6 & 6.2 & 9.7 \\
\hline 19 & 1 & 4 & 2 & Press & 71 & 7.6 & 3.3 & 8.9 \\
\hline 19 & 1 & 6 & 3 & Press & 75 & 1.8 & 3.2 & 2.1 \\
\hline 20 & 0 & 1 & 1 & Coater & 71 & 10.2 & 4.7 & 10.9 \\
\hline 20 & 0 & 3 & 2 & Coater & 70 & 12.9 & 7.0 & 15.4 \\
\hline 20 & 0 & 5 & 3 & Coater & 70 & 11.4 & 8.3 & 15.3 \\
\hline 20 & 1 & 2 & 1 & Coater & 70 & 16.4 & 7.3 & 18.9 \\
\hline 20 & 1 & 4 & 2 & Coater & 70 & 10.3 & 6.2 & 11.3 \\
\hline 20 & 1 & 6 & 3 & Coater & 72 & 15.8 & 5.6 & 17.2 \\
\hline 21 & 0 & 1 & 1 & Stacker & 71 & -2.3 & 1.5 & -2.1 \\
\hline 21 & 0 & 3 & 2 & Stacker & 70 & -1.7 & 2.4 & -1.2 \\
\hline 21 & 0 & 5 & 3 & Stacker & 70 & -1.1 & 1.8 & -1.2 \\
\hline
\end{tabular}


Table 28 (cont.). Aggregate results by important variables

\begin{tabular}{ccccccccc}
\hline Subject & Light & Period & Cycle & Department & N & NR Mean & NR Std Dev & Median \\
\hline 21 & 1 & 2 & 1 & Stacker & 70 & 11.7 & 8.3 & 15.9 \\
21 & 1 & 4 & 2 & Stacker & 70 & 3.9 & 3.6 & 4.5 \\
21 & 1 & 6 & 3 & Stacker & 71 & 2.0 & 3.2 & 2.3 \\
22 & 0 & 1 & 1 & Press & 71 & 11.7 & 6.0 & 12.9 \\
22 & 0 & 3 & 2 & Press & 70 & 13.5 & 4.2 & 14.9 \\
22 & 0 & 5 & 3 & Press & 70 & 16.7 & 4.9 & 17.5 \\
22 & 1 & 2 & 1 & Press & 70 & 15.6 & 8.4 & 16.0 \\
22 & 1 & 4 & 2 & Press & 70 & 19.1 & 4.2 & 19.9 \\
22 & 1 & 6 & 3 & Press & 69 & 13.6 & 5.8 & 15.9 \\
Overall & & & & & 8288 & 9.4 & 5.2 & 10.6 \\
\hline
\end{tabular}

